\title{
MATHEMATICAL MODELLING OF SOLUTE TRANSPORT IN A HETEROGENEOUS AQUIFER
}

by

James Phillip Dommisse

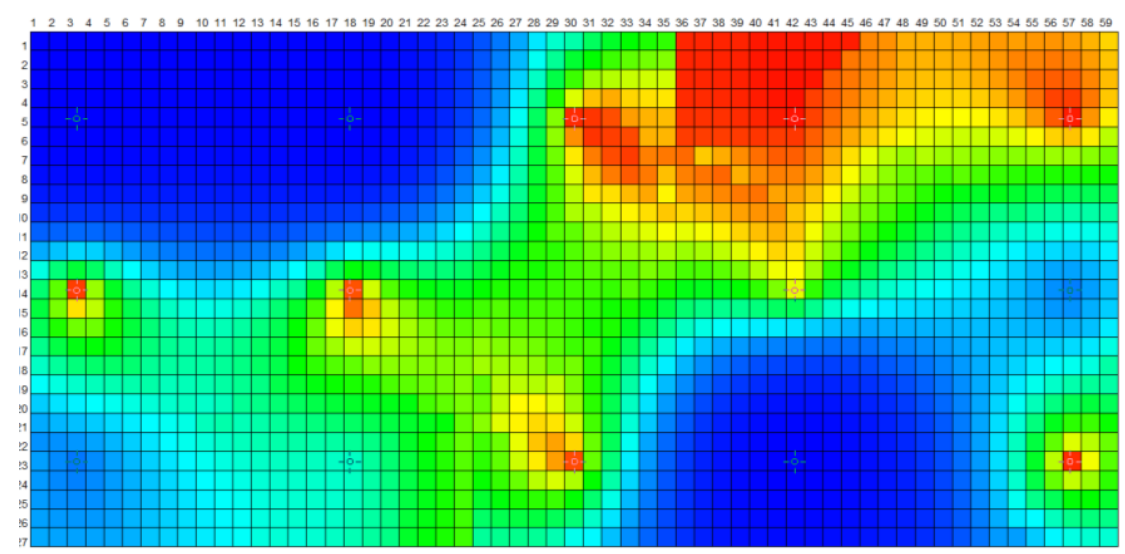

A thesis submitted to the Victoria University of Wellington in partial fulfilment of requirements for the degree of Master of Science

Victoria University of Wellington 


\begin{abstract}
This study provides a contribution to the understanding of parsimony and predictive uncertainty in the context of groundwater solute transport modelling. The study is unique because the modelling was undertaken using tracer test data from a heterogeneous artificial aquifer whose structure was known to a very high level of detail. The aquifer structure was based on a 'real life' Canterbury Plains alluvial aquifer (in New Zealand).
\end{abstract}

Parsimonious principles were applied by starting with a simple analytical model that assumed homogeneity then progressively adding heterogeneity using numerical models with varying degrees of parameterisation complexity. The results show that increased complexity did not necessarily make the model better at replicating the tracer test data. For example, the outputs from a numerical model that represented heterogeneity using a zone based approach based on the recorded distribution of all 2,907 blocks that comprised the artificial aquifer was little different to a simple numerical model that adopted a homogenous distribution and included a single value of dispersion. Parameterisation of numerical models using 'pilot points' provided the most complex representation of heterogeneity and resulted in the best replication of the tracer test data. However, increasing model complexity had its disadvantages such as decreasing parameterisation uniqueness.

The contribution to predictive uncertainty from model parameters and observations was assessed using a linear approach based on Bayes theorem. This approach has been applied to other groundwater modelling studies, but not to solute transport modelling within Canterbury Plains alluvial aquifers or to an artificial aquifer. A unique finding was the reduction in predictive uncertainty along the groundwater flow path. This finding correlated well with the numerical model outputs which showed closer fits to the observation data near the end of the aquifer compared to those near the top of the aquifer where the tracer was injected.

Physical solute transport processes were identified and described as part of the modelling. These included the increase in dispersivity with travel distance and the 
spatial distribution of the aquifer hydraulic properties. Analytical modelling was a useful tool in identifying physical processes, aquifer characteristics and the variation in aquifer hydraulic properties both spatially and with depth.

An important finding was the value of undertaking multiple modelling approaches. This is because each approach has its own advantages and disadvantageous and by comparing the results of different approaches, the true facts about the aquifer system are made clearer. 


\section{Acknowledgements}

I would like to thank all those people who have contributed in some way, both directly and indirectly to this thesis. Thank you to Murray, Lee, Bronwyn, Phil and Cath from ESR for your support and being a great bunch of people to work with. Thank you Lee for all your wise words both philosophical and about the intricate details of all things groundwater. Thank your Beth for your guidance along the way. I enjoyed catching up in Wellington. Lastly to my wife Nadeine for patiently supporting me during my studies. 


\section{Table of Contents}

Page

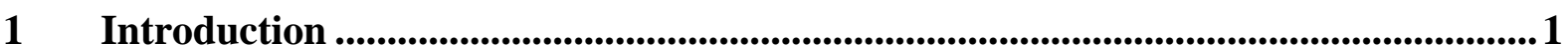

1.1 Alluvial Aquifers and Modelling Solute Transport ......................................... 1

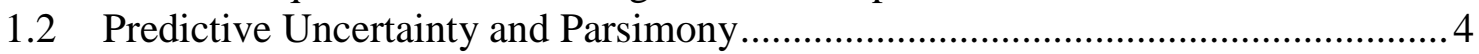

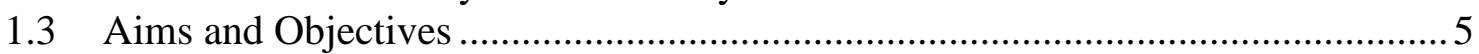

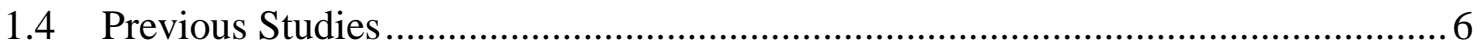

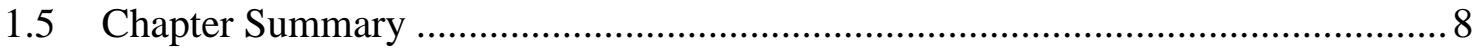

2 Heterogeneous Artificial Aquifer and Tracer Test Description................................11

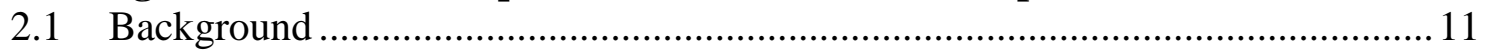

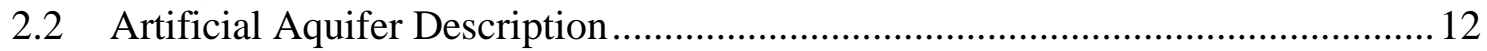

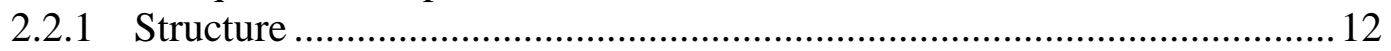

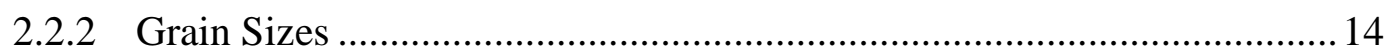

2.3 Instrumentation, Sampling and Hydraulic Measurements ................................. 15

2.4 Aquifer Conditions during the Tracer Test ................................................. 18

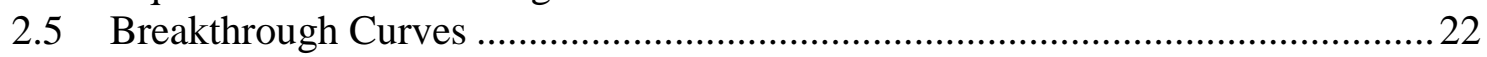

2.6 Tracer Mass Balance and By-Pass Flow Estimates ........................................ 28

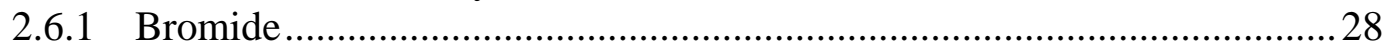

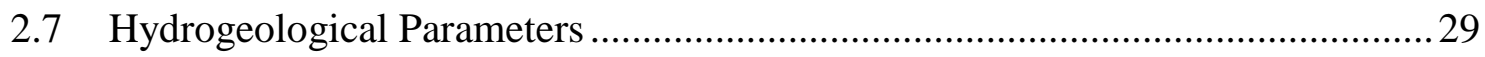

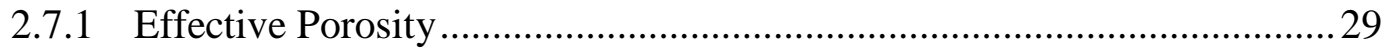

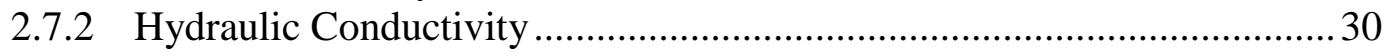

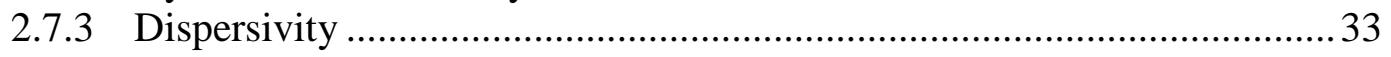

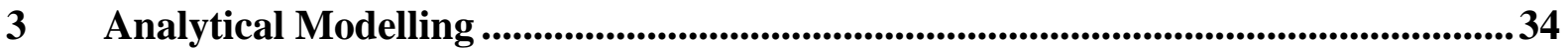

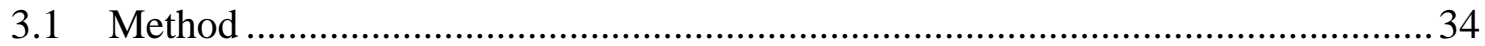

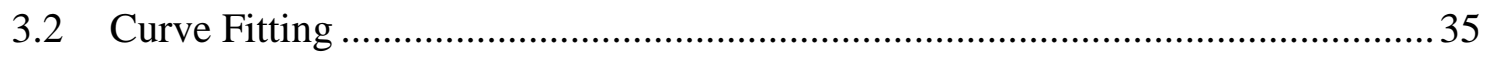

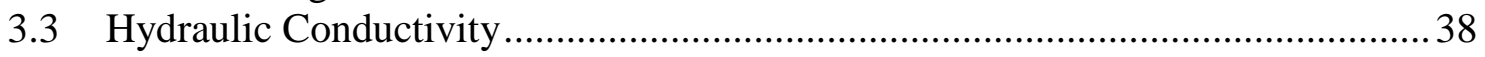

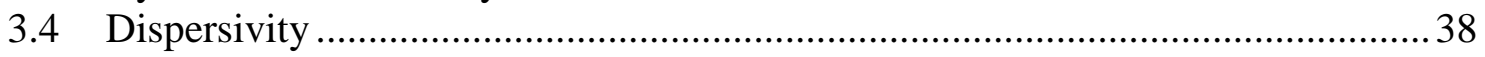

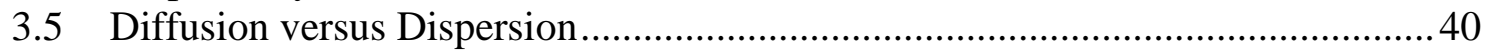

3.6 Comparison to the Homogeneous Artificial Aquifer ...................................... 41

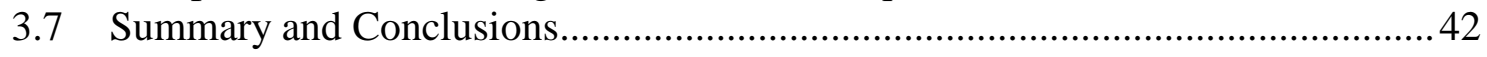

$4 \quad$ Numerical Model Design and Construction.............................................................443

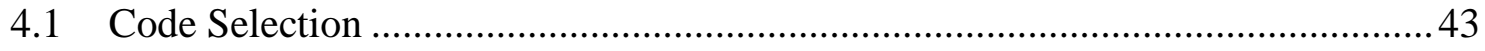

4.2 Numerical Solution for Solute Transport Modelling ........................................ 45

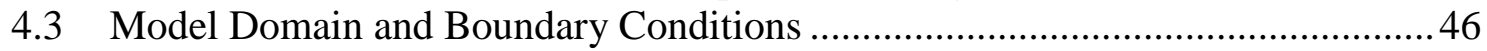

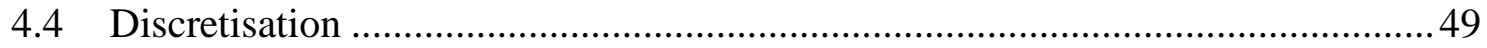

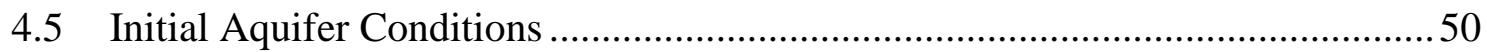

4.6 Design and Construction Uncertainty ...................................................... 50

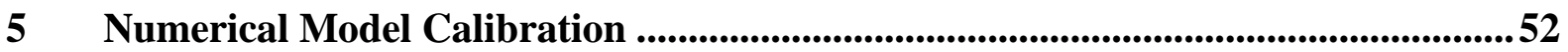

5.1 Weightings, Calibration Constraints and Starting Conditions .............................52

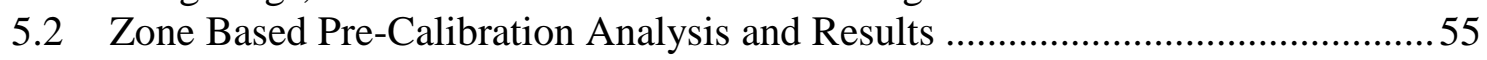

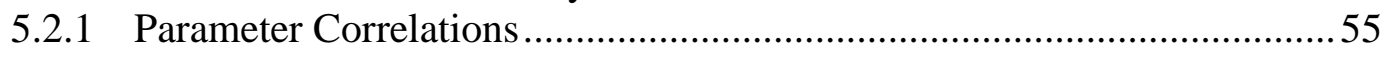

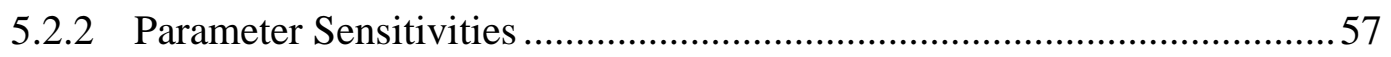

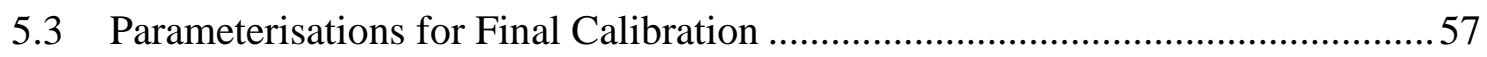

5.3.1 Zone Based Parameterisations ..........................................................59 


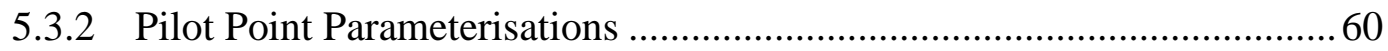

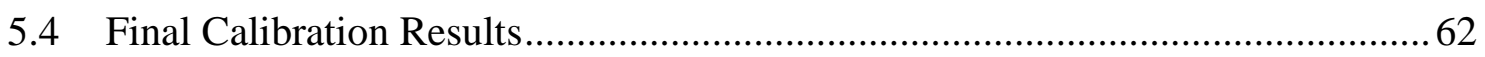

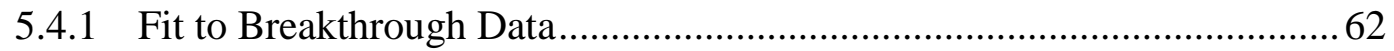

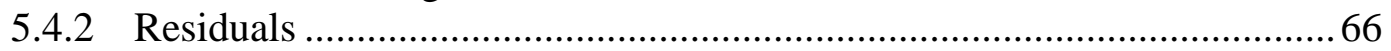

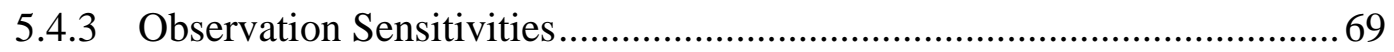

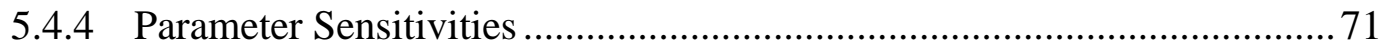

5.4.5 Calibrated Parameter Values ................................................................... 73

5.4.6 Parameterisation Uniqueness ......................................................... 74

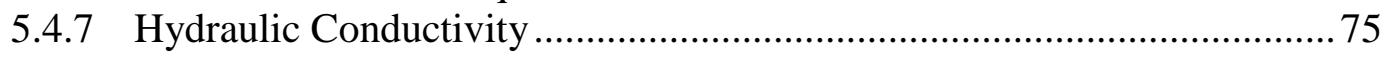

5.4.8 Flow and Transport Mass Balance …............................................... 83

$6 \quad$ Predictive Uncertainty and Data Worth .......................................................................86

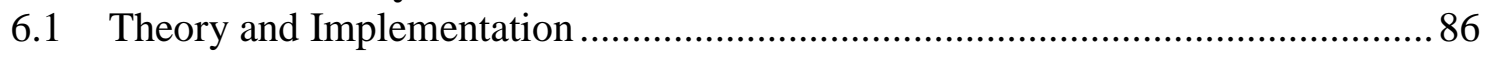

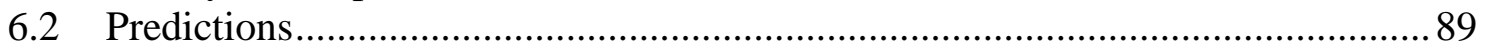

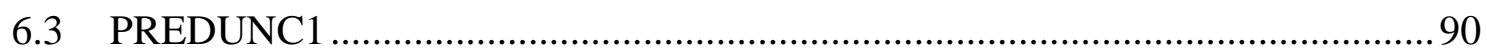

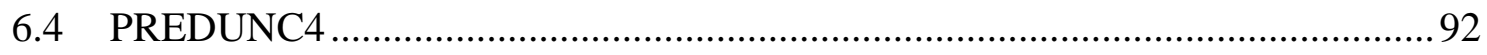

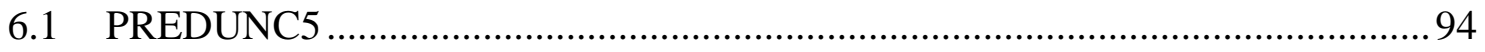

7 Summary, Application of Results and Recommendations .........................................99

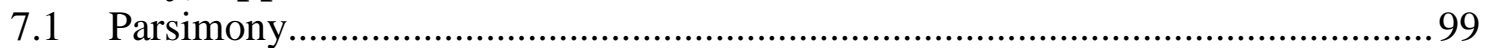

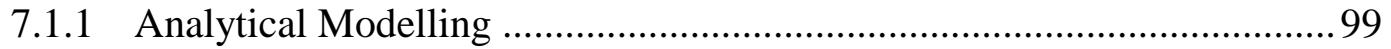

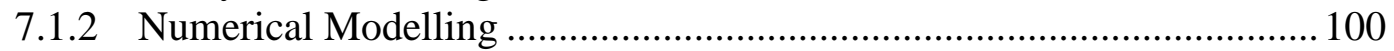

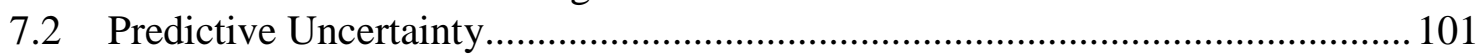

7.3 Practical Application of the Modelling Results ............................................... 102

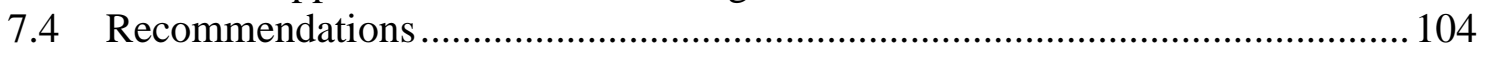

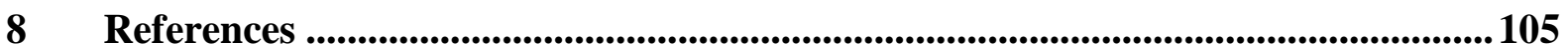




\section{Figures}

Page

Figure 1-1: Photo of an open framework work gravel lens out-cropping on a coastal cliff near

Lowcliffe, Canterbury Plains (photo taken by author).

Figure 1-2: Photo of groundwater flowing from an open framework gravel lens at a gallery near the Hinds River, Canterbury Plains (photo taken by author) .....

Figure 2-1: Structure and key features of the heterogeneous artificial aquifer....................... 13

Figure 2-2: Construction of the heterogeneous artificial aquifer showing placement of blocks, a monitoring well and a section of the end-wall (photo sourced from ESR archive)

Figure 2-3: Location of $\mathrm{Br}$ samples taken from monitoring wells (in red) and groundwater pressures taken from three piezometers (in green).

Figure 2-4: Heterogeneous artificial aquifer and monitoring wells (photo sourced from ESR archive).

Figure 2-5: Location and identification of the end-wall sampling points. The red, grey and black numbers correspond to the colour coding of plots in Figure 2-11 to Figure $2-13$.

Figure 2-6: Photograph of end-wall sampling points (photo sourced from ESR archive) ..... 18

Figure 2-7: Mean Br concentration measured in the head-tank......................................... 19

Figure 2-8: Aquifer inflow, outflow and groundwater pressures ..................................... 21

Figure 2-9: Outflow versus groundwater abstraction from sampling .................................. 21

Figure 2-10: Breakthrough curves at monitoring wells in Arrays E to A, at a distance of 0.75 $\mathrm{m}$ (green), $4.75 \mathrm{~m}$ (blue) and $8.75 \mathrm{~m}$ (red) from the head-tank. $\mathrm{X}$ axis shows the time (days), $\mathrm{Y}$ axis shows the concentration $(\mathrm{mg} / \mathrm{L})$....

Figure 2-11: Breakthrough curves measured at end-wall sampling points. Depth below top of aquifer (in $\mathrm{m}$ ) shown along left hand margin. $\mathrm{X}$ axis shows the time in days, $\mathrm{Y}$ axis shows the concentration in $\mathrm{mg} / \mathrm{L}$

Figure 2-12: Breakthrough curves measured at end-wall sampling points. Depth below top of aquifer (in $\mathrm{m}$ ) shown along left hand margin. $\mathrm{X}$ axis shows the time in days, $\mathrm{Y}$ axis shows the concentration in $\mathrm{mg} / \mathrm{L}$

Figure 2-13: Breakthrough curves measured at end-wall sampling points. Depth below top of aquifer (in $\mathrm{m}$ ) shown along left hand margin. $\mathrm{X}$ axis shows the time in days, $\mathrm{Y}$ axis shows the concentration in $\mathrm{mg} / \mathrm{L}$

Figure 2-14: Timing of tracer arrival, peak concentration and zero concentration at each endwall sampling point and the corresponding normal distribution.........................2. 27

Figure 2-15: End-wall 1D mass in units of $\mathrm{g} / \mathrm{m}^{2}$ with sampling points shown in grey ..........28

Figure 3-1: Breakthrough curve showing effects of changes in $\mathrm{Br}$ input concentration ........ 35

Figure 3-2: Observed versus modelled breakthrough curves a depth of $1.0 \mathrm{~m}$ below the top of the aquifer and at successive distances from the head-tank ................................... 36

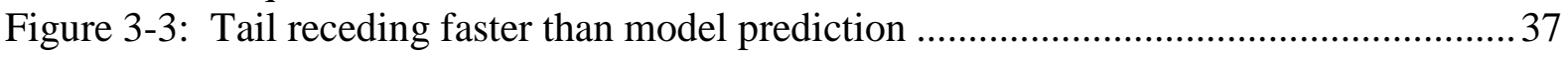

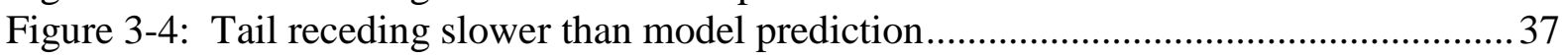

Figure 3-5: Arithmetic mean $\alpha_{\mathrm{x}}$ with travel distance in direction of groundwater flow .......... 38

Figure 3-6: Arithmetic mean values for the ratio of $\alpha_{\mathrm{x}}$ divided by the travel distance at increasing distance from the head-tank

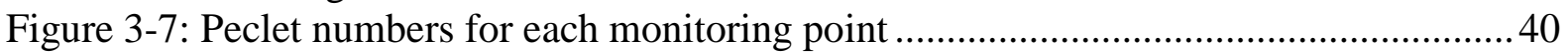

Figure 4-1: Domain, discretisation, boundary conditions (blue cells), and location of observation targets in model layer 32 . 
Figure 5-1: Parameter correlation coefficients greater than 0.5 for the heterogeneous block parameterisation

Figure 5-2: Relative composite sensitivities ................................................................ 58

Figure 5-3: Heterogeneous block parameterisation showing the three zones used for $K_{x, y}, K_{z}$ and $\eta_{\mathrm{e}}$. Blue is the finest grained blocks, green is the medium grained blocks and red is the coarsest grained blocks

Figure 5-4: Spatial distribution of pilot points for every model layer. Pilot points shown in red and some distances provided for scale

Figure 5-5: Modelled versus observed concentrations for different parameterisations...........63

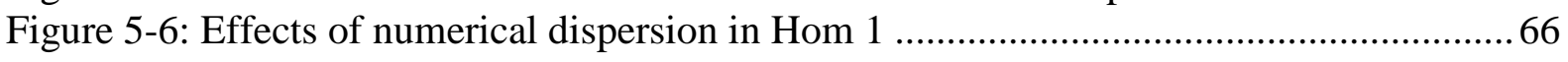

Figure 5-7: Arithmetic mean absolute residuals by group and parameterisation ....................67

Figure 5-8: Modelled versus observed concentrations at monitoring well A1_0.4 ............... 68

Figure 5-9: Arithmetic mean composite observation sensitivities by group ......................... 70

Figure 5-10: Arithmetic mean COS values versus the Eigen vector ratio for each

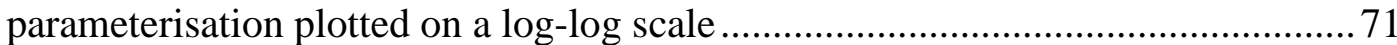

Figure 5-11: Mean relative composite sensitivities and standard deviations for Pil 1 ...........72 Figure 5-12: Comparison of the spatial distribution of $\mathrm{K}_{\mathrm{x}, \mathrm{y}}$ in Pil 1(top), Het 1 (middle) and Hom 1 (bottom) for model layer 1 . Red equals high $\mathrm{K}$, green equals medium $\mathrm{K}$, blue equals low $\mathrm{K}$ and grey equals single $\mathrm{K}$ value................................................ 76

Figure 5-13: Frequency distribution and probability density functions using horizontal $\mathrm{K}$ data from the analytical modelling, Het 1 and Pil 1..................................................... 78

Figure 5-14: Geometric mean $\mathrm{K}$ at different depths below the top of the aquifer ................... 79

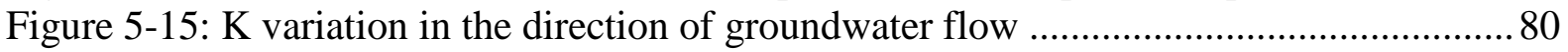

Figure 5-16: Mean standard deviation of $\mathrm{K}$ in the direction of groundwater flow ..................81

Figure 5-17: Lateral variation in $\mathrm{K}$ from Array A $(0 \mathrm{~m})$ to Array E $(4.66 \mathrm{~m})$........................ 82

Figure 6-1: Locations of predictions Pred 1, Pred 2 and Pred 3 in model layer 26................ 89

Figure 6-2: Predicted concentrations and the pre-calibration and post-calibration total predictive uncertainty standard deviations shown as error bars

Figure 6-3: Difference between pre and post-calibration uncertainty variance for $K_{x, y}$ pilot points. Blue data are where pre-calibration uncertainty is higher than postcalibration uncertainty, red data are where pre-calibration uncertainty is lower than post-calibration uncertainty

Figure 6-4: The spatial distribution of data worth as predictive uncertainty variance increase incurred through loss of observations (red bar charts), and predictive uncertainty variance decrease incurred through addition of observations (blue bar charts) for Pred 1.

Figure 6-5: The spatial distribution of data worth as predictive uncertainty variance increase incurred through loss of observations (red bar charts), and predictive uncertainty variance decrease incurred through addition of observations (blue bar charts) for Pred 2.

Figure 6-6: The spatial distribution of data worth as predictive uncertainty variance increase incurred through loss of observations (red bar charts), and predictive uncertainty variance decrease incurred through addition of observations (blue bar charts) for Pred 3 


\section{Tables}

Table 2-1: Grain size classification, grain size range and median grain size $\left(\mathrm{d}_{50}\right) \ldots \ldots \ldots \ldots \ldots . . . . .14$

Table 2-2: Specific yield (source, Morris and Johnson, 1967) ............................................ 30

Table 2-3: Hydraulic conductivity values for medium sand, coarse sand and gravel ............30

Table 2-4: Hydraulic conductivity values using the median grain sizes ............................... 31

Table 2-5: Hydraulic conductivity values using the Kozeny-Carmen equation ...................... 32

Table 3-1: Comparison of 1D analytical modelling from the full head-tank tracer tests undertaken in the homogeneous and heterogeneous artificial aquifers. Arithmetic mean values are shown in brackets. .............................................................. 41

Table 5-1: Calibration constraints and starting values used in both the pre-calibration

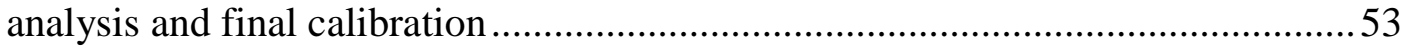

Table 5-2: Calibrated zone based parameter values using PEST …................................... 73

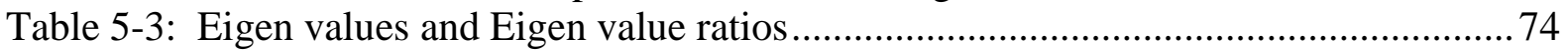

Table 5-4: Zone calibrated values and mean values of hydraulic conductivity.....................75

Table 5-5: Steady-state flow rate, Br mass input, Br mass output and by-pass flow ............. 83

Table 5-6: Percentage mass balance discrepancy for flow and transport .............................. 85 


\section{Appendices}

Appendix A: Block distribution of the heterogeneous artificial aquifer

Appendix B: 1D analytical modelling - Observed versus model results

Appendix C: 1D analytical modelling - Hydrogeological parameters results

\section{Digital Appendices}

Appendix A - Monitoring well and end-wall observation locations Appendix B - Monitoring well and end-wall observation data Appendix C - Aquifer inflows and outflows

Appendix D - Parameter correlation coefficient matrices

Appendix E - Parameter sensitivities

Appendix F - Final calibration results

Appendix G - Predictive uncertainty and data worth results 


\section{General Abbreviations}

\begin{tabular}{|l|l|l|}
\hline $1 \mathrm{D}$ & $=$ & One dimensional \\
\hline 3D & $=$ & Three dimensional \\
\hline ADE & $=$ & Advection-dispersion equation \\
\hline Br & $=$ & Bromide \\
\hline COS & $=$ & Composite observation sensitivity \\
\hline GENLINPRED & $=$ & General linear predictive analysis (used with PEST) \\
\hline GUI & $=$ & Graphical user interface \\
\hline Het 1 & $=$ & Heterogeneous block parameterisation one \\
\hline Het 2 & $=$ & Heterogeneous block parameterisation two \\
\hline Hom 1 & $=$ & Homogeneous parameterisation one \\
\hline Hom 2 & $=$ & Homogeneous parameterisation two \\
\hline Hom 2-B & $=$ & Hom 2 but with a different boundary condition for Br input \\
\hline MAROS & $=$ & Monitoring and remediation optimisation system \\
\hline $\mathrm{P}_{\mathrm{e}}$ & $=$ & Peclet number \\
\hline $\mathrm{P}_{\mathrm{e}(\mathrm{x})}$ & $=$ & Peclet number calculated in horizontal direction $\mathrm{x}$ \\
\hline PCCM & $=$ & Parameter correlation coefficient matrix \\
\hline PDF & $=$ & Probability density function \\
\hline Pil 1 & $=$ & Pilot point parameterisation one \\
\hline Pil 2 & $=$ & Pilot point parameterisation two \\
\hline Pil 3 & $=$ & Pilot point parameterisation three \\
\hline PREDUNC & $=$ & Linear predictive uncertainty analysis (used with PEST) \\
\hline RCS & $=$ & Relative composite sensitivity \\
\hline $\mathrm{R}^{2}$ & $=$ & Coefficient of determination \\
\hline RWT & $=$ & Rhodamine WT \\
\hline SRMS & $=$ & Scaled root mean square error \\
\hline TVD & $=$ & Total variation diminishing \\
\hline USGS & $=$ & United Sates geological survey \\
\hline & \\
\hline
\end{tabular}




\section{Parameter Abbreviations}

\begin{tabular}{|c|c|c|c|}
\hline A & $=$ & Area perpendicular to groundwater flow & $\mathrm{m}$ \\
\hline $\mathrm{b}$ & $=$ & Aquifer thickness & $\mathrm{m}$ \\
\hline $\mathrm{C}_{\mathrm{o}}$ & $=$ & Initial concentration & $\mathrm{mg} / \mathrm{L}$ \\
\hline $\mathrm{C}_{\mathrm{i}}$ & $=$ & Observed concentration & $\mathrm{g} / \mathrm{m}^{3}$ \\
\hline $\mathrm{C}^{\mathrm{k}}$ & $=$ & Dissolved solute concentration modelled with MT3DMS & $\mathrm{M} / \mathrm{L}^{3}$ \\
\hline $\mathrm{C}_{\mathrm{s}}^{\mathrm{k}}$ & $=$ & $\begin{array}{l}\text { Dissolved solute concentration source/sink modelled with } \\
\text { MT3DMS }\end{array}$ & $\mathrm{M} / \mathrm{L}^{3}$ \\
\hline $\mathrm{D}$ & $=$ & Hydrodynamic dispersion & $\mathrm{m}^{2} / \mathrm{d}$ \\
\hline $\mathrm{D}_{\mathrm{d}}$ & $=$ & Diffusion coefficient & $\mathrm{m}^{2} / \mathrm{d}$ \\
\hline $\mathrm{D}_{\mathrm{i}, \mathrm{j}}$ & $=$ & Hydrodynamic dispersion used with MT3DMS & $\mathrm{L}^{2} / \mathrm{T}$ \\
\hline $\mathrm{D}_{\mathrm{x}}$ & $=$ & Longitudinal hydrodynamic dispersion in the $\mathrm{x}$ direction & $\mathrm{m}^{2} / \mathrm{d}$ \\
\hline $\mathrm{d}_{50}$ & $=$ & Median grain diameter & $\mathrm{mm}$ \\
\hline $\mathrm{F}$ & $=$ & One dimensional mass flux & $\mathrm{g} / \mathrm{m}^{2}$ \\
\hline $\mathrm{g}$ & $=$ & Acceleration due to gravity & $\mathrm{m} / \mathrm{s}^{2}$ \\
\hline $\mathrm{h}$ & $=$ & Potentiometric head & $\mathrm{L}$ \\
\hline $\mathrm{i}$ & $=$ & Hydraulic gradient & $\mathrm{m} / \mathrm{m}$ \\
\hline $\mathrm{K}$ & $=$ & Hydraulic conductivity & $\mathrm{m} / \mathrm{d}$ \\
\hline $\mathrm{K}_{\mathrm{eff}}$ & $=$ & Effective value of hydraulic conductivity & $\mathrm{m} / \mathrm{d}$ \\
\hline $\mathrm{K}_{\mathrm{x}}, \mathrm{K}_{\mathrm{y}}$ & $=$ & Hydraulic conductivity in the horizontal direction & $\mathrm{m} / \mathrm{d}$ \\
\hline $\mathrm{K}_{\mathrm{z}}$ & $=$ & Hydraulic conductivity in the vertical direction & $\mathrm{m} / \mathrm{d}$ \\
\hline $\mathrm{M}_{\mathrm{advection}}$ & $=$ & Mass from advection during one MODFLOW stress period & $\mathrm{g}$ \\
\hline $\mathrm{L}$ & $=$ & Characteristic length & $\mathrm{m}$ \\
\hline $\mathrm{L}_{\text {cell }}$ & $=$ & Model cell size & $\mathrm{m}$ \\
\hline $\mathrm{Q}$ & $=$ & Aquifer discharge volume per unit time & $\mathrm{m}^{3} / \mathrm{d}$ \\
\hline $\mathrm{q}_{\mathrm{s}}$ & $=$ & Volumetric water flux modelled with MT3DMS & $\mathrm{L}^{3} / \mathrm{T}$ \\
\hline Sy & $=$ & Aquifer specific yield & $\mathrm{n} / \mathrm{a}$ \\
\hline $\mathrm{t}$ & $=$ & Time & $\mathrm{d}$ \\
\hline $\mathrm{t}_{\text {flow }}$ & $=$ & MODFLOW time step duration & $\mathrm{d}$ \\
\hline$t_{\text {transport }}$ & $=$ & MT3DMS time step duration & $\mathrm{d}$ \\
\hline $\mathrm{v}$ & $=$ & Average linear groundwater flow velocity & $\mathrm{m} / \mathrm{d}$ \\
\hline$v_{i}$ & $=$ & Average linear groundwater flow velocity in MT3DMS & $\mathrm{L} / \mathrm{T}$ \\
\hline $\mathrm{v}_{\mathrm{x}}$ & $=$ & Average linear groundwater flow velocity in the $\mathrm{x}$ direction & $\mathrm{m} / \mathrm{d}$ \\
\hline $\mathrm{W}$ & $=$ & Volumetric water flux modelled with MODFLOW & $\mathrm{L}^{3} / \mathrm{T}$ \\
\hline $\mathrm{x}_{\mathrm{i}, \mathrm{j}}$ & $=$ & Distance along the Cartesian co-ordinate axis in MT3DMS & $\mathrm{L}$ \\
\hline
\end{tabular}




\section{Symbols}

\begin{tabular}{|l|l|l|}
\hline$\alpha$ & $=$ & Dispersivity \\
\hline$\alpha_{\mathrm{x}}$ & $=$ & Longitudinal dispersivity \\
\hline$\alpha_{\mathrm{y}}$ & $=$ & Transverse dispersivity \\
\hline$\alpha_{\mathrm{z}}$ & $=$ & Vertical dispersivity \\
\hline$\Delta$ & $=$ & Change in \\
\hline$\theta$ & $=$ & Porosity \\
\hline$\eta_{\mathrm{e}}$ & $=$ & Effective porosity \\
\hline$\eta$ & $=$ & Total porosity \\
\hline$\rho_{\mathrm{w}}$ & $=$ & Fresh water density corrected for temperature \\
\hline$\mu$ & $=$ & Dynamic viscosity of water \\
\hline$\Psi$ & $=$ & Groundwater pressure \\
\hline
\end{tabular}




\section{Units}

\section{Velocity}

\begin{tabular}{|l|l|l|}
\hline $\mathrm{m} / \mathrm{d}$ & $=$ & Meter per day \\
\hline $\mathrm{L} / \mathrm{T}$ & $=$ & Arbitrary unit for velocity such as meters per day \\
\hline
\end{tabular}

\section{Flow rate}

\begin{tabular}{|l|l|l|}
\hline $\mathrm{m}^{3} / \mathrm{d}$ & $=$ & Meter cubed per day \\
\hline $\mathrm{L}^{3} / \mathrm{T}$ & $=$ & Arbitrary volumetric water flux such as meters cubed per day \\
\hline
\end{tabular}

\section{Time}

\begin{tabular}{|l|l|l|}
\hline $\mathrm{d}$ & $=$ & Day \\
\hline
\end{tabular}

\section{Area}

\begin{tabular}{|l|l|l|}
\hline $\mathrm{m}^{2}$ & $=$ & Meter squared \\
\hline
\end{tabular}

\section{Concentration}

\begin{tabular}{|l|l|l|}
\hline $\mathrm{mg} / \mathrm{L}$ & $=$ & Milligram per liter \\
\hline $\mathrm{g} / \mathrm{m}^{3}$ & $=$ & Gram per cubic meter \\
\hline $\mathrm{g} / \mathrm{m}^{2}$ & $=$ & Gram per square meter \\
\hline $\mathrm{ML}^{3}$ & $=$ & Arbitrary unit for concentration such as grams per meter cubed \\
\hline
\end{tabular}

\section{Mass}

\begin{tabular}{|l|l|l|}
\hline $\mathrm{g}$ & $=$ & Gram \\
\hline
\end{tabular}

\section{Length}

\begin{tabular}{|l|l|l|}
\hline $\mathrm{cm}$ & $=$ & Centimeter \\
\hline $\mathrm{m}$ & $=$ & Meter \\
\hline $\mathrm{L}$ & $=$ & Arbitrary unit of length such as meters \\
\hline
\end{tabular}




\section{Glossary}

Advection: The entrainment of solutes with the flowing groundwater in which they are dissolved. The rate of advection is controlled by the average linear groundwater flow velocity which is a function of hydraulic conductivity, hydraulic gradient and effective porosity (Kasenow, 2001).

Confined aquifer: An aquifer that is underlain and overlain by less permeable strata causing groundwater to flow under-pressure with water levels rising above the top of the aquifer.

Dispersivity: The degree of mixing by hydrodynamic dispersion as a function of time, distance and measurement scale. Dispersion in the direction of flow is controlled by longitudinal dispersivity, dispersion perpendicular to flow is controlled by transverse dispersivity and dispersion vertically is controlled by vertical transverse dispersivity (Kasenow, 2001).

$\mathbf{d}_{\mathbf{5 0}}$ : The median grain size diameter or the effective grain size $50 \%$ finer by weight as determined from a sieve analysis.

Effective porosity: When pore spaces between sediment or rock are inter-connected allowing groundwater to flow from one location to another (Kasenow, 2001).

Heterogeneous: Where the hydraulic properties of the aquifer are non-uniform and vary spatially and with depth (Kasenow, 2001).

Homogeneous: Where the hydraulic properties of an aquifer are uniform throughout its thickness (Kasenow, 2001).

Hydraulic conductivity: Coefficient of proportionality describing the rate of fluid flow for an isotropic porous medium and homogeneous fluid. It is also the volume of water at the existing kinematic viscosity that will move in unit time under a unit 
hydraulic gradient through a unit area measured at right angles to the direction of flow (Kasenow, 2001).

Hydraulic gradient: Controls the direction of groundwater flow and may be measured in the horizontal or vertical direction. The horizontal hydraulic gradient is measured by the change in head between two points, divided by the horizontal distance between the two points.

Mass flux: Product of the flow rate and the solute concentration of the water.

Parameter: An independent variable selected for input into a mathematical model and which values can be changed in to match model outputs to measured or observed calibration targets such as head or solute concentration. Parameters may be split into hydrogeological parameters and parameters that represent model boundary conditions.

Parsimony: Beven (2009) defines the concept of parsimony in the context of environmental modelling as the idea that a model should be no more complex than necessary to predict the observations of sufficient accuracy to be useful.

Parameterisation: The selection of hydrogeological parameters and model boundary condition parameters that will be used in a mathematical model and the process of determining their value.

Residual: Difference between the modelled data and observation data

Rhodamine WT: An orange coloured fluorescent dye that is often used in tracer studies and may be subject to sorption onto the aquifer media.

Steady-state: When groundwater inflow or solute input is equal to groundwater outflow or solute output such that heads or concentrations do not change with time.

Specific yield: Is defined as the ratio of the volume of water that a saturated rock or soil will yield by gravity to the total volume of the rock or soil (Johnson, 1967). 
Transient: When groundwater inflow or solute input is not equal to groundwater outflow or solute output such that heads or concentrations change with time. 


\section{INTRODUCTION}

This study assesses parsimony and predictive uncertainty in the context of groundwater solute transport modelling. Parsimony is assessed by comparing the outputs of different models with varying levels of complexity. Predictive uncertainty is assessed through a comparison of three hypothetical predictions made using a simple linear method. Physical solute transport processes such as scale effects along with aquifer characteristics such as the spatial distribution of aquifer properties were also assessed as a result of the modelling.

Modelling was undertaken using tracer test data from a heterogeneous artificial aquifer designed to represent a 'real life' alluvial aquifer on the Canterbury Plains in New Zealand. The results contribute to a better understanding of how to model solute transport within Canterbury Plains alluvial aquifers as well as solute transport modelling in general.

\subsection{Alluvial Aquifers and Modelling Solute Transport}

Un-consolidated sand and gravel deposits of Quaternary age or slightly older form the most widespread and most exploited aquifer systems in the world (Margat and van der Gun, 2013). This type of aquifer system is dominant over most of the Canterbury Plains region (Brown, 2001). As in many other parts of the world, this aquifer system is highly utilised and under pressure from deteriorating water quality. In terms of groundwater quantity, the Canterbury Plains aquifers are the most highly utilised aquifers in New Zealand with groundwater abstraction accounting for approximately $25 \%$ of all the country's water allocations (excluding hydropower generation) (Aqualinc Research Ltd, 2010). In terms of groundwater quality, these aquifers show deteriorating trends, mainly as a result of land use change to dairying (Parliamentary Commission for the Environment (PCE), 2013). A recent quote from the PCE (2013) states that "It is almost inevitable that without significantly more intervention, we will continue to see an on-going deterioration in water quality in many catchments across the country, particularly in Canterbury". With respect to Canterbury, the two contaminants of most concern are nitrogen and phosphorus. 
It is clear that the non-exploitive allocation of groundwater quantity and proper management of groundwater quality are both highly important when it comes to making sustainable decisions about groundwater resources at a global scale and at local scale with respect to Canterbury aquifers. One way of helping to achieve this is through mathematical modelling which attempts to quantify predictions of stresses such as groundwater abstraction or nutrient contamination of a groundwater system.

The focus of this study is mathematical modelling of solute transport in groundwater. For accurate predictions of solute transport, mathematical models require an accurate representation of the distribution in hydraulic properties of an aquifer system (Close, Bright, Wang, Pang and Manning, 2008). However, the Canterbury Plains alluvial aquifers, like most other aquifer systems, have a very complex heterogeneous distribution of hydraulic properties which can be difficult to measure. Doherty (2010a) states that variations in hydraulic properties are impossible to represent within models at the actual scales they exist in nature.

The photos of an open framework gravel lens surrounded by sandy-gravels, silt and thin layers of clay (Figure 1-1) and photo of groundwater flowing from an open framework gravel lens (Figure 1-2) show what the heterogeneous distribution of hydraulic properties looks like in Canterbury Plains alluvial aquifers.

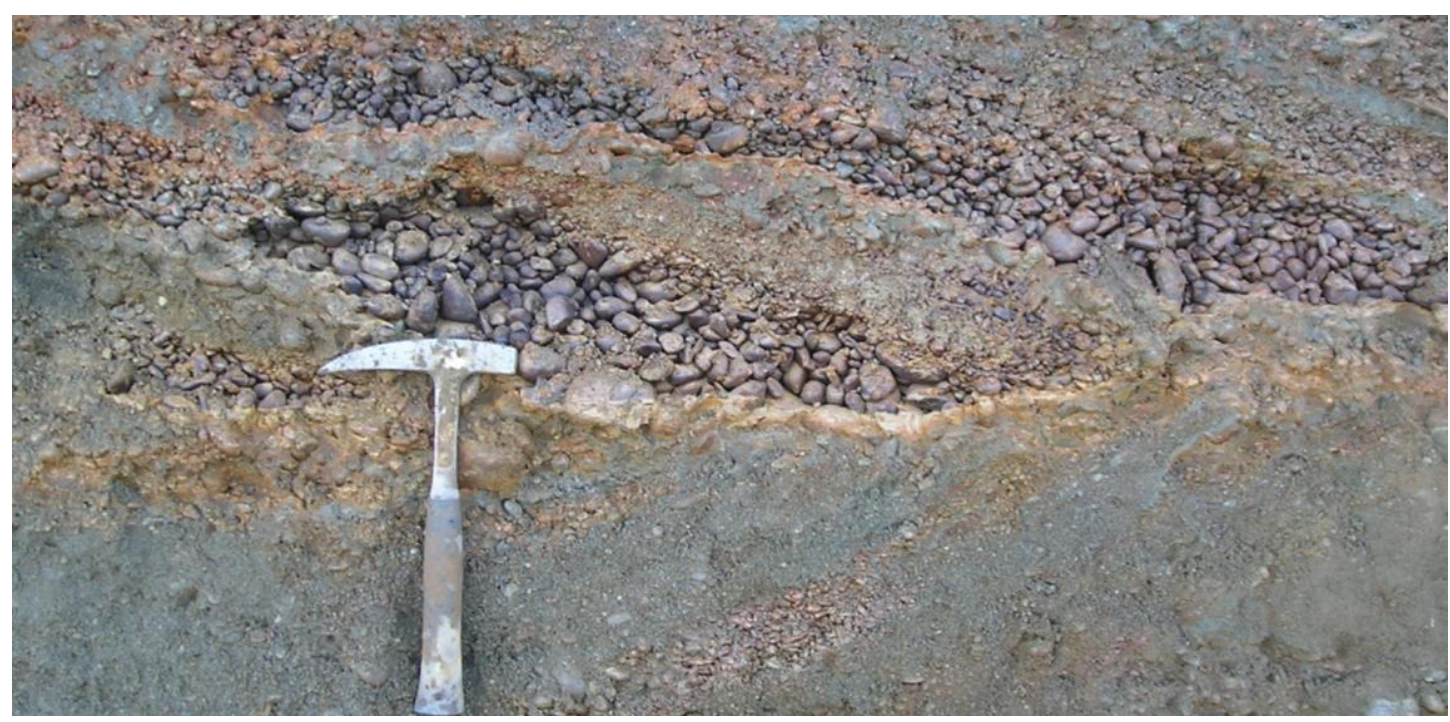

Figure 1-1: Photo of an open framework work gravel lens out-cropping on a coastal cliff near Lowcliffe, Canterbury Plains (photo taken by author) 


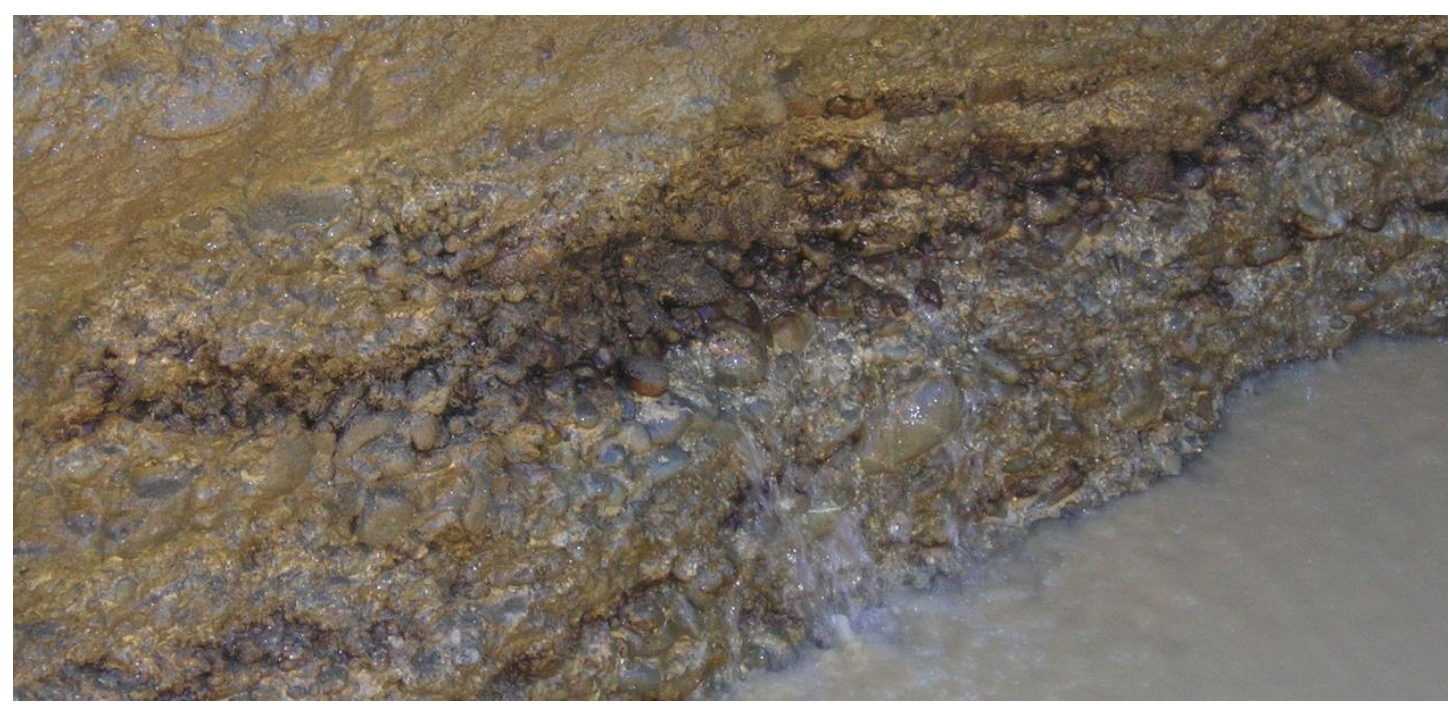

Figure 1-2: Photo of groundwater flowing from an open framework gravel lens at a gallery near the Hinds River, Canterbury Plains (photo taken by author)

Preferential flow through highly permeable macro scale lenses such as those shown in Figure 1-1 and Figure 1-2 has a large effect on solute transport for it is within these lenses that the majority of solute is transported. For example, at a site within the Canterbury Plains alluvial aquifers near Burnham, Dann, Close, Pang, Flintoft, and Hector (2008) estimated that that the permeable open framework gravel lenses comprised approximately $1.2 \%$ of aquifer profile but sustained approximately $98 \%$ of the groundwater flow. Geological characterisation of these lenses is discussed by Davey (2006) and their effect on solute transport is discussed by authors such as Dann et al. (2008).

A model can not represent all variations in hydraulic properties. For example, a regional scale model with a cell size of $100 \mathrm{~m}$ by $100 \mathrm{~m}$ would not account for preferential solute transport through the relatively small open framework gravel lenses shown in Figure 1-1 and Figure 1-2. However, it is not just a matter of reducing the model cell to an infinite size so that attempts can be made to include all this heterogeneity because cell sizes must be finite for a model to have a finite run-time. In addition, the level of complexity as a result of such small cell sizes would be too large to handle in either probabilistic or deterministic analysis (Doherty, 2010b).

Therefore, mathematical models of an aquifer system are always simplified versions of reality. This holds true for the Canterbury Plains alluvial aquifers, where it is 
general practise to treat the aquifer as homogeneous when modelling solute transport (L. Burbery, personal communication, September 9, 2013), at least initially. In cases where a simple model produces a poor fit to the observation data, heterogeneity may be added. Simplifications may cause problems. For example, when predictions of solute migration from a point-source are made using a simple model that assumes homogeneous aquifer conditions, the results may be highly questionable when applied to a heterogeneous aquifer system. The need for simplification of a model is implicit in the discussion of prediction uncertainty and parsimony.

\subsection{Predictive Uncertainty and Parsimony}

Doherty (2007) states that a model of a natural system can never promise a correct prediction, thus there is a need for information given to a decision maker to be accompanied by an assessment of predictive uncertainty. In New Zealand, model prediction uncertainty is largely dealt with by local government through the resource consent process in accordance with the Resource Management Act (Freeman, 2011). In practise, these uncertainties can range from a relatively trivial matter that has little or no environmental consequence, through to major factors that can have significant implications for resource consent decisions and environmental effects (Freeman, 2011).

Despite its importance, many authors note that predictive uncertainty is still not widely adopted. For example, Beven (2006) states that 'uncertainty estimation is still not yet standard practise in environmental modelling'. In New Zealand (Freeman, 2011) discusses the lack of published examples of assessments of environmental effects that have been submitted as part of a resource consent application where the environmental modelling has included an explicit account of uncertainty. However, Doherty (2010b) states that there is growing recognition that model predictions may be seriously wrong and that decision makers are pushing more strongly for guidance on the level of uncertainty.

Model predictions are uncertain because a model must simplify the complex natural system, and because the data they are supplied with is not perfect (Beven, 2009). For example, the data may be subject to measurement errors or parameter values that are fixed may be based on other modelling tools which have their own unique limitations. 
With regards to simplification, the concept of parsimony is highly relevant. The view of parsimony expressed by Beven (2009) is that a model should be no more complex than necessary to make sufficiently useful predicts of the observations. The definition of 'sufficiently accurate to be useful' suggests that model complexity is also dependent upon the significance of the prediction.

\subsection{Aims and Objectives}

\section{Aim One - Assessment of Parsimony}

A solute transport model may be simple or complex. Simple models may adopt lumped or uniformly distributed model parameters which assume homogenous aquifer conditions. In contrast, complex models may use a fully distributed, non-uniform distribution of parameters to represent heterogeneity by means of a mathematical numerical solution.

The main aim of this study is to assess the concept of parsimony and the process of starting with a simple analytical model that assumes homogenous conditions, then progressing through a range of progressively more complex numerical models, some of which include heterogeneity. The criteria for assessment will include how well each model was able to replicate the observation data-set and the extent to which adding more complexity may or may not be advantageous. By applying the concept of parsimony, another aim is to address some concerns about the current widely used approach of using simplistic homogeneous models to heterogeneous alluvial aquifers within the Canterbury Plains.

\section{Aim Two - Assessment of Predictive Uncertainty}

Although there have been many studies on predictive uncertainty within the scientific community, the uptake amongst general practitioners has been low. However, there is growing interest in this topic as well as a need to demonstrate its importance for wider uptake, especially in the day-to-day management and decision making process.

For these reasons, predictive uncertainty is assessed in this study using a method first developed by Moore (2005). The method is part of the PREDUNC suite of analysis used in PEST and is described in some detail by Doherty (2010b). Though the 
method has been applied to other groundwater modelling studies, it has not been applied to solute transport modelling within the Canterbury Plains alluvial aquifers (C. Moore personal communication, April 23, 2013). In addition, its application to a well understood artificial aquifer makes this aim unique because in most cases, modelling is undertaken using an aquifer for which there is little data, or using a synthetic data-set.

The aim is to assess PREDUNC as an appropriate geo-statistical tool for predictive uncertainty analysis and to provide some interpretation of the results in the context of the solute transport modelling undertaken for this study.

\subsection{Previous Studies}

\section{Parsimony}

Similar to this study, Scheibe and Chien (2003) apply parsimonious principles to modelling of a groundwater tracer test by comparing the results of six numerical models ranging from simple deterministic homogenous models through to complex stochastic models. The major difference between this thesis and the work of Scheibe and Chien (2003) is that they also focused on conditioning the observation data-set through calibration with differing amounts of observation data.

Hill (2006) writes about the practical use of simplicity in developing groundwater models based on the principle of parsimony. Hill (2006) put forward a view that simplicity should come first, and they demonstrate the advantages of starting with a simple model and building complexity slowly.

For modelling solute transport in groundwater systems, Konikow (2011) suggest using relatively simple models to test and improve the conceptual understanding of a groundwater system. The advantages and disadvantages of increased model complexity are also discussed and Konikow (2011) shares a similar view to that of Hill (2006) when it comes to starting simple and adding complexity slowly. However, simplicity first is just one view, and there has been active discussion in the earth science literature about the advantages and disadvantages of taking this approach (Hill, 2006). 
For example, Hunt, Doherty and Tonkin (2007) refute the idea that models should be as simple as possible, suggesting that too much simplification may degrade a model's performance. They illustrate this view by comparing a simple zone based model with a small number of parameters to a more complex model with many parameters.

\section{Predictive Uncertainty}

Some of the main sources of uncertainty in numerical modelling relate to structural errors, model parameters and input data. There have been many studies undertaken on different aspects of predictive uncertainty in environmental modelling. Most of these focus on the contributions to uncertainty which come from model parameterisation and observation data addition or subtraction (C. Moore, personal communication, November 8, 2013). Beven (2006) presents many different ways of assessing predictive uncertainty. Doherty (2010b) states that even a casual inspection of the literature reveals large differences in the means through which model predictive uncertainty is assessed. A background to the PREDUNC method used in this thesis is discussed in Chapter 6.1 whilst some examples of the different techniques applied to other studies are discussed as follows.

Using the homogeneous artificial aquifer (built at the same site as the heterogeneous artificial aquifer used in this study), Bright, Wang and Close (2002) undertook numerical modelling of a full head-tank tracer test. Their objective was to quantify how the amount of hydraulic conductivity $(\mathrm{K})$ data affected uncertainty about contaminant transport predictions. The calibrated values of $\mathrm{K}$ were used in a Monte Carlo Multiple Indicator Conditional Stochastic Simulation to generate three equally possible realisations of the $\mathrm{K}$ field. The results showed that the confidence band reduced with increasing $\mathrm{K}$ data and the authors suggested that Monte Carlo numerical simulations are a potentially useful tool for assessing how much data may be required for a field investigation.

Refsgaard, Jeroen, van der Sluijs, Brown, van der Keur (2006) provide a framework for dealing with uncertainty due to model structure error. Many authors acknowledge that structural errors are the main source of uncertainty in numerical model predictions (Refsgaard et al., 2006). The authors provide examples of how different 
conceptual models lead to quite different model outputs. As a consequence, using a single conceptual model provides no way of assessing the uncertainty of model structural errors. To deal with this problem, Refsgaard et al. (2006) discuss a framework that involves the use of multiple conceptual models.

Ammar, Khalil, McKee and Jagath Kaluarachchi (2008) used a Bayesian deduction model to optimise a monitoring network for groundwater Nitrate-Nitrogen concentrations in the West Bank Palestinian province. The model known as a Relevance Vector Machine produced probabilistic predictions that quantified the uncertainty in Nitrate-Nitrogen observation data and model parameters. The model was used to explore trade-offs such as monitoring cost versus uncertainty in NitrateNitrogen predictions produced by the model.

There is often the question of how much data is required and value or worth of collecting extra data or removing data when it comes to making predictions at a satisfactory level. In Chapter 6, the concept of data worth is also explored using PREDUNC. An alternative method used by Aziz, Ling, Rifai, Newell and Gonzales (2003) is decision support software for long term Monitoring and Remediation Optimisation System (MAROS) of groundwater contaminant monitoring networks. MAROS optimises an existing monitoring network using temporal and spatial data to determine the location and frequency of monitoring. The objective is to minimise monitoring locations and reduce sampling frequency without unacceptable loss of information (resulting in increased uncertainty) in order to ensure that the contaminant plume is adequately characterised.

\subsection{Chapter Summary}

\section{Chapter One - Introduction}

Chapter one provided the aims and objectives of this study. These were put into context through a discussion of solute transport modelling within the Canterbury Plains alluvial aquifers, through a discussion of the views on parsimony and through a discussion of why predictive uncertainty is important. The broader context of predictive uncertainty and parsimony was also discussed with some examples of similar work undertaken by other authors. 


\section{Chapter Two-Artificial aquifer and tracer test description}

Chapter two provides a description of the heterogeneous artificial aquifer, an overview of the test method, a description of what happened during the tracer test and a preliminary assessment of the aquifer properties.

\section{Chapter Three - Analytical modelling}

Chapter three details the analytical model used to replicate the tracer test data, a discussion of the model predictions and a discussion of the hydrogeological parameters used in the modelling.

\section{Chapter Four - Numerical model design and construction}

Chapter four details how the tracer test was modelled using numerical techniques. It discusses what model codes were used and why. It also discusses how the numerical models were designed to represent the physical properties of the artificial aquifer.

\section{Chapter Five - Numerical model calibration}

Chapter five provides a description of the different numerical model parameterisations that were used to replicate the tracer test data and how each parameterisation produces quite different results. The results are discussed in relation to how well each parameterisation replicates the observation data, the observations and parameter sensitivities, parameterisation uniqueness, $\mathrm{K}$ heterogeneity and the mass balance for flow and transport.

\section{Chapter Six - Predictive uncertainty and data worth}

Chapter six provides a description of PREDUNC as a tool for assessing predictive uncertainty and data worth. PREDUNC is linear predictive uncertainty analysis tool included in the PEST suite of programs detailed by Doherty (2010b). This method is used to assess: 1) the total pre and post-calibration contributions to predictive uncertainty from one of the models, 2) pre and post-calibration contributions to predictive uncertainty from the parameters used in model calibration and 3) the worth of observations for reducing predictive uncertainty. PREDUNC is applied to three 
hypothetical predictions and the results are assessed in the context of what has been learnt about the physical processes and characteristics of the artificial aquifer.

\section{Chapter Seven - Summary, Application of Results and Recommendations}

Chapter seven uses the results of this study and lessons learnt to provide some guidance on solute transport modelling in general and within heterogeneous alluvial aquifers. It also provides a summary of the results with regards to the aims of this study and some recommendations for future work. 


\section{HETEROGENEOUS ARTIFICIAL AQUIFER AND TRACER TEST DESCRIPTION}

The purpose of this chapter is to give a physical description of the heterogeneous artificial aquifer, an overview of the test method, a description of what happened during the tracer test and a preliminary assessment of the aquifer properties.

\subsection{Background}

The heterogeneous artificial aquifer was one of two artificial aquifers built at Lincoln University (Canterbury, New Zealand) in 1995 to investigate the influence of spatial variations in hydrogeological parameters on contaminant transport in alluvial aquifers (Close et al., 2008). The other artificial aquifer was designed to be homogenous.

At the time of construction, the artificial aquifer facility was one of only three artificial aquifers of this type and size known in the world (Close et al., 2008). The author could not find any other more recent laboratory based artificial aquifers of this size reported by Close et al. (2008). However outside the laboratory, large scale artificial aquifers in the field have been created for purposes such as water storage (Helweg and Smith, 1978).

After its construction, two tracer tests were undertaken in the heterogeneous artificial aquifer. One was a point source injection tracer test undertaken in 2000 and the other was a full head-tank tracer test undertaken in 2003. Until now, neither test has been analysed or published. This study uses data from the full head-tank tracer test undertaken in 2003. 


\subsection{Artificial Aquifer Description}

\subsubsection{Structure}

The heterogeneous artificial aquifer was constructed inside a tank. The internal dimensions were $9.5 \mathrm{~m}$ lengthwise in the direction of groundwater flow, $4.66 \mathrm{~m}$ wide perpendicular to groundwater flow and $2.6 \mathrm{~m}$ deep in the vertical direction. The structure and key features of the artificial aquifer are shown in Figure 2-1.

The aquifer consisted of 17 layers of un-consolidated sediment. Each layer consisted of blocks that were $0.50 \mathrm{~m}$ wide, $0.50 \mathrm{~m}$ long and $0.15 \mathrm{~m}$ thick when packed. A total of 2,907 blocks were laid down by hand over a six month period. The block placement was based on Ground Penetrating Radar images of an alluvial aquifer at Burnham, located $25 \mathrm{~km}$ north of Christchurch (J. Bright, personal communication, August 30, 2013). Details of the geophysical survey are discussed by Close and Pang (1995).

Pea gravel applied to the roof of the tank acted as a weight for the confining layer which consisted of an impermeable high-density polyethylene geotextile. All blocks in column 1 and column 19 were uniformly filled with coarse to very coarse sand. This was done with the aim of creating a diffusive layer that would allow the tracer to spread more evenly into and out of the aquifer. The remaining blocks were filled with one of three different grain size ranges ranging from medium sand to very fine gravel based on the classification after Wentworth (1922).

Figure 2-2 shows blocks being put in place with a monitoring well used to take groundwater samples placed in the centre of a block. The block distribution based on the grain sizes is provided in Appendix A. 
Chapter Two - Heterogeneous Artificial Aquifer and Tracer Test Description

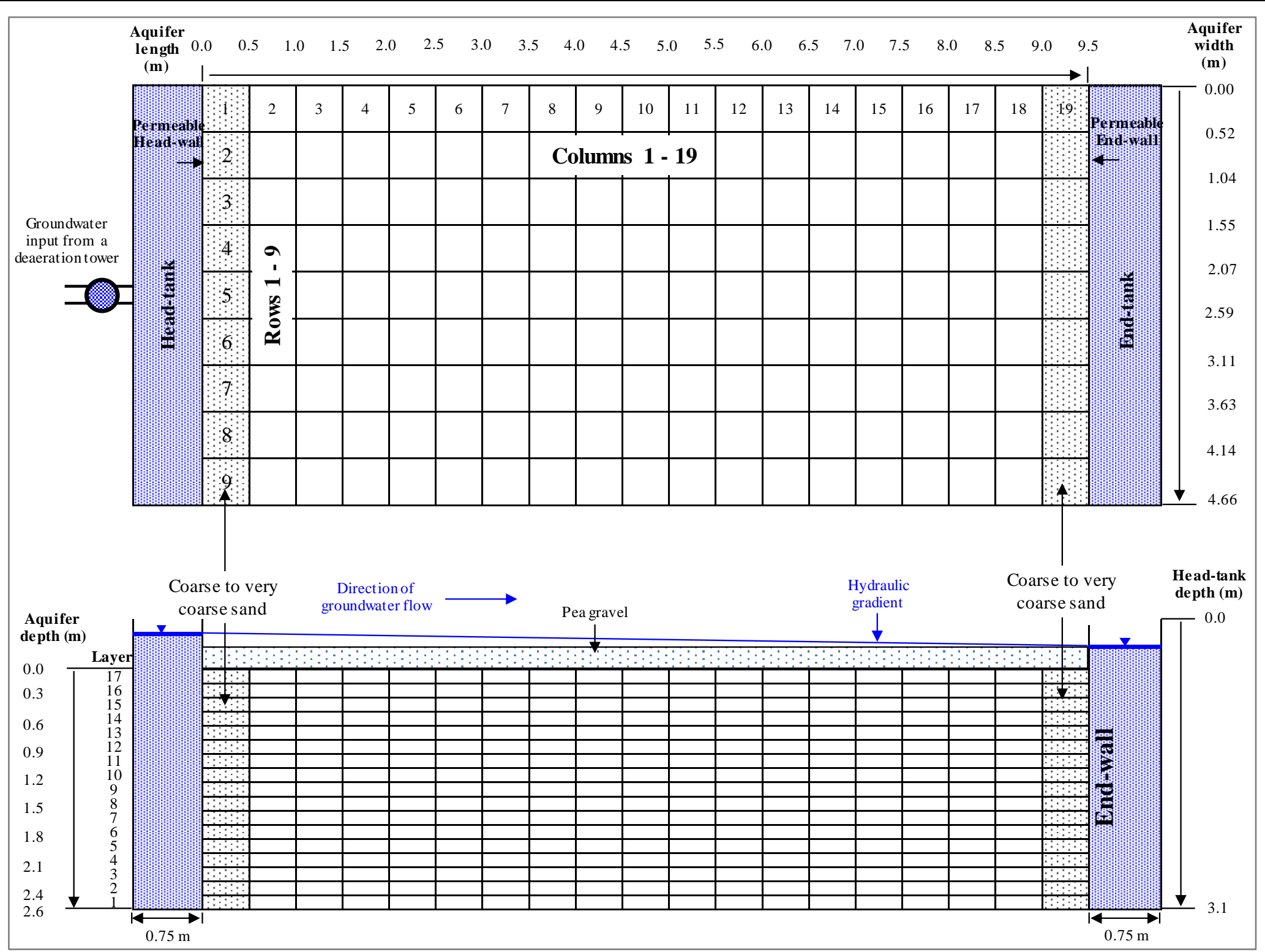

Figure 2-1: Structure and key features of the heterogeneous artificial aquifer 


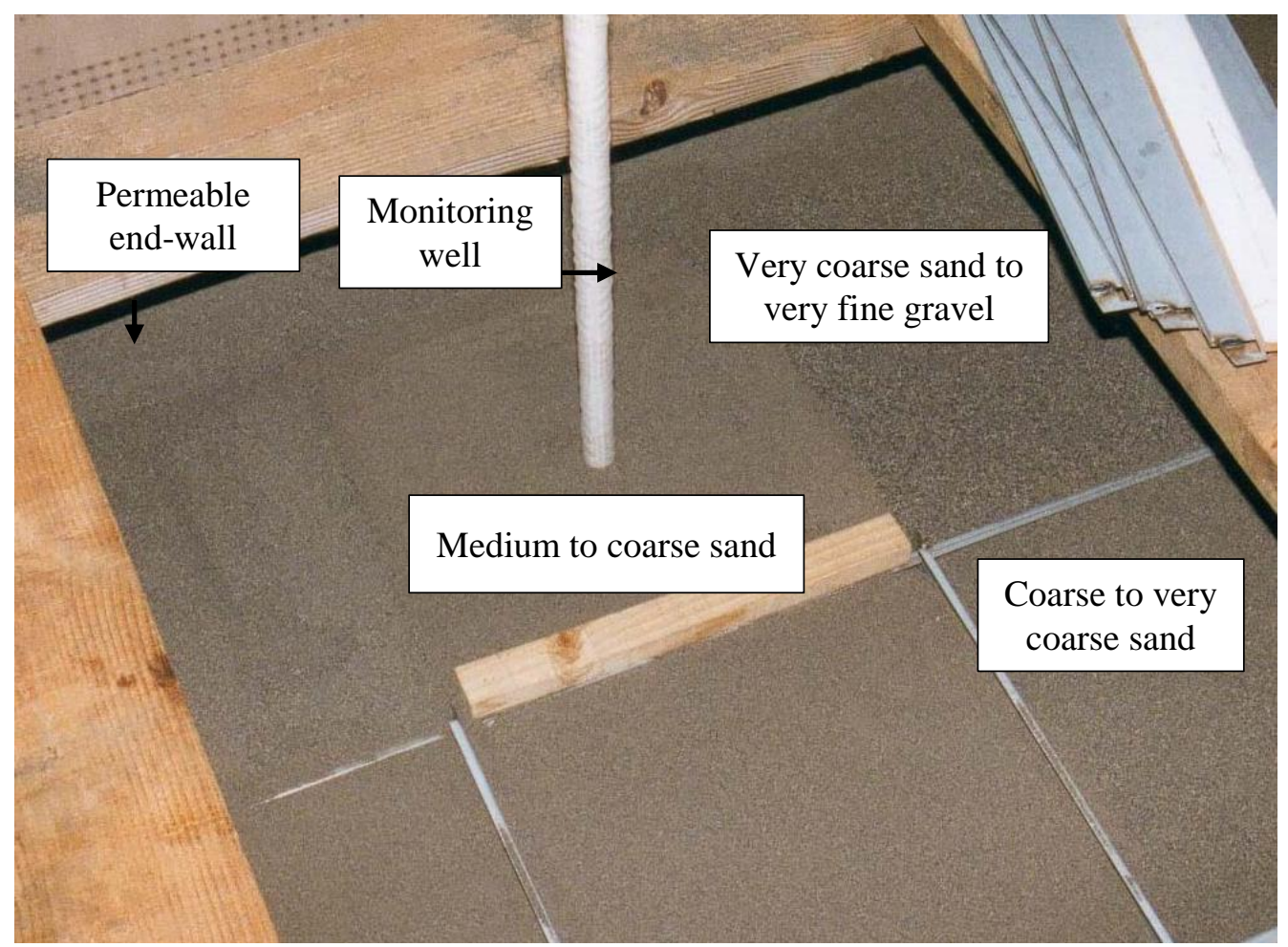

Figure 2-2: Construction of the heterogeneous artificial aquifer showing placement of blocks, a monitoring well and a section of the end-wall (photo sourced from ESR archive)

\subsubsection{Grain Sizes}

The aquifer consisted of three grain size ranges determined through dry sieving of sand and gravel sourced from Birdlings Flat near Lake Ellesmere in Canterbury (M. Close personal communication, August 5, 2013). The actual grain size ranges used to construct the aquifer, the Wentworth classification and the median grain size $50 \%$ finer by weight $\left(\mathrm{d}_{50}\right)$ are shown in Table $2-1$.

Table 2-1: Grain size classification, grain size range and median grain size $\left(d_{50}\right)$

\begin{tabular}{|l|c|c|}
\hline \multicolumn{1}{|c|}{ Wentworth classification } & $\begin{array}{c}\text { Grain size range } \\
(\mathbf{m m})\end{array}$ & $\begin{array}{c}\text { Median grain } \\
\text { size }-\mathbf{d}_{\mathbf{5 0}}(\mathbf{m m})\end{array}$ \\
\hline Medium to coarse sand & $0.25-0.60$ & 0.5 \\
\hline Coarse to very coarse sand & $0.60-1.18$ & 0.8 \\
\hline Very coarse sand to very fine gravel & $1.18-2.36$ & 1.2 \\
\hline
\end{tabular}




\subsection{Instrumentation, Sampling and Hydraulic Measurements}

The tracer test was undertaken over 102 days. Figure 2-3 shows the location of piezometers used to take groundwater pressure readings and monitoring wells used to take $\mathrm{Br}$ concentration samples. Figure 2-4 shows the arrangement of monitoring wells, direction of groundwater flow and location of the end-wall. Figure 2-5 shows the location and identification system used to record Br concentrations from the endwall and Figure 2-6 shows the end-wall sampling points. The colour coding of orange, grey and black (in Figure 2-5) corresponds with the orange, grey and black breakthrough curves at each depth interval shown in Figure 2-11 and Figure 2-12 and Figure 2-13.

Groundwater pressure readings were taken from the three piezometers labelled $U, M$ and $\mathrm{D}$. The piezometers were located at the bottom of the aquifer, spanned the entire aquifer width and were constructed of perforated PVC pipe. The aquifer contained 45 monitoring wells. Fifteen were used during the test and each was identified using a system of column ID's in the direction of groundwater flow labelled 1, 5 and 9 and a system of arrays perpendicular to groundwater flow labelled A to E. Bromide samples from these wells were taken at depths of $0.4 \mathrm{~m}, 1.0 \mathrm{~m}, 1.6 \mathrm{~m}$ and $2.2 \mathrm{~m}$ below the top of the aquifer. Flow into the aquifer was monitored with an inline flow meter and flow out of the aquifer was monitored with a V-notch weir.

A total of $5,679 \mathrm{Br}$ concentration measurements were taken during the test. Modelling undertaken prior to commencing the test predicted that more $\mathrm{Br}$ would come out of one side of the end-wall, thus a greater number of sampling points were placed in the Clear, Brown, Blue and White columns (J. Bright, personal communication, August 30, 2013) shown in Figure 2-5.

The $\mathrm{x}, \mathrm{y}$ and $\mathrm{z}$ coordinates for each monitoring well and end-wall sampling point is provided in digital Appendix A. Bromide observation data are provided in digital Appendix B and the aquifer inflows and outflows are provided in digital Appendix C. 
Chapter Two - Heterogeneous Artificial Aquifer and Tracer Test Description

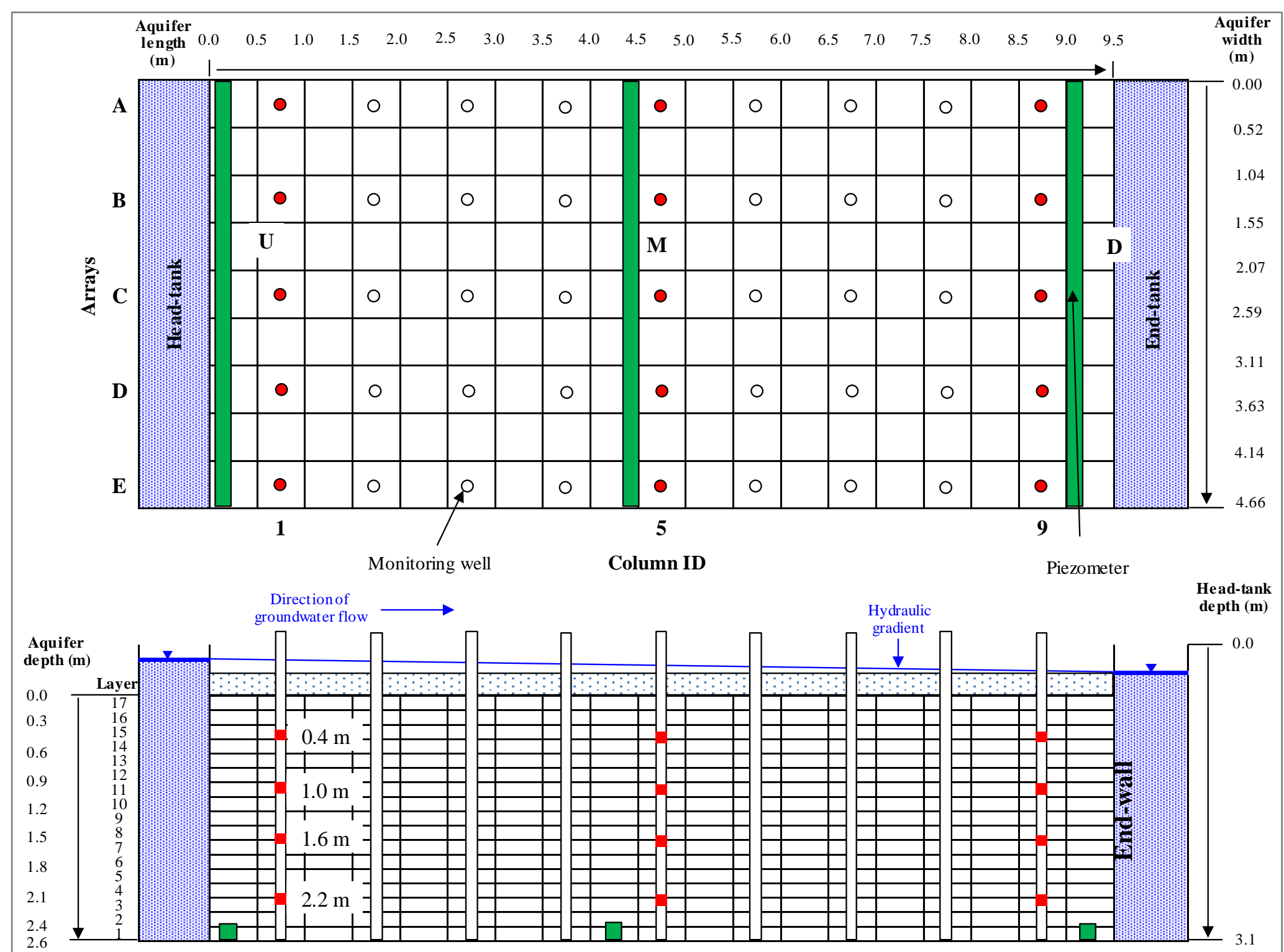

Figure 2-3: Location of $\mathrm{Br}$ samples taken from monitoring wells (in red) and groundwater pressures taken from three piezometers (in green) 


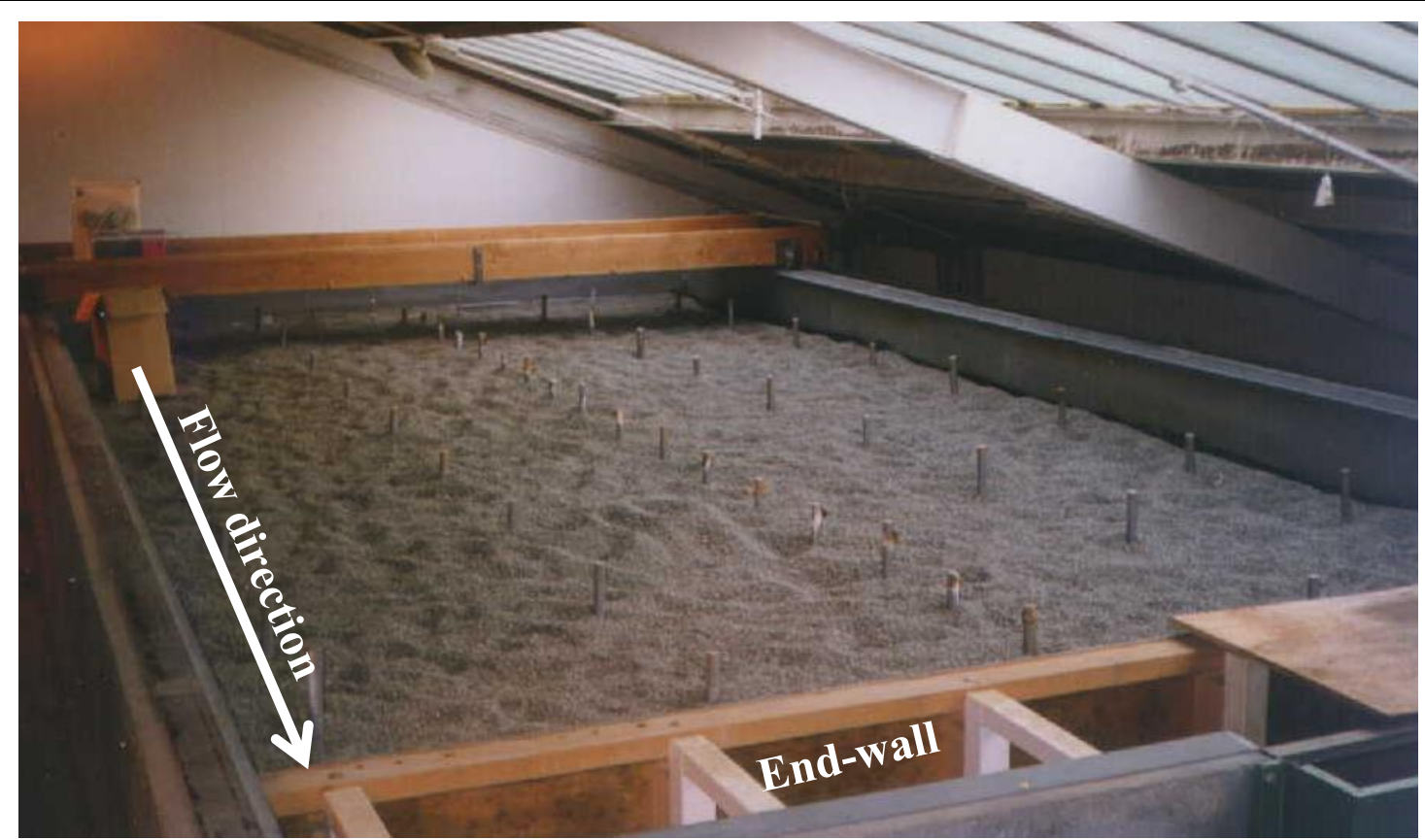

Figure 2-4: Heterogeneous artificial aquifer and monitoring wells (photo sourced from ESR archive)

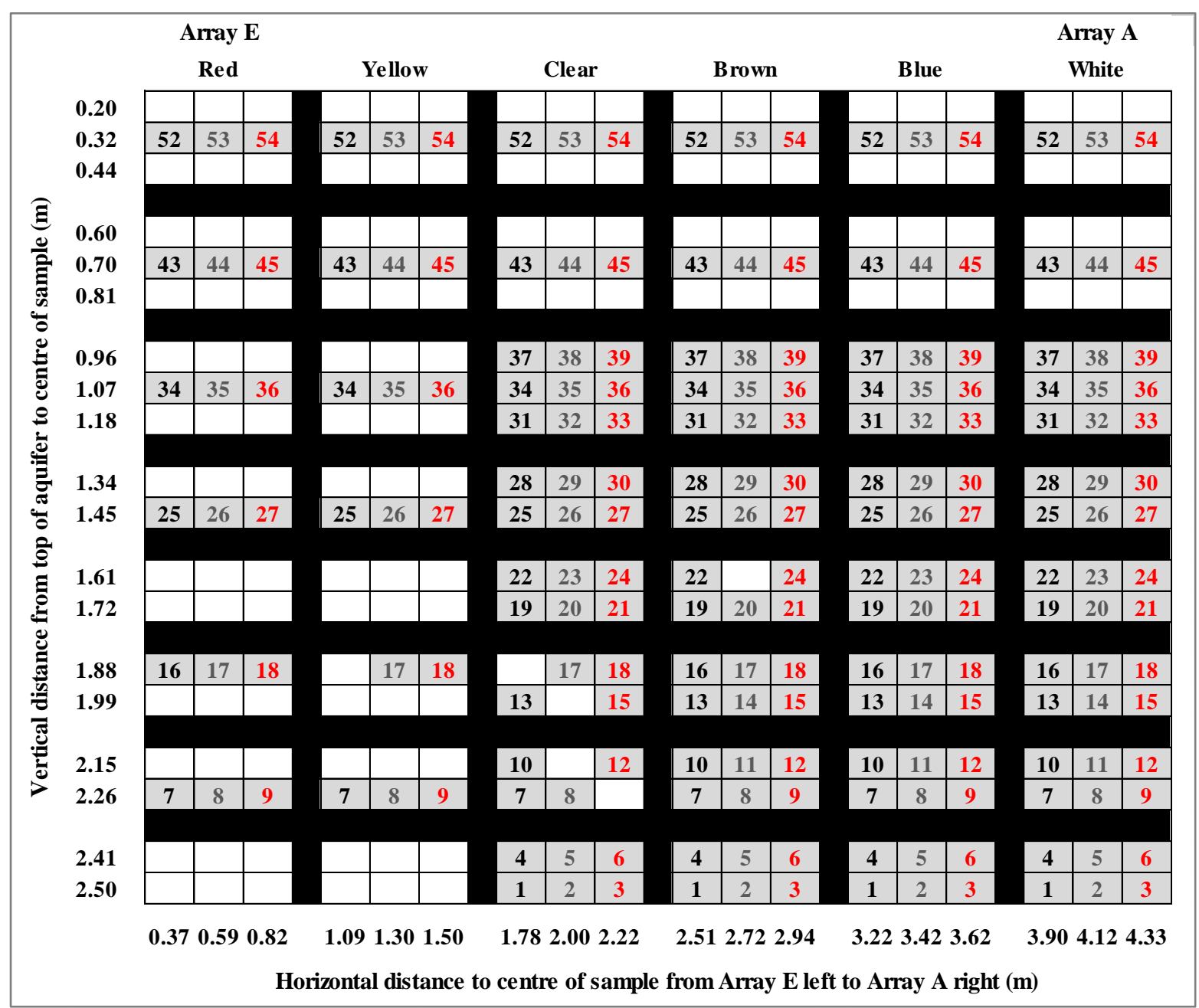

Figure 2-5: Location and identification of the end-wall sampling points. The red, grey and black numbers correspond to the colour coding of plots in Figure 2-11 to Figure 2-13 


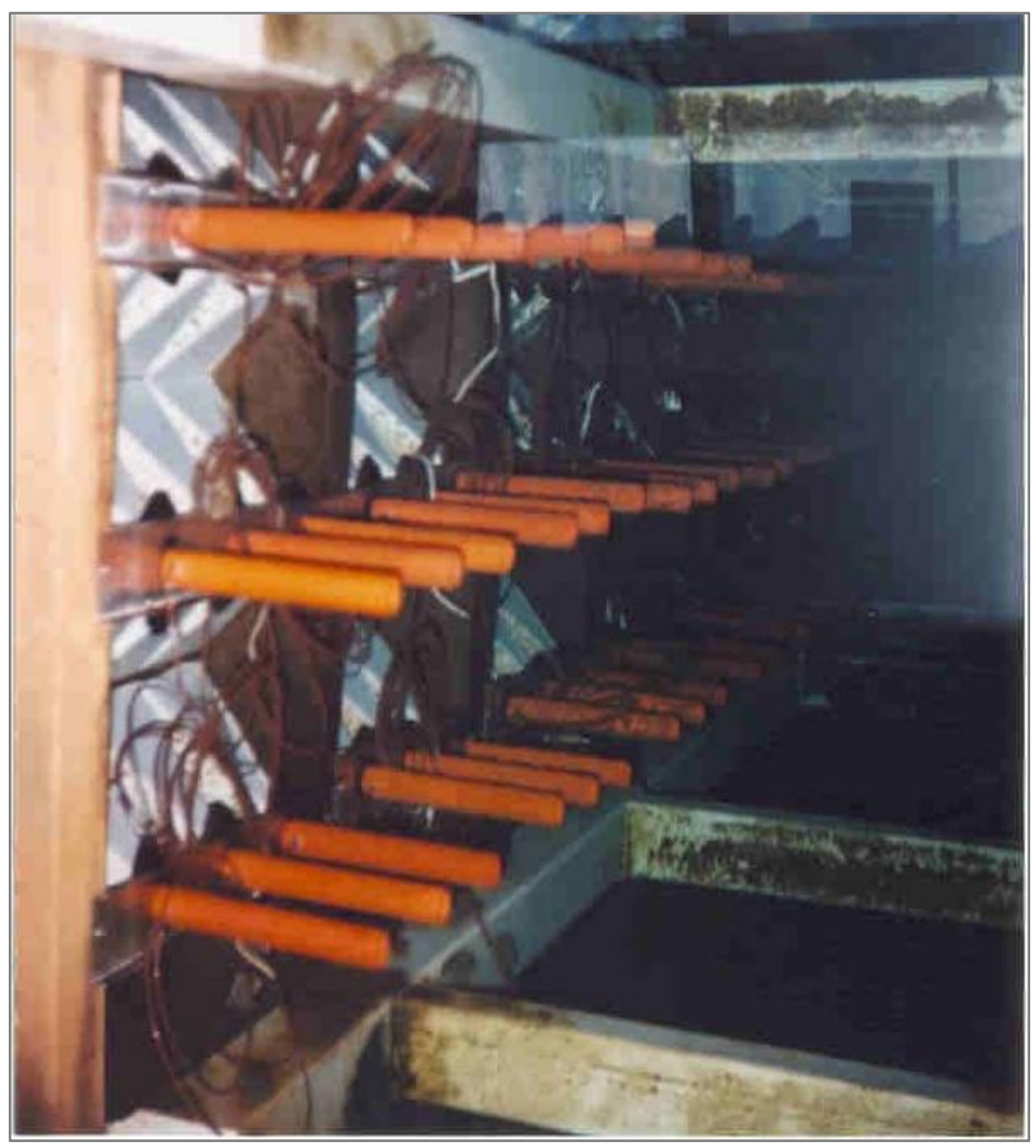

Figure 2-6: Photograph of end-wall sampling points (photo sourced from ESR archive)

\subsection{Aquifer Conditions during the Tracer Test}

\section{Groundwater Source}

Water for the aquifer was sourced from an $85 \mathrm{~m}$ deep well that was screened into an alluvial greywacke derived aquifer. No $\mathrm{Br}$ concentration measurements were taken from the well water. However, previous test results showed $\mathrm{Br}$ concentrations below the detection limit (L. Burbery personal communication, October 22, 2013). Because the detection limit is not known, an assumption has been made that the background $\mathrm{Br}$ concentration is zero.

\section{Groundwater Flow and Transport Boundaries}

The $9.5 \mathrm{~m}$ long floor and roof of the tank, and the two $9.5 \mathrm{~m}$ long walls were impermeable to groundwater flow, and acted as no flow and zero concentration boundaries. The $4.66 \mathrm{~m}$ wide and $2.6 \mathrm{~m}$ deep head-wall and end-wall were permeable to groundwater flow and $\mathrm{Br}$. Groundwater flow and $\mathrm{Br}$ were released over the full 
thickness and width of the aquifer from the head-tank via the head-wall. Likewise groundwater flow and $\mathrm{Br}$ were discharged over the full thickness and width of the aquifer via the end-wall and into the end-tank. The head-tank and end-tank were connected to the aquifer using a permeable mesh. The aquifer type was confined.

\section{Bromide Injection}

A Lithium Bromide solution containing $\mathrm{Br}$ at a concentration $730 \mathrm{mg} / \mathrm{L}$ was injected into the head-tank for a period of 7.2 days. The total mass of $\mathrm{Br}$ added was 146 grams. Bromide concentrations were measured at 3 depths within the head-tank. Figure 2-7 shows the mean concentration measured over time. The concentration was relatively constant during the 7.2 day injection period with a mean concentration of $3.3 \mathrm{mg} / \mathrm{L}$ and two small peaks at days 1.5 and 7.2. The peaks relate to small increases in the rate of injection. Tracer concentration in the head-tank and therefore tracer input into the aquifer declined after 7.2 days. By day 38 , the $\mathrm{Br}$ concentration in the head-tank was zero.

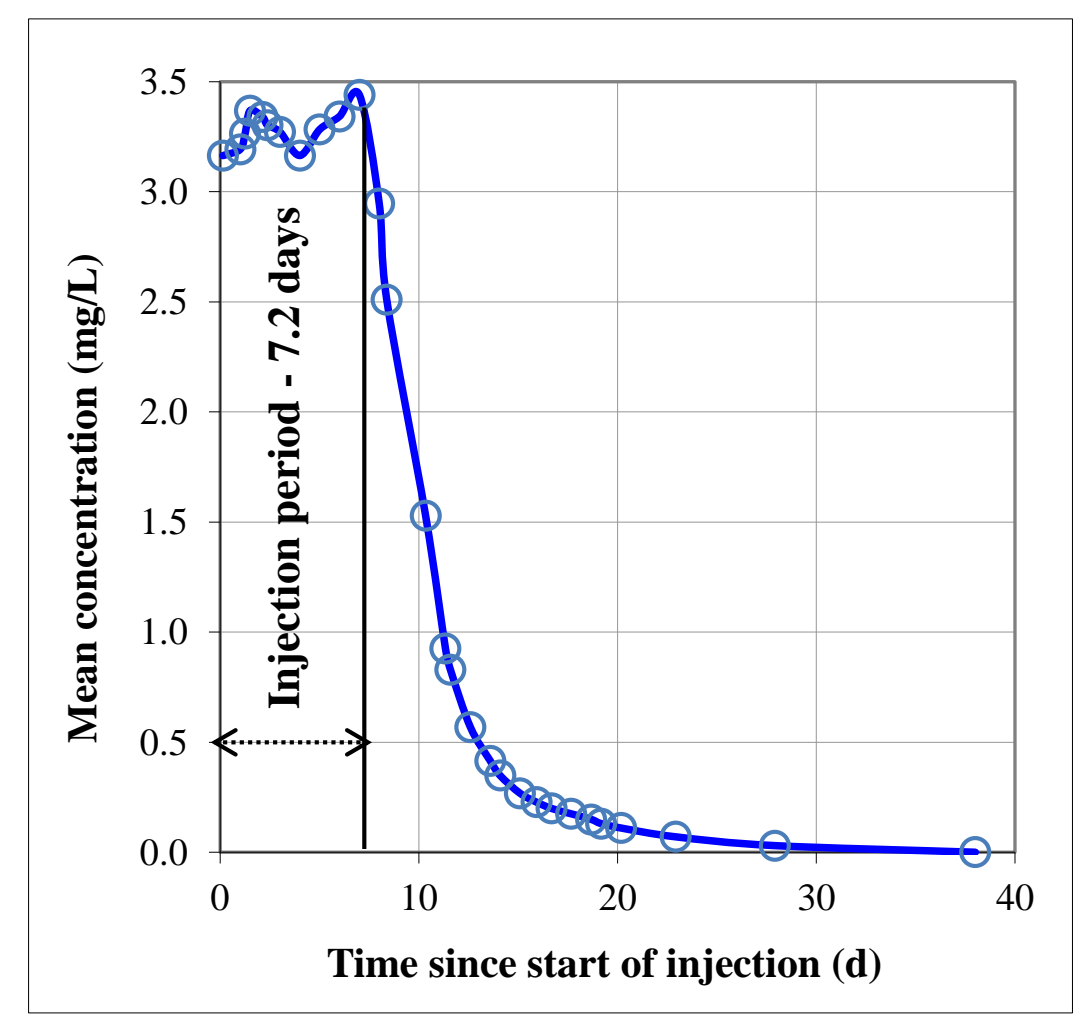

Figure 2-7: Mean Br concentration measured in the head-tank 


\section{Horizontal Hydraulic Gradient}

The horizontal hydraulic gradient (i) is measured using Equation 2-1.

$$
\mathrm{i}=\frac{\Delta \Psi}{\mathrm{L}}
$$

Equation 2-1

The change in groundwater pressure $(\Delta \Psi)$ between piezometers $U$ and $M$, and piezometers $\mathrm{M}$ and $\mathrm{D}$ was $0.004 \mathrm{~m}$ on day one and the horizontal distance (L) between the piezometers $\mathrm{U}, \mathrm{M}$ and $\mathrm{D}$ was $4.55 \mathrm{~m}$. Therefore, $\mathrm{i}$ on day one was $0.00088 \mathrm{~m} / \mathrm{m}$. For the remainder of the test, $\Delta \Psi$ between piezometers $\mathrm{U}, \mathrm{M}$ and D was $0.002 \mathrm{~m}$ and i remained a constant $0.00044 \mathrm{~m} / \mathrm{m}$. The $\Psi$ drops of $0.002 \mathrm{~m}$ represent the minimum recordable $\Delta \Psi$. Given the small $\mathrm{i}$ and coarse resolution of measurements, $i$ has a high degree of uncertainty.

\section{Through-flow}

Figure 2-8 shows inflow rate to the head-tank, outflow rate from the end-tank, and $\Delta \Psi$ from the piezometers. Groundwater pressures were relatively stable and the $\Delta \Psi$ occur at the same time in each piezometer. The mean inflow rate was $4.3 \mathrm{~m}^{3} / \mathrm{d}$ and the mean outflow rate was $3.4 \mathrm{~m}^{3} / \mathrm{d}$. The difference between is due a portion of the inflow going to waste before it entered the aquifer; therefore the true aquifer throughflow is represented by the outflow. Inflow and outflow decline during the test. Since aquifer K and Storativity do not change with time, theoretically, a reduction in flow will cause a change in storage reflected by a drop in $\Psi$. However, probably due to the coarse resolution of measurements, $\Psi$ observations appeared relatively constant.

In Figure 2-9, the effects of groundwater abstraction on outflow were assessed by plotting outflow against groundwater abstraction from all monitoring wells and endwall sampling points. Since there is no obvious correlation between groundwater abstraction and outflow, it is unlikely that groundwater abstraction caused this decline. Thus the cause in declining flow rates is unknown. 


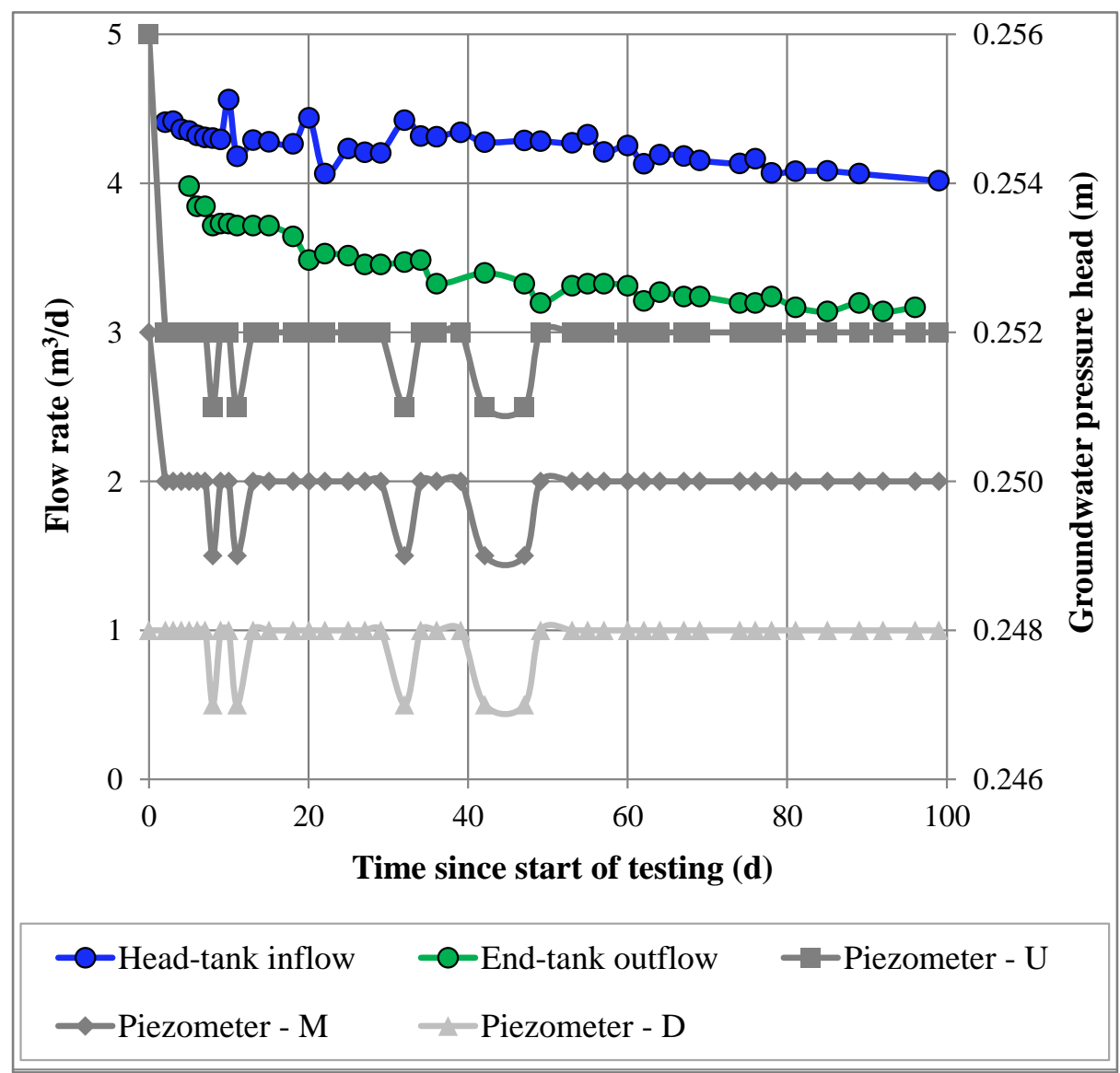

Figure 2-8: Aquifer inflow, outflow and groundwater pressures

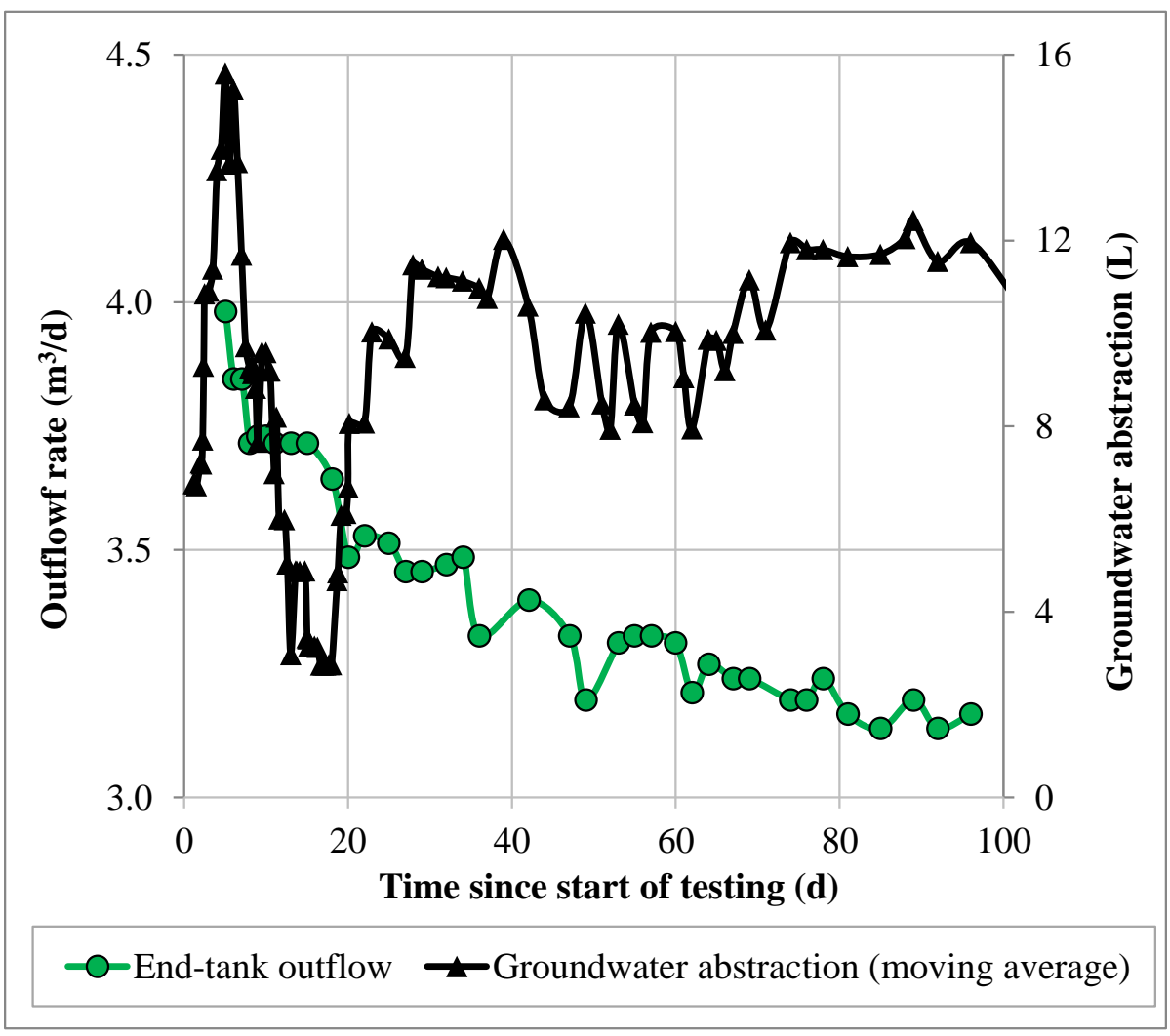

Figure 2-9: Outflow versus groundwater abstraction from sampling 


\subsection{Breakthrough Curves}

Changes in $\mathrm{Br}$ concentration with time at each monitoring well and end-wall sampling point created a breakthrough curve. Figure 2-10 shows breakthrough curves for each monitoring well at a distance of $0.75 \mathrm{~m}$ (green), $4.75 \mathrm{~m}$ (blue) and $8.75 \mathrm{~m}$ (red) from the head-tank. Figure 2-11, Figure 2-12 and Figure 2-13 present breakthrough curves for each end-wall sampling. Each graph plots the concentration of three individual sampling points with one in black, grey and orange. These match the black, grey and orange colour coding shown in Figure 2-5.

\section{Peak Concentrations}

Timing of the peak concentrations increased with increasing distance from the headtank as a consequence of increasing travel distance. The magnitude of peak concentrations decreased with increasing distance from the head-tank in response to spatial variations in $\mathrm{K}$ and effective porosity $\left(\eta_{\mathrm{e}}\right)$ which caused $\mathrm{Br}$ to disperse as it moved through the aquifer at different velocities. Some breakthrough curves show a bimodal distribution which could be a result of the fluctuating $\mathrm{Br}$ input shown in Figure 2-7 or due to aquifer heterogeneity causing pulses of $\mathrm{Br}$ to arrive at different times.

An early peak concentration measured in less than 10 days was observed in some endwall sampling points. The early peak was probably caused by water by-passing the aquifer through a gap between the surface of the aquifer and the roof of the tank which could occur through settlement and compaction of the aquifer media over time. Bypass flow may have occurred along the walls of the tank but this is considered less likely. For the early peak to be measured below the top of the aquifer, some of the tracer must have moved back through the permeable membrane that separates the down-gradient edge of the aquifer and the end-tank.

\section{Start and Finishing Concentrations}

Most observations show a background $\mathrm{Br}$ concentration between $0.01 \mathrm{mg} / \mathrm{L}$ and 0.2 $\mathrm{mg} / \mathrm{L}$. Since the background concentration was assumed to be zero (see Chapter 2.4) these low values probably resulted from analytical errors in converting raw data in millivolt to a concentration in $\mathrm{mg} / \mathrm{L}$ after measurements were taken using an ion selective electrode. This is referred to as limited dynamic range. 

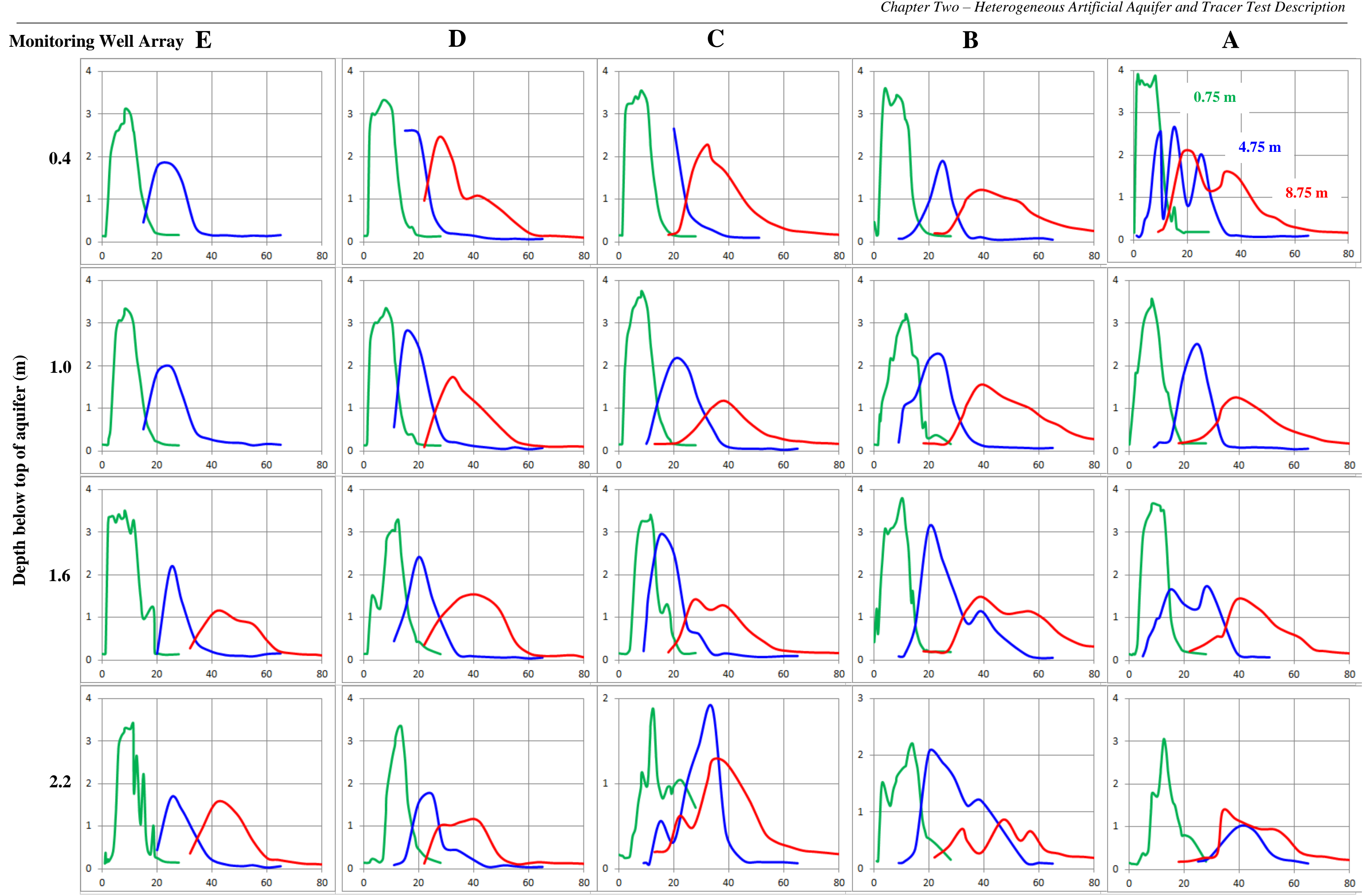

Chapter Two - Heterogeneous Artificial Aquifer and Tracer Test Description

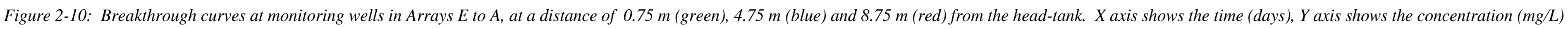




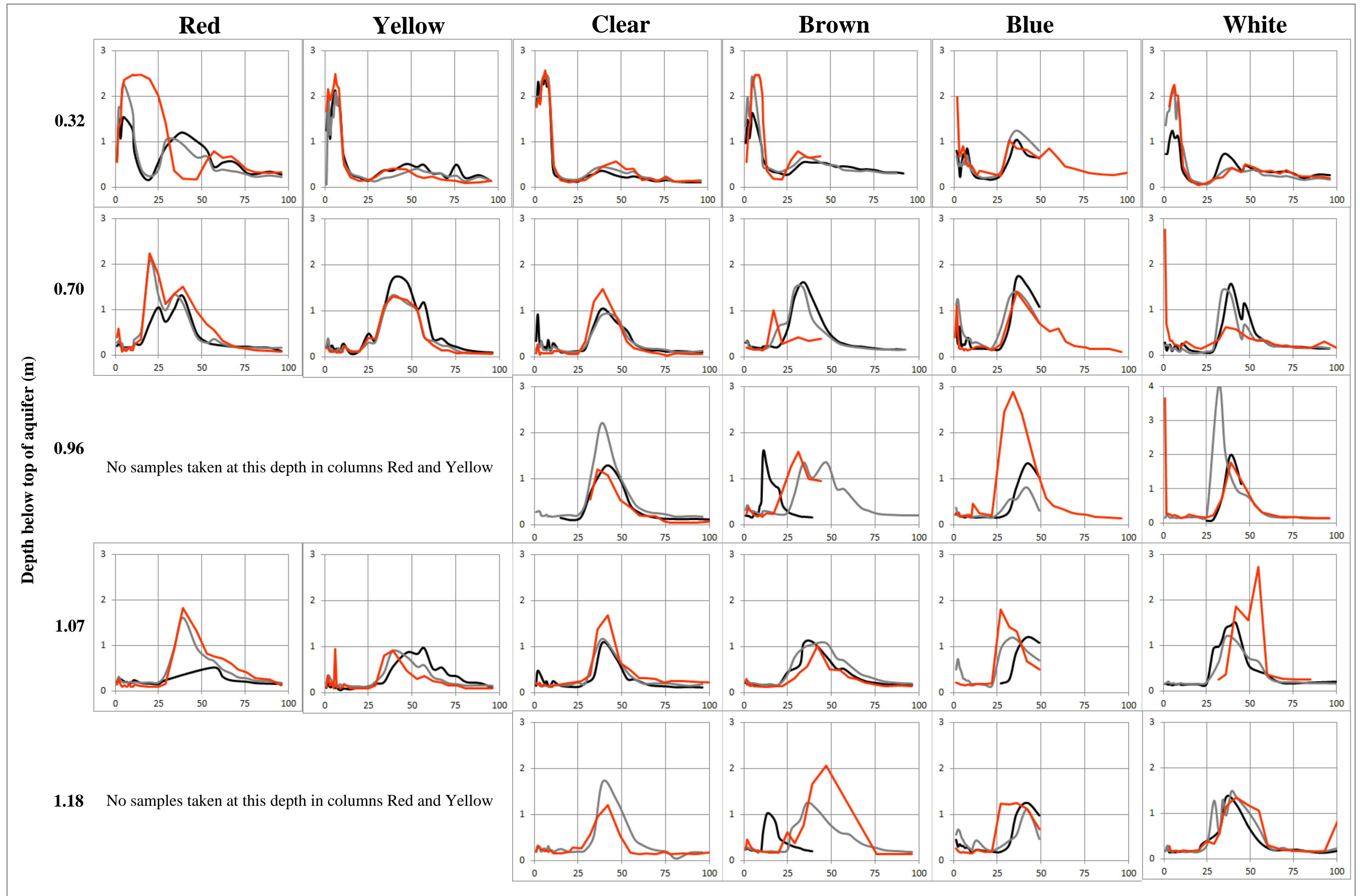

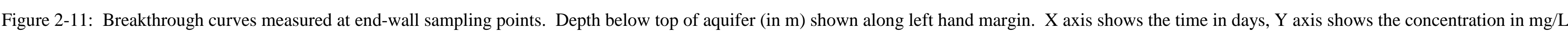




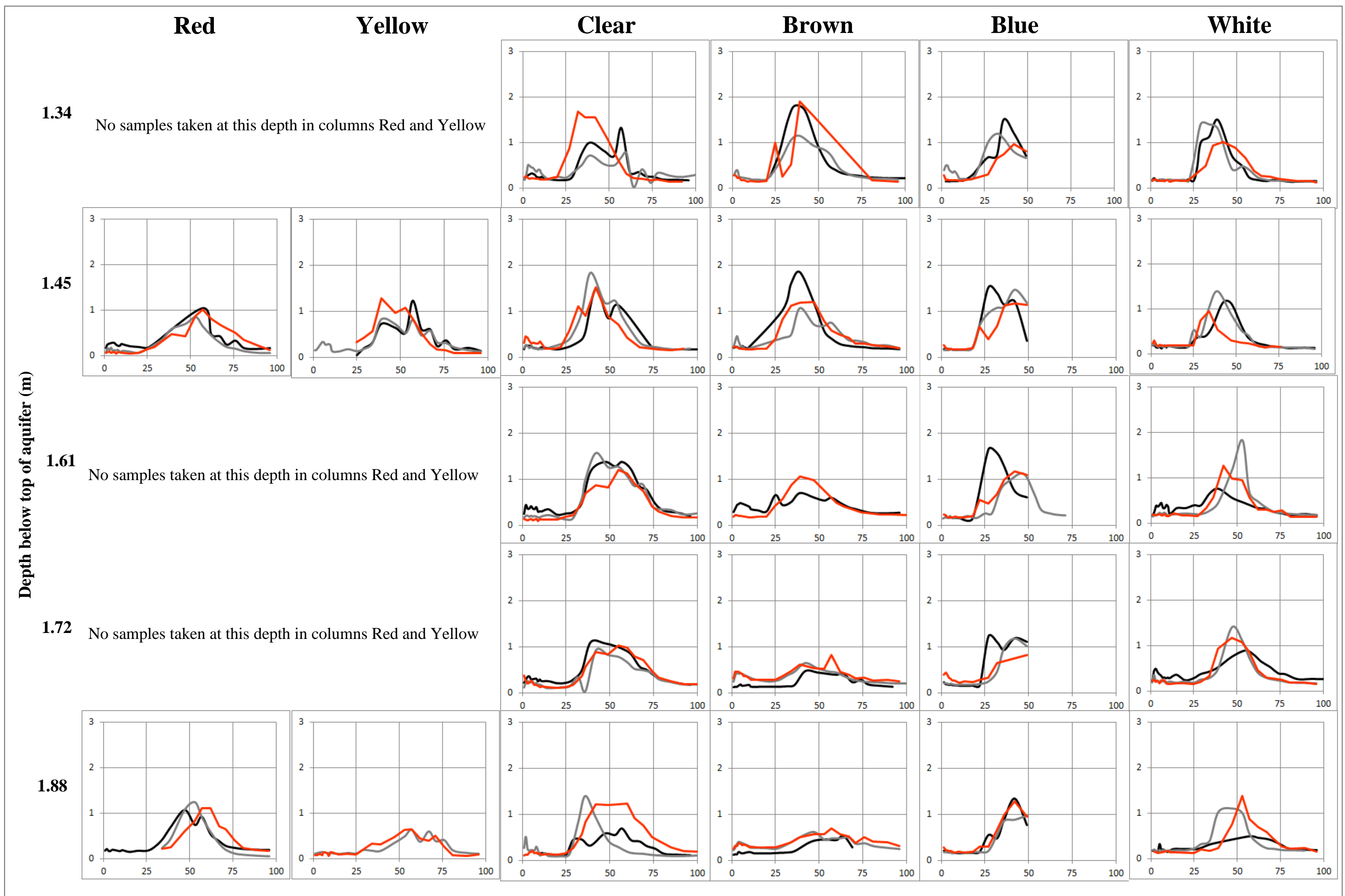

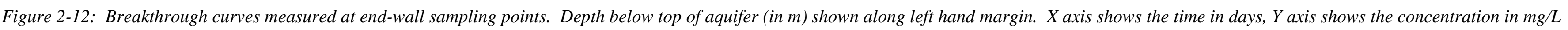




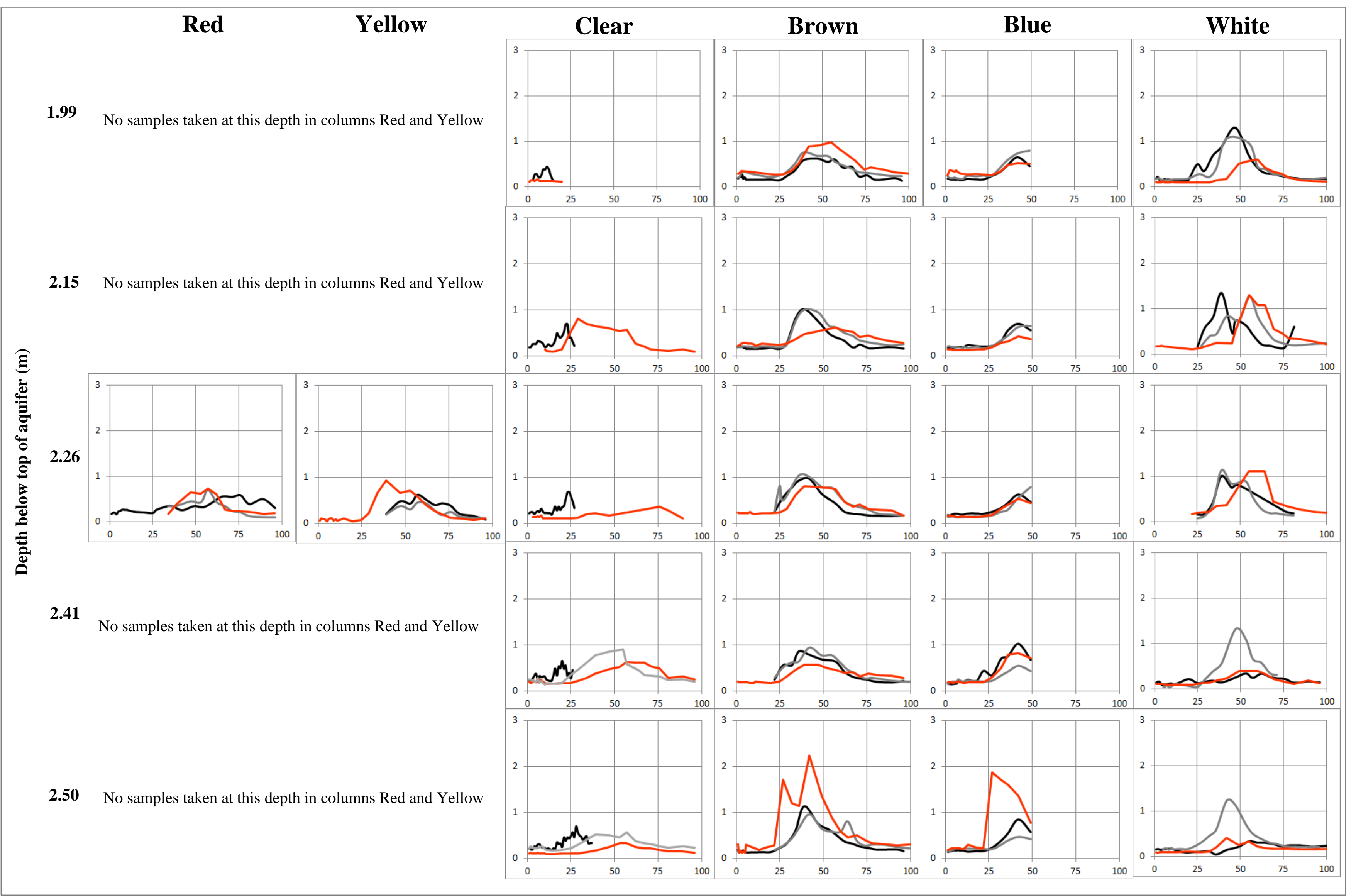

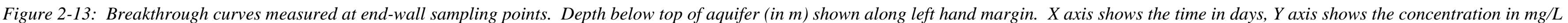




\section{End-wall Concentrations}

Figure 2-14 presents three histograms showing the number of observations for tracer arrival times (blue), peak concentration times (green) and times when entire tracer had passed (orange) at each end-wall sampling point. The normal distribution plotted as a Probability Density Function (PDF) is also shown. Data affected by the by-pass flow were excluded.

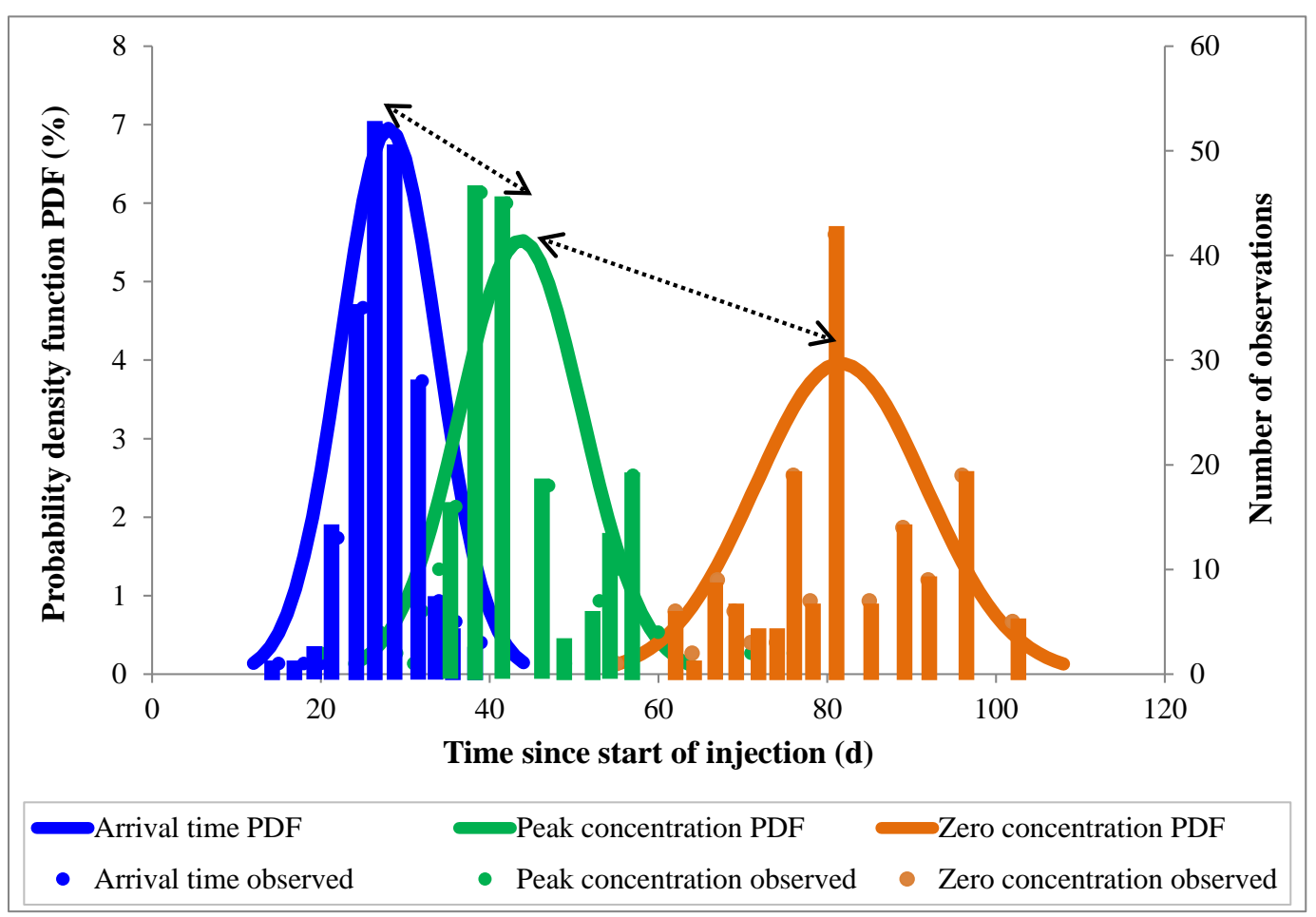

Figure 2-14: Timing of tracer arrival, peak concentration and zero concentration at each end-wall sampling point and the corresponding normal distribution

The mean arrival time occurs at day 28, the mean peak at day 44 and mean time of zero concentration after all $\mathrm{Br}$ has passed at day 82 . The first observation is that arrival times are roughly normally distributed but the timing of peak concentrations and zero concentrations are not. The larger variations in the timing of peak concentrations and zero concentrations probably occurred from increased dispersion with increased travel distance as a result of differential spreading of the tracer through high and low $\mathrm{K}$ blocks as it moves through the aquifer. The second observation is that the time difference between the mean tracer arrival time (blue) and the mean peak concentration (green) is just under half that of the time difference between the mean peak concentration (green) and mean zero concentration (orange). This is confirmed by looking at the breakthrough curves which generally show a steep rise in concentration with a slower decline. The third observation is that almost all the tracer had passed through the aquifer by day 102 . 


\subsection{Tracer Mass Balance and By-Pass Flow Estimates}

\subsubsection{Bromide}

Since no $\mathrm{Br}$ measurements were recorded from the end-tank or from the outflow, the total $\mathrm{Br}$ mass exiting the aquifer was estimated using a three step process utilising concentration data from the end-wall sampling points and $\mathrm{K}$ data obtained from the analytical modelling discussed in Chapter 3. Step one involved removing all of the end-wall concentration data that represented the by-pass flow. Step two involved the application of Equation 2-2 to calculate the total one dimensional (1D) mass ( $\left.\mathrm{M}_{1-\mathrm{D}}\right)$ in units of $\mathrm{g} / \mathrm{m}^{2}$ at each end-wall sampling point for which $\mathrm{K}$ data were available.

$$
\mathrm{M}_{1-\mathrm{D}}=\sum_{\mathrm{i}=1}^{\mathrm{n}} \mathrm{C}_{\mathrm{i}} \Delta \mathrm{t}_{\mathrm{i}} \mathrm{v}_{\mathrm{x}} \mathrm{\eta}_{\mathrm{e}}
$$

Equation 2-2

In Equation 2-2, $C_{i}$ is the observed concentration $\left(\mathrm{g} / \mathrm{m}^{3}\right)$ at the $\mathrm{i}^{\text {th }}$ time interval, $\Delta \mathrm{t}_{\mathrm{i}}$ is the change in time between successive observations (d), $v_{x}$ is the average groundwater linear flow velocity $(\mathrm{m} / \mathrm{d})$ determined from the analytical modelling and $\eta_{\mathrm{e}}$ is the effective porosity which was fixed at 0.3. Results for each end-wall sampling point with sufficient data to undertake this analysis have been contoured in Figure 2-15.

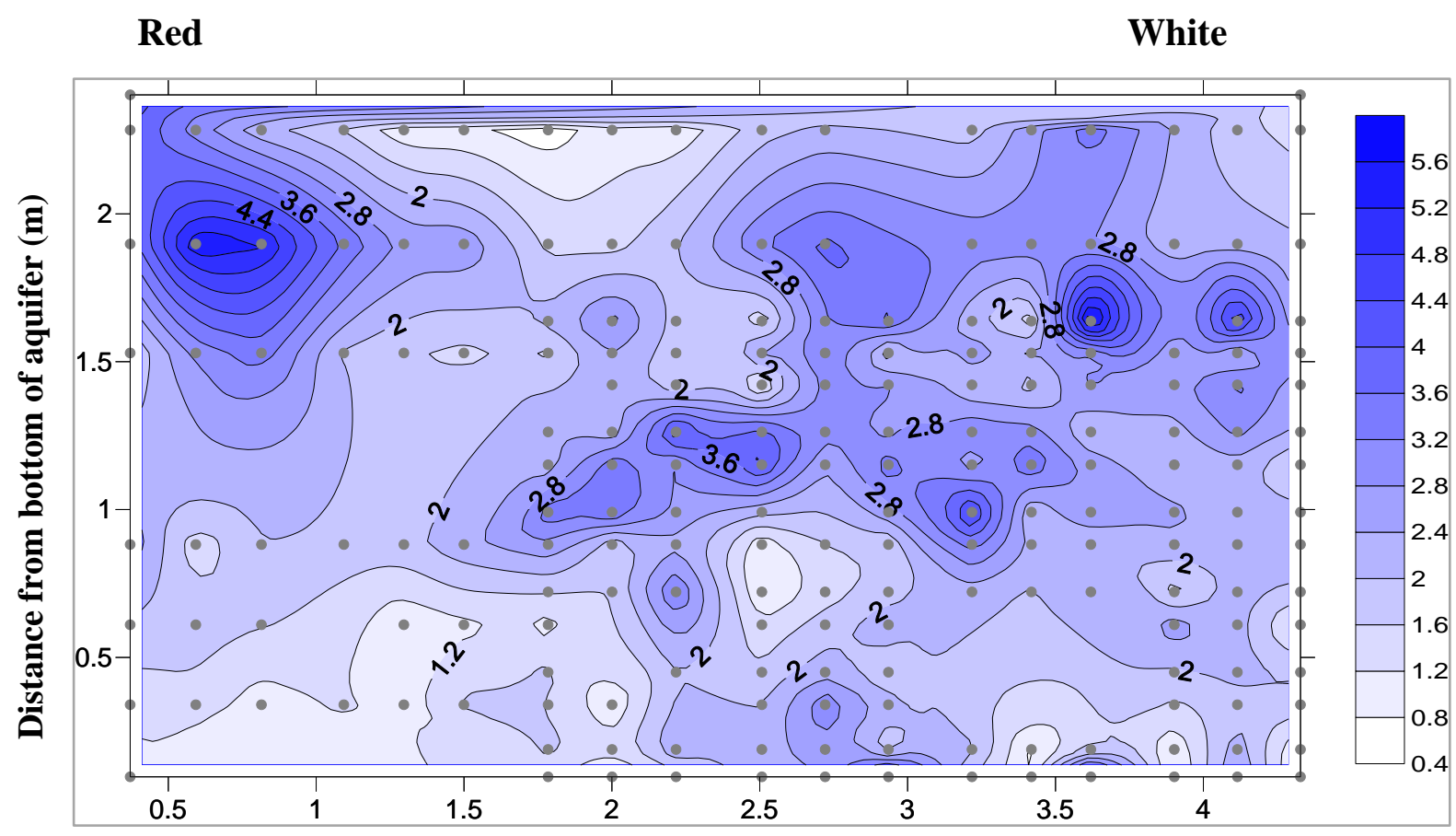

Aquifer width (m)

Figure 2-15: End-wall 1D mass in units of $\mathrm{g} / \mathrm{m}^{2}$ with sampling points shown in grey 
The contours show a non-uniform distribution with slightly less Br mass exiting from the base and left hand corner of the wall. The final step (step three) was to calculate the total mass exiting the end-wall. This involved extrapolating the 1D mass to points for which there was no $\mathrm{K}$ data using a method of linear interpolation. Then every point was multiplied by a specific area $\left(\mathrm{m}^{2}\right)$. Using this method, it is calculated that 26 grams of Br exited the aquifer. Given that 146 grams was injected and assuming that no $\mathrm{Br}$ was left in the aquifer after 102 days, this calculation implies that $82 \%$ of mass exited with the by-pass flow.

\subsection{Hydrogeological Parameters}

Initial estimates of hydrogeological parameter values are useful for determining whether the range and distribution of values used in the analytical and numerical models are realistic. The parameters relevant to this groundwater flow and transport problem are:

- Effective porosity $\left(\eta_{\mathrm{e}}\right)$,

- Hydraulic conductivity (K), and

- Dispersivity $(\alpha)$.

Because the modelling assumed stead-state groundwater flow, $\mathrm{K}$ was the sole parameter used to model groundwater flow. For transport modelling, $\eta_{\mathrm{e}}$ and dispersivity $(\alpha)$ were the sole parameters used. Fetter (1999) states that when Peclet numbers $\left(\mathrm{P}_{\mathrm{e}}\right)$ are high, the effects of diffusion can be ignored because. Since $\mathrm{P}_{\mathrm{e}(\mathrm{x})}$ values determined from analytical modelling were high (see Chapter 3.5), diffusion was excluded. In addition, diffusion included in the analytical modelling had virtually no effect on the modelled outputs.

\subsubsection{Effective Porosity}

Authors such as Bear (1979) and Kasenow (2001) state that for most practical purposes, specific yield (Sy) is equal to $\eta_{\mathrm{e}}$. The results of a detailed laboratory study of Sy by Morris and Johnson (1967) are summarised in Table 2-2. The results show an overall decrease in Sy with increasing grain size. 
Table 2-2: Specific yield (source, Morris and Johnson, 1967)

\begin{tabular}{|l|c|c|c|}
\hline \multicolumn{1}{|c|}{ Grain size $^{\mathbf{1}}$} & Lowest (\%) & Highest (\%) & Arithmetic mean (\%) \\
\hline Medium sand & 16 & 46 & 32 \\
\hline Coarse sand & 18 & 43 & 30 \\
\hline Very fine gravel & 13 & 40 & 28 \\
\hline
\end{tabular}

${ }^{1}$ Grain size classification based on Wentworth (1922)

Barnett, Townley, Post, Evans, Hunt, Peters, Richardson, Werner, Knapton and Boronkay (2012) suggest an alternative approach of assigning values for $\eta_{\mathrm{e}}$ in a model when the actual values are unknown. They suggest starting with the value of total porosity $(\eta)$ then adjusting the parameter to lower values, if needed during calibration. Kruseman and de Ridder (2000) give $\eta$ values of $25 \%$ to $50 \%$ for sand and $25 \%$ to $40 \%$ for gravel. For the largest grain size used in the heterogeneous aquifer (very coarse sand to very fine gravel), $\eta$ was measured at $42 \%$ (L. Burbery, personal communication, October, 2, 2013).

\subsubsection{Hydraulic Conductivity}

\section{Literature Values}

A range of $\mathrm{K}$ values for medium sand, coarse sand and gravel from Kruseman and deRidder (2000) and Domenico and Schwartz (1998) are presented Table 2-3.

Table 2-3: Hydraulic conductivity values for medium sand, coarse sand and gravel

\begin{tabular}{|l|l|c|c|}
\hline \multirow{1}{*}{ Grain size } & \multicolumn{1}{c|}{ Author } & Lowest $(\mathbf{m} / \mathbf{d})$ & Highest $(\mathbf{m} / \mathbf{d})$ \\
\hline \multirow{2}{*}{ Medium sand } & Kruseman and de-Ridder & 5 & 20 \\
\cline { 2 - 4 } & Domenico and Schwartz & 0.08 & 40 \\
\hline \multirow{2}{*}{ Coarse sand } & Kruseman and de-Ridder & 20 & 200 \\
\cline { 2 - 4 } & Domenico and Schwartz & 0.08 & 520 \\
\hline \multirow{2}{*}{ Gravel } & Kruseman and de-Ridder & 200 & 2,000 \\
\cline { 2 - 4 } & Domenico and Schwartz & 25 & 2,500 \\
\hline
\end{tabular}

The results show increasing $\mathrm{K}$ with increasing grain size and general agreement between the two authors. These results give some constrain on the upper and lower bounds but for further assessment a calculation of $\mathrm{K}$ based on grain-sizes was also undertaken. 


\section{Grain Size Analysis}

Values of $\mathrm{K}$ can be related to the grain size distribution of granular porous media. Two empirical equations have been used to calculate the potential range of $\mathrm{K}$ values based on the median grain size $\left(\mathrm{d}_{50}\right)$ for each of the three grain size ranges used in the artificial aquifer. Shepherd (1989) proposed a simple way to calculate K using Equation 2-3.

$$
\mathrm{K}=\mathrm{Cd}_{50}{ }^{1.65-1.85}
$$

Equation 2-3

Using the $\mathrm{d}_{50}$ grain sizes of $0.5 \mathrm{~mm}, 0.8 \mathrm{~mm}, 1.2 \mathrm{~mm}$ and upper and lower limits for the $\mathrm{C}$ coefficient and exponent, a range of $\mathrm{K}$ values in $\mathrm{m} / \mathrm{d}$ are presented in Table 2-4. The results show increasing $\mathrm{K}$ with increasing grain size, and $\mathrm{K}$ values ranging from $12 \mathrm{~m} / \mathrm{d}$ to $1,436 \mathrm{~m} / \mathrm{d}$.

Table 2-4: Hydraulic conductivity values using the median grain sizes

\begin{tabular}{|l|c|c|}
\hline \multicolumn{1}{|c|}{ Classification } & $\begin{array}{c}\text { Hydraulic } \\
\text { conductivity }(\mathbf{m} / \mathbf{d})\end{array}$ & $\begin{array}{c}\text { Median grain size - } \\
\mathbf{d}_{\mathbf{5 0}}(\mathbf{m m})\end{array}$ \\
\hline Medium to coarse sand & $12-327$ & 0.5 \\
\hline Coarse to very coarse sand & $28-709$ & 0.8 \\
\hline Very coarse sand to fine gravel & $58-1,436$ & 1.2 \\
\hline
\end{tabular}

A widely used empirical correlation of $\mathrm{K}$ that accounts for a range of grain sizes is the Kozeny-Carmen equation. This equation was modified from Bear (1972) and is shown in Equation 2-4.

$$
\mathrm{K}=\left(\frac{\rho_{\mathrm{w}} \mathrm{g}}{\mu}\right)\left(\frac{\eta^{3}}{(1-\eta)^{2}}\right)\left(\frac{\mathrm{d}_{50}}{180}\right) \quad \text { Equation 2-4 }
$$

A value of $999.5 \mathrm{~kg} / \mathrm{m}^{3}$ was used for the density of fresh water $\left(\rho_{\mathrm{w}}\right)$ at $12{ }^{\circ} \mathrm{C}$ (typical value from the source water), a value of $0.00124 \mathrm{~N}-\mathrm{s} / \mathrm{m}^{2}$ at $12{ }^{\circ} \mathrm{C}$ was used for dynamic viscosity $(\mu)$ and the acceleration due to gravity $(\mathrm{g})$ was $9.807 \mathrm{~m} / \mathrm{s}^{2}$. Using $d_{50}$ grain sizes of $0.5 \mathrm{~mm}, 0.8 \mathrm{~mm}$ and $1.2 \mathrm{~mm}$, and making $\eta$ equal to $\eta_{\mathrm{e}}$ where $\eta_{\mathrm{e}}$ is equal to the Sy values from Table 2-2, the K values in $\mathrm{m} / \mathrm{d}$ are presented in Table 2-5. 
Table 2-5: Hydraulic conductivity values using the Kozeny-Carmen equation

\begin{tabular}{|l|c|c|c|}
\hline \multicolumn{1}{|c|}{ Classification } & $\begin{array}{c}\text { Hydraulic } \\
\text { conductivity }(\mathbf{m} / \mathbf{d})\end{array}$ & $\begin{array}{c}\text { Effective } \\
\text { porosity }(\mathbf{\%})\end{array}$ & $\begin{array}{c}\text { Median grain } \\
\text { size - d } \mathbf{5 0}(\mathbf{m m})\end{array}$ \\
\hline Medium to coarse sand & 67 & 32 & 0.5 \\
\hline $\begin{array}{l}\text { Coarse to very coarse } \\
\text { sand }\end{array}$ & 134 & 30 & 0.8 \\
\hline $\begin{array}{l}\text { Very coarse sand to very } \\
\text { fine gravel }\end{array}$ & 232 & 28 & 1.2 \\
\hline
\end{tabular}

The results again show a general increase in $\mathrm{K}$ with increasing grain size. Hydraulic conductivity values ranged from $67 \mathrm{~m} / \mathrm{d}$ to $232 \mathrm{~m} / \mathrm{d}$ with a mean value of $139 \mathrm{~m} / \mathrm{d}$ when applied to all 2,907 blocks. These values occur within the general range for coarse sand (shown in Table 2-3)

\section{Darcy's Law}

Constant-head experiments were undertaken on individual blocks used to construct the artificial aquifer. Using Darcy's Law the results were $40 \mathrm{~m} / \mathrm{d}$ for the medium to coarse sand, $126 \mathrm{~m} / \mathrm{d}$ for the coarse to very coarse sand, and $404 \mathrm{~m} / \mathrm{d}$ for the very coarse sand to fine gravel. The main limitation with the constant-head $\mathrm{K}$ values is that they do not take account of changes in $\mathrm{K}$ due to settling and compaction after the blocks were packed. Knowing the number of blocks for each of the 3 grain size ranges, the arithmetic mean value is $174 \mathrm{~m} / \mathrm{d}$ and geometric mean value is $120 \mathrm{~m} / \mathrm{d}$. The lower geometric mean shows that the $\mathrm{K}$ distribution is skewed toward the lower values as a result of the aquifer containing more fine grained blocks compared to coarse grained blocks.

The effective $\mathrm{K}\left(\mathrm{K}_{\mathrm{eff}}\right)$ value is applied to the aquifer as a whole and incorporates all variations in $\mathrm{K}$. The $\mathrm{K}_{\mathrm{eff}}$ can be calculated using Darcy's Law in Equation 2-5 when the aquifer through-flow (Q), hydraulic gradient (i) and aquifer cross-sectional area (A) are known.

$$
\mathrm{K}_{\mathrm{eff}}=\frac{\mathrm{Q}}{\mathrm{A}} / \mathrm{i}
$$


During the experiment, Q outflow from the end-tank varied between $3.2 \mathrm{~m}^{3} / \mathrm{d}$ and 4.0 $\mathrm{m}^{3} / \mathrm{d}$, the piezometric data showed a constant $\mathrm{i}$ of $0.00044 \mathrm{~m} / \mathrm{m}$ for all but day one and A was $12.12 \mathrm{~m}^{2}$. Using these values, $K_{\text {eff }}$ ranges between $594 \mathrm{~m} / \mathrm{d}$ and $747 \mathrm{~m} / \mathrm{d}$. However, these two values are too high because a portion of $\mathrm{Q}$ outflow by-passed the aquifer. Using a lower value for $\mathrm{Q}$ outflow means that $\mathrm{K}_{\mathrm{eff}}$ will be lower. It should also be noted that taking pressure head readings with an accuracy of $0.002 \mathrm{~m}$ means that small changes in i may not be recorded and this would have an effect on the value of $\mathrm{K}$ calculated using Equation 2-5 and in later analysis. For example, a small pressure change of 0.001 could make $\mathrm{i}$ equal $0.0003 \mathrm{~m} / \mathrm{m}$ and $\mathrm{K}_{\text {eff }}$ would range between $792 \mathrm{~m} / \mathrm{d}$ and $996 \mathrm{~m} / \mathrm{d}$.

Re-arranging Equation 2-5 to solve for Q, and using the arithmetic mean K of $174 \mathrm{~m} / \mathrm{d}$ and geometric mean $\mathrm{K}$ of $120 \mathrm{~m} / \mathrm{d}$ from the constant-head experiments, the theoretical Q outflow from the aquifer varies between $0.63 \mathrm{~m}^{3} / \mathrm{d}$ and $0.94 \mathrm{~m}^{3} / \mathrm{d}$. Given that the measured outflow varied between $3.2 \mathrm{~m}^{3} / \mathrm{d}$ and $4.0 \mathrm{~m}^{3} / \mathrm{d}$, the by-pass flow would range between $70 \%$ and $84 \%$.

\subsubsection{Dispersivity}

It has been recognised that a correlation exists between the value of the dispersivity $(\alpha)$ and the spatial scale of the model. Based on a compilation of field study values, Gelhar (1986) suggested that longitudinal dispersivity $\left(\alpha_{\mathrm{x}}\right)$ is approximately $10 \%$ of the travel distance. Given that the maximum travel distance in the artificial aquifer is $9.5 \mathrm{~m}$, an approximate maximum value of $\alpha_{\mathrm{x}}$ would be $0.95 \mathrm{~m}$.

Data from field studies also suggest that transverse dispersivity $\left(\alpha_{\mathrm{y}}\right)$ in the horizontal direction is about one order of magnitude lower than $\alpha_{x}$ and vertical dispersivity $\left(\alpha_{z}\right)$ is about two orders of magnitude lower (Zheng and Bennett 2002). Thus for the artificial aquifer, $\alpha_{\mathrm{y}}$ and $\alpha_{\mathrm{z}}$ might be expected to occur within the range of $0.1 \mathrm{~m}$ to $0.01 \mathrm{~m}$. 


\section{ANALYTICAL MODELLING}

Analytical modelling is the most simplistic form of modelling undertaken in this study. Haitjema (2006) discusses the value of simple analytic solutions for gaining insights into parameterisation and calibration of more complex models. In a similar way, the analytical modelling undertaken in this study also provides a means of obtaining representative values for groundwater flow and transport parameters as well as insights into the physical processes occurring in the aquifer.

\subsection{Method}

Breakthrough curves measured from 15 monitoring wells at different depths and from 123 individual sampling points along the end-wall were modelled using Equation 3-1 after Sauty (1980).

$$
C=\frac{C_{o}}{2}\left[\operatorname{erfc}\left(\frac{L-v_{x} t}{2 \sqrt{D_{x} t}}\right)\right]
$$

Equation 3-1 is an approximate solution for 1D advection and dispersion of a nonreactive tracer, where $\mathrm{C}$ is the modelled concentration $(\mathrm{mg} / \mathrm{L}), \mathrm{C}_{\mathrm{o}}$ is the input concentration $(\mathrm{mg} / \mathrm{L}), \mathrm{L}$ is the distance from the head-tank to the sampling point (in the $\mathrm{x}$ direction) $(\mathrm{m}), \mathrm{v}_{\mathrm{x}}$ is the average linear groundwater flow velocity in the horizontal direction $(\mathrm{m} / \mathrm{d}), \mathrm{t}$ is time (d) from the start of the experiment and $D_{x}$ is longitudinal hydrodynamic dispersion in the horizontal direction $\left(\mathrm{m}^{2} / \mathrm{d}\right)$.

The value for $v_{\mathrm{x}}$ in Equation 3-1 was calculated using Equation 3-2 with $\eta_{\mathrm{e}}$ fixed at 0.3 , i fixed at $0.00044 \mathrm{~m} / \mathrm{m}$ and $\mathrm{K}_{\mathrm{x}}$ being the calibrated parameter.

$$
\mathrm{v}_{\mathrm{x}}=\frac{\mathrm{K}_{x}}{\eta_{\mathrm{e}}} \mathrm{i}
$$

Equation 3-2

Since $\eta_{\mathrm{e}}$ was fixed, $\mathrm{v}_{\mathrm{x}}$ was only affected by $\mathrm{K}_{\mathrm{x}}$ when in reality $\mathrm{v}_{\mathrm{x}}$ would also vary in response to $\eta_{\mathrm{e}}$. The choice to fix $\eta_{\mathrm{e}}$ was based on $\eta_{\mathrm{e}}$ having a perfect correlation with $\mathrm{K}_{\mathrm{x}}$, thus $\eta_{\mathrm{e}}$ was fixed to obtain unique values for $\mathrm{K}_{\mathrm{x}}$. 
The value for $\alpha_{\mathrm{x}}(\mathrm{m})$ was calculated using Equation 3-3.

$$
\alpha_{\mathrm{x}}=\frac{\left(\mathrm{D}_{\mathrm{x}}-\mathrm{D}_{\mathrm{d}}\right)}{\mathrm{v}_{\mathrm{x}}}
$$

Equation 3-3

A constant diffusion coefficient $\left(D_{d}\right)$ of $0.00043 \mathrm{~m}^{2} / \mathrm{d}$ for chloride (Fetter, 1999) was used as an approximate value for $\mathrm{Br}$.

Matches were made to all observations with sufficient data and which were not affected by the by-pass flow. These matches are provided in Appendix B and the resultant hydrogeological parameter and $\mathrm{P}_{\mathrm{e}(\mathrm{x})}$ values are provided in Appendix $\mathrm{C}$.

\subsection{Curve Fitting}

Figure 3-1 shows the effects of changes in Br input on the modelled concentration in well A1_0.4 located $0.75 \mathrm{~m}$ from the head-tank causing two roughly equal peaks in concentration. The model incorporates changes in $\mathrm{Br}$ input by applying the principal of superposition. A good description of this method is given by Hunt (2012).

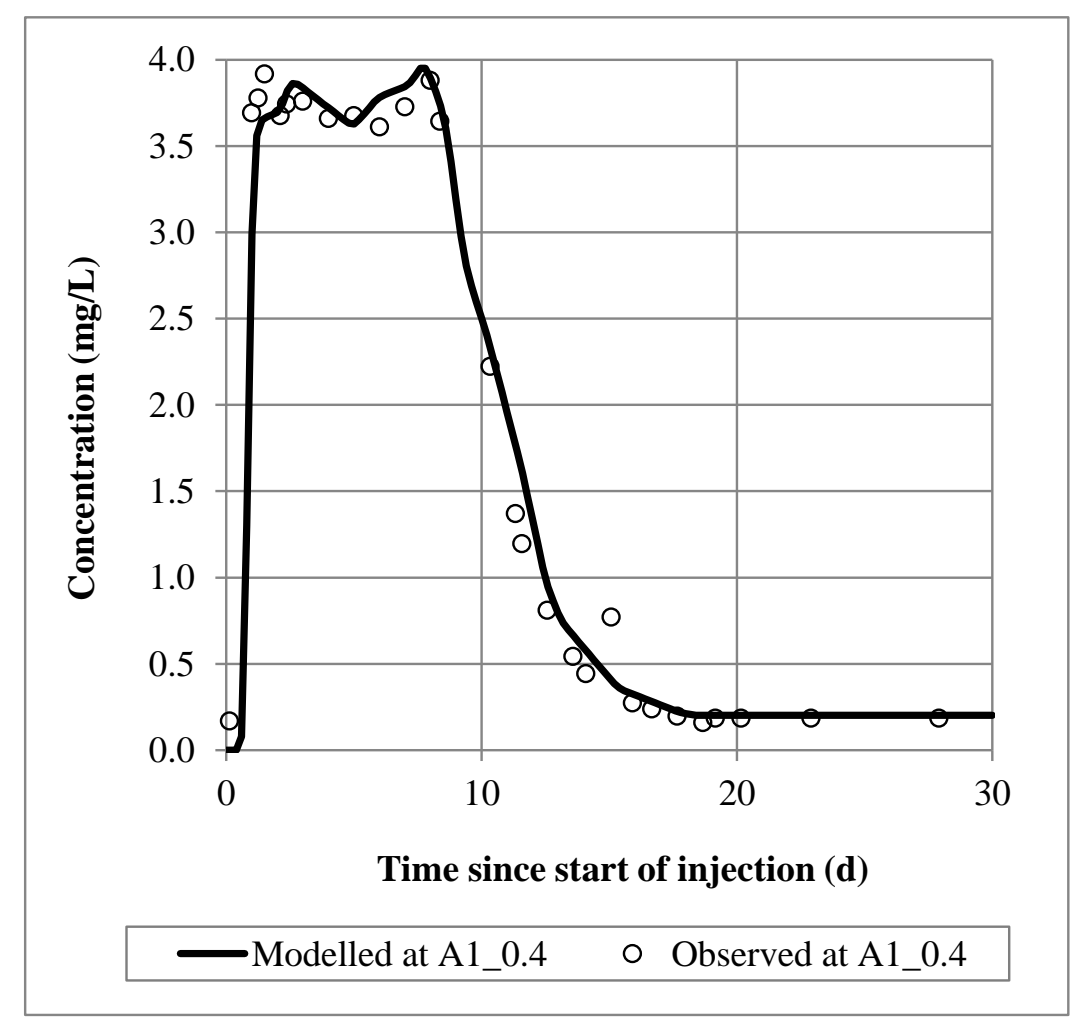

Figure 3-1: Breakthrough curve showing effects of changes in Br input concentration 
Figure 3-2 shows modelled and observed breakthrough curves at a depth of $1.0 \mathrm{~m}$ below the top of the aquifer in monitoring wells A1_1.0 (green), A5_1.0 (blue) and A9_1.0 (red) at distances of $0.75 \mathrm{~m}, 4.75 \mathrm{~m}$ and $8.75 \mathrm{~m}$ from the head-tank. The delayed concentration peaks in A5_1.0 and A9_1.0 reflect increasing travel distance from the head-tank and the progressively lower peak concentrations and more widely spread curves in A5_1.0 and A9_1.0 reflect the influence of dispersion which is modelled with transport parameter $\alpha_{x}$.

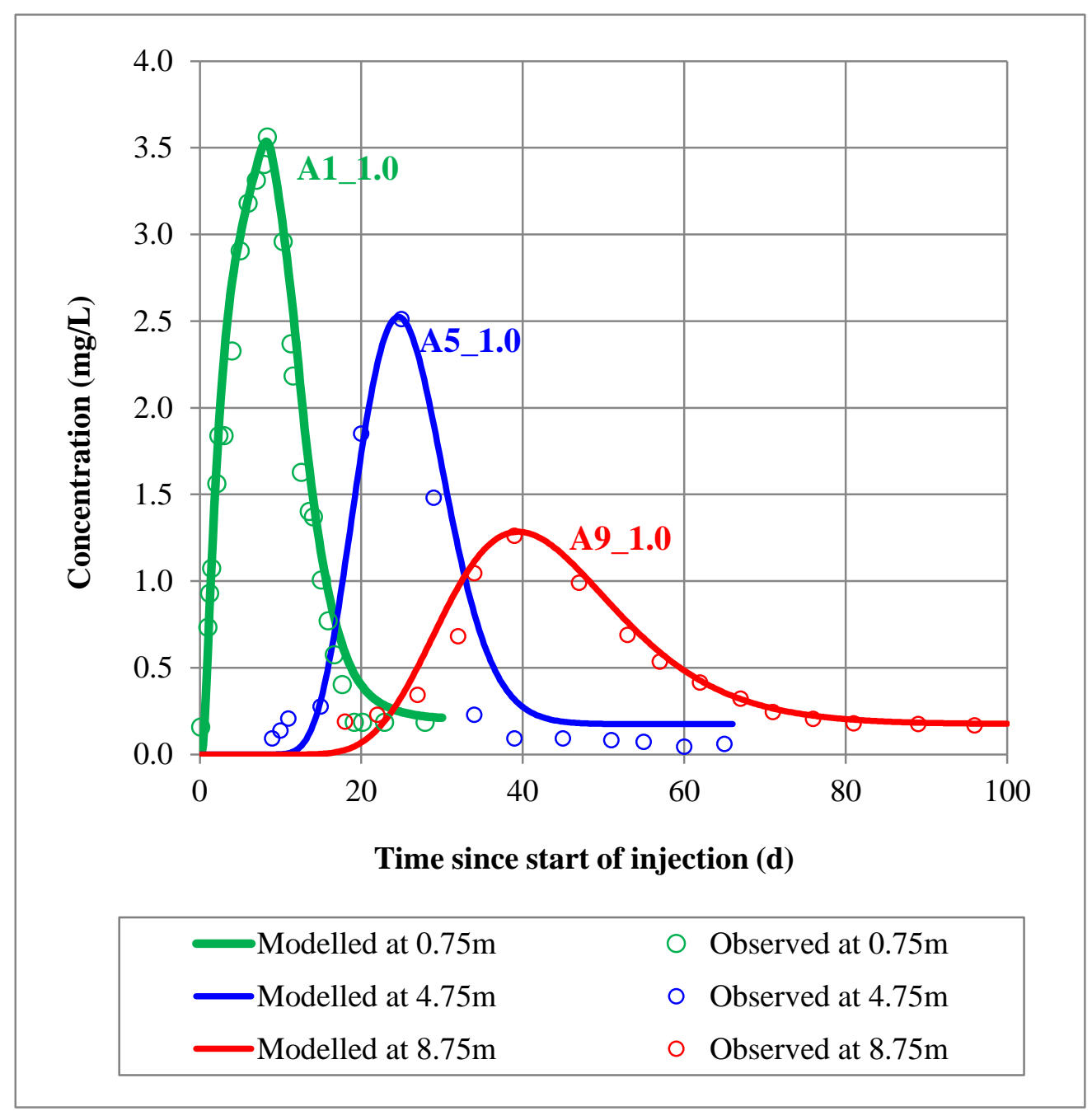

Figure 3-2: Observed versus modelled breakthrough curves a depth of $1.0 \mathrm{~m}$ below the top of the aquifer and at successive distances from the head-tank

Not all of the data (based on a visual assessment) could be modelled with a close fit. In some cases the breakthrough curve was asymmetric and the rising limb of the curve was generally steeper than the receding limb (tail). In these cases, a close match could often only be made to the rising limb of the curve. 
Figure 3-3 and Figure 3-4 show matches to asymmetric breakthrough curves from two end wall sampling points. At C_44, the tail recedes at a faster rate than what the model predicts and at $\mathrm{R} \_36$, the tail recedes at a slower rate. Aquifer heterogeneity and processes not accounted for in the model is the reason for this failure to match the entire curve.

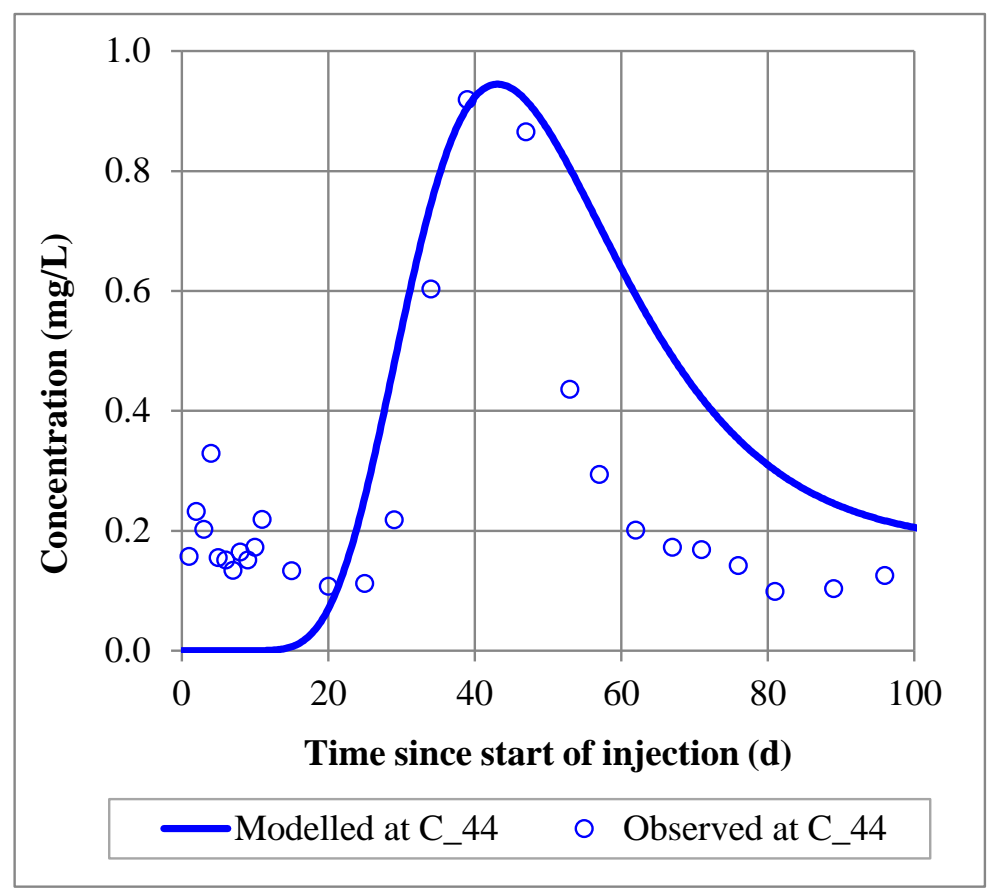

Figure 3-3: Tail receding faster than model prediction

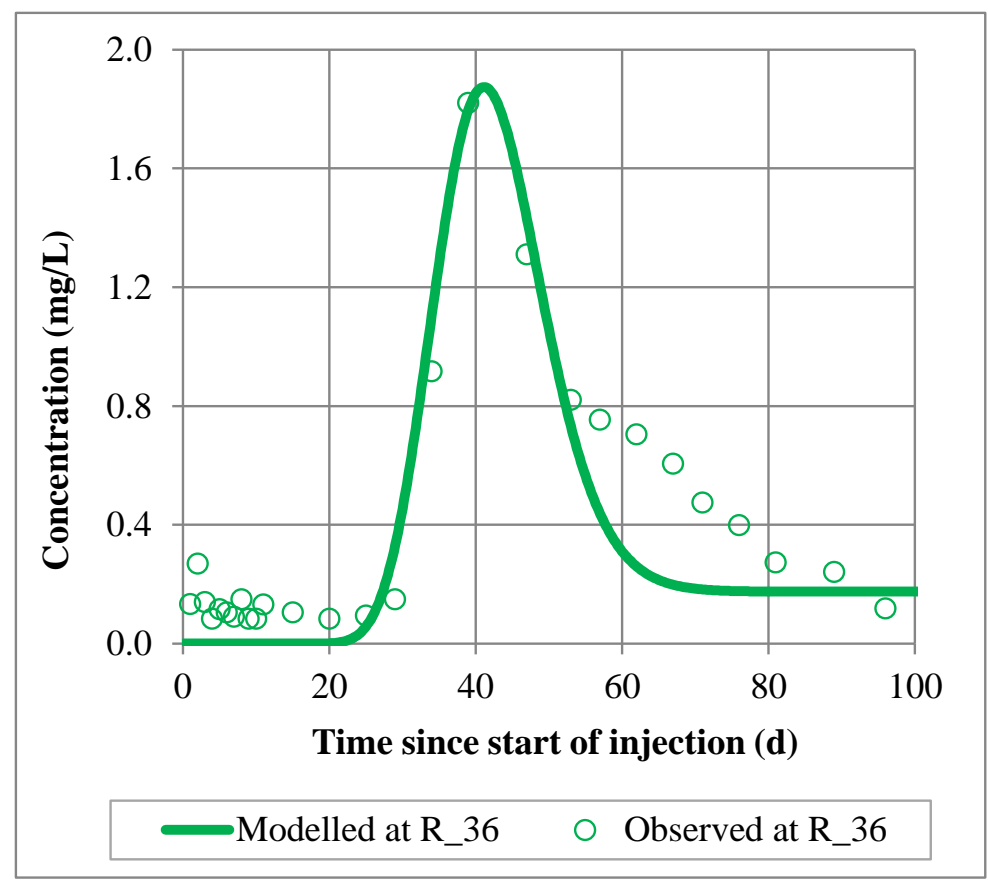

Figure 3-4: Tail receding slower than model prediction 


\subsection{Hydraulic Conductivity}

The mean values and range of values for $K_{x}$ determined through the analytical modelling are similar to the mean values and range of values determined from the constant-head experiments and also from the grain size analysis using the KozenyCarmen equation. From the analytical modelling, the arithmetic mean $K_{x}$ is $177 \mathrm{~m} / \mathrm{d}$, the geometric mean is $169 \mathrm{~m} / \mathrm{d}$ and values range from $40 \mathrm{~m} / \mathrm{d}$ to $600 \mathrm{~m} / \mathrm{d}$. The fact that similar values of $\mathrm{K}$ were determined using three independent methods gives a reasonably high degree of confidence. A more detailed assessment of $\mathrm{K}$ through a comparison of the analytical modelling, numerical modelling and constant-head experiments is provided in Chapter 5.4.7.

\subsection{Dispersivity}

Using data from the analytical modelling, Figure 3-5 shows the arithmetic mean value of $\alpha_{\mathrm{x}}$ at 4 separate distances down-gradient from the head-tank. Error bars represent one standard deviation from the mean. Despite the error bars over-lapping, especially at the largest distance, the data shows that $\alpha_{\mathrm{x}}$ is scale dependent with values increasing with increased distance from the head-tank.

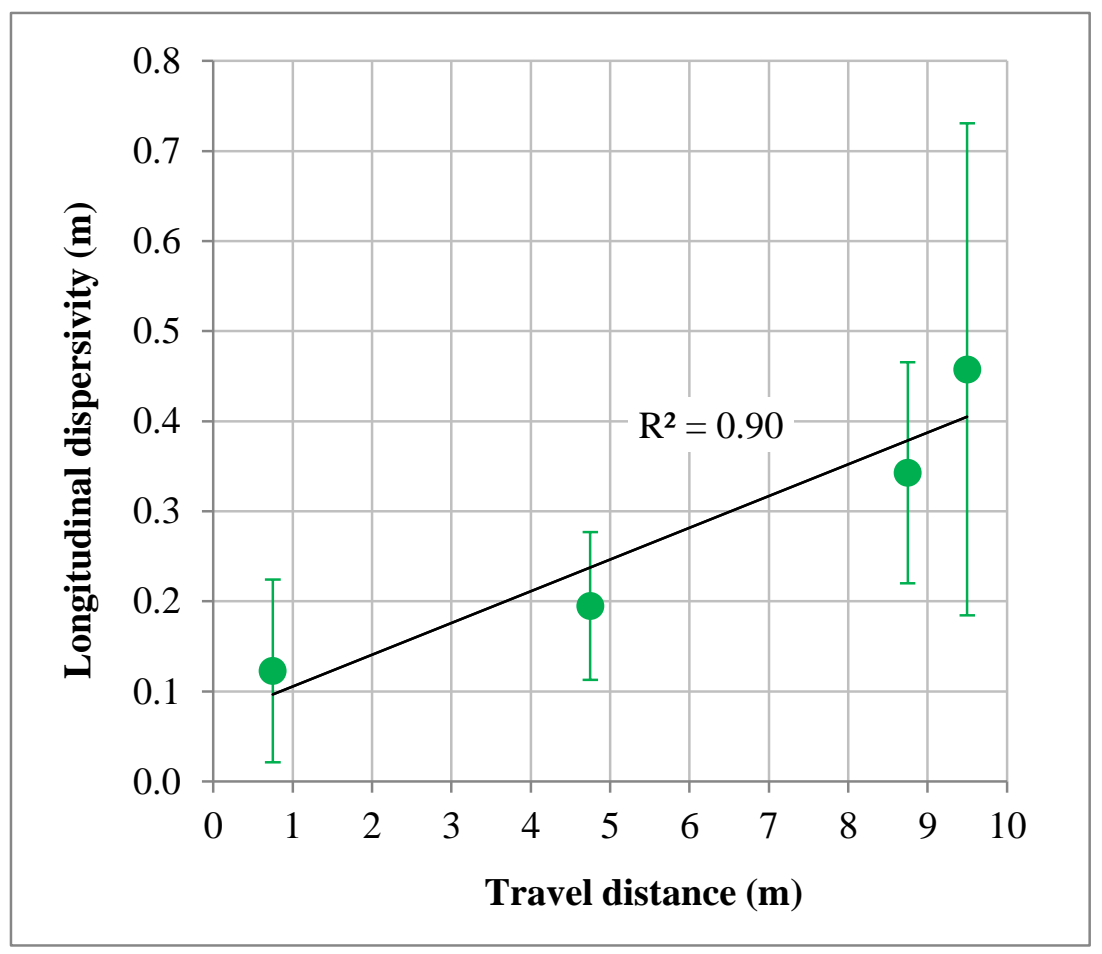

Figure 3-5: Arithmetic mean $\alpha_{x}$ with travel distance in direction of groundwater flow 
Fetter (1999) points out that eventually as the flow path becomes long enough it is possible that all variations in $\mathrm{K}$ will have been encountered and that the value of mechanical dispersion will reach a maximum. The way that $\alpha_{\mathrm{x}}$ is still increasing with travel distance indicates that all possible variations in $\mathrm{K}$ have not been encountered.

For Canterbury Plains alluvial aquifers, a ratio of $10 \%$ for $\alpha_{x}$ divided by the travel distance is commonly applied where measured values are not available (M. Close personal communication, October 20, 2013). Using data from the analytical modelling, Figure 3-6 shows the mean ratio of $\alpha_{x}$ to travel distance at different distances down-gradient of the head-tank. The ratios vary between approximately 4 $\%$ and $16 \%$. Error bars showing the standard deviation highlight the large variations observed closest to the head-tank. The results appear to show that the ratio remains unchanged at distance of at least $4.75 \mathrm{~m}$ or greater. The commonly applied ratio of 10 $\%$ lies roughly half way between the mean minimum and maximum values determined for the artificial aquifer. The lower standard deviation away from the head-tank may be due to variations in $\mathrm{K}$ averaging out with distance.

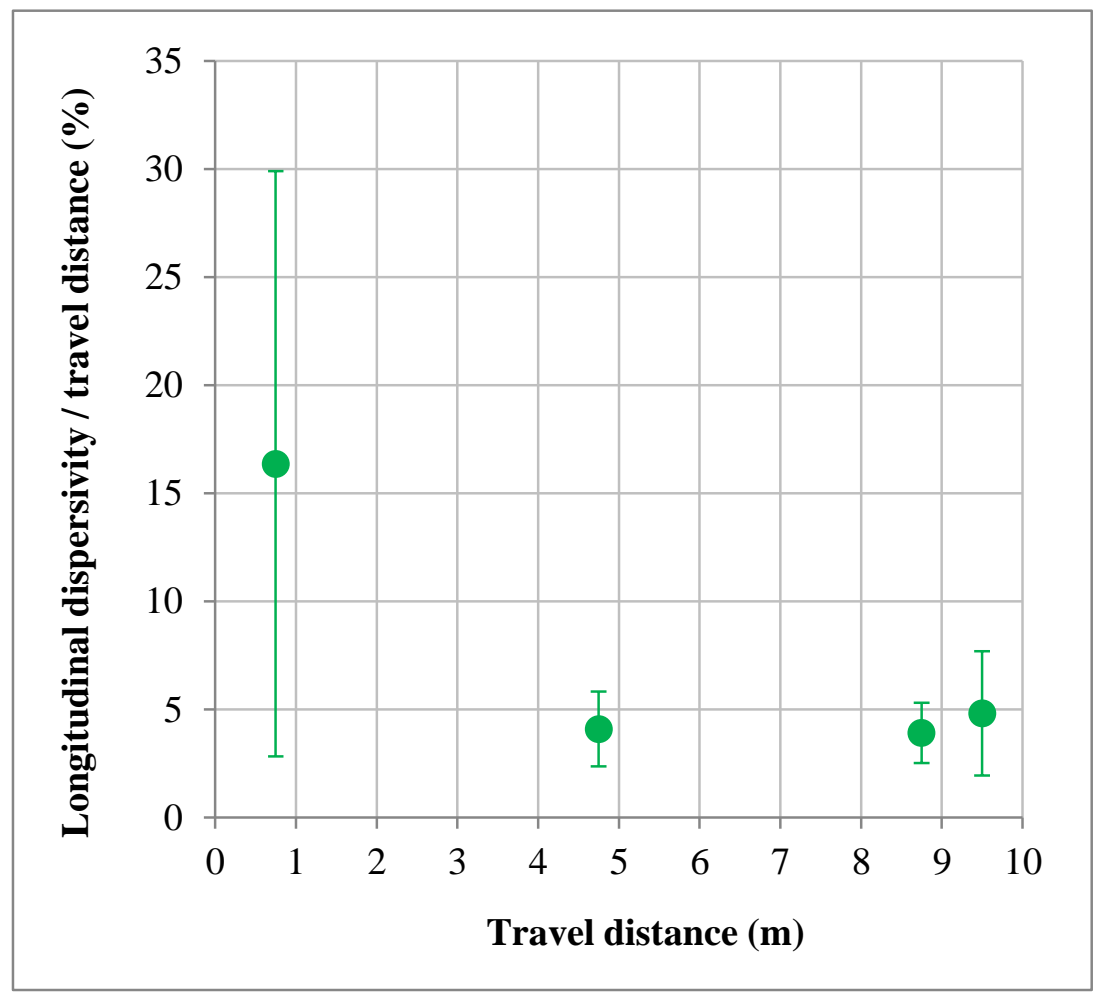

Figure 3-6: Arithmetic mean values for the ratio of $\alpha_{x}$ divided by the travel distance at increasing distance from the head-tank 


\subsection{Diffusion versus Dispersion}

By calculating $\mathrm{P}_{\mathrm{e}}$, the analytical modelling can be used to show the relative contributions of mechanical dispersion compared with diffusion. Peclet numbers are dimensionless numbers that relate the effectiveness of mass transport by advection to the effectiveness of mass transport by either dispersion or diffusion (Fetter, 1999). Using the analytical modelling results, $\mathrm{P}_{\mathrm{e}(\mathrm{x})}$ for each monitoring point was calculated using Equation 3-4.

$$
P_{e(x)}=\frac{v_{x} L}{D_{x}}
$$

Equation 3-4

Where $\mathrm{v}_{\mathrm{x}}$ is the average linear groundwater flow velocity in the $\mathrm{x}$ direction $(\mathrm{m} / \mathrm{d}), \mathrm{L}$ is the distance from the head-tank in the $\mathrm{x}$ direction $(\mathrm{m})$, and $\mathrm{D}_{\mathrm{x}}$ is the longitudinal hydrodynamic dispersion $\left(\mathrm{m}^{2} / \mathrm{d}\right)$. Figure 3-7 shows $\mathrm{P}_{\mathrm{e}(\mathrm{x})}$ for each monitoring point ordered from largest to smallest values. Fetter (1999) shows that when $\mathrm{P}_{\mathrm{e}(\mathrm{x})}$ is greater than about six, diffusion can be ignored because advection and dispersion are dominant. Based on the results shown in Figure 3-7, advection and dispersion are dominant over diffusion.

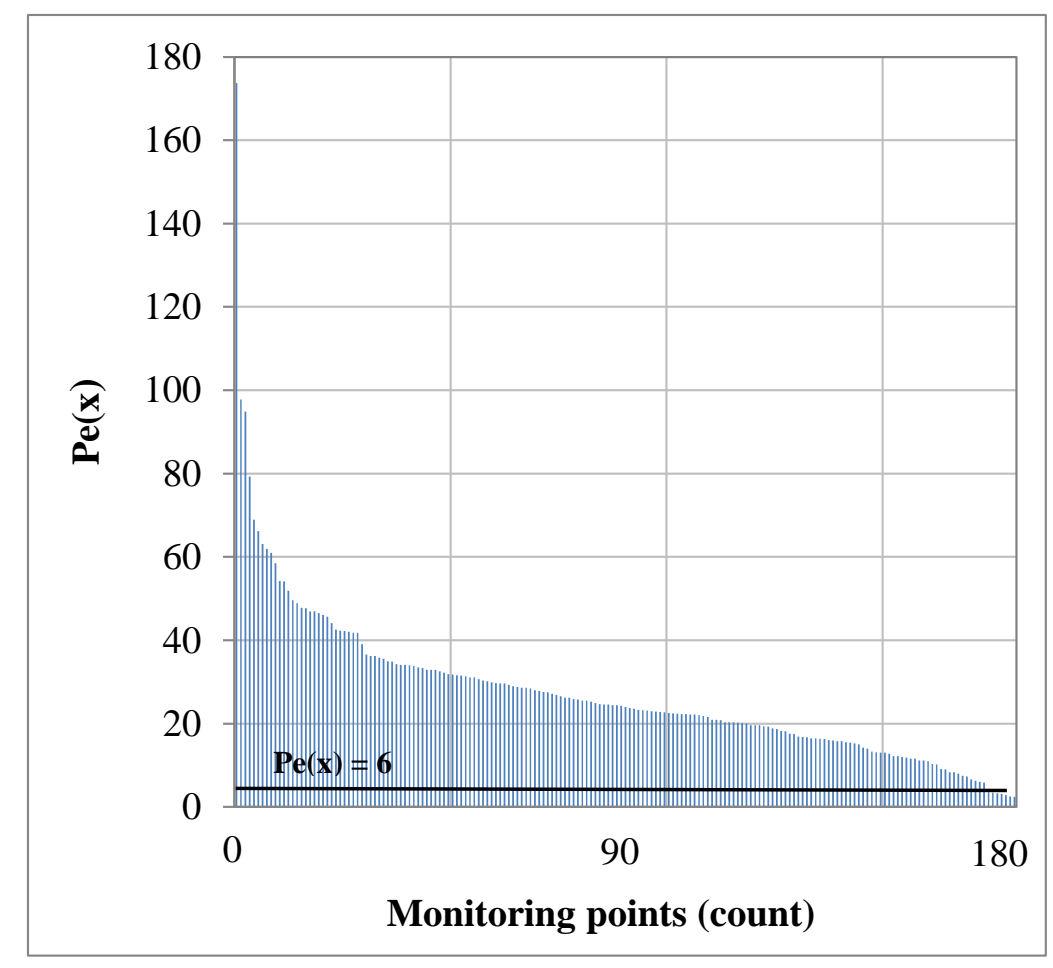

Figure 3-7: Peclet numbers for each monitoring point 


\subsection{Comparison to the Homogeneous Artificial Aquifer}

Close et al. (2008) undertook 1D and three dimensional (3D) modelling of a 3D box injection and full head-tank tracer test in the homogeneous artificial aquifer using $\mathrm{Br}$, tritium and Rhodamine WT (RWT) tracers. Both models assumed homogeneous aquifer conditions. Their aim was to test the spatial variation in hydrogeological parameters and describe key features of modelling contaminant transport in an artificial aquifer. A key finding was the significant spatial variation which showed that the aquifer was slightly heterogeneous.

Analytical modelling results from this study were compared with the analytical modelling results from the full-head tracer test by Close et al. (2008). An interesting finding is that the range and mean values of $K_{x}$ and $\alpha_{x}$ are markedly similar despite the homogeneous aquifer being uniformly filled with one grain size range and the heterogeneous aquifer being non-uniformly filled with three different grain sizes. A comparison of the results is shown in Table 3-1.

Table 3-1: Comparison of 1D analytical modelling from the full head-tank tracer tests undertaken in the homogeneous and heterogeneous artificial aquifers.

Arithmetic mean values are shown in brackets.

\begin{tabular}{|l|c|c|}
\hline \multicolumn{1}{|c|}{ Parameter } & Homogeneous aquifer & Heterogeneous aquifer \\
\hline Number of targets modelled & 68 & 181 \\
\hline $\mathrm{K}_{\mathrm{x}}(\mathrm{m} / \mathrm{d})$ & $80-621(149)$ & $42-600(177)$ \\
\hline$\alpha_{\mathrm{x}}(\mathrm{m})$ & $0.0006-1.59(0.24)$ & $0.001-1.61(0.38)$ \\
\hline
\end{tabular}

One reason for the similar values is probably due to both aquifers having similar grain sizes; $0.6 \mathrm{~mm}$ to $2.0 \mathrm{~mm}$ for the homogeneous aquifer and 0.3 to $2.4 \mathrm{~mm}$ for the heterogeneous aquifer. The grain size range and similar size of grains in the homogeneous aquifer provides the potential for heterogeneity, especially where any artificial effects or natural processes cause non-uniformity. Close et al. (2008) also discuss the potential for artificially introducing heterogeneity into the homogeneous aquifer by sorting of the sand into fine, medium and coarse zones as it was packed. 
Another reason for the apparent high degree of homogeneity in the heterogeneous artificial aquifer may be the result of releasing the tracer over the full width and depth of the aquifer. Had the point source tracer test been analysed instead, it may have been more difficult to match the observation data using a model that assumed homogeneous conditions because the tracer would have more ability to spread in both the transverse and vertical directions.

\subsection{Summary and Conclusions}

One dimensional analytical modelling of the breakthrough curves gave $\mathrm{K}_{\mathrm{x}}$ values ranging from $42 \mathrm{~m} / \mathrm{d}$ to $600 \mathrm{~m} / \mathrm{d}$ with an arithmetic mean of $177 \mathrm{~m} / \mathrm{d}$ and geometric mean of $169 \mathrm{~m} / \mathrm{d}$. These results are very similar to those calculated from the constanthead experiments and Kozeny-Carmen equation. In contrast, the mean values are three to four times less than the $\mathrm{K}_{\mathrm{eff}}$ calculated using Darcy's Law, thus confirming the by-pass flow along the top of the aquifer and maybe at other locations in the aquifer.

Mean values of $\alpha_{x}$ determined through analytical modelling were scale dependent and increased with distance from the head-tank. The mean values varied from $16 \%$ near the head-tank down to approximately $4 \%$ at distances of $4.75 \mathrm{~m}, 8.75 \mathrm{~m}$ and $9.5 \mathrm{~m}$ from the head-tank.

The heterogeneity of the heterogeneous artificial aquifer appears to be similar to that of the homogeneous aquifer based on the similar range and mean values of $K_{x}$ and $\alpha_{x}$. This was probably the result of similar grain sizes used in both aquifers, non-uniform packing in the homogeneous aquifer and the way the tracer was released over the entire width and thickness of the aquifer (rather than a point source). 


\section{NUMERICAL MODEL DESIGN AND CONSTRUCTION}

The analytical modelling produced some close fits to the observation data by using a unique set of parameters to match each breakthrough curve. However, the analytical modelling was limited by its inability to represent the spatial distribution of heterogeneity. To overcome this problem, 3D numerical models were applied using physics-based equations.

\subsection{Code Selection}

A groundwater flow model was needed to simulate hydraulic heads and groundwater flow rates and a solute transport model was needed to simulate solute concentrations. The three main numerical codes that could be used to do this are finite difference, finite element and finite volume.

\section{Finite Difference}

MODFLOW produced by the U.S. Geological Survey (USGS) is a commonly used finite difference code for groundwater modelling. MODFLOW is mass conservative, accounts for steady-state and transient flow in two and three dimensions, but it does not account for un-saturated flow (Harbaugh, Banta, Hill and McDonald, 2000). The main limitation of MODFLOW compared to finite element codes is that grid cells must be square or rectangular making it difficult to model around areas of complex geology or specified areas of interest. A commonly used code for modelling solute transport with MODFLOW is MT3DMS. MT3DMS is a public domain, 3D, finite difference code which simulates solute transport in saturated porous media and accounts for advection, dispersion and some simple chemical reactions (Zheng and Wang 1999).

\section{Finite Element}

FEFLOW produced by DHI (DHI, 2013) is a commonly used finite element code for groundwater modelling. Unlike MODFLOW, FEFLOW accounts for un-saturated flow and uses a finite element (triangular) mesh to represent the model domain. The use of triangles allows for a more efficient refinement around areas of complex geology or specified areas of interest (DHI, 2013). The finite element method also 
provides a better representation of anisotropy, whereas MODFLOW requires $\mathrm{K}$ to be perpendicular to the faces of the finite difference cells. However, one limitation compared with MODFLOW is that finite element boundaries can make it difficult to determine unique groundwater flow paths and local mass conservation is not guaranteed. FEFLOW can also simulate single-species and reactive multi-species solute transport in groundwater and the unsaturated zone (DHI, 2013).

\section{Finite Volume}

MODFLOW-USG (Un-Structured Grids) is a relatively new code based on a finite volume method. Released by the USGS in 2013, it follows a Control Volume Finite Difference formulation in which a cell can be connected to an arbitrary number of adjacent cells. This allows infinite possibilities for the cell geometry and means that the grid can be refined locally around areas of interest without adding extra cells. Essentially, MODFLOW-USG contains the best of the finite difference and finite element codes (Panday, Langevin, Niswonger, Ibaraki and Hughes 2013).

\section{Code Selection for this Study}

For this study, MODFLOW-2000 (MODFLOW) (Harbaugh et al., 2000) was chosen to simulate groundwater flow and MT3DMS Version 5.3 (MT3DMS) (Zheng and Wang 1999) was chosen to simulate solute transport. Given the very simple rectangular geometry of the aquifer boundaries and blocks that made up the aquifer, MODFLOW 2000 was considered perfectly acceptable. Both MODFLOW 2000 and MT3DMS were applied using the Groundwater Vistas Version 6.0 Graphical User Interface (GUI) produced by Environmental Simulations Incorporated. MODFLOW was chosen because the artificial aquifer structure could be easily and accurately represented using a block-centred finite difference model with a regular mesh structure. Flow modelling could have also been undertaken with other groundwater codes such as the finite element FEFLOW model (DHI, 2013), but since MODFLOW was included in the GUI, it was much simpler to use MODFLOW. MT3DMS was chosen to model the solute transport because the code is compatible with MODFLOW and because it was provided with the GUI making it simple to apply. 
The governing partial differential equation used by MODFLOW to calculate steadystate flow is presented in Equation 4-1

$$
\frac{\partial}{\partial \mathrm{x}}\left[\mathrm{K}_{\mathrm{x}} \frac{\partial \mathrm{h}}{\partial \mathrm{x}}\right]+\frac{\partial}{\partial \mathrm{y}}\left[\mathrm{K}_{\mathrm{y}} \frac{\partial \mathrm{h}}{\partial \mathrm{y}}\right]+\frac{\partial}{\partial \mathrm{z}}\left[\mathrm{K}_{\mathrm{z}} \frac{\partial}{\partial \mathrm{z}}\right]-\mathrm{W}=0.0 \quad \text { Equation 4-1 }
$$

Where $\mathrm{K}_{\mathrm{x}}, \mathrm{K}_{\mathrm{y}}, \mathrm{K}_{\mathrm{z}}$ are values of hydraulic conductivity along the $\mathrm{x}, \mathrm{y}$ and $\mathrm{z}$ coordinate axes $(\mathrm{L} / \mathrm{T}), \mathrm{h}$ is the potentiometric head $(\mathrm{L}), \mathrm{W}$ is the volumetric flux per unit volume (T) and represents sources and/or sinks of water per unit time (t).

The governing equation used in MT3DMS for describing the fate and transport of solutes in a 3D, transient groundwater model excluding any chemical reactions (from Zheng and Wang, 1999) is presented in Equation 4-2.

$$
\frac{\partial\left(\theta \mathrm{C}^{\mathrm{k}}\right)}{\partial \mathrm{t}}=\frac{\partial}{\partial \mathrm{x}_{\mathrm{i}}}\left[\theta \mathrm{D}_{\mathrm{ij}} \frac{\partial \mathrm{C}^{\mathrm{k}}}{\partial \mathrm{x}_{\mathrm{j}}}\right]-\frac{\partial}{\partial \mathrm{x}_{\mathrm{i}}}\left(\theta \mathrm{v}_{\mathrm{i}} \mathrm{C}^{\mathrm{k}}\right)+\mathrm{q}_{\mathrm{s}} \mathrm{C}_{s}^{\mathrm{k}}
$$

Equation 4-2

Where $C^{k}$ is the dissolved concentration of species $k\left(M / L^{3}\right), t$ is the time $(t), x_{i, j}$ is the distance along the respective Cartesian co-ordinate axis $(\mathrm{L}), \mathrm{D}_{\mathrm{i}, \mathrm{j}}$ is the hydrodynamic dispersion coefficient $\left(\mathrm{L}^{2} / \mathrm{T}\right), v_{\mathrm{i}}$ is the average linear groundwater flow velocity $(\mathrm{L} / \mathrm{T})$, $\mathrm{q}_{\mathrm{s}}$ is the volumetric flux of water per unit volume $(\mathrm{T})$ of the aquifer representing sources (positive) and sinks (negative), $\mathrm{C}_{\mathrm{s}}^{\mathrm{k}}$ is the concentration of the source or sink flux for species $\mathrm{k}\left(\mathrm{M} / \mathrm{L}^{3}\right)$ and $\theta$ is the porosity of the porous medium.

\subsection{Numerical Solution for Solute Transport Modelling}

The main role of MT3DMS is to solve the Advection-Dispersion Equation (ADE) shown in Equation 4-2 using one of a number of different numerical solvers. However, solving the ADE is difficult (Zheng and Wang 1999) because the spatial first derivative term for advection $\left(v_{\mathrm{i}}\right)$ and the spatial second derivative term for hydrodynamic dispersion $\left(\mathrm{D}_{\mathrm{i}, \mathrm{j}}\right)$ co-exist. Though many numerical solvers have been developed, there is still not a single technique that can yield completely satisfactory results under all conditions (Zheng and Wang, 1999). 
Most numerical solutions for solving the ADE can be classified as Eulerian, Lagrangian or mixed Eulerian-Lagrangian (Neuman 1984). Each solution has its own advantages and disadvantages depending upon factors such as grid structure and whether the problem is advection dominant or dispersion dominant. In order that different parameterisations with and without dispersion could be accurately modelled, the Total Variation Diminishing (TVD) solution was chosen.

TVD solutions are arguably the best compromise between the standard finitedifference method and the particle tracking based Lagrangian or mixed EulerianLagrangian methods (Zheng and Wang, 1999). The MT3DMS code is implemented with a third-order TVD solution based on the Ultimate algorithm which is best for advection dominated problems. This solution minimises artificial oscillations, is mass conservative without excessive numerical dispersion (caused by truncation errors of the discretisation) and works well with all values of $\mathrm{P}_{\mathrm{e}}$ (Zheng and Wang, 1999).

\subsection{Model Domain and Boundary Conditions}

Figure 4-1 shows the model domain, discretisation, boundary conditions (blue cells), and location of observation targets in model layer 32 (as an example).

\section{Model Domain}

Both the flow and transport domains were $9.83 \mathrm{~m}$ long in the direction of groundwater flow, $4.66 \mathrm{~m}$ wide perpendicular to groundwater flow and $2.6 \mathrm{~m}$ deep in the vertical direction. The domain has the same width and depth as the artificial aquifer but is $0.33 \mathrm{~m}$ longer because a $0.1667 \mathrm{~m}$ wide column was added to both ends of the aquifer. These are represented by column 1 and column 59 shown as blue cells in Figure 4-1.

\section{Boundary Conditions}

The two $9.5 \mathrm{~m}$ long walls of the aquifer were impermeable to groundwater flow, and were represented in the model as no flow boundaries. The $4.66 \mathrm{~m}$ wide and $2.6 \mathrm{~m}$ deep head-wall and end-wall were both permeable to groundwater flow and $\mathrm{Br}$ transport. Therefore groundwater flow into and out the aquifer was represented in columns 1 and 59 using the Dirichlet boundary condition (Zheng and Bennett, 2002). In this case the head in columns 1 and 59 were fixed for the entire duration of the 
simulation which created steady-state groundwater flow conditions, even though the measured outflow was shown to decrease with time. The distance between the fixed heads at the centre of each column is $9.67 \mathrm{~m}$ and the $\Delta \Psi$ is $0.00429 \mathrm{~m}$. This made $\mathrm{i}$ equal to $0.00044 \mathrm{~m} / \mathrm{m}$ so it matched the value measured by the three piezometers from day 2 to 102 of testing as described in Chapter 2.4. It should be noted here that there is some uncertainty about what $\mathrm{i}$ actually was given the coarse resolution of head measurements in the aquifer combined with the low $i$.

The two $9.5 \mathrm{~m}$ long walls of the aquifer were impermeable to $\mathrm{Br}$, and were represented in the model as zero concentration boundaries. In reality, $\mathrm{Br}$ input from the head-tank to the aquifer occurred from advection only. However, in the numerical models where dispersivity was included in every model cell (to mimic the actual heterogeneity), Br input from column 1 occurred from both advection and dispersion. The modelled $\mathrm{Br}$ input from advection was proportional to the concentration of $\mathrm{Br}$ in column 1 and the flow rate between column 1 and column 2 which was a function of $\mathrm{K}$, $\mathrm{i}$ and $\mathrm{A}$ as expressed in Equation 2-5. The modelled $\mathrm{Br}$ input from dispersion was proportional to the concentration gradient between column 1 and column 2 . Therefore the modelled $\mathrm{Br}$ input from the column one is represented by a Cauchy type boundary condition (Zheng and Wang, 1999). As discussed later on in Chapter 5.4.8, the way that dispersivity was applied to the parameterisation affected whether or not dispersive mass was included. This had a small effect on the values of other parameters estimated during calibration. Bromide exited the model through column 59. 

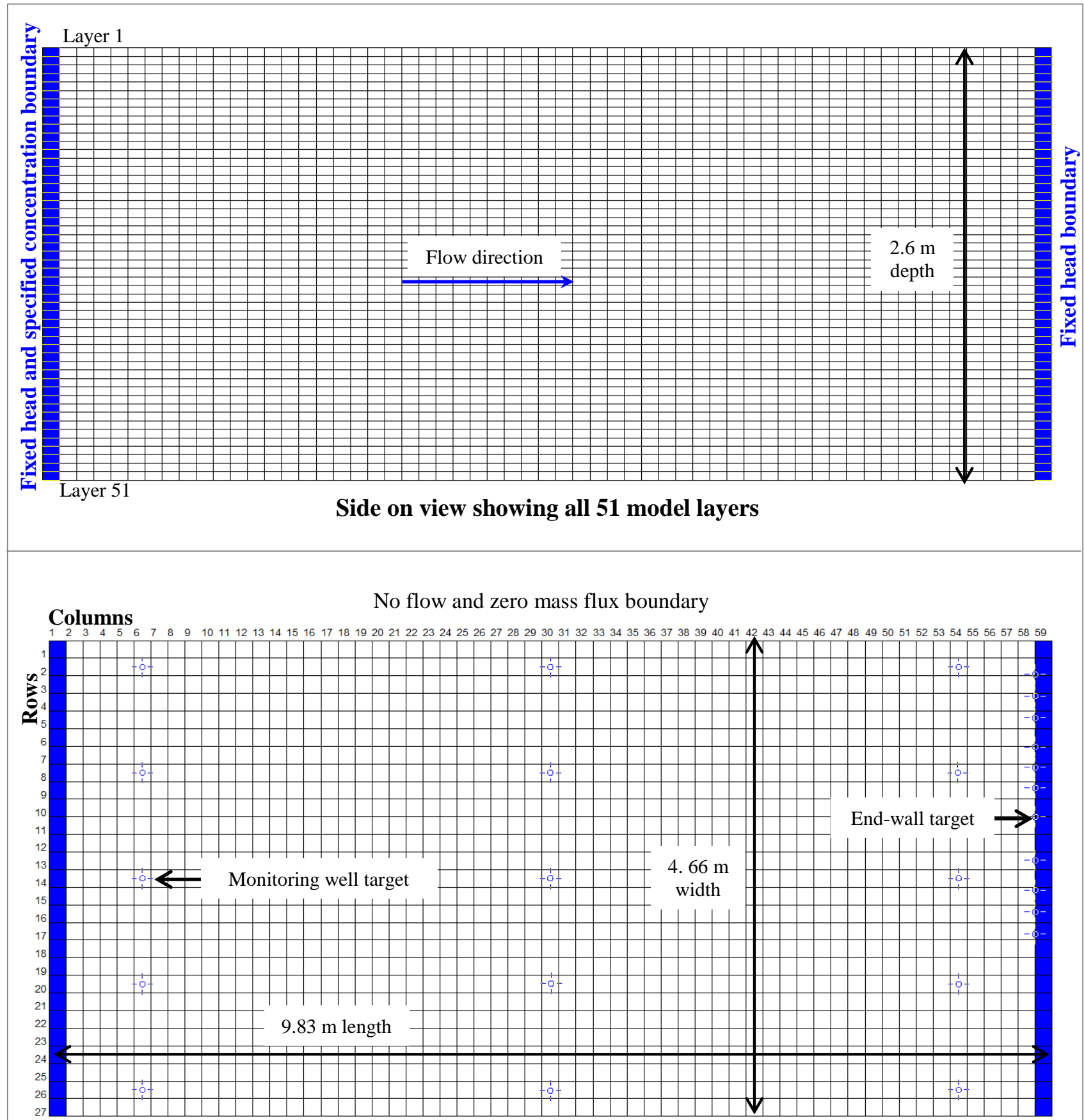

No flow and zero mass flux boundary

Plan view of model layer 32

Figure 4-1: Domain, discretisation, boundary conditions (blue cells), and location of observation targets in model layer 32 


\subsection{Discretisation}

\section{Spatial}

The model grid describes the spatial discretisation of model parameters. The domain was discretised into a uniform grid with 27 rows, 59 columns, and 51 layers totalling 8,1243 cells. Each cell had the dimensions of $16.67 \mathrm{~cm}$ (column width), by $17.26 \mathrm{~cm}$ (row width) by $5.098 \mathrm{~cm}$ (layer thickness).

Artificial oscillation and numerical dispersion related to grid discretisation are two major problems encountered when applying a numerical solute transport solution to an advection dominated problem (Zheng and Bennett, 2002). Using $\mathrm{P}_{\mathrm{e}}$ it is possible to evaluate the dominance of advection (Zheng and Wang, 1999). The dimensionless $\mathrm{P}_{\mathrm{e}}$ for a 1D uniform flow field is shown in Equation 4-3.

$$
\mathrm{P}_{\mathrm{e}}=\frac{\mathrm{vL}_{\mathrm{cell}}}{\mathrm{D}}
$$

Equation 4-3

Where $\mathrm{L}_{\text {cell }}$ is the cell size $(\mathrm{m})$ in relation to the average linear velocity of groundwater flow (v) $(\mathrm{m} / \mathrm{d})$ and hydrodynamic dispersion (D) $\left(\mathrm{m}^{2} / \mathrm{d}\right)$. It has been found that $\mathrm{P}_{\mathrm{e}}$ numbers less than four are usually effective in suppressing artificial oscillations (Barnett et al., 2012). However, at high $\mathrm{P}_{\mathrm{e}}$ some numerical dispersion can be present. As discussed later, some numerical dispersion was evident in those parameterisations where dispersivity was not included (see Figure 5-6 for an example). Based on the range of values for $\mathrm{v}$ used in these parameterisations, the cell dimensions would need to be anywhere from two times smaller and up to 750 times smaller in order to keep $\mathrm{P}_{\mathrm{e}}$ less than four.

\section{Temporal}

In MODFLOW, a total of 29 stress periods were used to model the change in $\mathrm{Br}$ input from the head-tank. The actual change in $\mathrm{Br}$ concentration in the head-tank over time is shown in Figure 2-7. Stress periods one to 28 had five flow time steps each, and stress period 29 had 75 flow time steps. 
In MT3DMS, each MODFLOW time step is broken down further into transport time steps (Zheng and Wang, 1999). When modelling solute transport, it is important that a solute particle can not traverse more than a single model cell during any given transport time step (Barnett et al., 2012). This can be achieved by setting the Courant number $(\mathrm{Cr})$ shown in Equation 4-4 to a value less than or equal to one.

$$
\mathrm{Cr}=\frac{\mathrm{vt}_{\text {transport }}}{\mathrm{L}_{\text {cell }}} \leq 1
$$

Equation 4-4

Where $\mathrm{v}$ is the average linear groundwater flow velocity $(\mathrm{m} / \mathrm{d}), \mathrm{t}_{\text {transport }}$ is the transport time step duration (d) and $\mathrm{L}_{\text {cell }}$ is the cell size (m). To honour this criterion, $\mathrm{Cr}$ was set to one in MT3DMS.

\subsection{Initial Aquifer Conditions}

\section{Flow}

The starting heads for the steady-state groundwater flow model were set at 10.00429 $\mathrm{m}$ in column 1 and $10.0 \mathrm{~m}$ in column 59. These heads remained fixed throughout the simulation. The values are not measured, rather they were arbitrary values that gave the same difference in head and thus same $\mathrm{i}$ as that measured in the piezometers from days 2 to 102 of testing. See Chapter 2.2 for more details.

\section{Transport}

Since the background concentration of $\mathrm{Br}$ in the aquifer was below the limit of detection, the initial $\mathrm{Br}$ concentration in columns 2 to 59 were set to zero. The starting $\mathrm{Br}$ concentration for all cells in model column 1 was $3.16 \mathrm{mg} / \mathrm{L}$.

\subsection{Design and Construction Uncertainty}

There will always be some uncertainty and simplification when it comes to representing the physical structure with a numerical mathematical model. In this case there is considered to be a low degree of uncertainty about background concentration of $\mathrm{Br}$ since the value is so close to zero. With regards to assuming steady-state flow, 
and constant $i$ there is considered to be a moderate degree of uncertainty because of the apparent variation in $\mathrm{i}$ on day one of the test. There is also considered to be a moderate degree of uncertainty around the numerical model being designed in such a way as to ignore the by-pass flow of groundwater that occurred along the top of the aquifer. In addition, the numerical dispersion is a source of error. 


\section{NUMERICAL MODEL CALIBRATION}

Calibration is a process known as 'model fitting', 'history matching', 'parameter estimation' or the 'inverse problem'. It occurs after model design and construction where selected parameters describing the hydrological properties and boundary conditions of the model are adjusted, ideally within realistic limits, in order to achieve the closest fits between the model data and the observation data (often referred to as calibration targets) (Anderson and Woessner, 1992).

This study compares three types of parameterisation. The first and most simple type assumes homogeneous aquifer conditions. The second and third types assume heterogeneous aquifer conditions, with one based on the known block distribution as shown in Appendix A and the other based on a method of spatial parameter definition defined by Doherty (2003) using what will be referred to throughout the rest of this study as 'pilot points'. The aim of this approach is to assess the effects of increasing parameterisation complexity on the models ability to replicate the tracer test observations.

Calibration was undertaken manually through a trial and error approach and automatically using PEST (Doherty, 2010a). PEST is an industry standard software package for parameter estimation and uncertainty analysis and is commonly used with groundwater and surface water models (Doherty, 2010a).

\subsection{Weightings, Calibration Constraints and Starting Conditions}

Each parameterisation was calibrated against transient $\mathrm{Br}$ concentration measurements taken from monitoring well and end-wall sampling points. Most monitoring wells and end-wall sampling points appear to show a background concentration between about $0.01 \mathrm{mg} / \mathrm{L}$ and $0.2 \mathrm{mg} / \mathrm{L}$. Given that the background concentration was assumed to be zero (see Chapter 2.4) these low values occurring prior to and after the breakthrough curve were all excluded from the calibration by giving them a weighting of zero There were 16 dubious observations given a weighting of 0.5 . These data were still part of the calibration but by giving them a weighting less than one, meant they had 
less effect on the modelled outputs. All other target observations were given a weighing of one. The observation weightings can be reviewed in digital Appendix B.

The calibration constraints used in PEST and the pre-calibration (starting) parameter values are summarised in Table 5-1. The calibrated parameters included hydraulic conductivity $\left(\mathrm{K}_{\mathrm{x}, \mathrm{y}}\right.$ and $\left.\mathrm{K}_{\mathrm{z}}\right)$, effective porosity $\left(\mathrm{n}_{\mathrm{e}}\right)$ and dispersivity $\left(\alpha_{\mathrm{x}}, \alpha_{\mathrm{y}}\right.$ and $\left.\alpha_{\mathrm{z}}\right)$. The same starting values and constraints were applied to the pre-calibration analysis (see Chapter 5.2) and final calibration (see Chapter 5.3).

Table 5-1: Calibration constraints and starting values used in both the precalibration analysis and final calibration

\begin{tabular}{|l|l|c|c|c|l|}
\hline \multicolumn{1}{|c|}{ Model } & Parameter & $\begin{array}{c}\text { Lower } \\
\text { bound }\end{array}$ & $\begin{array}{c}\text { Upper } \\
\text { bound }\end{array}$ & Starting values & Units \\
\hline Flow & $\mathrm{K}_{\mathrm{x}, \mathrm{y}}$ and $\mathrm{K}_{\mathrm{z}}$ & 1 & 1,000 & 177 and $40,126,404$ & $\mathrm{~m} / \mathrm{d}$ \\
\hline Transport & $\eta_{\mathrm{e}}$ & Fixed & Fixed & Fixed $-0.28,0.30,0.32$ & dec.frac \\
\hline Transport & $\alpha_{\mathrm{x}}$ & 0.001 & 10 & 0.38 & $\mathrm{~m}$ \\
\hline Transport & $\alpha_{\mathrm{y}}$ & 0.0001 & 1 & 0.038 & $\mathrm{~m}$ \\
\hline Transport & $\alpha_{\mathrm{z}}$ & 0.00001 & 0.1 & 0.0038 & $\mathrm{~m}$ \\
\hline
\end{tabular}

\section{Hydraulic Conductivity}

The lower and upper bounds for $\mathrm{K}_{\mathrm{x}, \mathrm{y}}$ and $\mathrm{K}_{\mathrm{z}}$ were adopted as $1 \mathrm{~m} / \mathrm{d}$ and 1,000 m/d respectively. These are lower and higher than minimum value of $42 \mathrm{~m} / \mathrm{d}$ and maximum value of $600 \mathrm{~m} / \mathrm{d}$ determined from the analytical modelling. The bounds were increased to allow for the possibility of greater parameter variability. Values for $\mathrm{K}_{\mathrm{x}, \mathrm{y}}$ in the homogeneous and heterogeneous pilot point parameterisations had starting values of $177 \mathrm{~m} / \mathrm{d}$. This is the arithmetic mean value determined from analytical modelling. For the heterogeneous block parameterisations, starting values for $\mathrm{K}_{\mathrm{x}, \mathrm{y}}$ were based on the values of $40 \mathrm{~m} / \mathrm{d}, 126 \mathrm{~m} / \mathrm{d}$ and $404 \mathrm{~m} / \mathrm{d}$ as determined for the three different grain sizes through the constant-head experiments. The starting values for $\mathrm{K}_{\mathrm{z}}$ in the heterogeneous block and pilot point parameterisations were assigned the same values as $K_{x, y}$. The only exception to the values listed in Table 5-2 was for the heterogeneous pilot point parameterisations which had an upper bound of $700 \mathrm{~m} / \mathrm{d}$. 


\section{Effective Porosity}

Effective porosity was fixed at 0.3 for the homogeneous parameterisations. For the heterogeneous block and pilot point parameterisations, the spatial distribution of $\eta_{\mathrm{e}}$ was based on the block distribution and a fixed value of $0.28,0.30$ and 0.32 was assigned to the coarsest grain, medium grain and finest grain blocks respectively. The $\eta_{\mathrm{e}}$ values were based on typical values for Sy shown in Table 2-2. These values take into account the probable reduction in $\eta_{e}$ with increasing grain size. Effective porosity was fixed because $\eta_{\mathrm{e}}$ was highly correlated with $\mathrm{K}$ as discussed later in Chapter 5.2.

\section{Dispersivity}

The lower and upper bounds for $\alpha_{\mathrm{x}}$ were larger than the range of values determined through analytical modelling. This was to allow for the possibility of greater parameter variability. Values for $\alpha_{\mathrm{x}}$ in all parameterisations had a starting value of $0.38 \mathrm{~m}$ which is the arithmetic mean value determined from the analytical modelling. For $\alpha_{y}$ the lower bound, upper bound and starting value was one order of magnitude lower than $\alpha_{x}$. For $\alpha_{z}$ the values were two orders of magnitude lower. This was based on the general rule which states that dispersivity decreases in the transverse and vertical directions by one and two orders of magnitude respectively relative to $\alpha_{\mathrm{x}}$ (see Chapter 2.7.3).

\section{Bromide Mass and Head Data}

Bromide mass and groundwater head data were not used in model calibrations. Bromide mass was admitted on the basis of not having accurate measurements of the bypass flow and therefore not knowing exactly how much $\mathrm{Br}$ mass actually exited the aquifer itself. Therefore including $\mathrm{Br}$ mass as part of the calibration could place unrealistic bounds if the estimates made using the analytical modelling and grain size analysis were found to be inaccurate. The aim of not constraining $\mathrm{Br}$ mass in the calibration is to see if the resultant mass values are similar to the values estimated from the analytical modelling. If they are then there the agreement of different methods gives more certainty of the bypass flow and resultant bypass mass. 
Given the uncertainty of $i$, head data could have formed part of the calibration. Since both $\mathrm{K}$ and i play a role in determining the groundwater velocity, varying the head to give different values for $\mathrm{i}$ would provide a more detailed assessment of $\mathrm{K}$. Thus a result of excluding $\mathrm{i}$ from the calibration is not exploring the full range of values for $\mathrm{K}$.

\subsection{Zone Based Pre-Calibration Analysis and Results}

Where two parameters are correlated, one parameter is usually fixed to avoid the problem of a non-unique solution. Where a parameter is insensitive, its value may be be fixed or the parameter may be excluded from the parameterisation on the basis that its inclusion has little worth on model calibration or predictions (Barnett et al., 2012).

A pre-calibration analysis was undertaken on the homogeneous and heterogeneous block parameterisations (both zoned based methods) through a trial and error approach and automatically using PEST. The aim was to identify highly correlated parameters (see Chapter 5.2.1) and insensitive parameters (see Chapter 0). The results were used to decide which parameters should be included in the final calibrations (see Chapter 5.3) and which should be excluded.

\subsubsection{Parameter Correlations}

PEST can be used to create a Parameter Correlation Coefficient Matrix (PCCM) showing the parameter correlation with 1 or -1 being perfectly correlated and zero being no correlation. Results for the homogeneous and heterogeneous block parameterisations discussed in Chapter 5.2.1 are provided in digital Appendix D.

For the homogeneous parameterisation using $K_{x, y}, K_{z}, \eta_{e}$, and $\alpha_{x}$, it was found that $\mathrm{K}_{\mathrm{x}, \mathrm{y}}$ and $\eta_{\mathrm{e}}$ had a correlation of $0.99, \mathrm{~K}_{\mathrm{x}, \mathrm{y}}$ and $\alpha_{\mathrm{x}}$ had a correlation of 0.95 and all other parameters had correlations less than 0.1. Figure 5-1 shows PCCM values greater than 0.5 for the heterogeneous block parameterisation using a single value of $\mathrm{K}_{\mathrm{x}, \mathrm{y}}, \mathrm{K}_{\mathrm{z}}$ and $\eta_{\mathrm{e}}$ for each of the three grain sizes and a single value of $\alpha_{\mathrm{x}}, \alpha_{\mathrm{y}}$ and $\alpha_{\mathrm{z}}$ for every model cell (negative PCCM values were converted to positive values for plotting). Each parameter shown in Figure 5-1 has a number assigned to it. Numbers 1, 2 and 3 refer to the finest, medium and coarsest grain blocks respectively. 


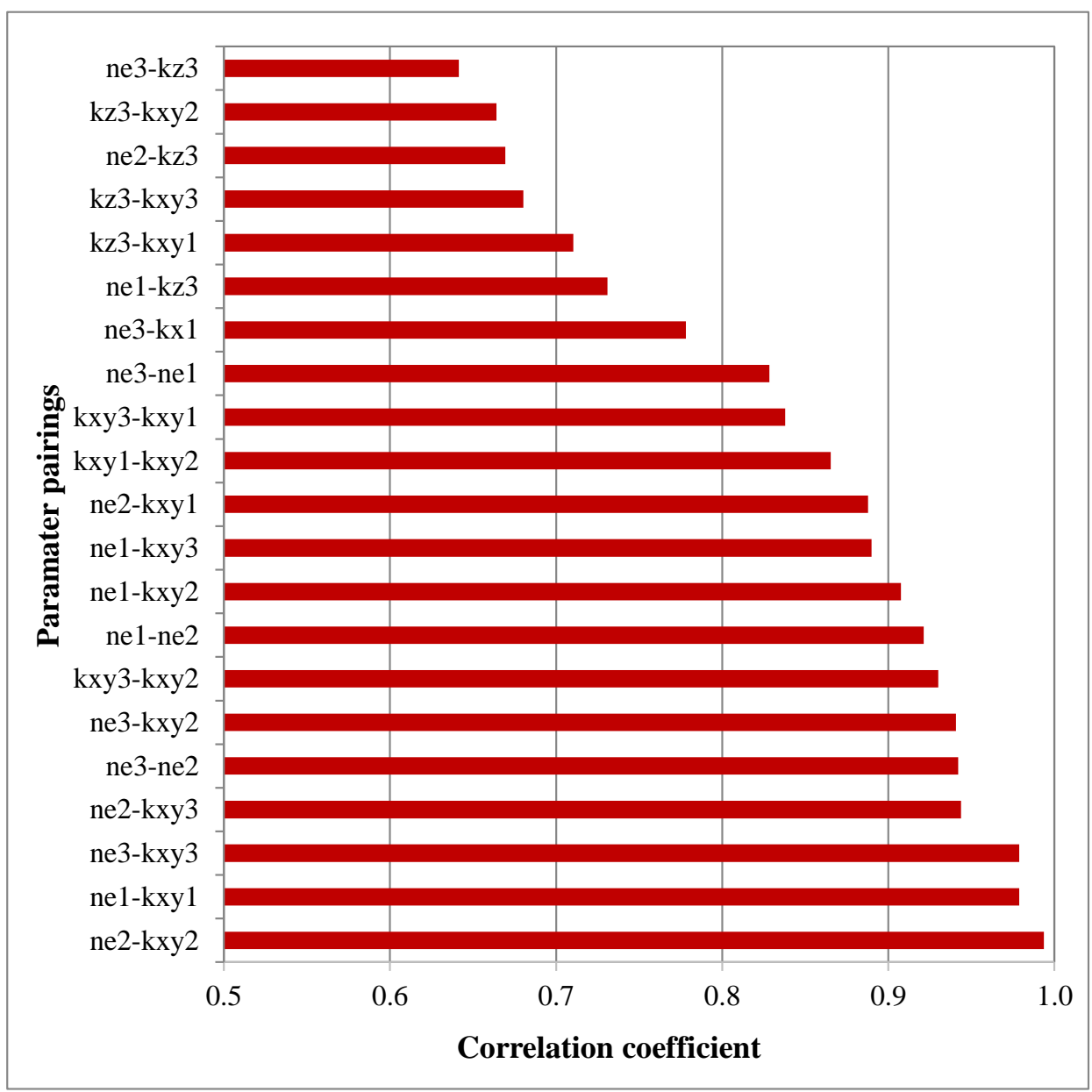

Figure 5-1: Parameter correlation coefficients greater than 0.5 for the heterogeneous block parameterisation

The results show again that the greatest correlations occur between $K_{x, y}$ and $\eta_{e}$ with a lower but still significant correlation between $\mathrm{K}_{\mathrm{z}}$ and $\eta_{\mathrm{e}}$. An explanation why $\mathrm{K}_{\mathrm{x}, \mathrm{y}}$ and $\eta_{\mathrm{e}}$ are so well correlated is that both parameters control the advective velocity, thus exactly the same velocity can be calculated using a high value of $\mathrm{K}_{\mathrm{x}, \mathrm{y}}$ and low value of $\eta_{e}$ or low value of $K_{x, y}$ and high value of $\eta_{e}$. Consequently, the decision was made to fix the value of $\eta_{\mathrm{e}}$ in every parameterisation. In the homogeneous parameterisation $\mathrm{K}_{\mathrm{x}, \mathrm{y}}$ and $\alpha_{\mathrm{x}}$ were also highly correlated. This might occur because mass from model column 1 was the product of advection and dispersion, thus one could get similar mass by having high mass from advection and low mass from dispersion or vice versa. 


\subsubsection{Parameter Sensitivities}

Using PEST, the sensitivity of modelled concentration to changes in the value of each parameter was assessed using the Relative Composite Sensitivity (RCS) method presented by Doherty (2010a). The RCS method utilises a dimensionless statistic of the composite changes in model output incurred by a fractional change in the value of a parameter (Doherty, 2010a). Results for the homogeneous and heterogeneous block parameterisations are provided in digital Appendix E.

Figure 5-2 shows RCS values for parameters trialled in the homogeneous and heterogeneous block parameterisations. It is clear that both parameterisations are most sensitive to $K_{x, y}$, least sensitive $K_{z}, \alpha_{y}, \alpha_{z}$ and moderately sensitive to $\alpha_{x}$. Through trial and error calibration with the homogeneous parameterisation it was also found that $K_{z}, \alpha_{y}$ and $\alpha_{z}$ had no effect on model outputs. In contrast, changing the values of $\mathrm{K}_{\mathrm{z}}, \alpha_{\mathrm{y}}$ and $\alpha_{\mathrm{z}}$ in the heterogeneous block parameterisation produced observable changes in the modelled concentrations even though they had relatively low sensitivities.

\subsection{Parameterisations for Final Calibration}

Three general types of parameterisation were compared. The first and most simple parameterisation assumes homogeneous aquifer conditions. The second and third parameterisations assume heterogeneous aquifer conditions with one based on the known block distribution and the other based on a $\mathrm{K}$ distribution determined using pilot points. Results from the PCCM and relative composite sensitivities were used to decide which parameters should be included in the final parameterisations and which should be excluded. The final parameterisations were then subject to a final calibration using PEST. 


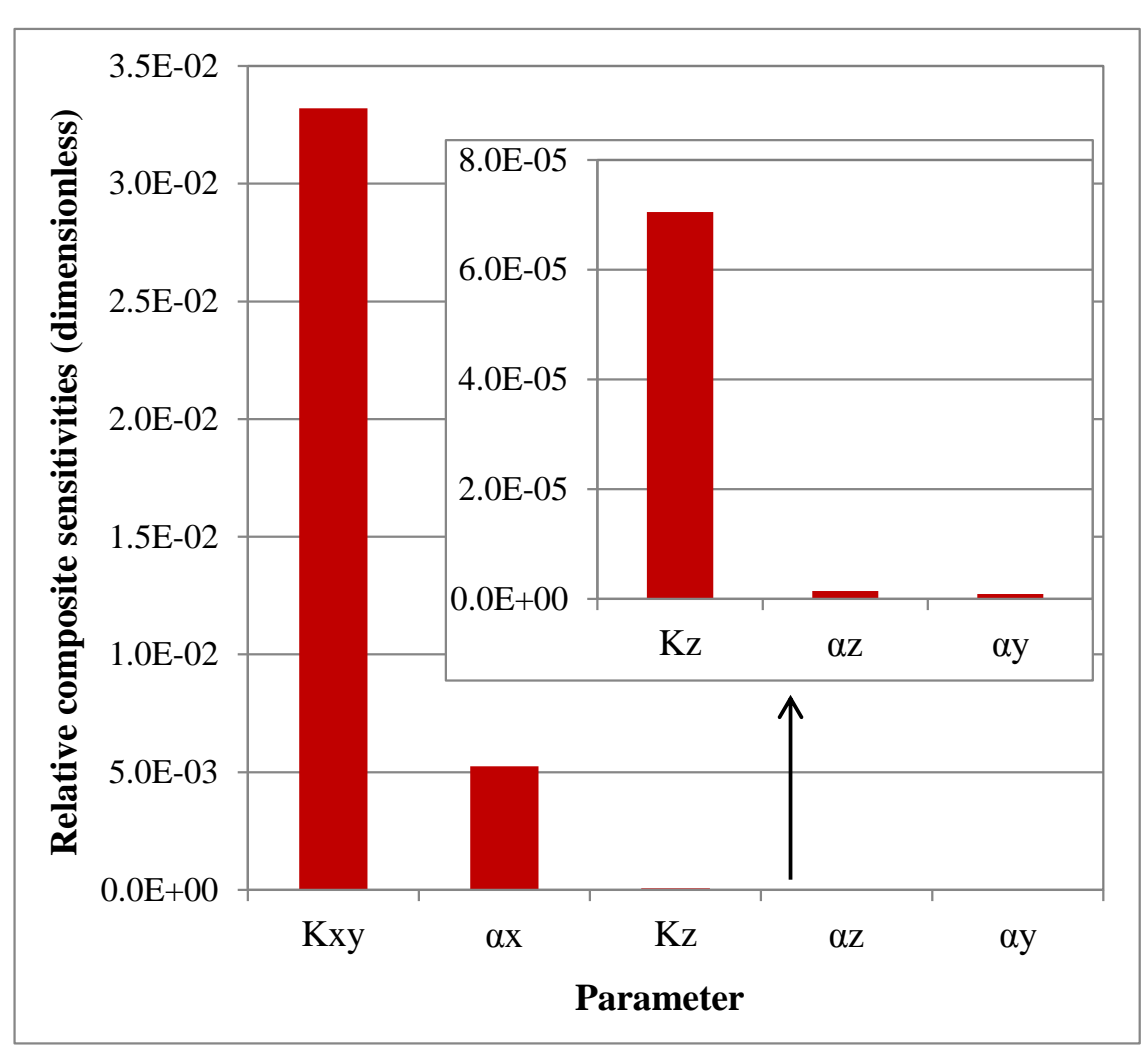

Homogeneous parameterisation

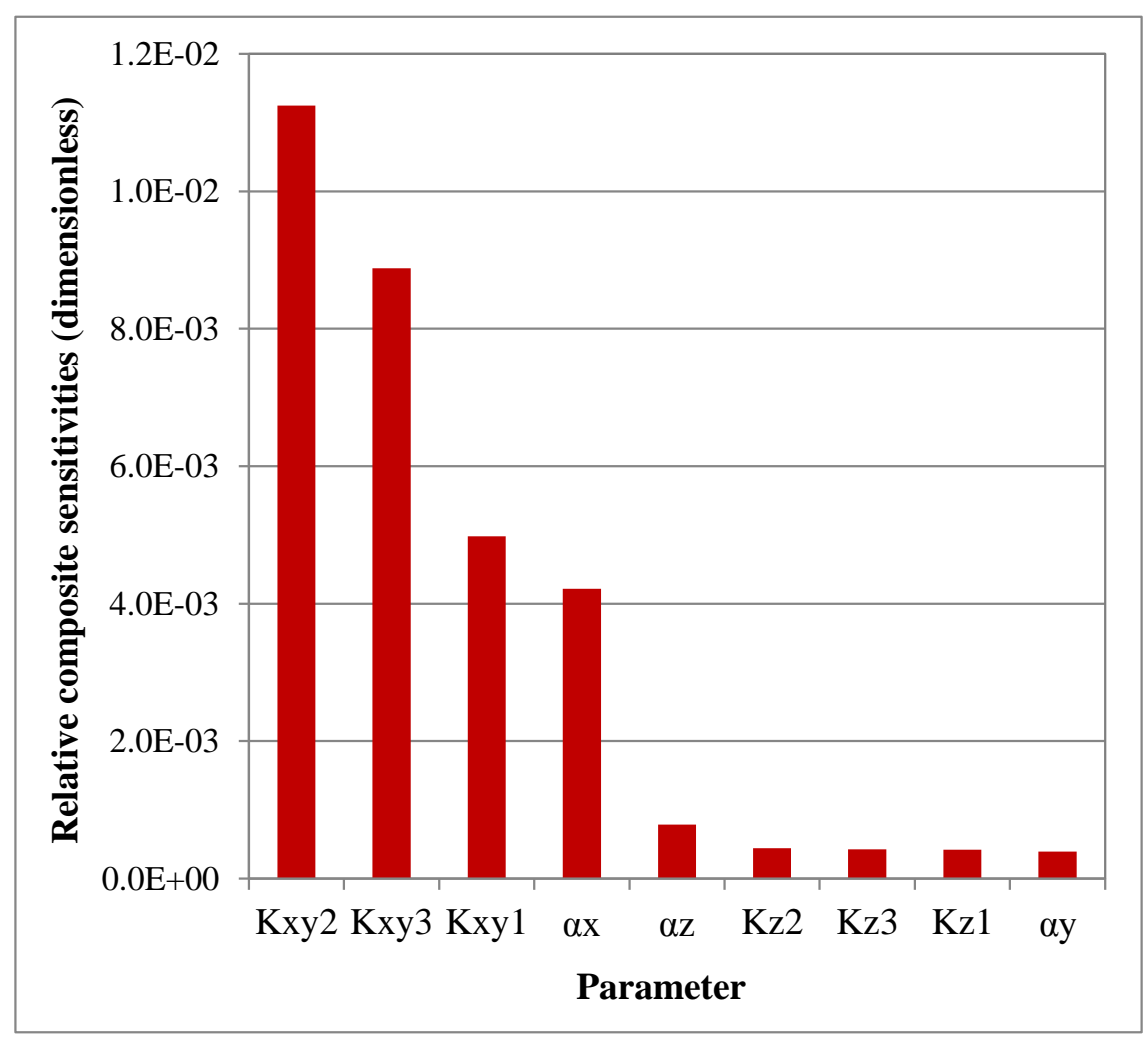

Heterogeneous block parameterisation

Figure 5-2: Relative composite sensitivities 


\subsubsection{Zone Based Parameterisations}

The homogeneous and heterogeneous block parameterisations use zones for the spatial distribution of parameters. Delineation of zone boundaries relies heavily on an accurate conceptual understanding, and zones often have the problem of being oversimplified representations of a much more complex 'real world' system (Doherty, 2010b). In many studies, zone boundaries are often based on knowledge of the geological structure (for example bore logs or predictions from a geological model) and spatial variation of hydrogeological parameters (for example $\mathrm{K}$ values determined from pump tests). The artificial aquifer is a unique case in that the zones of unique hydrogeological characteristics are known to a very high level of detail.

For the homogeneous models, two different parameterisations were investigated. Homogenous parameterisation one (Hom 1) consisted of a single value of $K_{x, y}$ which was subject to calibration and a single fixed value of 0.3 for $\eta_{\mathrm{e}}$ which was not subject to calibration. The value for $K_{z}$ was fixed to the same value of $K_{x}$. Homogenous parameterisation two (Hom 2) consisted of a single value for $K_{x, y}$ and $\alpha_{\mathrm{x}}$ which were both subject to calibration and a single fixed value of 0.3 for $\eta_{\mathrm{e}}$ which was not subject to calibration. In Hom $2, K_{z}$ was fixed to the same value of $K_{x}$, whilst $\alpha_{y}$ and $\alpha_{z}$ were set at zero so that they did not play a part in the calibration.

For the heterogeneous block models, two different parameterisations were investigated. Heterogeneous block parameterisation one (Het 1) consisted of three zones assigned to $\mathrm{K}_{\mathrm{x}, \mathrm{y}}$ and $\mathrm{K}_{\mathrm{z}}$ which are abbreviated to $\mathrm{K}_{\mathrm{x}, \mathrm{y}} 1, \mathrm{~K}_{\mathrm{x}, \mathrm{y}} 2, \mathrm{~K}_{\mathrm{x}, \mathrm{y}} 3, \mathrm{~K}_{\mathrm{z}} 1, \mathrm{~K}_{\mathrm{z}} 2$, $\mathrm{K}_{\mathrm{z}} 3$. Zone 1 was assigned to the medium to coarse grained sand blocks, Zone 2 to the very coarse grained sand blocks and Zone 3 to the very coarse sand to very fine gravel blocks. Values for $\alpha_{x}, \alpha_{y}$ and $\alpha_{z}$ were set at zero so that they did not play a part in the calibration. Discretisation of the three zones used in model layer one is shown in Figure 5-3. Effective porosity was not included in the calibration and a fixed value of 0.32 was applied to Zone 1, 0.30 to Zone 2 and 0.28 to Zone 3. Heterogeneous block parameterisation two (Het 2) was the same as Het 1 except that that one single value for $\alpha_{x}, \alpha_{y}$ and $\alpha_{z}$ (applied to every model cell) was added to the calibration. 


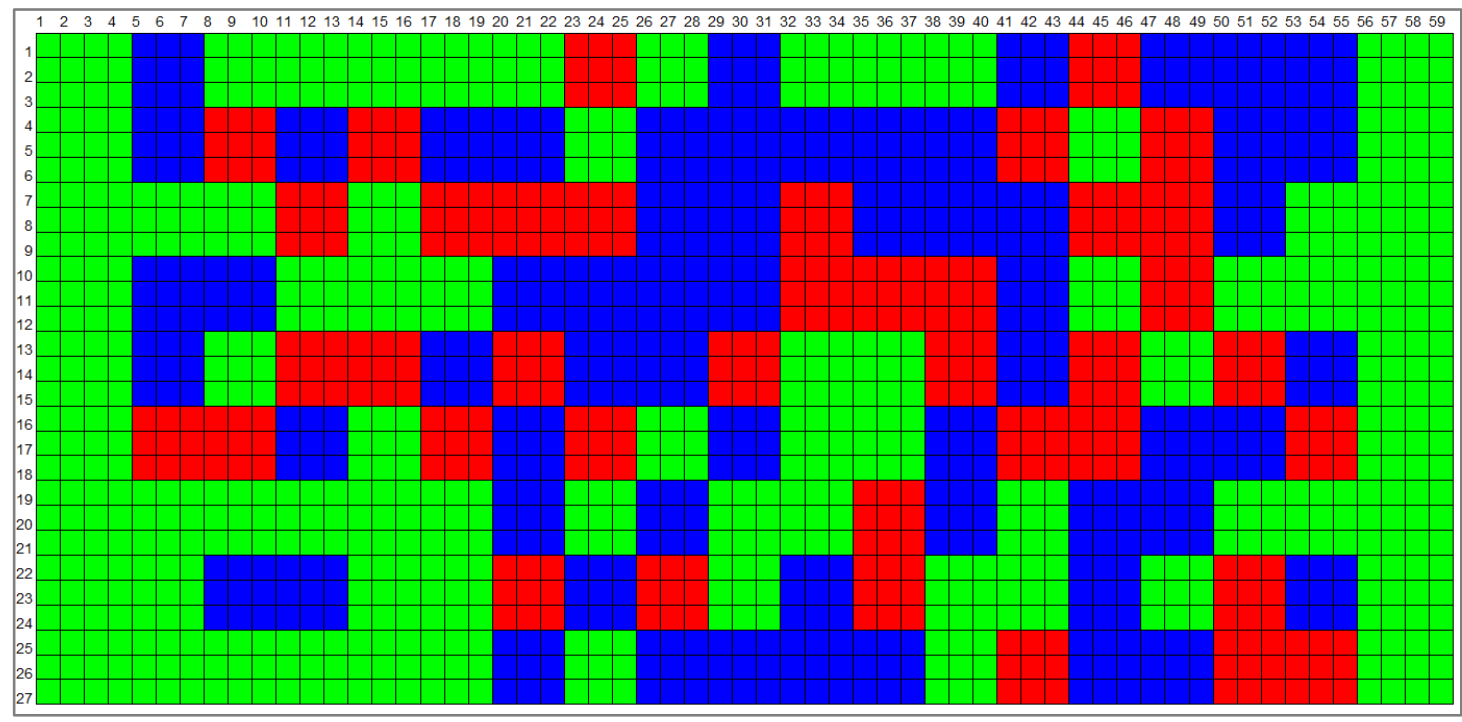

Figure 5-3: Heterogeneous block parameterisation showing the three zones used for $K_{x, y}, K_{z}$ and $\eta_{e}$. Blue is the finest grained blocks, green is the medium grained blocks and red is the coarsest grained blocks

\subsubsection{Pilot Point Parameterisations}

Pilot points can be used as an alternative way of representing heterogeneity of aquifer properties rather than using a 'hard wired' zone based approach (Doherty, 2003). Pilot points are placed at various locations within the model and are assigned starting parameter values which are subject to calibration. As calibration occurs, the pilot point values are altered and values are assigned to the rest of the model cells through spatial interpolation (Doherty, 2003). This results in a smoother representation of the aquifer properties over the model domain compared with the zone based parameterisations.

For the heterogeneous pilot point models, three parameterisations were investigated. In Heterogeneous pilot point parameterisation one (Pil 1) $K_{x, y}$ was the only calibrated parameter. A total of $714 \mathrm{~K}_{\mathrm{x}, \mathrm{y}}$ pilot points were used with 14 pilot points located in each model layer as shown in Figure 5-4. Pilot points were located to give a relatively even coverage over for each model layer and in hindsight a pilot point should have also been placed at the center of each layer to keep a more consistent spacing and aid in the interpolation. Furthermore, running the model with more and then fewer pilot points would have also been useful to assess how many points were actually necessary. The starting value for each pilot point was $177 \mathrm{~m} / \mathrm{d}$ (arithmetic mean value from the analytical modelling). 


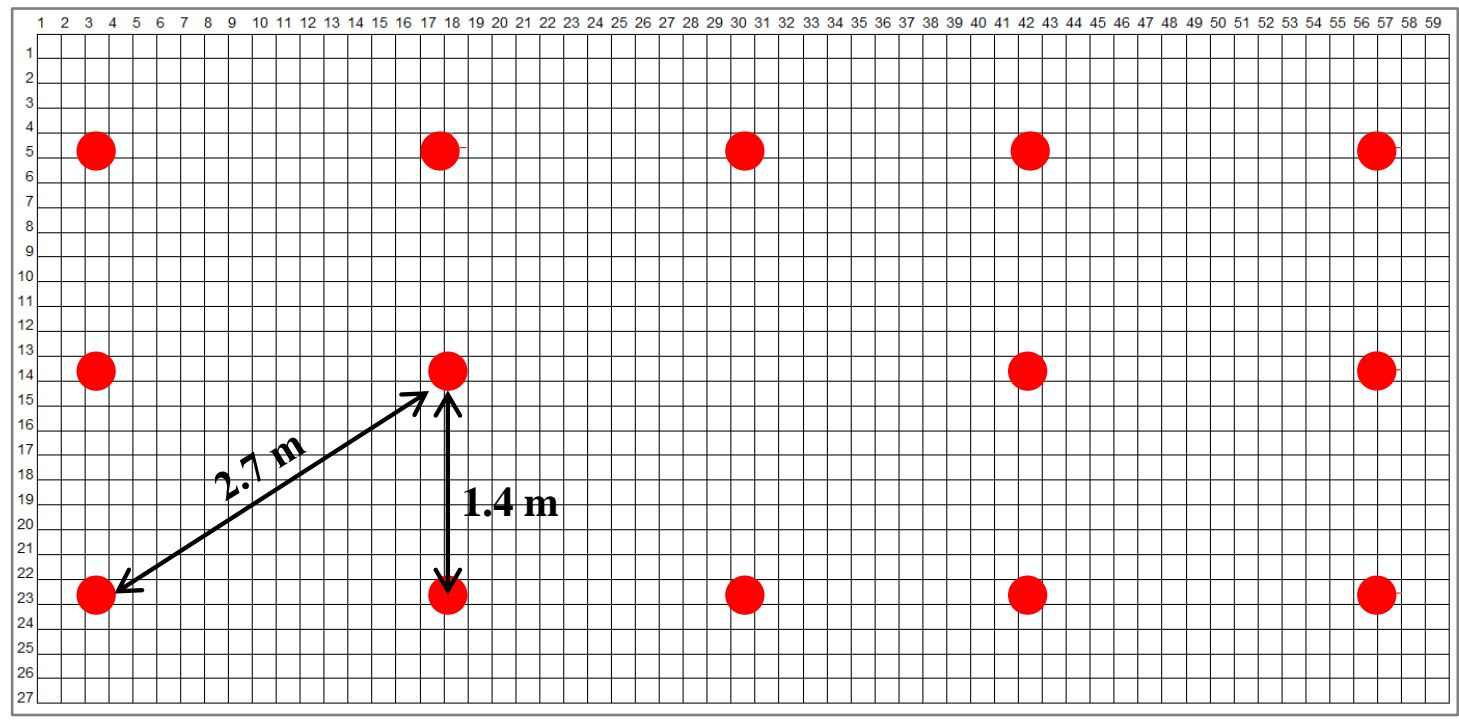

Figure 5-4: Spatial distribution of pilot points for every model layer. Pilot points shown in red and some distances provided for scale

Kriging was used to interpolate the pilot point values to every model cell (Doherty, 2003). Kriging was undertaken using an exponential variogram, with alpha set to 20 $\%$ of the longest dimension of the model, the bearing set to zero, and both the anisotropy ratio and contribution were set to one. For kriging, the search radius from any pilot point was $2.95 \mathrm{~m}$ so the interpolation accounted for 5 to 7 points. The transform was set to log and kriging was ordinary. A comparison of the kriged distribution of $\mathrm{K}_{\mathrm{x}, \mathrm{y}}$ for model layer 1 in Pil 1 with the zone based block distribution of $\mathrm{K}_{\mathrm{x}, \mathrm{y}}$ for model layer 1 in Het 1 is provided in Figure 5-12.

Values for $\mathrm{K}_{\mathrm{z}}$ and $\eta_{\mathrm{e}}$ were fixed and spatially distributed using zones based on the block distribution. Vertical K was fixed at $40 \mathrm{~m} / \mathrm{d}, 126 \mathrm{~m} / \mathrm{d}$ and $404 \mathrm{~m} / \mathrm{d}$ for the finest grained, medium grained and coarsest grained blocks respectively. A zone based approach for $\mathrm{K}_{\mathrm{z}}$ was used to minimise the number of parameters thus making the model potentially more unique. The down-side was that a better fit could potentially be obtained by including $\mathrm{K}_{\mathrm{z}}$ pilot points. Effective porosity was also based on the zone based block distribution with values fixed at $0.32,0.30$ and 0.28 for the finest grained, medium grained and coarsest grained blocks respectively.

Heterogeneous pilot point parameterisation two (Pil 2) was the same as Pil 1 except that that one single value for $\alpha_{x}, \alpha_{y}$ and $\alpha_{z}$ (applied to every model cell) was added to the calibration. 
In Heterogeneous pilot point parameterisation two (Pil 3) only a single uniform value for $\alpha_{\mathrm{x}}, \alpha_{\mathrm{y}}$ and $\alpha_{\mathrm{z}}$ (applied to every model cell) was subject to calibration. The value for $K_{x, y}$ was based on the final calibration results from Pil 1, and the values for $\mathrm{K}_{\mathrm{z}}$ and $\eta_{\mathrm{e}}$ were fixed in the same way that they were for Pil 1.

\subsection{Final Calibration Results}

The final calibration results for Hom 1, Hom 2, Het 1, Het 2, Pil 1, Pil 2 and Pil 3 are provided in digital Appendix F. The results include modelled versus observation data, residuals, observation sensitivities, parameter sensitivities, PEST run record, PEST control file, calibrated parameter values, flow mass balances, transport mass balances and the Groundwater Vistas GUI file.

\subsubsection{Fit to Breakthrough Data}

Figure 5-5 shows modelled versus observed concentrations for all observations with a weighting greater than zero, a list of the calibrated parameters for each parameterisation, the Scaled Root Mean Square (SRMS) error described in Equation 5-1 and Phi value from PEST described in Equation 5-2.

$$
\mathrm{SRMS}=\frac{100\left(\sqrt{\left(\sum\left(\mathrm{C}_{\mathrm{m}}-\mathrm{C}_{\mathrm{o}}\right) \mathrm{i}^{2}\right) / \mathrm{n}}\right)}{\mathrm{C}_{\mathrm{o}(\max )}-\mathrm{C}_{\mathrm{o}(\min )}}
$$

In Equation 5-1, $\mathrm{C}_{\mathrm{m}}$ is the modelled concentration $(\mathrm{mg} / \mathrm{L}), \mathrm{C}_{\mathrm{o}}$ is the observed concentration $(\mathrm{mg} / \mathrm{L}), \mathrm{C}_{\mathrm{o}(\max )}$ and $\mathrm{C}_{\mathrm{o}(\min )}$ are the maximum and minimum observed concentrations $(\mathrm{mg} / \mathrm{L})$ and $\mathrm{n}$ is the total number of observations. The SRMS values exclude all observations with a weighting less than 1 .

The Phi value used by PEST is the sum of square residuals for every observation including those with a weighting less than 1 .

$$
\text { Phi }=\sum\left(C_{m}-C_{o}\right) i^{2}
$$

The data in Figure 5-5 will plot on the 1:1 ratio solid black line for a perfectly calibrated model. The amount of scatter around this line provides an indication of the goodness of fit. The results show that: 


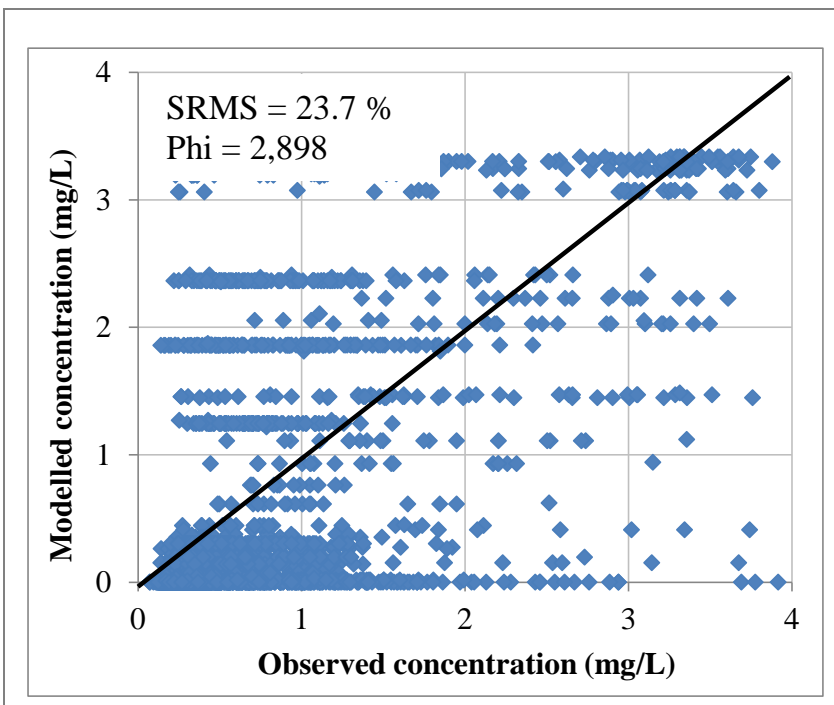

Homogenous (Hom 1) - $\mathbf{K}_{\mathbf{x}, \mathbf{y}}$

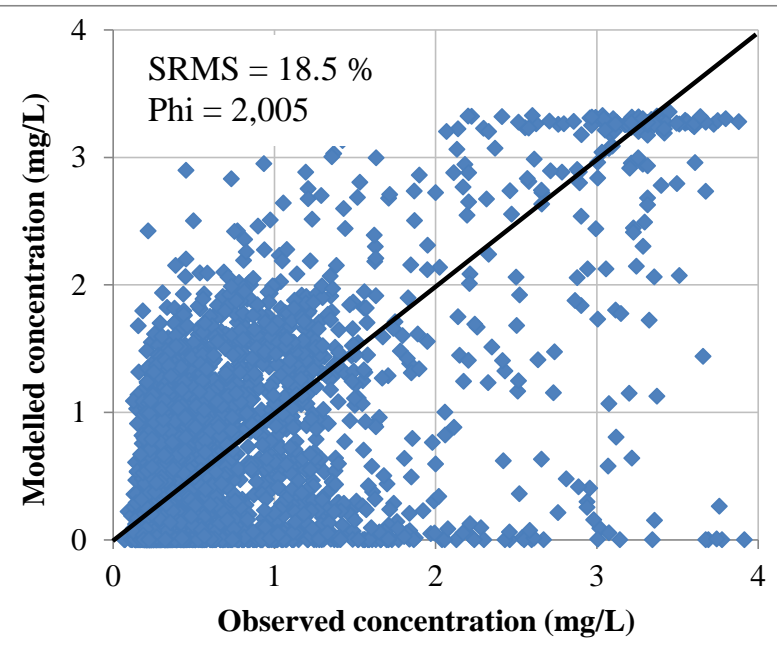

Heterogeneous block (Het 1) - $\mathbf{K}_{x, y} K_{z}$

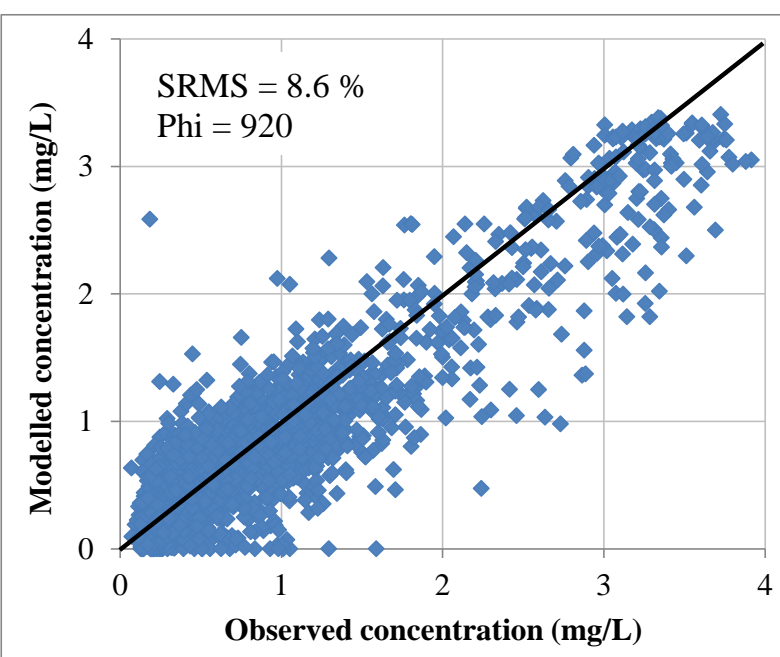

Heterogeneous pilot point (Pil - 1) - $\mathbf{K}_{\mathrm{x}, \mathrm{y}}$

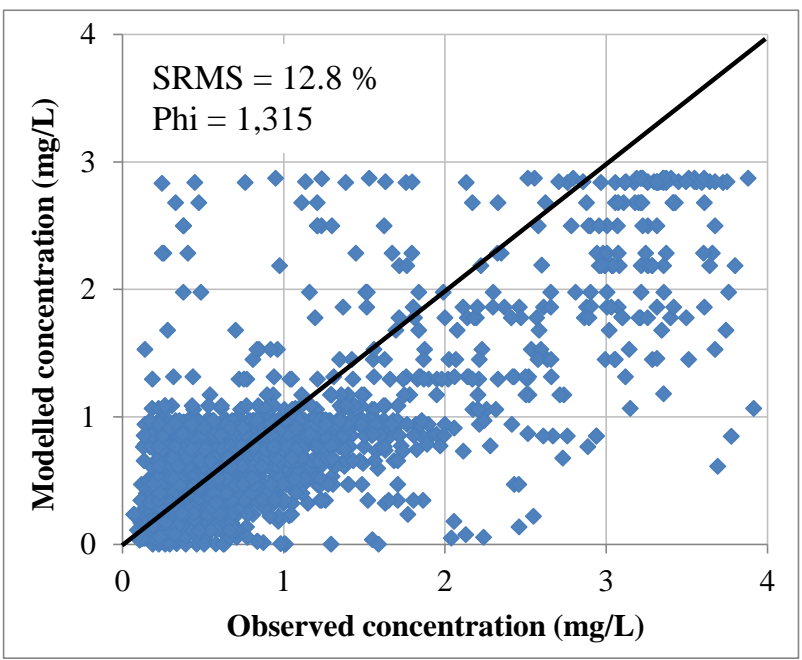

Homogenous (Hom 2) - $\mathbf{K}_{\mathrm{x}, \mathrm{y}} \boldsymbol{\alpha}_{\mathrm{x}}$

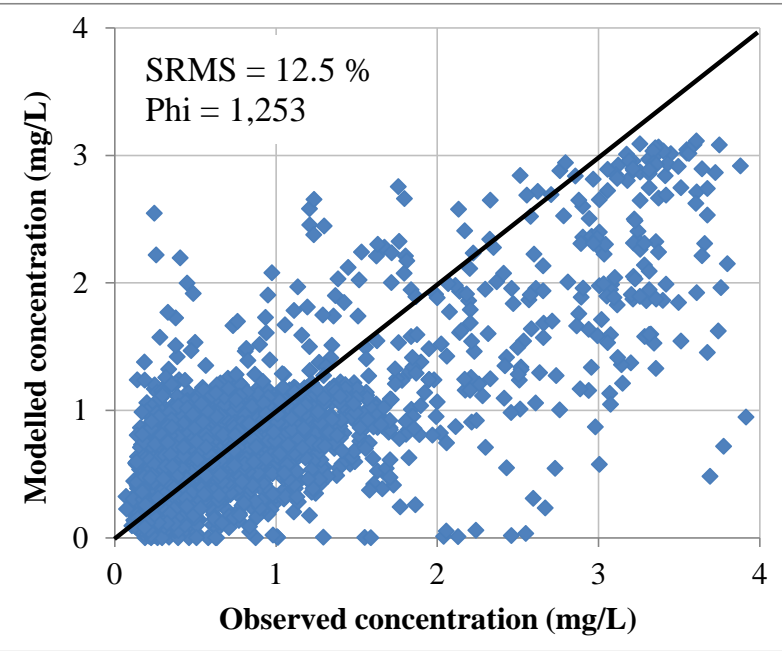

Heterogeneous block (Het 2) - $\mathbf{K}_{\mathrm{x}, \mathrm{y}} \mathbf{K}_{\mathrm{z}} \boldsymbol{\alpha}_{\mathrm{x}}, \boldsymbol{\alpha}_{\mathrm{y}}, \boldsymbol{\alpha}_{\mathrm{z}}$

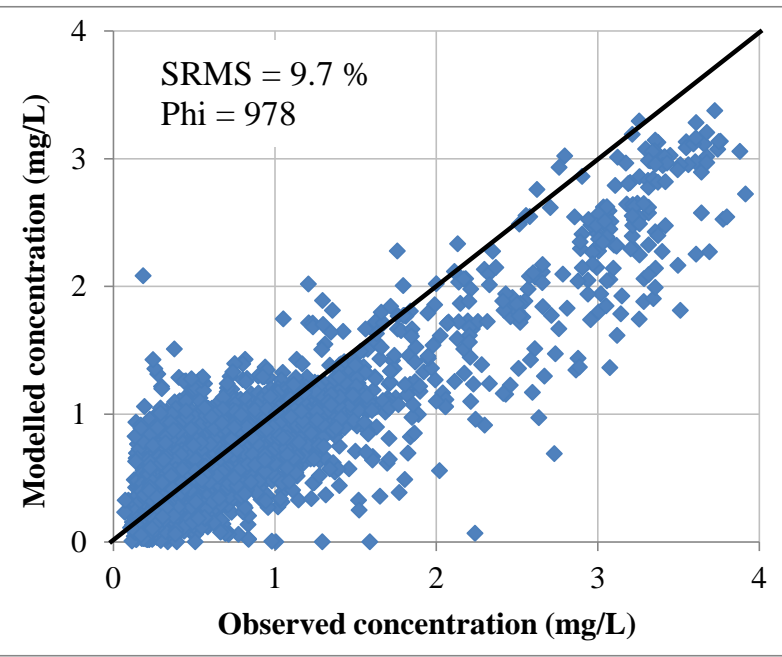

Heterogeneous pilot point (Pil - 2) - $\mathbf{K}_{\mathrm{x}, \mathrm{y}} \boldsymbol{\alpha}_{\mathrm{x}}, \boldsymbol{\alpha}_{\mathrm{y}}, \boldsymbol{\alpha}_{\mathrm{z}}$

Figure 5-5: Modelled versus observed concentrations for different parameterisations 
1. Increasing parameterisation complexity generally improves the fit.

2. There is a high degree of correlation between the SRMS and Phi in terms of determining the goodness of fit.

3. There is little difference between fits to the measured data in Pil 1 and Pil 2, nor is there much difference in the fits between Hom 2 and Het 2.

4. A reduction in SRMS through inclusion of dispersivity is reduced when the parameterisation of $\mathrm{K}$ becomes more complex. This is seen by comparing the difference in SRMS between Hom 1 and Hom 2, with that of Het 1 and Het 2 and then Pil 1 and Pil 2. This occurs because dispersivity is a parameter that accounts for some of the un-modelled heterogeneity using $K$ and $\eta_{\mathrm{e}}$, hence when more heterogeneity is included, dispersivity has less effect and a high value of dispersivity is not required. Another good example is parameterisation Pil 3. Though not shown in Figure 5-5, the values for dispersivity estimated by PEST were so low in Pil 3 (see Table 5-2) that the modelled results could not be distinguished from that of Pil 1.

5. The reduction in SRMS between Hom 1 and Het 1 demonstrates that knowledge of the block distribution has some relationship to actual movement of $\mathrm{Br}$ through the aquifer. However, the inclusion of this detailed block distribution is still not enough to describe all the heterogeneity that occurs within the aquifer. This probably highlights one short-coming of using zoned based approach to modelling solute transport modelling.

6. Parameterisation Het 2 shows slightly less scatter than Hom 2, but overall, there is little difference in the SRMS. This shows that a single value of $\alpha_{\mathrm{x}}$ in Hom 1 accounted for almost as much heterogeneity in $\mathrm{K}$ as that accounted for by knowing the grain size distribution at every block. This poses the practical problem of knowing how much structural detail and aquifer property information is required to get any significant increase in the accuracy of model outputs. It also suggests that for some transport problems, the assumption of a homogenous $\mathrm{K}$ and incorporation of dispersivity may be quite an acceptable and cost effective alternative to collecting large amounts of $\mathrm{K}$ data in the field.

7. Dispersivity used in Hom 2, Het 2 and Pil 2 causes the under-prediction of concentrations greater than $2 \mathrm{mg} / \mathrm{L}$ which was mainly seen in monitoring wells 
closest to the head-tank. This occurred because dispersivity flattens and widens the modelled breakthrough curves, thus reducing the peak modelled concentration and creating a worse fit to the observations closest to the source. It has also occurred because the parameterisations used a single value for dispersivity, meaning that the scale effects of dispersivity were not taken into account. A number of parameterisations using multiple dispersivity zones were trialled in order to see if a PEST calibration resulted in low values of dispersivity near the head-tank and higher values near the end-tank. The results gave quite an odd mix of values with no pattern of increasing dispersivity with increasing travel distance. With possibly more time and also fixing dispersivity ratios between zones it may have been possible to model the apparent increase in dispersivity with increased travel distance which was observed in the analytical modelling (see Chapter 3.4).

8. Pil 2 is the only parameterisation where inclusion of dispersivity increased the SRMS. There are a number of reasons why this occurred. Firstly the heterogeneity of $\mathrm{K}_{\mathrm{x}, \mathrm{y}}$ is much greater in the pilot point parameterisations thus dispersivity has less effect an improving the model fit. Second is that $\alpha_{\mathrm{x}}, \alpha_{\mathrm{y}}$ and $\alpha_{\mathrm{z}}$ in Pil 2 were less sensitive parameters relative to the $\mathrm{K}_{\mathrm{x}, \mathrm{y}}$. Thirdly Pil 2 (as discussed later on) is a less unique parameterisation. Thus there is high chance that the dispersivity values estimated by in Pil 2 are not representative.

9. Much of the data from Hom 1 plots on parallel horizontal lines because the model does not include dispersivity. For example, Hom 1 predicts maximum concentrations of around $3 \mathrm{mg} / \mathrm{L}$ at all locations in the aquifer, even near the endwall when concentrations are lower because of dispersion in the aquifer.

Parameterisation Hom 1 does not include dispersivity, therefore the modelled breakthrough curves should be the same shape as the input curve for Br. However, the breakthrough curves shown in Figure 5-6 show smoothing which is more pronounced with increased travel distance. This smoothing has resulted from numerical dispersion which can occur using the TVD numerical solution when dispersion is low or zero relative to advection and $\mathrm{P}_{\mathrm{e}}$ is much greater than four (Zheng and Wang, 1999). To have made $\mathrm{P}_{\mathrm{e}}$ less than four for Hom 1, the cell sizes would need to be approximately 250 times smaller. 


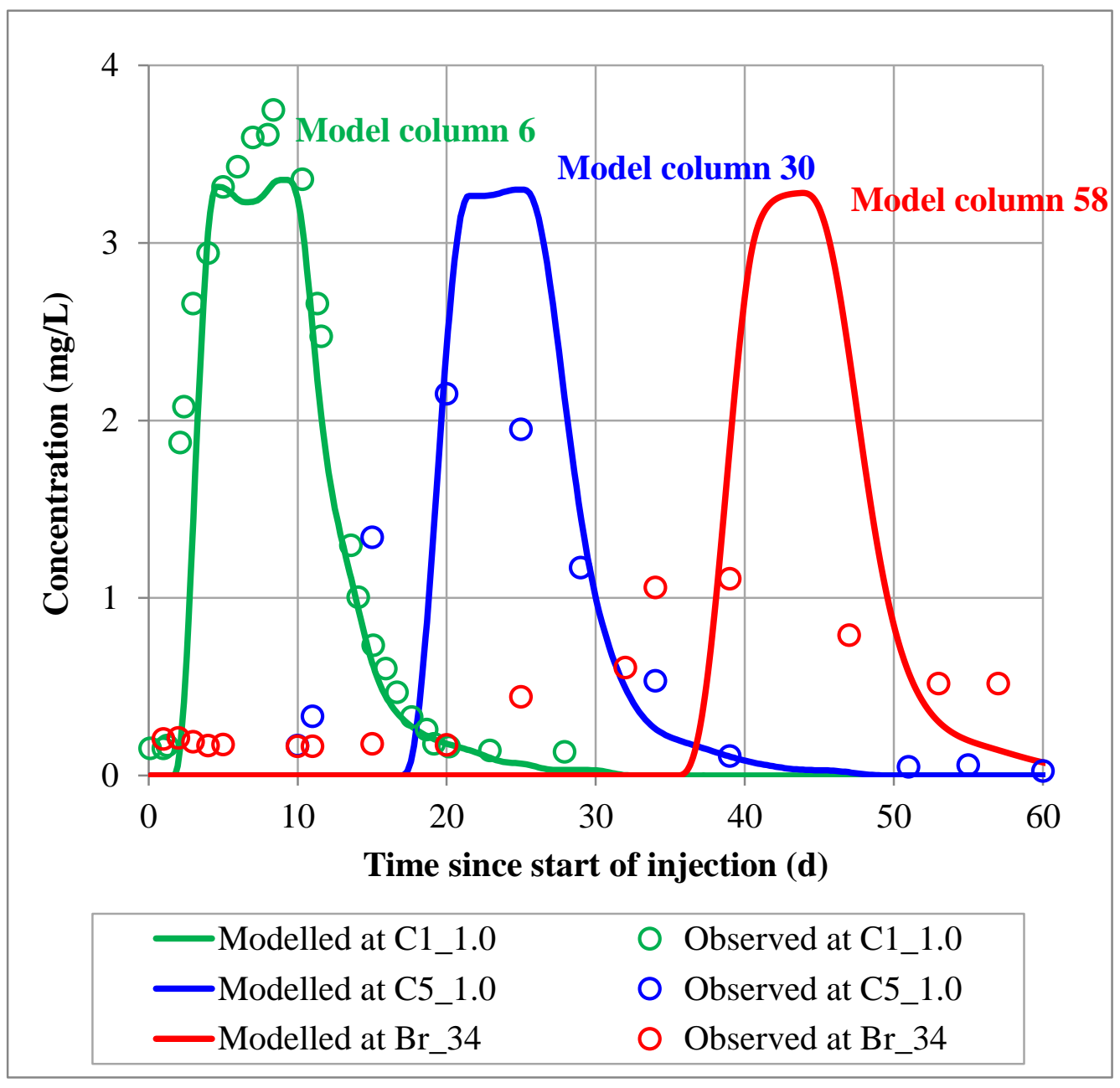

Figure 5-6: Effects of numerical dispersion in Hom 1

\subsubsection{Residuals}

Figure 5-7 shows the mean absolute residuals and standard deviation for monitoring wells at each array, column ID and depth interval and all end-wall sampling points for all parameterisations apart from Pil 2 and Pil 3. Pil 3 was excluded because the modelled concentrations were essentially the same as Pil 1. The location of monitoring well arrays, column IDs, depth intervals and the end-wall are shown in Figure 2-3. The mean absolute residuals were calculated by subtracting the observed concentration from the modelled concentration for every observation with a weighting of one, then converting all negative values to positive values. Then the sum for each observation group was divided by the count in order to obtain the arithmetic mean. The purpose was to show the spatial variation in model to observation fits. 


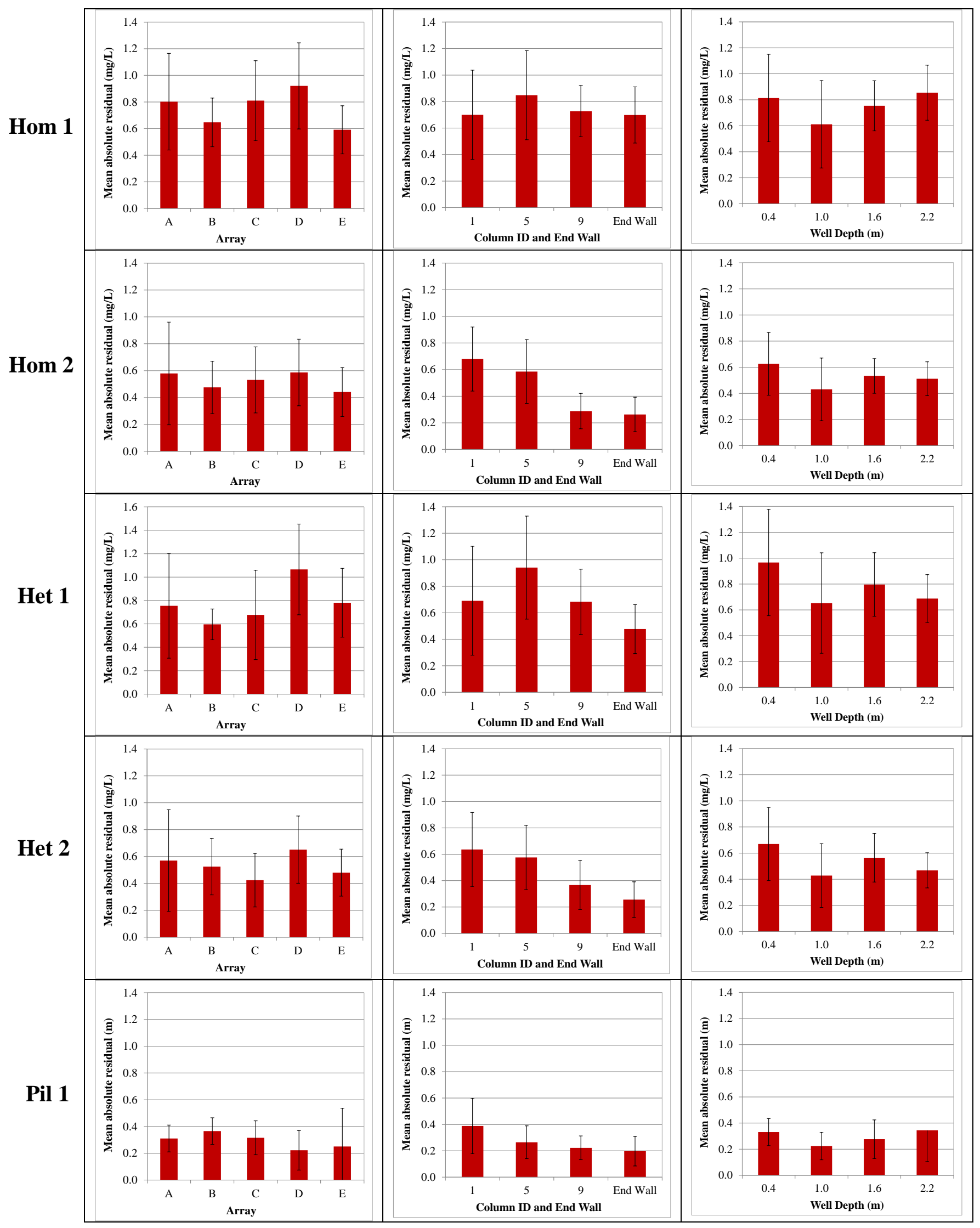

Figure 5-7: Arithmetic mean absolute residuals by group and parameterisation 
As expected, Figure 5-7 shows that lower residuals correlate with lower SRMS values. In every parameterisation, the worst model fits occur with observation data from the monitoring wells located in closer to the head-tank in Column ID 1 and 5. This may have been due to the higher observed concentrations nearer the head-tank which increases the potential for large residuals as well as larger differences between the modelled and observation arrival times. A good example is shown in Figure 5-8 which plots the modelled versus observed concentrations in monitoring well A1_0.4 located in column ID 1. The largest residuals occur within the first 6 days because the modelled time of tracer arrival is much later than the observed arrival time. In the case of A1_0.4, it is difficult to know whether the early arrival time is either a true reflection of the hydraulic properties of the aquifer within and near the well, or whether there is something else happening such as leakage of the by-pass flow from the surface of the aquifer down the outside of the well casing.

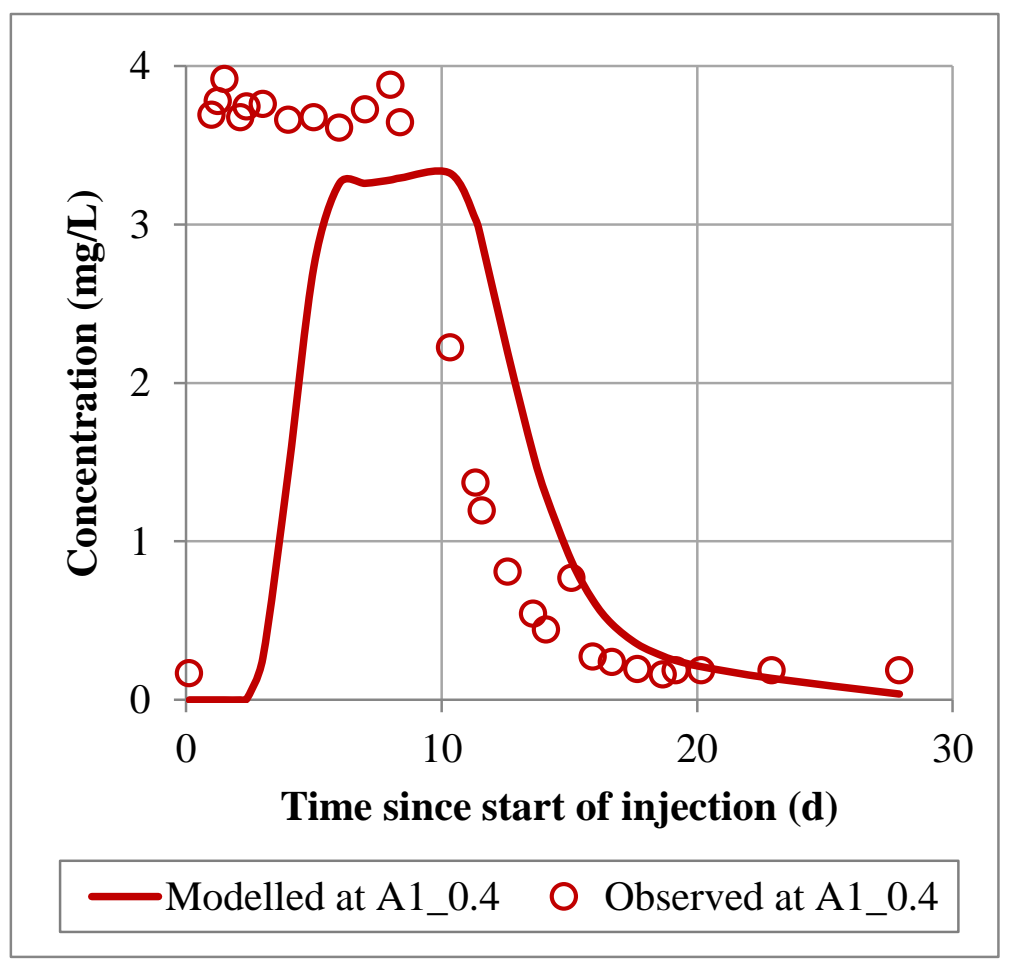

Figure 5-8: Modelled versus observed concentrations at monitoring well A1_0.4 
An interesting feature is that the mean absolute residual in column ID 1 very similar for the zone based parameterisations (Hom 1, Hom 2, Het 1 and Het 2) despite large differences in the structural detail and number of parameters used. In contrast the, residuals in column ID 1 were much lower in the pilot point parameterisations.

Mean absolute residuals from the end-wall sampling points were very similar for all parameterisations. For example, the mean residuals for Hom 2 where just two parameters were calibrated is similar to Pil 1 in which 714 parameters were calibrated. This might be showing that it is more important to know the fine structural detail at short distances from the source of injection in order to accurately model the movement of the tracer but at greater distance from the source, much less fine structural detail is required. One reason for this could be an averaging effect in tracer velocity as it passes through more combinations of high and low $\mathrm{K}$ zones on its way to the end-wall. The small difference in residuals between Hom 2 and Pil 1 at the end-wall might also mean the pilot parameterisation is quite non-unique near the endwall.

\subsubsection{Observation Sensitivities}

Figure 5-9 shows the arithmetic mean composite observation sensitivities (COS) and standard deviations for monitoring wells at each array, column and depth interval and all end-wall sampling points for all parameterisations apart from Pil 3. Pil 3 was excluded because the results were virtually the same as Pil 1. The location of monitoring well arrays, column IDs, depth intervals and the end-wall are shown in Figure 2-3. Composite observation sensitivities are calculated as the derivative of each observation with respect to each calibrated parameter multiplied by the weight associated with that observation which is then divided by the total number of calibrated parameters (Doherty, 2010a). It is thus a measure of the sensitivity of that observation to all parameters involved in the parameter estimation process (Doherty, 2010a). Composite observation sensitivities can be used to identify those observations that have the highest information content and are thus most crucial to the calibration process (Doherty, 2010a). 


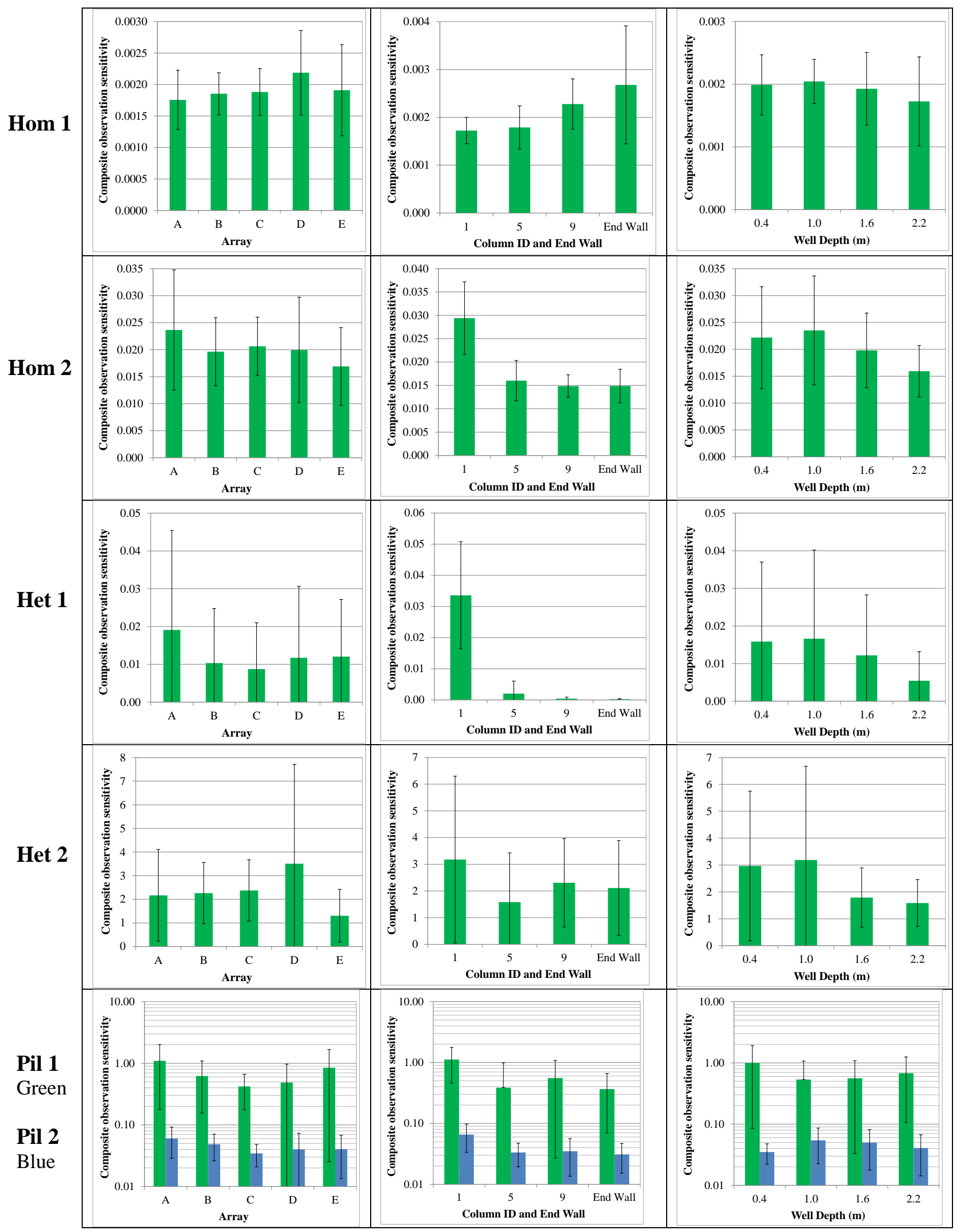

Figure 5-9: Arithmetic mean composite observation sensitivities by group 
In all of parameterisations apart from Hom 1, column ID 1 shows the highest information content and the end-wall generally shows the lowest. In terms of the monitoring wells, the $1.0 \mathrm{~m}$ depth interval shows the highest information in all of the parameterisations. Figure 5-10 appears to show some correlation between the mean COS for each parameterisation and the uniqueness of the parameterisation expressed using the Eigen vector ratio discussed later in Chapter 5.4.6. Apart from Het 1, the other parameterisations show increasing COS values as the parameterisations become less unique.

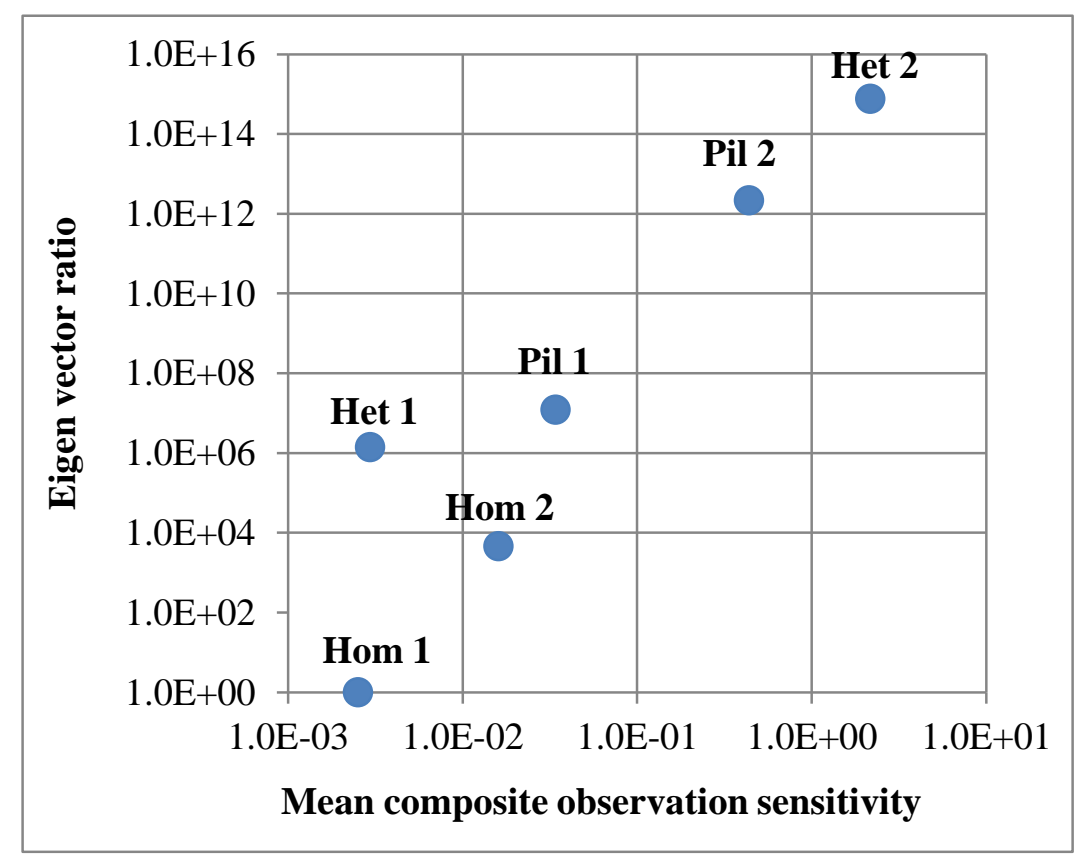

Figure 5-10: Arithmetic mean COS values versus the Eigen vector ratio for each parameterisation plotted on a log-log scale

\subsubsection{Parameter Sensitivities}

The RCS values were calculated for each parameterisation using the final calibrated parameter values. Again it was found that $\mathrm{K}_{\mathrm{x}, \mathrm{y}}$ was the most sensitive parameter. Figure 5-11 shows the mean RCS and standard deviations for pilot point parameters in Pil 1. The results show an overall increase in the mean RCS with depth as indicated by the rising slope of the linear trend line. Closest to the head-tank, model column three shows the lowest RCS and highest standard deviation whilst model row 23 shows the highest RCS and highest standard deviation. 


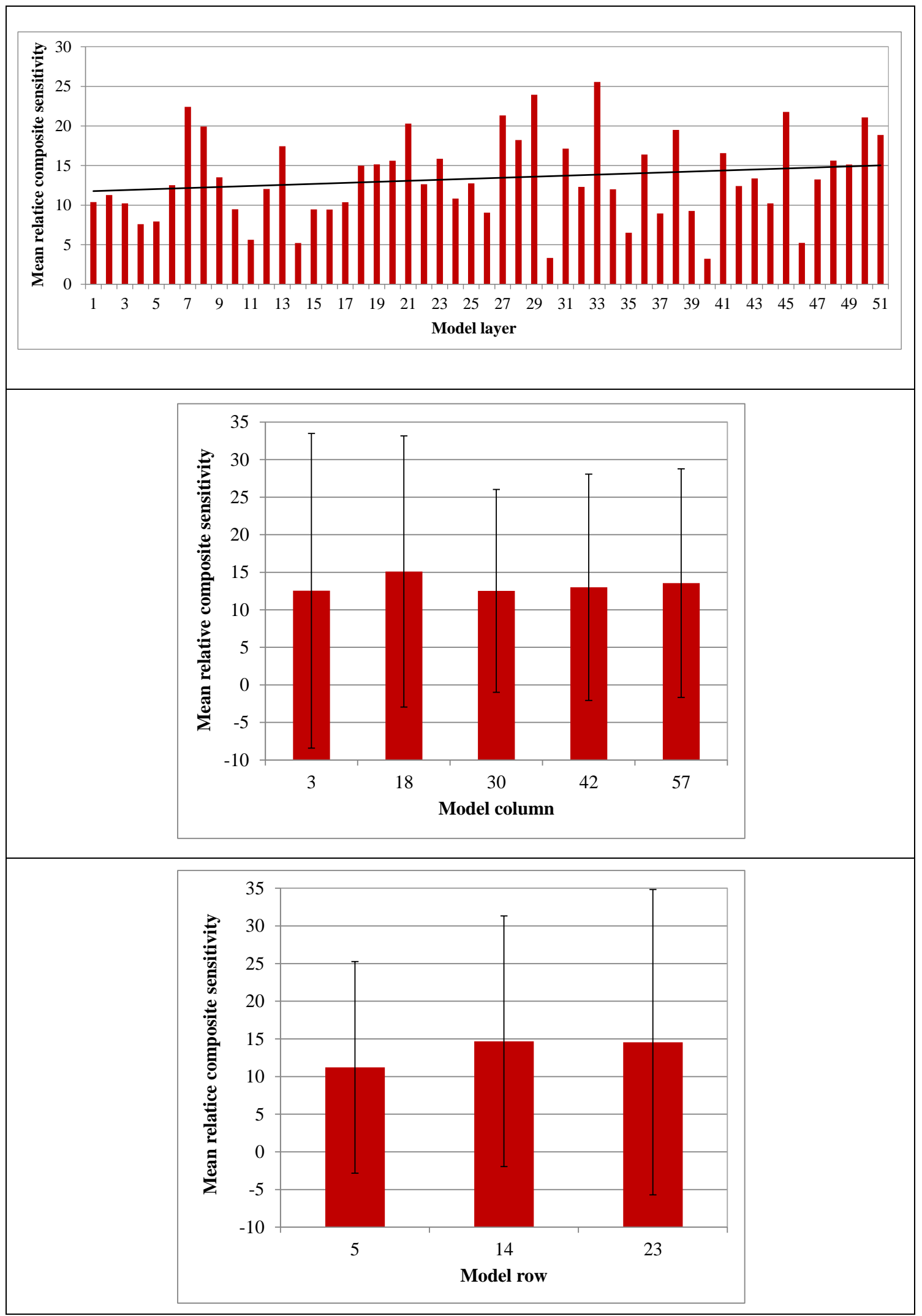

Figure 5-11: Mean relative composite sensitivities and standard deviations for Pil 1 


\subsubsection{Calibrated Parameter Values}

Table 5-2 shows calibrated parameters values used in zones for each parameterisation.

Table 5-2: Calibrated zone based parameter values using PEST

\begin{tabular}{|l|c|c|c|c|c|c|c|}
\hline Parameter & Hom 1 & Hom 2 & Het 1 & Het 2 & Pil 1 & Pil 2 & Pil 3 \\
\hline $\mathrm{K}_{\mathrm{x}, \mathrm{y}}$ & 169 & 145 & - & - & - & - & - \\
\hline $\mathrm{K}_{\mathrm{x}, \mathrm{y}} 1$ & - & - & 37 & 27 & - & - & - \\
\hline $\mathrm{K}_{\mathrm{x}, \mathrm{y}} 2$ & - & - & 126 & 169 & - & - & - \\
\hline $\mathrm{K}_{\mathrm{x}, \mathrm{y}} 3$ & - & - & 404 & 394 & - & - & - \\
\hline $\mathrm{K}_{\mathrm{z}} 1$ & - & - & 39 & 61 & - & - & - \\
\hline $\mathrm{K}_{\mathrm{z}} 2$ & - & - & 123 & 942 & - & - & - \\
\hline $\mathrm{K}_{\mathrm{z}} 3$ & - & - & 405 & 138 & - & - & - \\
\hline$\alpha_{\mathrm{x}}$ & - & 0.66 & - & 0.46 & - & 0.36 & 0.001 \\
\hline$\alpha_{\mathrm{y}}$ & - & - & - & 0.007 & - & 0.0001 & 0.0001 \\
\hline$\alpha_{\mathrm{z}}$ & - & - & - & 0.00001 & - & 0.00001 & 0.0001 \\
\hline
\end{tabular}

Units for $\mathrm{K}_{\mathrm{x}, \mathrm{y}}$ and $\mathrm{K}_{\mathrm{z}}$ are in $\mathrm{m} / \mathrm{d}$ and units for $\alpha_{\mathrm{x}}, \alpha_{\mathrm{y}}$ and $\alpha_{\mathrm{z}}$ are in $\mathrm{m}$

Parameter values for $\mathrm{K}_{\mathrm{x}, \mathrm{y}}$ used in Hom 1 and $\mathrm{K}_{\mathrm{x}, \mathrm{y}}$ and $\alpha_{\mathrm{x}}$ used in Hom 2 are similar to the values determined through analytical modelling. Parameter values for $\mathrm{K}_{\mathrm{x}, \mathrm{y}}$ used in the Het 1 and Het 2 are similar to those determined from the constant-head experiments. In Het 2 the value for $\alpha_{x}$ is slightly lower than in Hom 2. This was probably due to more of the dispersion being accounted for by the additional $\mathrm{K}$ heterogeneity in Het 2. The pilot point values for $\mathrm{K}_{\mathrm{x}, \mathrm{y}}$ in Pil 1 and Pil 2 ranged from 1 $\mathrm{m} / \mathrm{d}$ to $712 \mathrm{~m} / \mathrm{d}$.

During calibration of Hom 1 and Hom 2 it was found that starting values of $\mathrm{K}_{\mathrm{x}, \mathrm{y}}$ and $\alpha_{\mathrm{x}}$ made little or no difference to the final calibrated parameter values. In contrast, the final calibrated parameter values in both Het 1 and Het 2 were affected by the starting values, though the global minimum remained about the same. The most likely reason is that starting parameter values generally matter less when the parameterisation is more unique (as is the case for Hom 1 and Hom 2 discussed later in Chapter 5.4.6) because PEST will usually find a unique set of parameter values. However, when the parameterisation is very non-unique (as is the case for Het 2), there will be multiple objective function minima, thus the starting parameter values have a much larger 
effect on the final values selected by PEST. In order to try and predict the most realistic parameter values, the starting values of $\mathrm{K}$ for each of the three grain sizes were based on the values determined from the constant-head tests.

\subsubsection{Parameterisation Uniqueness}

PEST was used to calculate the Eigen value for each parameter in order to quantify the uniqueness of each parameterisation. As a general rule, a ratio of highest to lowest Eigen value greater than approximately $10^{8}$ indicates a non-unique parameterisation (Doherty, 2010a). Table 5-3 shows the Eigen value ratios for the different parameterisations.

Table 5-3: Eigen values and Eigen value ratios

\begin{tabular}{|l|c|c|c|c|}
\hline Parameterisation & $\begin{array}{c}\text { Calibrated } \\
\text { parameters }\end{array}$ & Lowest value & Highest value & Ratio \\
\hline Hom 1 & 1 & $1.0 \times 10^{0}$ & $1.0 \times 10^{0}$ & $1.0 \times 10^{0}$ \\
\hline Hom 2 & 2 & $6.1 \times 10^{0}$ & $2.8 \times 10^{4}$ & $4.6 \times 10^{3}$ \\
\hline Het 1 & 6 & $5.5 \times 10^{1}$ & $7.7 \times 10^{7}$ & $1.4 \times 10^{6}$ \\
\hline Het 2 & 9 & $1.3 \times 10^{-5}$ & $9.5 \times 10^{9}$ & $1.0 \times 10^{14}$ \\
\hline Pil 1 & 714 & $3.7 \times 10^{-5}$ & $4.5 \times 10^{2}$ & $1.2 \times 10^{7}$ \\
\hline Pil 2 & 717 & $3.6 \times 10^{-8}$ & $7.9 \times 10^{4}$ & $2.2 \times 10^{12}$ \\
\hline Pil 3 & 3 & $3.8 \times 10^{-5}$ & $1.1 \times 10^{-1}$ & $2.9 \times 10^{3}$ \\
\hline
\end{tabular}

Results from the zone based parameterisations (Hom 1, Hom 2, Het 1, Het 2 and Pil 3) generally show a reduction in uniqueness as the number of calibrated parameters increases. With only one calibrated parameter, Hom 1 is completely unique. This was evident during calibration because no matter what starting value was used, the final calibrated value was always the same.

An interesting observation is that Pil 1 with 714 calibrated parameters is more unique than Het 2 which has only 9 calibrated parameters. In addition, the Eigen value ratio for Pil 1 is less than $10^{8}$, suggesting that the parameterisation is unique. Both these statistics are a surprise given the large number of parameters used in the calibration. In contrast, the uniqueness of the pilot point parameterisation is vastly reduced when the three dispersivity parameters $\alpha_{x}, \alpha_{y}$ and $\alpha_{z}$ are introduced in Pil 2. 


\subsubsection{Hydraulic Conductivity}

Hydraulic conductivity values determined through numerical modelling are compared with values determined through analytical modelling and through constant-head experiments. The aim is to look at variations in mean values, and how values varied spatially and with depth in order to decipher trends in heterogeneity.

\section{Zone Calibration and Mean Values}

Table 5-4 shows zone calibrated $\mathrm{K}_{\mathrm{x}, \mathrm{y}}$ values determined from numerical modelling, mean values of $K_{x}$ determined from analytical modelling and the values of $K$ and the mean values determined from the constant-head experiments. The main reason for presenting these data is to show how similar the $\mathrm{K}$ values are even when using quite different methods to assess their values.

Table 5-4: Zone calibrated values and mean values of hydraulic conductivity

\begin{tabular}{|l|c|c|c|c|c|c|}
\hline \multicolumn{1}{|c|}{ Model } & $\mathbf{K}_{\mathbf{x}, \mathbf{y}}$ & $\mathbf{K}_{\mathbf{x}, \mathbf{y}} \mathbf{1}$ & $\mathbf{K}_{\mathbf{x}, \mathbf{y}} \mathbf{2}$ & $\mathbf{K}_{\mathbf{x}, \mathbf{y}} \mathbf{3}$ & $\begin{array}{c}\text { Arith. } \\
\mathbf{m e a n}\end{array}$ & $\begin{array}{c}\text { Geo. } \\
\text { Mean }\end{array}$ \\
\hline Constant-head experiments & - & 40 & 126 & 404 & 174 & 124 \\
\hline Analytical modelling & - & - & - & - & 177 & 169 \\
\hline Hom 1 & 169 & - & - & - & - & - \\
\hline Hom 2 & 145 & - & - & - & - & - \\
\hline Het 1 & - & 37 & 126 & 404 & 173 & 117 \\
\hline Het 2 & - & 27 & 169 & 394 & 185 & 119 \\
\hline Pil 1 & - & - & - & - & 219 & 151 \\
\hline Pil 2 & - & - & - & - & 165 & 133 \\
\hline
\end{tabular}

Arith. mean $=$ Arithmetic mean and Geo.mean $=$ Geometric mean

\section{Distribution}

The distribution of horizontal $\mathrm{K}$ was analysed in terms of spatial trends and frequency distribution. Figure 5-12 compares the spatial distribution of $K_{x, y}$ in model layer 1 for parameterisations Pil 1, Het 1 and Hom 1. Pil 1 includes the most heterogeneity and Hom 1 includes the least. An interesting observation is that the distribution of $\mathrm{K}_{\mathrm{x}, \mathrm{y}}$ in Pil 1 is quite different to that of Het 1 and is something which is repeated in all the other model layers. One explanation is that zone based approach is un-realistic because the $\mathrm{K}$ values probably changed after the blocks were laid down due to settling and overburden pressure. Another other explanation is that 

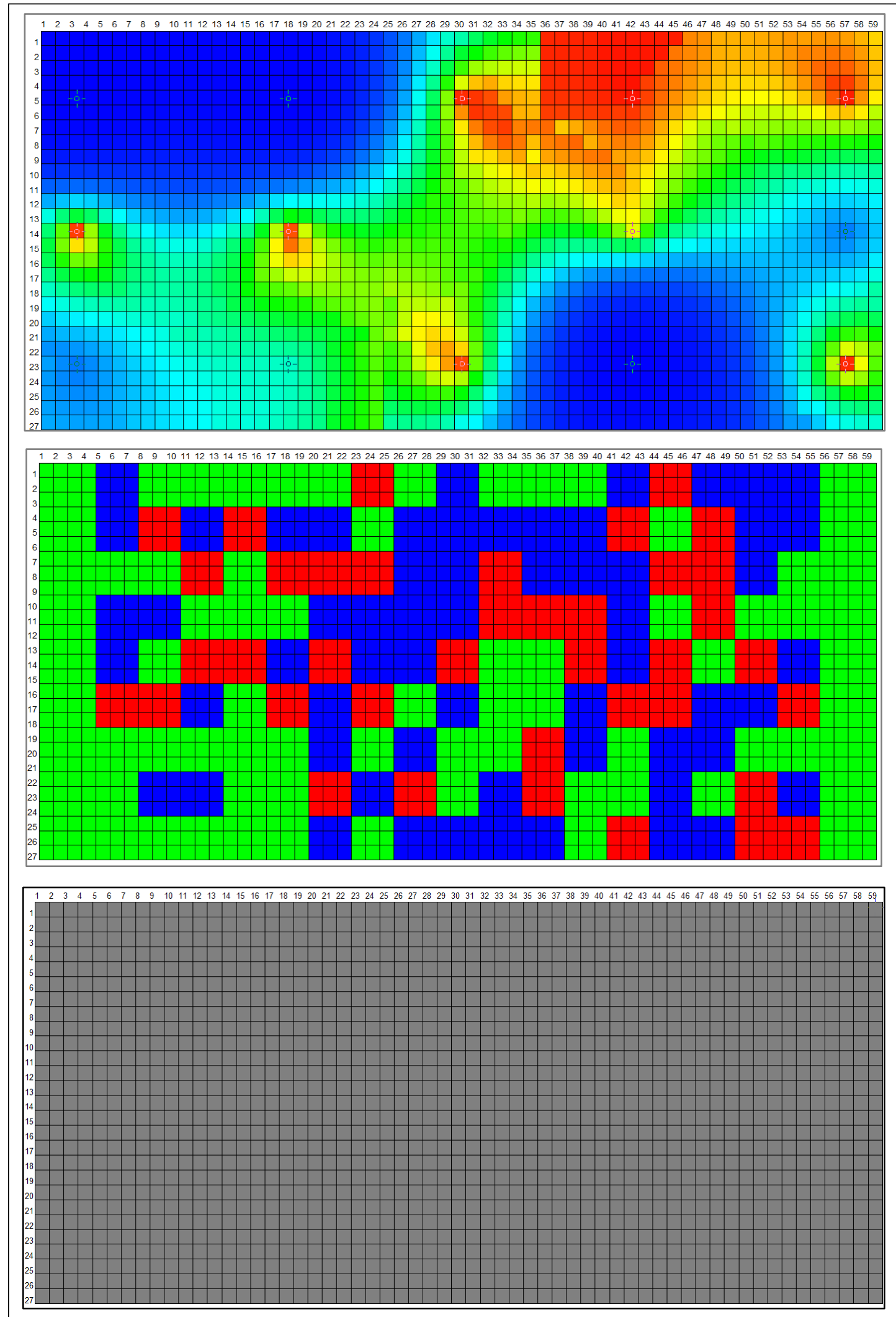

Figure 5-12: Comparison of the spatial distribution of $K_{x, y}$ in Pil 1(top), Het 1 (middle) and Hom 1 (bottom) for model layer 1 . Red equals high $K$, green equals medium $K$, blue equals low $K$ and grey equals single $K$ value 
non-uniqueness in pilot point parameterisation means that a distribution that is more similar (or less similar) to Het 1 could produce similar model outputs. The last explanation is that the pilot point parameterisation of $\mathrm{K}_{\mathrm{x}, \mathrm{y}}$ is affected by structural defects in the model such as differences between the actual location of each monitoring point and its position in the model. In reality it is likely to be a combination of these explanations, plus any other factors not identified.

Figure 5-13 shows the frequency distribution for $\mathrm{K}_{\mathrm{x}, \mathrm{y}}$ in Het 1, Pil 1 and for $\mathrm{K}_{\mathrm{x}}$ values determined through analytical modelling. The plots also show the normal PDF and log-normal PDF. The analytical modelling values for $\mathrm{K}_{\mathrm{x}}$ show a normal distribution which is evident by the arithmetic mean and geometric mean being quite similar (see Table 5-4). In contrast, $K_{x, y}$ values for Het 1 and Pil 1 show a more log-normal distribution, as evident by the skewed frequency distributions and larger difference between the arithmetic mean and geometric mean (see Table 5-4). The log-normal distribution in Pil 1 might have been artificially introduced as a result of the kriging used to interpolate values to other model cells. As evident from the high SRMS of Het 1 compared to Pil 1 , the $K_{x, y}$ heterogeneity is much greater than that represented using three zones based on the block distribution. As a consequence the frequency distributions for Het 1 are incomplete. The frequency distribution also suggests that the lower bound of $1 \mathrm{~m} / \mathrm{d}$ of $\mathrm{K}_{\mathrm{x}, \mathrm{y}}$ was probably too high for Pil 1. If Pil 1 was calibrated again, a lower bound of $0.1 \mathrm{~m} / \mathrm{d}$ might have been a better value.

\section{Variation with Depth}

Figure 5-14 shows the geometric mean $\mathrm{K}$ at different depths below the top of the aquifer using $\mathrm{K}_{\mathrm{x}}$ values determined from analytical modelling, $\mathrm{K}_{\mathrm{x}, \mathrm{y}}$ values determined from Pil 1, Het 1, Het 2 and $\mathrm{K}$ values determined from the constant-head experiments. The K distribution for Het 1, Het 2 and the constant-head experiments were all based on the block distribution. Geometric mean values are not the value for each individual depth interval. Rather they are the geometric mean that includes all the values at a depth interval, plus all the other values at depth intervals shallower than the depth interval being presented. Thus the geometric mean is a cumulative value.

Het 1 , Het 2 and the constant-head experiments all show a similar trend of increasing $\mathrm{K}$ values from $0.2 \mathrm{~m}$ to $1.0 \mathrm{~m}$, then decreasing $\mathrm{K}$ from $1.0 \mathrm{~m}$ down to $2.6 \mathrm{~m}$. They share the same trend because each shares the same zone based block distribution and 


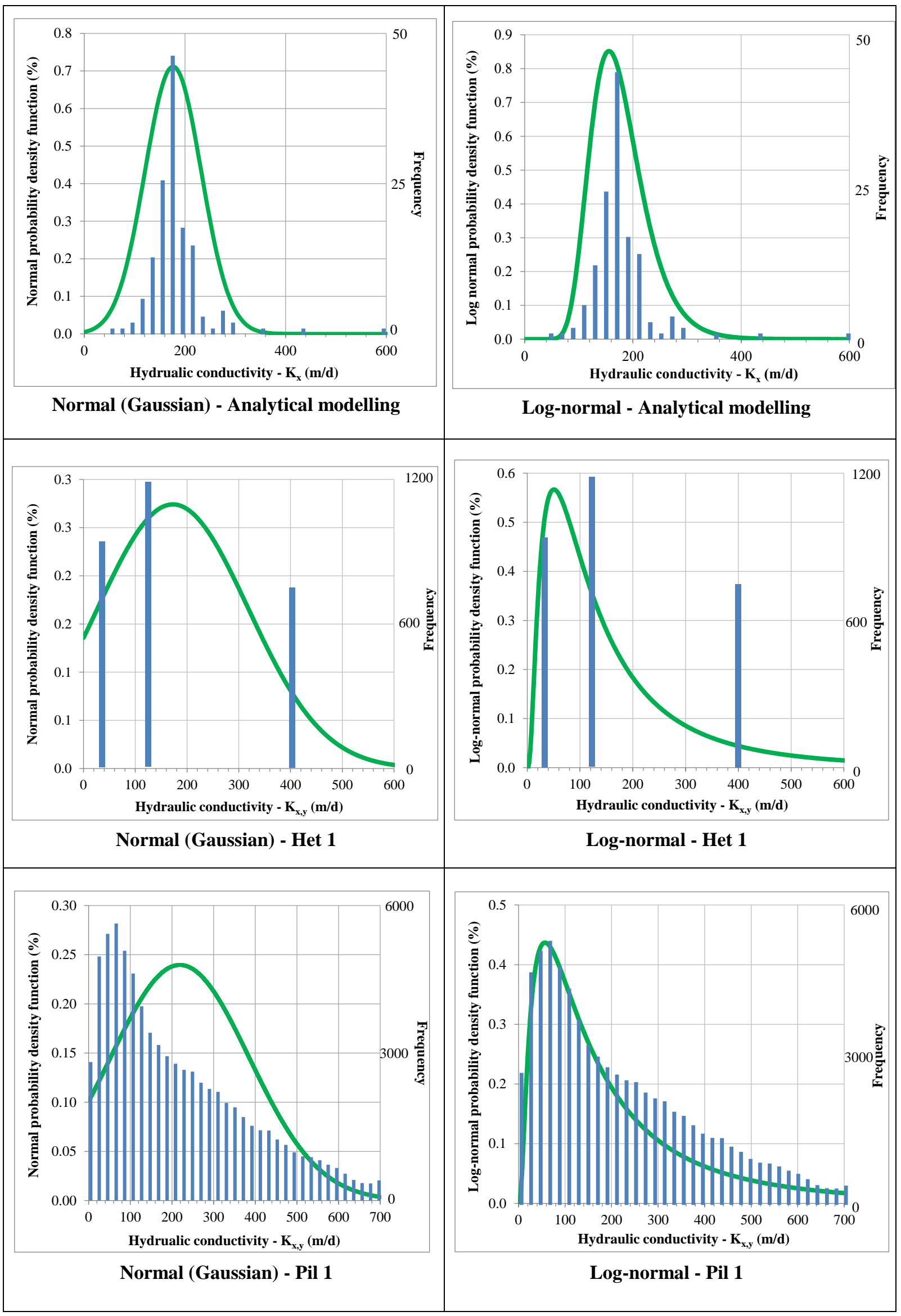

Figure 5-13: Frequency distribution and probability density functions using horizontal $K$ data from the analytical modelling, Het 1 and Pil 1 


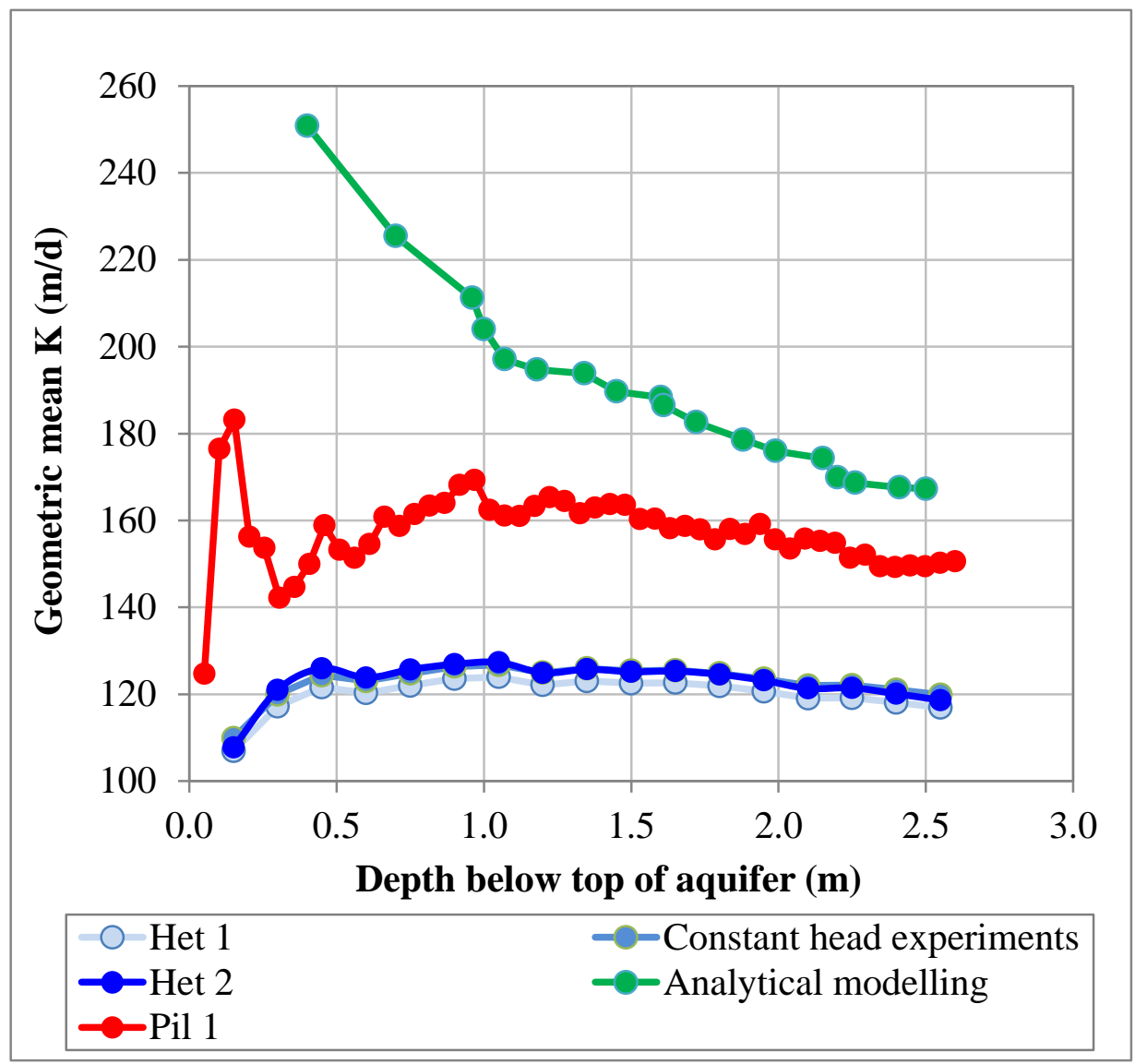

Figure 5-14: Geometric mean K at different depths below the top of the aquifer

$\mathrm{K}$ values are similar. Pil 1 shows a markedly similar trend to Het 1 , Het 2 and the constant-head experiments apart from the overall $\mathrm{K}$ values being higher and the spike in high $\mathrm{K}$ values at around $0.2 \mathrm{~m}$. In contrast the analytical modelling shows a steady decline in $\mathrm{K}_{\mathrm{x}}$ values from the top down to the bottom of the aquifer. Higher $\mathrm{K}$ near the top of the aquifer recorded in the analytical modelling and spike in $\mathrm{K}$ recorded in Pil 1 might be associated with leakage of by-pass flow down the sides of the monitoring well casing. This would artificially reduce the time to tracer arrival, thus meaning that a higher value of $\mathrm{K}$ would be needed to match the observations.

What all methods have in common is a decrease in $\mathrm{K}$ from about $1.0 \mathrm{~m}$. Close et al. (2008) also found a trend of decreasing $\mathrm{K}$ with depth in the homogeneous artificial aquifer. They suggested this might have resulted from the increased overburden weight with depth causing additional compaction of sand grains near the bottom of the aquifer. Authors such as Freeze and Cherry (1979) also discuss the same effecting of decreasing $\mathrm{K}$ with depth in natural aquifer systems. Assuming that $\eta_{\mathrm{e}}$ reduces with depth as a result of increased compaction and reduction in pore space, lower values of 
$\mathrm{K}$ would be needed to maintain model fits to the measured data. Thus, because all the models used a fixed value for $\eta_{e}$, the actual $K$ reduction with depth might be even greater than that shown in Figure 5-14.

\section{Variation with Travel Distance}

Figure 5-15 shows the geometric mean $\mathrm{K}$ at successive distances from the head-tank determined using the same method used to describe the $\mathrm{K}$ variation with depth. The analytical modelling and Pil 1 show a similar overall trend of increasing $\mathrm{K}$ with increasing travel distance up until about $8 \mathrm{~m}$, at which point $\mathrm{K}$ values remain unchanged or drop slightly in the case of the analytical modelling. In contrast, the zonebased block distribution methods show an overall decreasing $\mathrm{K}$ with travel distance. With higher SRMS values in Het 1 and Het 2 compared with Pil 1, it is likely the zone-based methods are misleading when interpreting the spatial variation in $\mathrm{K}$ with travel distance. It is possible that the $\mathrm{K}$ distribution has changed after the blocks were put in place down. Though the cause is not known, re-working of the aquifer media over time through the movement of flowing groundwater could be one explanation.

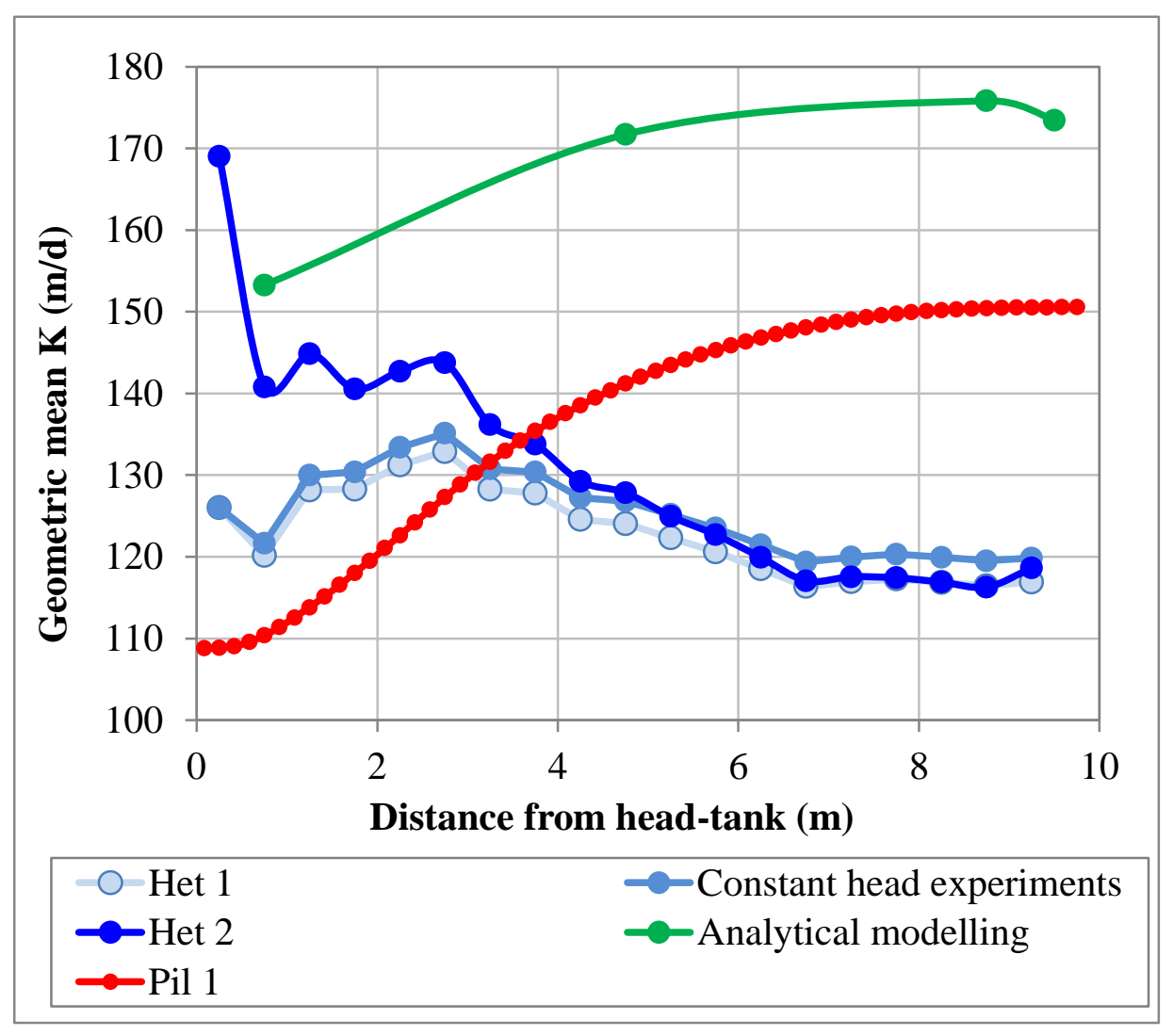

Figure 5-15: K variation in the direction of groundwater flow 
Figure 5-16 shows the changes in the mean standard deviation of $\mathrm{K}$ in the direction of groundwater flow. From around $2 \mathrm{~m}$ distance from the head-tank through to the endwall, Het 1, Het 2, Pil 1 and the constant-head experiments show a similar trend of slightly increasing variation. In contrast the analytical modelling shows a decline in variation with increasing travel distance. One explanation for the trend observed in the analytical modelling data is that $\mathrm{K}_{\mathrm{x}}$ values become more averaged with increasing travel distance as a result of the tracer moving through different combinations of high and low $\mathrm{K}$ zones. If this is the case then this effect may have a practical significance for the interpretation of tracer tests, and pump tests that are undertaken in the field using other analytical models The practical significance is that aquifer parameters derived from an analytical models such as $\mathrm{K}, \mathrm{S}$ and leakage (K'/B') will be more representative of average values applicable to a larger area when the concentration or drawdown measured at a point is further from the source concentration (for a tracer test) or abstraction well (for a pump test).

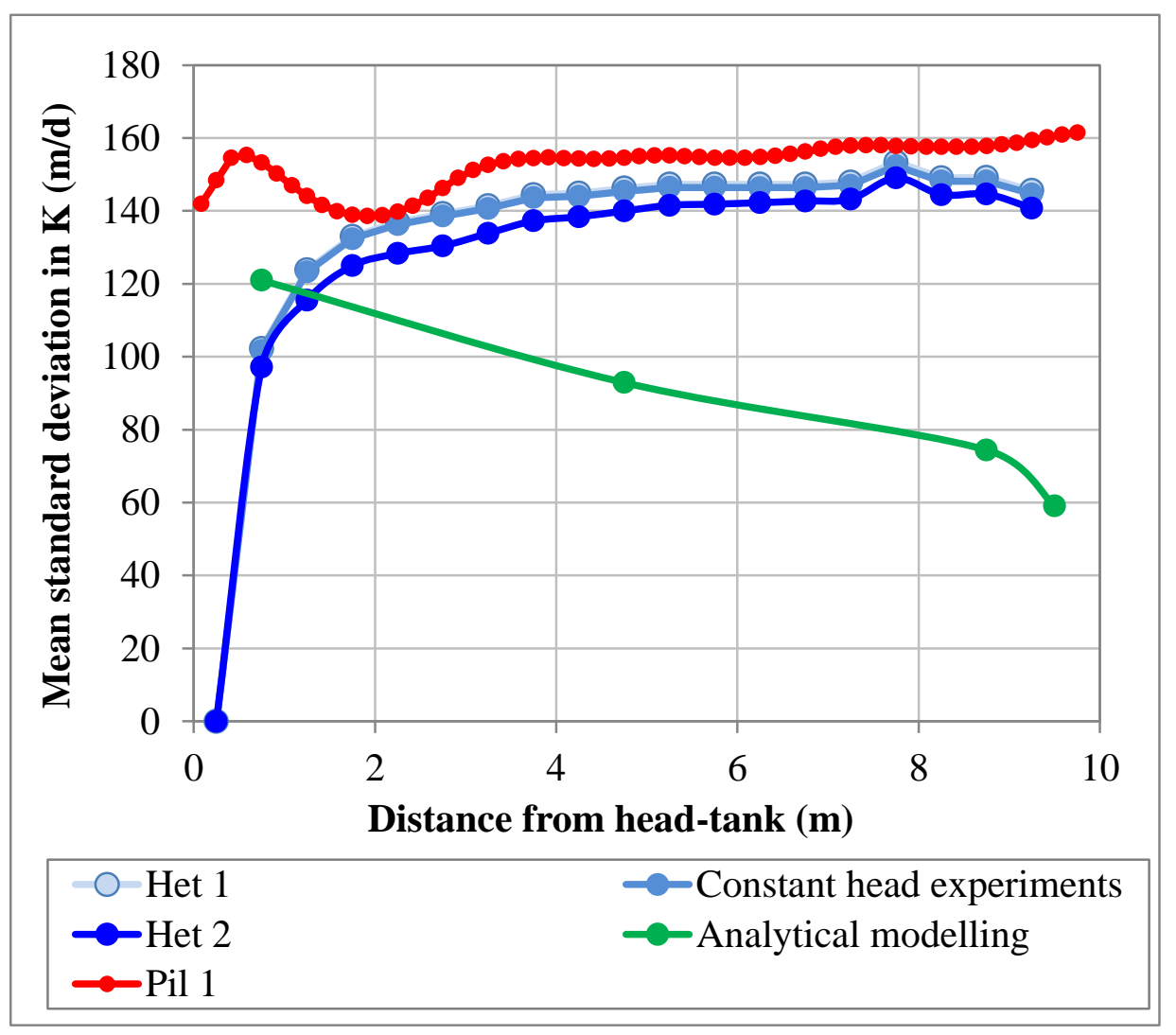

Figure 5-16: Mean standard deviation of $K$ in the direction of groundwater flow 


\section{Lateral Variation}

Figure 5-17 shows the lateral variation in geometric mean $\mathrm{K}$ determined using the same method used to describe the $\mathrm{K}$ variation with depth. Trends across the aquifer are relatively similar. All methods show an overall increase in K between Array A and Array E. Het 1, Het 2 and the constant-head experiment have a very close trend because these methods share the same zoned-based block distribution. The analytical modelling, apart from having higher $\mathrm{K}$ values overall, shares a markedly similar trend to the zoned based block distribution methods which sees $\mathrm{K}$ increase from about $0 \mathrm{~m}$ to $1.2 \mathrm{~m}$ then, then gradually decrease from about $1.2 \mathrm{~m}$ to $4.66 \mathrm{~m}$.

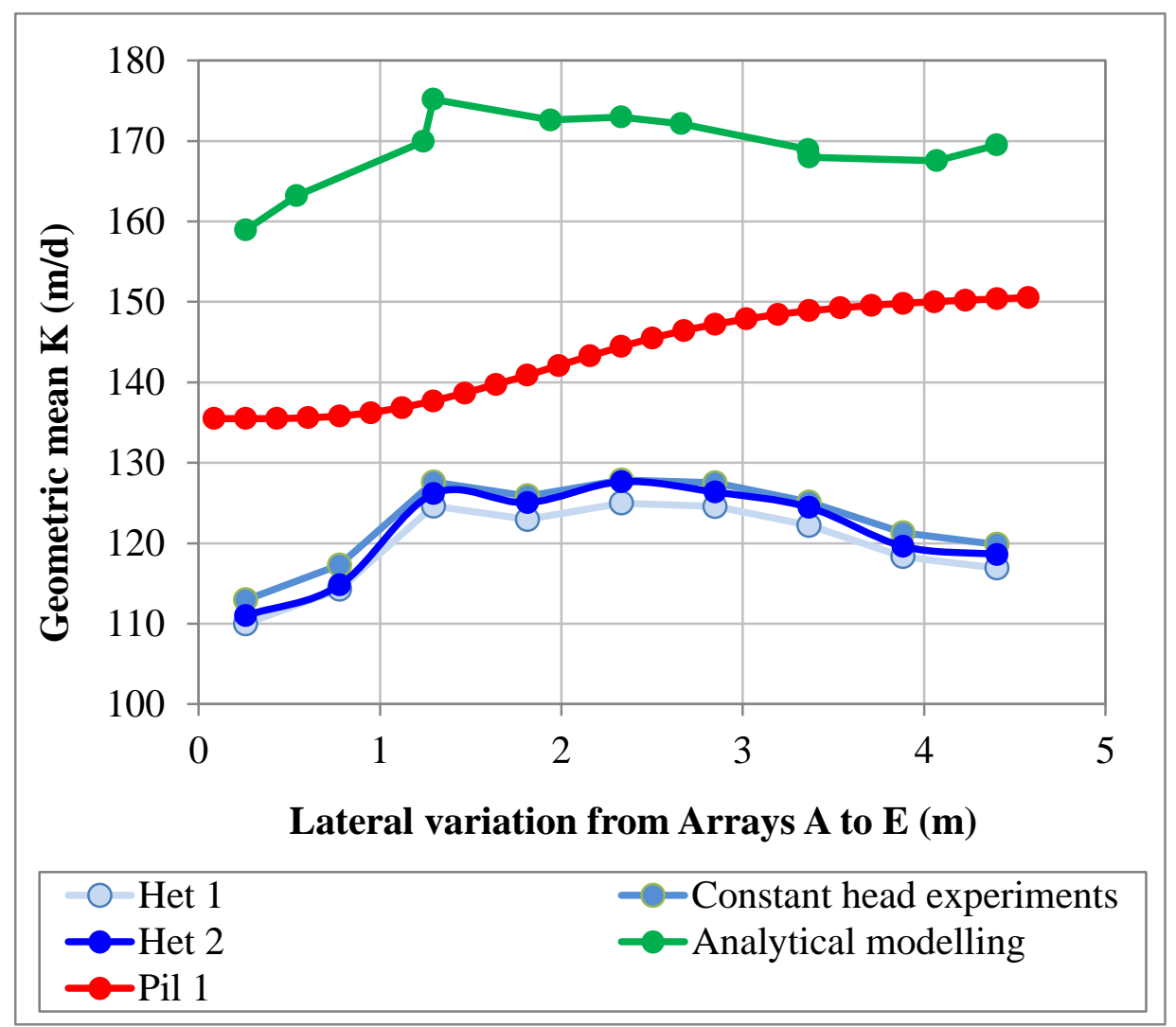

Figure 5-17: Lateral variation in K from Array A $(0 \mathrm{~m})$ to Array E $(4.66 \mathrm{~m})$ 


\subsubsection{Flow and Transport Mass Balance}

\section{Mass Balance}

Table 5-5 shows the flow rate (calculated using MODFLOW), the mass of $\mathrm{Br}$ that entered the model from column 1 after 102 days and the mass that exited the model from column 59 after 102 days (calculated using MT3DMS). Pil 3 is excluded because the results are essentially the same as Pil 1.

Table 5-5: Steady-state flow rate, Br mass input, Br mass output and by-pass flow

\begin{tabular}{|l|c|c|c|c|c|c|}
\hline \multicolumn{1}{|c|}{ Results } & Hom 1 & Hom 2 & Het 1 & Het 2 & Pil 1 & Pil 2 \\
\hline Flow rate $\left(\mathrm{m}^{3} / \mathrm{d}\right)$ & 0.90 & 0.77 & 0.70 & 0.76 & 1.14 & 0.86 \\
\hline Bromide input (g) & 30.2 & 32.1 & 23.4 & 29.6 & 38.4 & 32.4 \\
\hline Bromide output (g) & 30.2 & 32.0 & 23.2 & 29.0 & 38.3 & 32.0 \\
\hline By-pass flow (\%) & $72-78$ & $76-81$ & $77-81$ & $76-81$ & $63-72$ & $76-81$ \\
\hline By-pass bromide (\%) & 79 & 78 & 84 & 79 & 74 & 78 \\
\hline
\end{tabular}

The flow rates are all relatively similar apart from Hom 1 and Pil 1 which are slightly higher. Based on the analytical modelling, the mass exiting the end-wall was calculated to be 26 grams (see Chapter 2.6.1 for more detail). In general the numerical modelling suggests that the mass exiting the end-wall should be slightly higher than 26 grams, especially Pil 1 . The difference probably reflects errors in the calculations and assumptions applied using different methods. The parameterisations also show that all or most of the $\mathrm{Br}$ was removed from the aquifer after 102 days which is consistent with observation data from the end-wall (see Figure 2-14).

By-pass flow estimated using the modelled flow rate (modelled flow rate / the minimum and then maximum observed outflow to give a range) is comparable to estimates based on the modelled $\mathrm{Br}$ output (modelled $\mathrm{Br}$ output / the observed $\mathrm{Br}$ input). The results occur within the range of by-pass flow estimates determined through analytical modelling and Darcy's Law which ranged between $70 \%$ and $84 \%$. 


\section{Effects of Changing the Boundary Condition}

As discussed in Chapter 4.3, Br input from model column 1 resulted from advection plus dispersion when dispersivity was used in the parameterisation. For Hom 2, MT3DMS predicted 32.1 grams of Br entering the model of which 26.1 grams came from advection and the remaining 6.1 grams from dispersion. Using Equation 5-3 the mass from advection $\left(\mathrm{M}_{\text {advection }}\right)$ in grams for each MODFLOW stress period was calculated.

$$
\mathrm{M}_{\mathrm{advection}}=\mathrm{t}_{\mathrm{flow}}\left[\mathrm{C}\left(\mathrm{K}_{\mathrm{x}, \mathrm{y}} \mathrm{iA}\right)\right]
$$

Equation 5-3

Where, where $\mathrm{t}_{\text {flow }}$ is the duration of each MODFLOW stress period (d), $\mathrm{C}$ is the mean concentration for each stress period $\left(\mathrm{g} / \mathrm{m}^{3}\right), \mathrm{K}_{\mathrm{x}, \mathrm{y}}$ is the calibrated hydraulic conductivity $(145 \mathrm{~m} / \mathrm{d})$ listed in Table $5-2, \mathrm{i}$ is the fixed hydraulic gradient $(0.00044$ $\mathrm{m} / \mathrm{m})$ and $\mathrm{A}$ is the cross-section area of the aquifer $\left(12.12 \mathrm{~m}^{2}\right)$. The total mass from advection was determined by summing $\mathbf{M}_{\mathrm{advection}}$ for each stress period.

Using Hom 2 as an example, an alternative model design was tested to look at how the boundary condition in column 1 affected $\mathrm{Br}$ input. This was carried out using another parameterisation referred to as Hom 2-B. In Hom 2-B, $\alpha_{x}$ was set to zero in every cell in model column 1 and column 2 . When PEST was re-run using the same starting values and bounds as Hom 2 the total Br mass input was 31.1 grams and the total mass from advection calculated using Equation 5-3 for each stress period using a $\mathrm{K}_{\mathrm{x}, \mathrm{y}}$ value of $174 \mathrm{~m} / \mathrm{d}$ was also 31.1 grams.

Therefore, setting $\alpha_{\mathrm{x}}$ to zero in every cell in columns 1 and 2 completely eliminates $\mathrm{Br}$ input from dispersion. In both Hom 2 and Hom 2-B the calibrated value for $\alpha_{\mathrm{x}}$ was $0.66 \mathrm{~m}$ and the total mass input from $\mathrm{Br}$ was practically the same. Therefore, the higher value for $\mathrm{K}_{\mathrm{x}, \mathrm{y}}$ in Hom 2-B probably resulted from the need to compensate for the absence of mass being added from dispersion. A practical significance of this is that the value (s) for $\mathrm{K}_{\mathrm{x}, \mathrm{y}}$ in Hom 2 and Het 2 could be about $15 \%$ higher if the boundary condition for mass input was set up in the same way that it was for Hom 2B. The results for Hom 2-B are provided in digital Appendix F. 


\section{Mass Balance Discrepancy}

The solution to groundwater equations in any numerical model is approximate. As a result, there is always some discrepancy in the mass balance (Barnett et al., 2012). The mass balance discrepancies using MODFLOW and MT3DMS were calculated using Equation 5-4, where $\mathrm{T}_{\text {in }}$ is the total cumulative mass in and $\mathrm{T}_{\text {out }}$ is the total cumulative mass out.

$$
\text { Mass balance discrepencey }(\%)=\frac{\mathrm{T}_{\text {in }}-\mathrm{T}_{\text {out }}}{\left[0.5\left(\mathrm{~T}_{\text {in }}+\mathrm{T}_{\text {out }}\right] 100\right.} \quad \text { Equation 5-4 }
$$

For MODFLOW, the mass was measured as a flow rate $\left(\mathrm{m}^{3} / \mathrm{d}\right)$ or flow volume $\left(\mathrm{m}^{3}\right)$ and for MT3DMS, Br was measured as a mass (grams). Barnett et al., (2012) suggests that the mass balance discrepancy should be less than $0.5 \%$. Errors larger than this value indicate inconsistencies or errors in the model. The results in Table 5-6 show that mass balance discrepancies are all below $0.5 \%$, therefore any inconsistencies or model errors are unlikely.

Table 5-6: Percentage mass balance discrepancy for flow and transport

\begin{tabular}{|l|c|c|}
\hline Parameterisation & Flow (\%) & Transport (\%) \\
\hline Hom 1 & 0.04 & 0.0003 \\
\hline Hom 2 & 0.04 & 0.004 \\
\hline Hom 2-B & 0.03 & 0.009 \\
\hline Het 1 & 0.1 & 0.0008 \\
\hline Het 2 & 0.04 & 0.001 \\
\hline Pil 1 & 0.01 & 0.0005 \\
\hline Pil 2 & 0.03 & 0.004 \\
\hline Pil 3 & 0.01 & 0.0003 \\
\hline
\end{tabular}




\section{PREDICTIVE UNCERTAINTY AND DATA WORTH}

Since most groundwater models are used to make predictions, it is important that the uncertainty of a prediction is made clear so that decision makers are given the best information. Predictive uncertainty occurs because no groundwater model is a perfect predictor of system behaviour. This is the result of factors such as model structural error, imperfect data, unknown parameter values and limited parameter sampling procedures. Out of all the different contributions to uncertainty, Refsgaard et al. (2006) states that model structural error is the main source of uncertainty in model predictions. To some extent, model structural error has been assessed by using different parameterisations which represent different conceptual models of the aquifer system.

For this study, predictions have been made of the $\mathrm{Br}$ concentration on day 20 at three separate locations (Pred 1, Pred 2 and Pred 3) within model layer 26 using pilot point parameterisation Pil 1 (see Figure 6-1). These locations and times were choosen arbitrarily for ease of programing. More useful for applied problems would be uncertainty estimates made of the arrival times or peak concentrations. The purpose is to assess uncertainty of the predictions, the contribution to predictive uncertainty from parameters used in model calibration, and to assess the contribution of observations to predictive uncertainty (data worth). The results and workings are provided in Digital Appendix G.

\subsection{Theory and Implementation}

There are many different approaches for assessing predictive uncertainty. One common approach is the Monte-Carlo analysis which involves running a model many times with different parameter values held within a pre-defined range or probability distribution. With respects to model structural error, Refsgaard et al. (2006) used multiple conceptual models and then assessed the extent to which they adequately represent the space of plausible models. A common problem faced in many modelling is the uncertainty associated with up-scaling. Henriksen, Troldborg, Nyegaard, Sonnenborg, Refsgaard and Madsen (2003) provided a way of assessing the predictive uncertainty of up-scaling both at a spatially and temporally. 
For this study, a linear analysis of predictive uncertainty variance has been undertaken using a Bayesian conditioning framework with a program called PREDUNC (Moore, 2005 and Doherty, 2010b). The framework includes both a priori source of uncertainty and epistemic source of uncertainty (Fienen, Doherty, Hunt and Reeves, 2010). The a priori uncertainty is estimated before calibration and pertains to the parameters being estimated. The epistemic uncertainty is also estimated before calibration but pertains to the observations. Both types of uncertainty are considered in the posterior estimates of parameter and prediction uncertainty. Further details of the Bayesian framework are provided by Fienen, Doherty, Randall, Hunt and Reeves (2010) and Moore (2005).

PREDUNC was chosen because of its ability to deal with very complex problems, and because it has not been used on Canterbury Plains alluvial aquifers. One advantage over a non-linear analysis using something like Monte-Carlo is that predictive uncertainty can be determined quickly and with little computational effort, even in a very complex model with many parameters (Doherty, 2010b). One disadvantage is that the results of linear analysis can only be approximate because the relationship between model outputs and model parameters is in reality nonlinear (Doherty, 2010b).

PREDUNC originated from Moore (2005) and has been used by many authors such as Fienen et al. (2010), Dausman, Doherty, Christian, Langevin and Sukop (2010), Moore, Wöhling and Wolf (2011) and Dvořáček (2013). PREDUNC is a public domain tool included with the PEST utility GENLINPRED which stands for General Linear Predictive Analysis. PREDUNC can be used to calculate the predictive uncertainty variance on either a calibrated or un-calibrated model (Doherty, 2007). Three PREDUNC utilities were applied. PREDUNC1 was used to calculate the notional predictive uncertainty reduction. PREDUNC4 was used to calculate the precalibration and post-calibration contribution to predictive uncertainty variance for each $\mathrm{K}_{\mathrm{x}, \mathrm{y}}$ pilot point parameter. PREDUNC5 was used to calculate the data worth by observation addition and reduction.

Using PREDUNC, the uncertainty variance $\left(\sigma^{2}\right)$ of a prediction (s) can be expressed using Equation 6-1 from Dausman et al. (2010). 


$$
\sigma^{2} s=y^{t} C(p) y-y^{t} C(p) X^{t}\left[X C(p) X^{t}+C(\varepsilon)\right]-1 X C(p) y \quad \text { Equation 6-1 }
$$

Where $\mathrm{p}$ is the parameter set used by the model, $\mathrm{C}(\mathrm{p})$ is the diagonal covariance matrix of innate parameter variability which assumes statistical independence of each model parameter, $\mathrm{C}(\varepsilon)$ is the covariance matrix of measurement noise, $\mathrm{X}$ is the observation sensitivity matrix representing the change in observation values as a result of applying small perturbations to each parameter, and $\mathrm{y}$ is the prediction sensitivity vector or the derivative of the prediction of interest with respect to each parameter. The first term on the right side of the Equation 6-1 depends only on the pre-calibration parameter uncertainties defined by the sensitivity of the prediction to the parameters and to the inherent parameter variability. The second term represents the reduction of pre-calibration predictive uncertainty variance through including observations (Dausman et al., 2010 and Doherty, 2010b).

The $\mathrm{C}(\mathrm{p})$ matrix for this study was computed using GENLINPRED. It was based on a calculation of the standard deviation of each $\mathrm{K}_{\mathrm{x}, \mathrm{y}}$ parameter by dividing the difference between the calibration upper bound of $700 \mathrm{~m} / \mathrm{d}$ and calibration lower bound of $1 \mathrm{~m} / \mathrm{d}$ by a value of four. This method (provided by Doherty, 2013) assumed that the $\mathrm{K}_{\mathrm{x}, \mathrm{y}}$ parameters were normally distributed, and that the upper and lower bounds approximately demarcate the $95 \%$ confidence intervals.

Doherty (2010b) states that the weighting of observation data used in the $\mathrm{C}(\varepsilon)$ matrix should be such that the objective function relating to the calibrated model should be roughly equal to the number of observations featured in the calibration data-set. For this study, Pil 1 had a final calibration objective function of 277 based on the sum of squared weighted residuals. The calibration data-set comprised 5,682 observations of which 2,477 had a weighting of one, 16 had a weighting of 0.5 and the remainder had a weighting of zero. To make the sum of squared weighted residuals equal 2,477, all observations with a weighting of one were multiplied by a factor of 3.008 . Observations with a weighting of zero stayed at zero because they were incorrect and observations with a weighing of 0.5 stayed at the same because they showed what appear to be measurement errors and smaller relative weighting was considered acceptable. 


\subsection{Predictions}

Hypothetical predictions were made of the $\mathrm{Br}$ concentration on day 20 at three separate locations within model layer 26 (1.3 m below the top of model layer 1$)$ using pilot point parameterisation Pil 1. The predicted concentrations are $1.06 \mathrm{mg} / \mathrm{L}$ at Pred $1,1.56 \mathrm{mg} / \mathrm{L}$ at Pred 2 and $0.84 \mathrm{mg} / \mathrm{L}$ at Pred 3. In many applied problems, it is common to make predictions of the arrival time and time of peak concentration. The prediction locations for this study are shown in Figure 6-1.

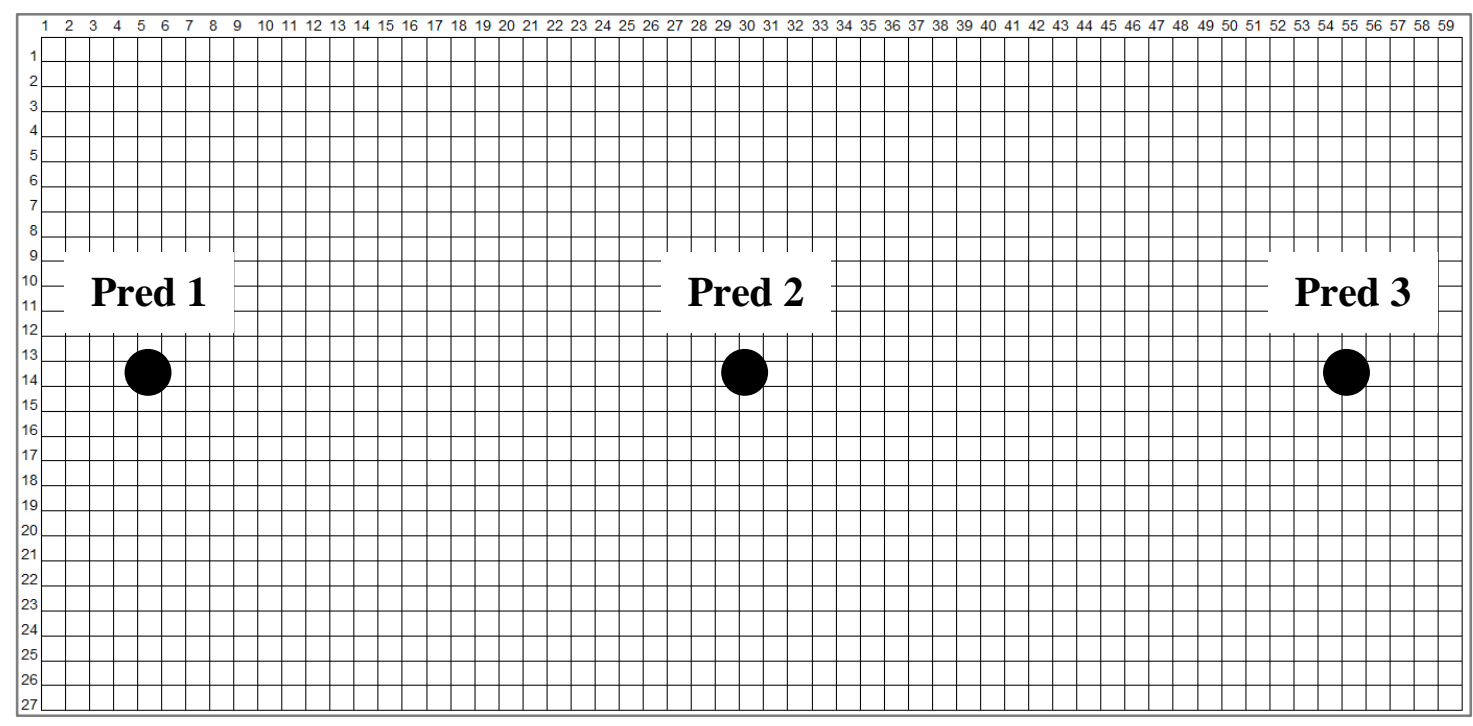

Figure 6-1: Locations of predictions Pred 1, Pred 2 and Pred 3 in model layer 26

Moore (2005) and Fienen et al. (2010) state that a non-unique parameterisation with a large number of parameters is required for the proper application of Equation 6-1. Using Equation 6-1 with a highly unique parameterisation with low parameter numbers as is the often the case for zone based parameterisations would compromise the analysis by way of misinformation. Therefore, Pil 1 was chosen because it contained a large number of parameters and was less unique than most of the zone based parameterisations. Pil 1 was also chosen because it provided the best overall fit to the observations. 


\subsection{PREDUNC1}

PREDUNC1 was used to compute the pre-calibration and post-calibration total predictive uncertainty variance for each prediction (so for Pred 1, Pred 2 and Pred 3). The total predictive uncertainty standard deviation (which is one standard deviation from the predicted value) can be calculated as the square root of the total predictive uncertainty variance. Figure 6-2 shows the difference between the pre-calibration and post-calibration total predictive uncertainty variance for Pred 1, Pred 2 and Pred. Errors bars show the total predictive uncertainty standard deviation.

Two trends are obvious. Firstly, the post-calibration predictive uncertainty standard deviation is reduced as a consequence of calibration. In theory one could suggest that there is a $67 \%$ chance that the predicted values will occur within the limits shown by the error bars. However, Doherty (2010b) states that using PREDUNC, it will rarely, if ever, be possible to quantify predictive uncertainty with a high level of precision. Thus it will rarely, if ever, be possible to make statements such as, 'these thresholds mark the $95 \%$ confidence interval of this prediction', or 'there is only a $5 \%$ chance that such an event will occur'. This is because the assessment of model predictive uncertainty using PREDUNC involves a high degree of subjectivity such as the decision made by the modeller as to what values should be assigned to the bounds on parameter values for the calculation of pre-calibration uncertainty.

The second obvious trend is that post-calibration predictive uncertainty standard deviation reduces along the groundwater flow path as shown by the highest value at Pred 1, intermediate value at Pred 2 and lowest value at Pred 3. This suggests that the uncertainty of the model prediction reduces along the flow path. One reason why this might occur is if there is a greater averaging out of groundwater flow velocities with increasing travel distance. This was indicated by the analytical modelling which showed a reduction in the standard deviation of $\mathrm{K}_{\mathrm{x}}$ with increasing travel distance (see Figure 5-16). Another reason might be that uncertainty decreases where there is a closer fit between the modelled and observation data. An example is Pil 1 where both uncertainty and error between the model and observed data are less near the end wall (see Figure 5-7). 


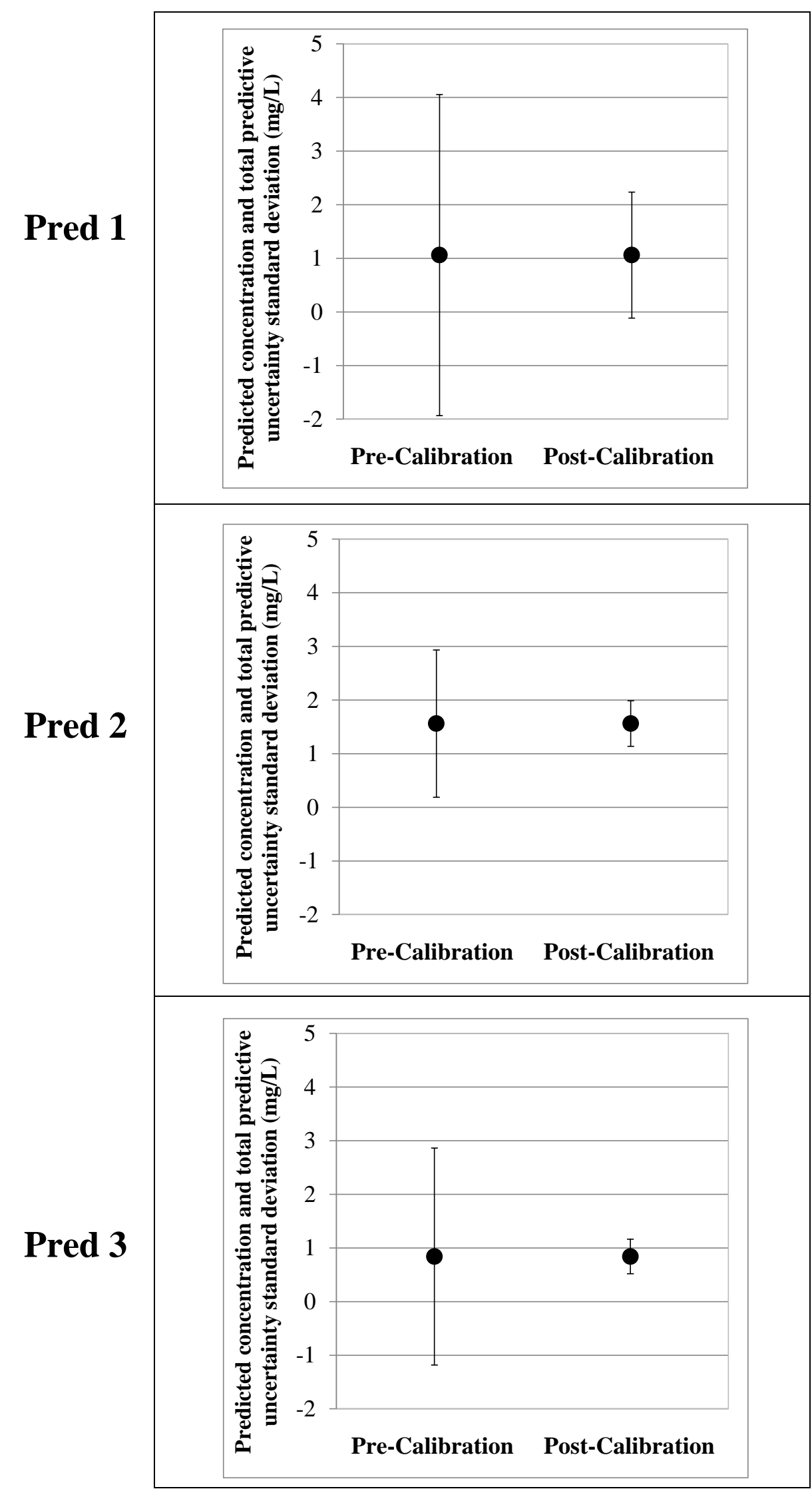

Figure 6-2: Predicted concentrations and the pre-calibration and post-calibration total predictive uncertainty standard deviations shown as error bars 


\subsection{PREDUNC4}

PREDUNC4 was used to compute the pre-calibration and post-calibration total predictive uncertainty variance for each of the $714 \mathrm{~K}_{\mathrm{x}, \mathrm{y}}$ pilot point parameters. This was used to identify which parameters contributed most to predictive uncertainty variance. Figure 6-3 shows the difference between the pre-calibration and postcalibration predictive uncertainty variance for all $\mathrm{K}_{\mathrm{x}, \mathrm{y}}$ pilot points for each of the three predictions. The data in blue are where pre-calibration uncertainty is higher than postcalibration uncertainty. The data in red data are where pre-calibration uncertainty is lower than post-calibration uncertainty. The plots show the cumulative distribution with points listed in order from largest to smallest difference in uncertainty.

One observation is the overall reduction in predictive uncertainty variance along the flow path which would be expected based on the results of PREDUNC1. Another interesting observation is the high number of pilot point parameters showing a lower pre-calibration uncertainty near the head-tank compared with those near the end-wall. 


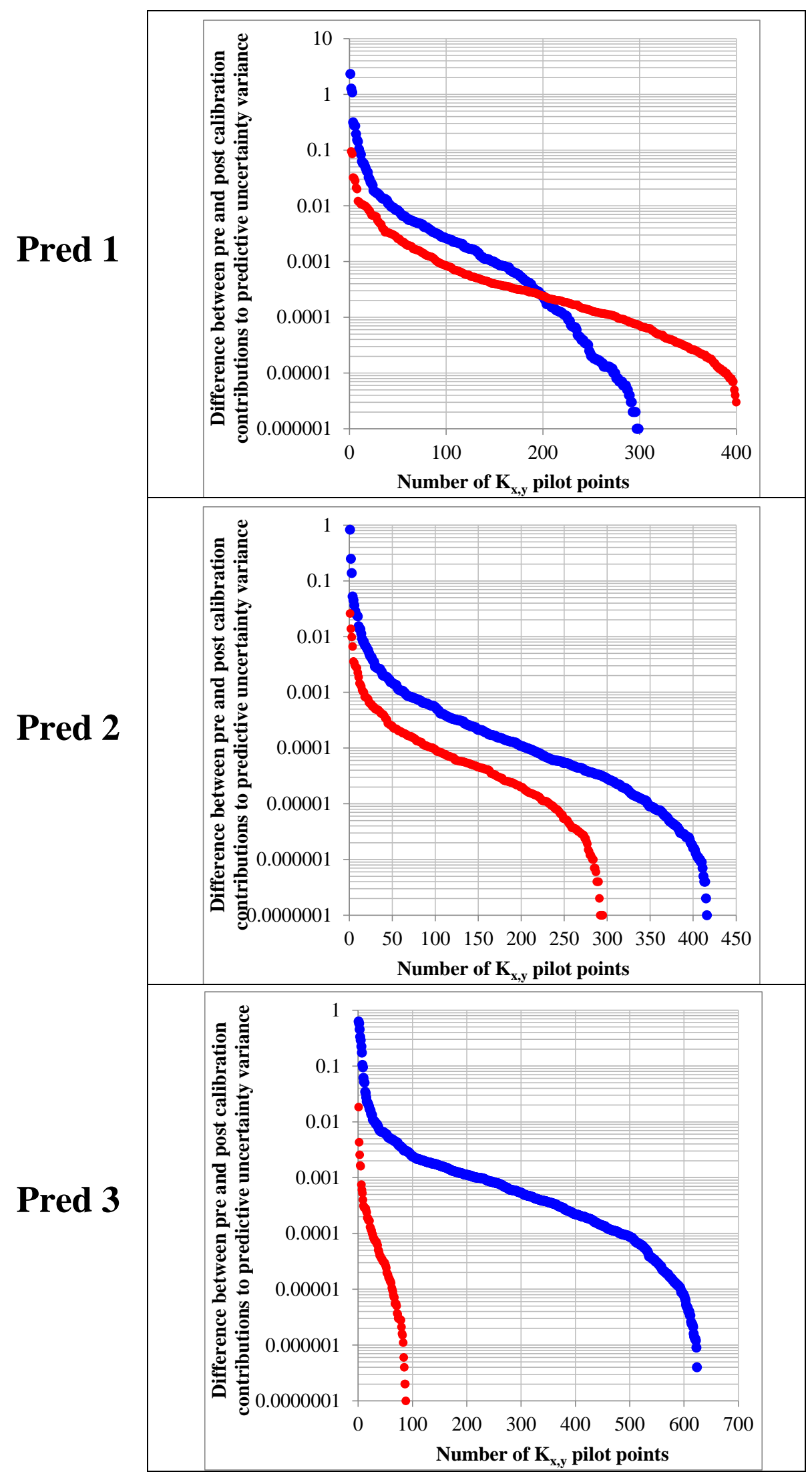

Figure 6-3: Difference between pre and post-calibration uncertainty variance for $K_{x, y}$ pilot points. Blue data are where pre-calibration uncertainty is higher than post-calibration uncertainty, red data are where pre-calibration uncertainty is lower than post-calibration uncertainty 


\subsection{PREDUNC5}

PREDUNC5 was used to compute the increase in predictive uncertainty variance incurred through loss of observation groups and the decrease in predictive uncertainty variance incurred through addition of observation groups. In this case, an observation group included all the observations at a single monitoring point. For example, observation group one includes all Br observations at monitoring well A1_0.4. The analysis performed by PREDUNC5 is often referred to as a data worth analysis and in summary it enables a ranking of those observations which contribute most to reducing predictive uncertainty.

Not only can the worth of existing observation data be assessed (as is the case for this study), PRECDUNC5 can also be used to assess the worth of adding new observation data. In a practical sense of reducing model predictive uncertainty, PREDUNC5 could be used to inform decision makers or a modeller on where the best locations might be for new monitoring wells. On the other, it could be used to assess where and how many existing monitoring wells could be removed from an existing monitoring network in order to reduce costs but to not lose important data that would significantly reduce the accuracy of a models predictions. A good example of its practical application is shown by Moore et al. (2011) who used PREDUNC5 to look at the optimisation of monitoring data for increased predictive reliability of regional water allocation models in Lockyer Valley, Australia.

Figure 6-4, Figure 6-5 and Figure 6-6 show the spatial distribution of data worth incurred through loss of observations (red bar charts), and through addition of observations (blue bar charts) for Pred 1, Pred 2 and Pred 3 respectively. All charts represent the arithmetic mean values for observation groups defined for each location. Error bars show one standard deviation either side of the mean.

All three predictions are located at the center of monitoring well Array $\mathrm{C}$ and as expected, observation data collected from monitoring wells in Array $\mathrm{C}$ have the highest data worth. All three predictions are located at $1.3 \mathrm{~m}$ depth below the top of model layer 1 . This is half way between monitoring well observations located at 1.0 $\mathrm{m}$ and $1.6 \mathrm{~m}$ depth. 


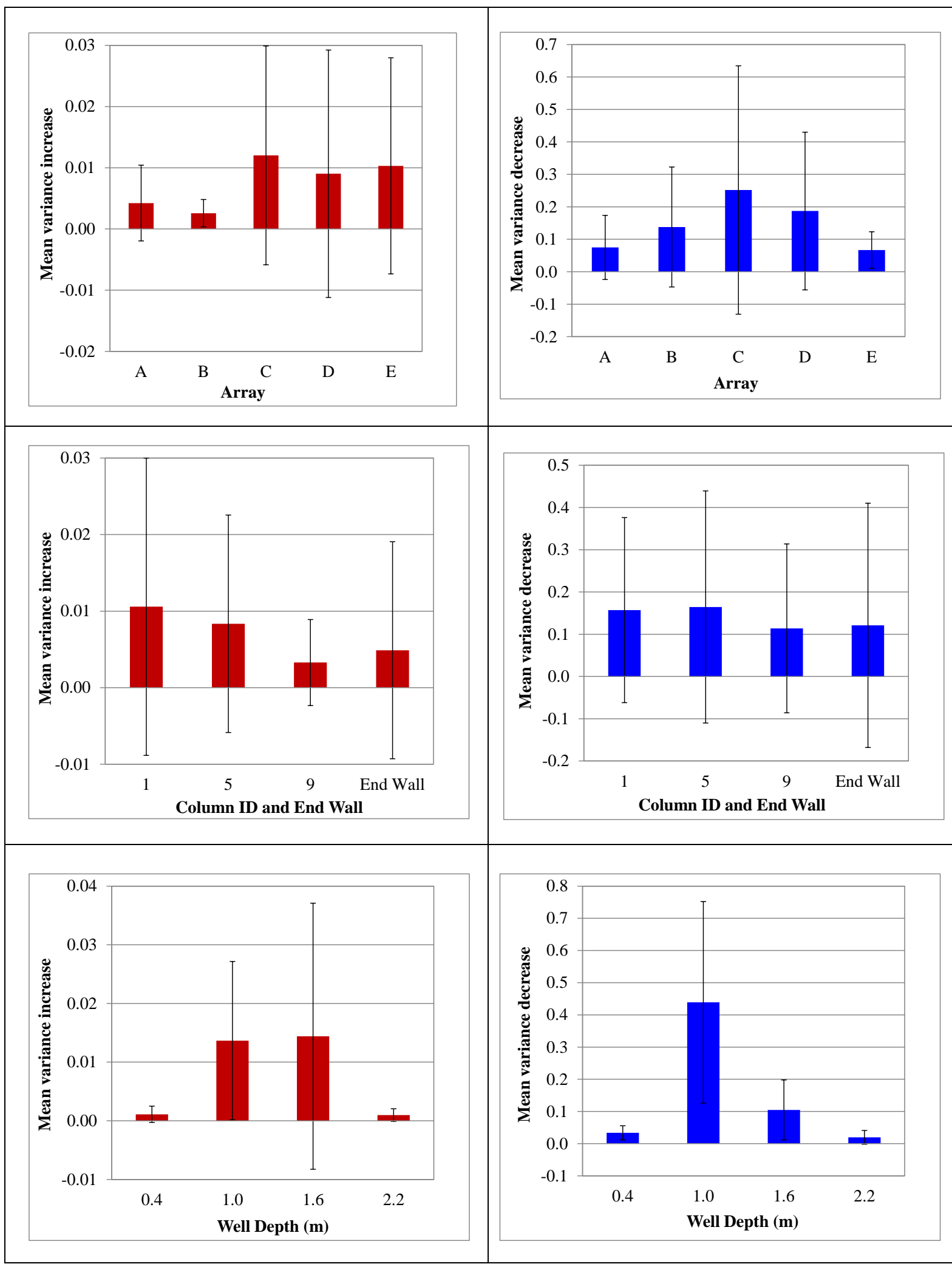

Figure 6-4: The spatial distribution of data worth as predictive uncertainty variance increase incurred through loss of observations (red bar charts), and predictive uncertainty variance decrease incurred through addition of observations (blue bar charts) for Pred 1 


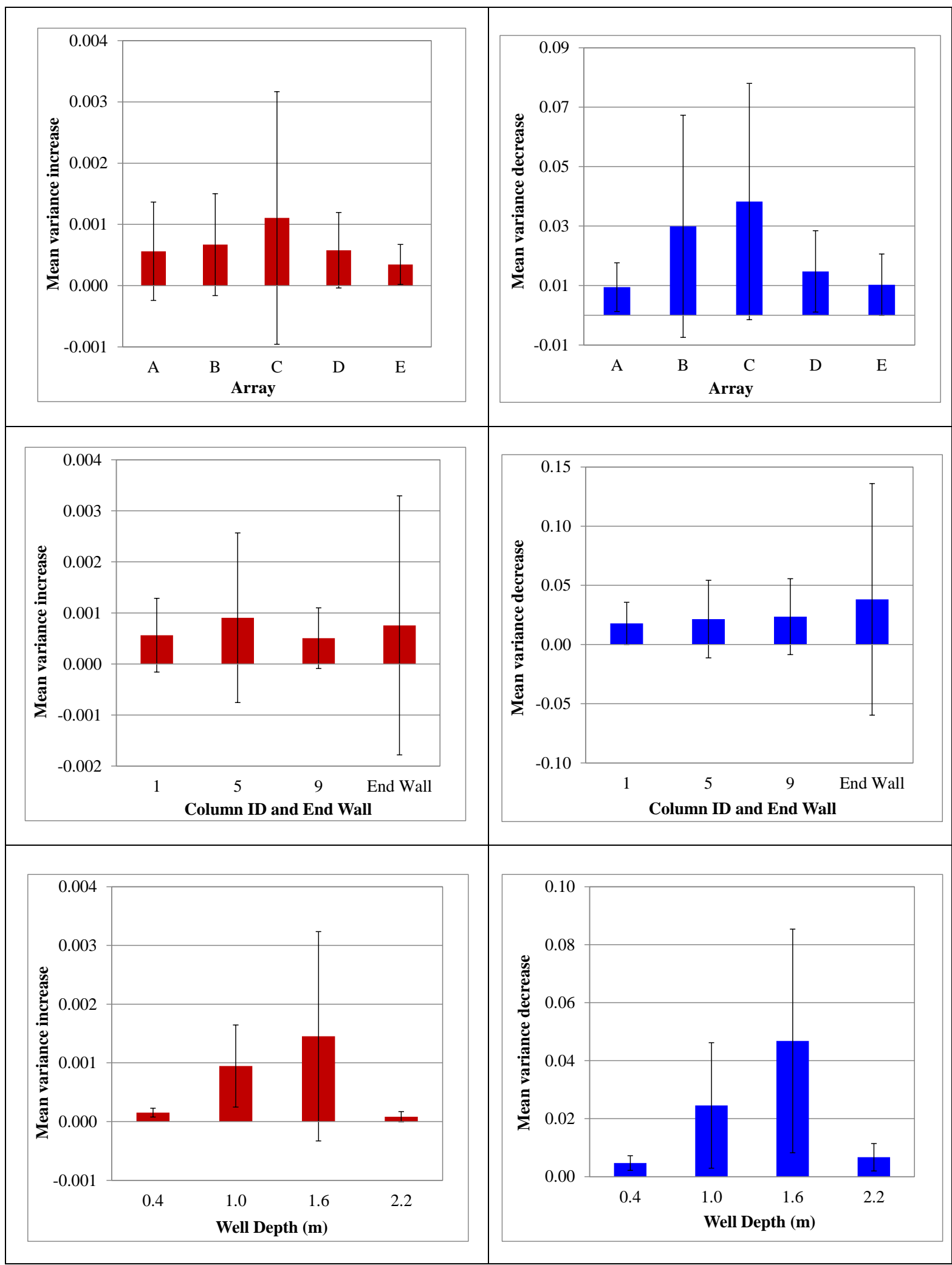

Figure 6-5: The spatial distribution of data worth as predictive uncertainty variance increase incurred through loss of observations (red bar charts), and predictive uncertainty variance decrease incurred through addition of observations (blue bar charts) for Pred 2 


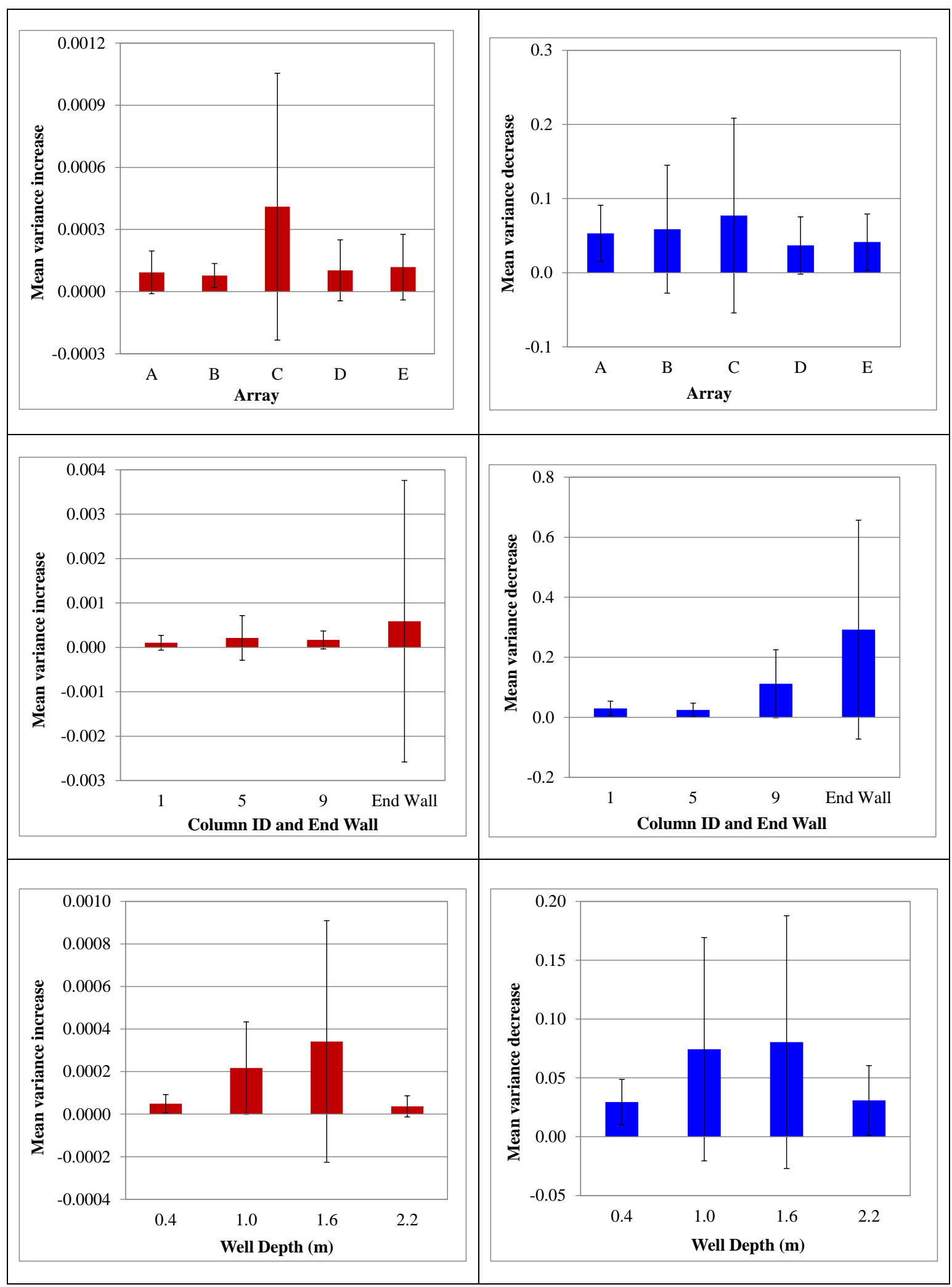

Figure 6-6: The spatial distribution of data worth as predictive uncertainty variance increase incurred through loss of observations (red bar charts), and predictive uncertainty variance decrease incurred through addition of observations (blue bar charts) for Pred 3 
The graphs show large standard deviations in mean variance for some of the locations. This suggests that there may not be a large statistical difference in some of the data, despite clearly different mean values.

As expected, the results show that monitoring wells at $1.0 \mathrm{~m}$ and $1.6 \mathrm{~m}$ depth contribute the most to data worth. More interestingly, observations at $1.6 \mathrm{~m}$ depth appear to be slightly more important for reducing uncertainty compared with those at $1.3 \mathrm{~m}$ depth. Also as expected, the results show data worth changing along the flow path from Pred 1 through to Pred 3. At Pred 1, observation data from monitoring wells at columns 1 and 5 contribute most to data worth whilst at Pred 3, observation data from the end-wall contributes most to data worth.

An interesting observation is the difference in data worth computed as a result of data exclusion (red bar charts) compared to that of data inclusion (blue bar charts). Moore et al. (2011) found the same results in their study. Their interpretation was that when observation data are scarce, the data worth analysis derived from adding or removing an observation can be similar. In contrast, when the two are different, this indicates that there is more than sufficient observation data. With 2,477 observation used for model calibration and predictive uncertainty analysis compared to 714 adjustable parameters, the interpretation of sufficient observation data is the most likely reason for the differences. 


\section{SUMMARY, APPLICATION OF RESULTS AND RECOMMENDATIONS}

This study modelled data from a tracer test undertaken in a heterogeneous artificial aquifer, $9.5 \mathrm{~m}$ lengthwise in the direction of groundwater flow, $4.66 \mathrm{~m}$ wide perpendicular to groundwater flow and $2.6 \mathrm{~m}$ deep in the vertical direction. The aquifer consisted of 17 layers of un-consolidated sediment. Each layer consisted of fine, medium or coarse sand blocks that were $0.50 \mathrm{~m}$ wide, $0.50 \mathrm{~m}$ long and $0.15 \mathrm{~m}$ thick when packed with a total of 2,907 blocks. The amount of detailed information known about the aquifer structure makes this study unique from most modelling studies which use data from a natural aquifer or synthetic data-set.

For the tracer test, $\mathrm{Br}$ was injected for a period of 7.2 days along the entire face of the head-tank. A total of 5,679 concentration readings were taken at various monitoring points within the aquifer over a period of 102 days from the start of injection. Pressure readings of head within the aquifer were recorded from three piezometers. The concentrations measured at different monitoring points over time provided breakthrough curves which were modelled using analytical and numerical techniques.

\subsection{Parsimony}

The main aim of this study was to assess the concept of parsimony by modelling tracer test data starting with a simple analytical model that assumed homogenous conditions, then moving through a range of progressively more complex numerical models, some of which included heterogeneity. Adopting this process has added to the understanding of how well simplistic models might represent heterogeneous alluvial aquifers such as those on the Canterbury Plains.

\subsubsection{Analytical Modelling}

Analytical modelling was the most simplistic form of modelling undertaken. Haitjema (2006) presented a view that simple analytic solutions can be useful for gaining insights into model parameterisation and calibration. The results from this study confirmed this view as was evident by information gained about the spatial 
distribution and variation of $\mathrm{K}$, and improved understanding of heterogeneity through the calculation of dispersion.

In terms of dispersion, the analytical modelling showed that $\alpha_{\mathrm{x}}$ in the artificial aquifer is scale dependent and increases with travel distance. This process also occurs in nature and has been documented in the field by authors such as Gelhar (1986). The analytical modelling also showed that ratios of $\alpha_{\mathrm{x}}$ to travel distance varied from $4 \%$ to $16 \%$ and thus occur within the general range of observations documented in the field by Gelhar (1986). These values are comparable with the value of $10 \%$ commonly applied to alluvial aquifers in the Canterbury Plain. This suggests that a value in the range of $4 \%$ to $16 \%$ is a good starting value in the absence of any measured values.

In terms of $\mathrm{K}$, the analytical modelling was successfully used to present one depiction of the spatial distribution of heterogeneity that was consistent with the most complex pilot point numerical parameterisation and in some cases. It is possible that some of that analytical modelling were more realistic than the complex zone based heterogeneous numerical models because the zone based models did not take account of any changes in any $\mathrm{K}$ spatially and with depth after the blocks were put in place. The range of $\mathrm{K}$ values was consistent with the numerical modelling. In addition the analytical modelling results helped decide on parameter bounds and realistic starting values for the numerical modelling.

\subsubsection{Numerical Modelling}

The numerical modelling compared eight different parameterisations. From a view of keeping the model simple and keeping the parameterisation unique, the homogenous parameterisation with dispersion (Hom 2) was arguably the best. The two zoned based parameterisations (Het 1 and Het 2) showed that prior knowledge of the aquifer structure helped improve the model predictions. However, based on the SRMS and Phi values used as statistical measures of the goodness of fit, Het 2 was little or no better than Hom 2 which included a homogeneous parameterisation with dispersion. This may have been caused by changes in the $\mathrm{K}$ distribution after the blocks were installed for reasons such as settling and compaction over time or re-working of the sands from water moving through the aquifer. 
The inclusion of a block distribution using zones in Het 1 and Het 2 made the models less unique. It also appeared to impose a distribution of $\mathrm{K}$ that was sometimes at odds with both the analytical modelling and pilot point numerical parameterisations. The most complex models were the pilot point numerical parameterisations (Pil 1, Pil 2 and Pil 3). These models gave the best fit to the observation data but had the disadvantage of being less unique due to the much larger number of parameters used.

Despite the intention of creating a heterogeneous artificial aquifer, the full head-tank tracer test results were quite similar to those of the homogeneous artificial aquifer. It was also found that some of the simple modelling techniques produced results as well as those with more detailed parameterisations. This may have occurred because the tracer was released over the entire width and thickness of the aquifer rather than from a point source. At a practical level, this suggests that simple models may be quite adequate when it comes to making predictions in Canterbury Plains alluvial aquifers when the contaminant is released over a large area, such as Nitrate contaminant from dairying. In contrast, point source discharges from say a sceptic tank or small waste water treatment plant may require more detailed parameterisations.

\subsection{Predictive Uncertainty}

Another aim of this study was an assessment of PREDUNC as an appropriate geostatistical tool for predictive uncertainty analysis. At face value the results show that PREDUNC is appropriate for heterogeneous alluvial aquifers. The results showed that the predictive uncertainty was greatly reduced at a distance of $9 \mathrm{~m}$ from the source of injection. This correlated well with a general improvement of model fits to observations with increasing travel distance. PREDUNC was also used to assess data worth through addition and subtraction of observation data. Generally, data worth increased with decreasing distance to the prediction of interest which appears intuitive. To more robustly test the appropriateness of PREDUNC, it would be useful to compare the results with other methods that do not assume linearity in a similar way to that undertaken by Doherty (2010b). 


\subsection{Practical Application of the Modelling Results}

A summary of how the results from this study could be used to help inform model design and parameterisation is discussed as follows.

\section{Travel Distance}

Numerical modelling showed that less detailed heterogeneity was required for making close model fits to the observations furthest from the head-tank. For example, the overall fit to observations at the end-wall was almost as good using a simple homogeneous parameterisation in Hom 2 as it was using a complex pilot point parameterisation in Pil 1. In addition, the uncertainty of predictions made using PREDUNC also reduced with increasing travel distance. This suggests that heterogeneity required in a model might be reduced for predictions that are made at distances further from the source.

\section{Dispersivity}

Analytical modelling showed that dispersivity was scale dependent. This suggests that predictions made using an analytical model in the absence of available field data should include a value of dispersivity that is scale dependent. Using a value of $\alpha_{\mathrm{x}}$ that is equal to $10 \%$ of the total distance between the source and the location of the prediction would appear to be a reasonable approach given the results of this study and the results of field studies.

Numerical modelling showed that dispersivity become a less important parameter when the heterogeneity of the parameterisation was increased by including greater $\mathrm{K}$ variability. It also showed that when $\mathrm{K}$ variability reached a sufficiently high level, the calibration of dispersivity and $\mathrm{K}$ together made the parameterisation much less unique and the calibrated values of dispersivity could be quite inaccurate. If a highly heterogeneous $\mathrm{K}$ parameterisation is used in a model then it is probably good practise to calibrate the model with dispersivity then again without dispersivity so that some assessment can be made to determine the worth of attempting to optimise dispersivity values during calibration. 


\section{Predictions of Total Mass versus Spatial and Temporal Variations in Mass}

Numerical modelling showed that different parameterisations can have similar flow and solute mass balances but the predictions of $\mathrm{Br}$ concentration both spatially and temporally may be very different. For example, if the aim was to estimate the mass of flow or Br exiting the end-wall then the degree of fit to target observations would have mattered less because the mass balances were generally similar for all of the parameterisations, regardless of how much $\mathrm{K}$ detail was included. In a practical sense, if the aim was to estimate the mass of flow or solute entering a river then the amount of detail required in the parameterisation would probably be less than if the aim was to estimate the arrival time and peak concentration at a specific location.

\section{Model Boundary Conditions}

The two types of boundary conditions used to model $\mathrm{Br}$ mass input gave comparable values for total mass but gave slightly different parameter values because one boundary condition included mass from dispersion and the other did not. Though in this study the effects on parameter values were only small, models that include significant dispersive mass from a model boundary should provide an analysis of its effects on the parameter values estimated during calibration.

\section{Analytical Modelling}

This study showed that analytical modelling can be a useful first step in helping to understand the transport processes occurring in the aquifer, providing representative ranges of parameter values and for gaining insight into the spatial distribution and heterogeneity of the aquifer.

\section{Hydraulic Conductivity Data Collection and Parameterisation}

For modelling solute transport in the Canterbury Plains alluvial aquifers (and potentially many other aquifer systems), results from this study suggest that collecting large amounts of $\mathrm{K}$ data and then applying it to a zone based parameterisation may not be a cost effective way of getting accurate model results. The results suggest that mapping the aquifer structure in fine detail for the purpose of building a groundwater transport model may not be necessary, at least in some cases. 
The results suggest a good cost effective approach is to start with a simple homogeneous parameterisation with dispersion, then if necessary, add more complexity and fine detail using a pilot point parameterisation of $\mathrm{K}$. Zone based numerical parameterisations of $\mathrm{K}$ may still be useful to include, but relying on zones to capture the true heterogeneity of very complex natural systems is probably asking too much. One argument against this approach is that a model calibrated using pilot points may not be based on a realistic geological structure. This could have negative implications when it comes to making predictions. The final decision about how much data to collect will invariably come down to cost and significance of effects being modelled.

\subsection{Recommendations}

Building from this study, it would be useful to test the same models using data from the point source injection test undertaken in the heterogeneous artificial aquifer in 2000 in order to see if the results are similar. This would help to confirm whether the simple analytical and homogenous numerical models performed well because the tracer was released over dimensions of the aquifer. Under conditions where the tracer was released from a point-source and could spread in potentially more directions, the performance of these more simple models may reduce.

It is recommended that tools like PREDUNC which are simple to use and which have a low computational burden be applied more frequently to both solute transport modelling and other forms of environmental modelling. However, given the assumption of linearity in PREDUNC, where computationally feasible, it would be wise to also assess predictive uncertainty using non-linear methods as well.

The difference in data worth through addition and subtraction of data indicated that that there was more than sufficient observation data used in this study. Thus it would be useful to look at model results using different amounts of observation data as was done by Scheibe and Chien (2003). 


\section{REFERENCES}

Ammar, K., Khalil, A., McKee, M., \& Kaluarachchi, J. (2008). Bayesian deduction for redundancy detection in groundwater quality monitoring networks. Water Resources Research, 44.

Anderson, P., \& Woessner, W. (1992). Applied groundwater modelling: simulation of flow and advective transport. San Diego, USA: Academic Press.

Aqualinc Research Ltd (2010). Update of water allocation data and estimate of actual water use of consented takes 2009-10. Report No H10002/3.

Aziz, J., Ling, M., Rifai, H., Newell, C., \& Gonzales, J. (2003). MAROS: A decision support system for optimising monitoring plans. Ground Water, 41(3), 355-367.

Barnett, B., Townley, L., Post, V., Evans, R., Hunt, R., Peters, L., Richardson, S., Werner, A., Knapton, A. \& Boronkay, A. (2012). Australian groundwater modelling guidelines. Canberra, Australia. National Water Commission, Canberra.

Bear, J. (1972). Dynamics of fluids in porous media. New York, USA: Dover Publications Inc.

Beven, K. (2009). Environmental modelling: An uncertain future? Wiltshire, Great Britain: The Cromwell Press.

Bright, J., Wang, F., \& Close, M. (2002). Influence of the amount of available K data on uncertainty about contaminant transport prediction. Ground Water, $40(5), 529-534$.

Brown., L. (2001). Groundwaters of the Canterbury region. Environment Canterbury Report, No. R00/10. 
Close, M., \& Pang, L. (1995). Hydrogeological characteristics of the Burnham groundwater contamination experiment. Christchurch Science Centre, Institute of Environmental Science and Research. Report 95/9.

Close, M., Bright, J., Wang, F., Pang, L., \& Manning, M. (2008). Key features of artificial aquifers for use in modelling contaminant transport. Ground Water, 46(6), 814-828.

Dann, R., Close, M., Pang, L., Flintoft, M., \& Hector, R. (2008). Complementary use of tracer and pumping tests to characterize a heterogeneous channelized aquifer system in New Zealand. Hydrogeology Journal 16, 1177-1191.

Dvořáček, P. (2013). Hydrogeological framework, conceptual and numerical groundwater flow model of Laidley Creek catchment, Queensland, Australia. Thesis submitted in accordance with the regulations for the Degree of Doctor of Philosophy. School of Earth, Environmental and Biological Sciences Science and Engineering Faculty Queensland University of Technology. Australia.

Davey, G. (2006). A contribution to the understanding of Canterbury Plains aquifers. Environment Canterbury Technical Report. U06/08.

DHI. (2013). FEFLOW 6.2. Finite element subsurface flow and transport simulation. Berlin, Germany.

Dausman, A., Doherty, J., Christian, D., Langevin, \& Sukop, M. (2010). Quantifying data worth toward reducing predictive uncertainty. Ground Water, 48(5), 729-740.

Doherty, J. (2003). Ground water model calibration using pilot points and regularisation. Ground Water, 41(2), 170-177. 
Doherty, J. (2007). Use of PEST and some of its utilities in model calibration and predictive error variance analysis: A roadmap. Watermark Numerical Computing. Retrieved from http://www.pesthomepage.org/Downloads.php

Doherty, J. (2010a). PEST Model-Independent Parameter Estimation User Manual: 5th Edition. Watermark Numerical Computing. Retrieved from http://www.pesthomepage.org/Downloads.php

Doherty, J. (2010b). Methodologies and Software for PEST based model predictive uncertainty analysis. Watermark Numerical Computing. Retrieved from http://www.pesthomepage.org/Downloads.php

Doherty, J. (2013). Addendum to the PEST Manual. Watermark Numerical Computing. Watermark Numerical Computing. Retrieved from http://www.pesthomepage.org/Downloads.php

Fetter, C. (1999). Contaminant hydrogeology. Second Edition. New Jersey, USA: Prentice-Hall, Inc.

Fienen, M, Doherty, J., Hunt, R., \& Reeves, H. (2010). Using prediction uncertainty analysis to design hydrologic monitoring networks: Example applications from the Great Lakes water availability pilot project. Scientific Investigations Report 2010-5159 U.S.

Freeman, M. (2011). The resource consent process: Environmental models and uncertainty. Journal of the Resource Management Law Association of New Zealand Inc. August 2011, 1-8.

Freeze, R and Cherry, J. (1979). Groundwater. Prentice Hall Inc. New Jersey.

Gelhar, W. (1986). Stochastic subsurface hydrology from theory to application. Water Resources Research, 22(9), 135-145. 
Haitjema, H. (2006). The role of hand calculations in ground water modeling. Ground Water 44( 6), 786-791.

Harbaugh, W., Banta, R., Hill, M., \& McDonald, G. (2000). MODFLOW-2000, the U.S. Geological Survey modular ground-water model - User guide to modularization concepts and the Ground-Water Flow Process. U.S. Geological Survey Open-File Report 00-92.

Helweg, O., \& Smith, G. (1978). Appropriate technology for artificial aquifers. Ground water, 16(3), 144-148.

Henriksen, H. J., Troldborg, L., Nyegaard, P., Sonnenborg, T. O., Refsgaard, J. C., and Madsen, B. (2003). Methodology for construction, calibration and validation of a national hydrological model for Denmark. Journal of Hydrology, 280, 52-71.

Hill, M. (2006). The practical use of simplicity in developing ground water models. Ground Water, 44(6), 775-781.

Hunt, B. (2012). Groundwater analysis using function.xls. Retired from Civil Engineering Department, University of Canterbury. Retrieved from http://www.civil.canterbury.ac.nz/staff/hunt/Groundwater\%20Analysis\%20Usi $\underline{\text { ng\%20Function.pdf }}$

Hunt, J., Doherty, J., \& Tonkin, M. (2007). Are models too simple? Arguments for increased parameterization. Ground Water 45(3), 254-262.

Johnson, A.I. (1967). Specific yield - compilation of specific yields for various materials. Geological Survey - Water Supply Paper 1662-D. United States Government Printing Office, Washington.

Kasenow, M. (2001). Applied ground-water hydrology and well hydraulics, $2^{\text {nd }}$ Edition. Colorado, USA: Water Resources Publications. 
Konikow, L. (2011). The secret to successful solute transport modeling. Ground Water 49(2), 144-159.

Kruseman, G., \& de Ridder, N (2000). Analysis and evaluation of pumping test data. Second Edition. Wageningen, Netherlands: International Institute for Land Reclamation and Improvement.

Margat, J. \& van der Gun, J. (2013). Groundwater around the world: A geographic synopsis. Hoboken: Taylor and Francis

Moore, C. (2005). The use of regularized inversion in groundwater model calibration and prediction uncertainty analysis. A thesis submitted for the degree of Doctor of Philosophy at The University of Queensland, Australia.

Moore, C., Wöhling, T., \& Wolf, L. (2011). Optimisation of monitoring data for increased predictive reliability of regional water allocation models. 19th International Congress on Modelling and Simulation, Perth, Australia, 12-16 December 2011. Modelling and Simulation Society of Australia and New Zealand. Sourced from http://www.mssanz.org.au/modsim2011/19/moore.pdf

Morris, D., \& Johnson, A. (1967). Summary of Hydrologic and physical Properties of rock and Soil Materials, as analyzed by the Hydrologic laboratory of the U.S. Geological Survey, 1948 - 60. Geological Survey water-supply paper 1839-D. Washington, USA: United States Government Printing Office.

Neuman, S. (1984). Adaptive Eulerian-Lagrangian finite element method for advection-dispersion. International Journal of Numerical Methods in Engineering 20, 321-37.

Panday, S., Langevin, C., Niswonger, R., Ibaraki, M. \& Hughes, J. (2013). MODFLOW-USG Version 1: An unstructured grid version of MODFLOW for simulating groundwater flow and tightly coupled processes using a control 
volume finite-difference formulation. U.S. Geological Survey Techniques and Methods, book 6, Chapter. A45. http://pubs.usgs.gov/tm/06/a45/pdf/tm6$\underline{\text { A45.pdf }}$

Pang, L., Close M., \& Noonan, M. (1998). Rhodamine WT and Bacillus subtilis transport through an alluvial gravel aquifer. Ground Water 36(1), 112-122.

Pang, L., \& Close M. (1999). A field study of nonequilibrium and facilitated transport of $\mathrm{Cd}$ in an alluvial gravel aquifer. Ground Water 37(5), 785-792.

Parliamentary Commissioner for the Environment. (2013). Water quality in New Zealand: Land use and nutrient pollution. November 2013.

Sauty, J. (1980). An analysis of hydrodispersive transfer in aquifers. Water Resources Research, 27(16), 145-158.

Scheibe, T., \& Chien, Y. (2003). An evaluation of conditioning data for solute transport prediction. Ground Water 41(2), 128-141.

Shepherd, R. (1998). Correlations of permeability and grain size. Ground Water 27(5), 633-638.

Van der Gun, J. (1979). Estimation of the elastic storage coefficient of sandy aquifers (in Dutch). TNO Dienst Grondwaterverkenning, Jaarverslag 51-61

Wentworth, K. (1922). A scale of grade and class terms for clastic sediments: Journal of Geology 30, 377-392.

Zheng, C., \& Bennett, G. (2002). Applied contaminant transport modelling. Second Edition. New York, USA. John Wiley and Sons, Inc..

Zheng, C., \& Wang, P. (1999). MT3DMS: A modular three-dimensional multispecies transport model for simulation of advection, dispersion, and chemical 
reactions of contaminants in groundwater systems; documentation and user's guide. Washington DC, USA. U.S. Army Engineer Research and Development Center Cataloging-in-Publication Data. 


\section{Appendix A}

Block Distribution of the Heterogeneous Artificial Aquifer 


\section{Layer 1}

MAR 22 'G2 11:56FM LINCOLN VENTUFES 643 3253725

P. $2 / 18$

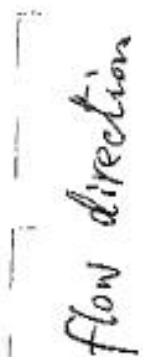

Layer 1 ibottom)

(17)

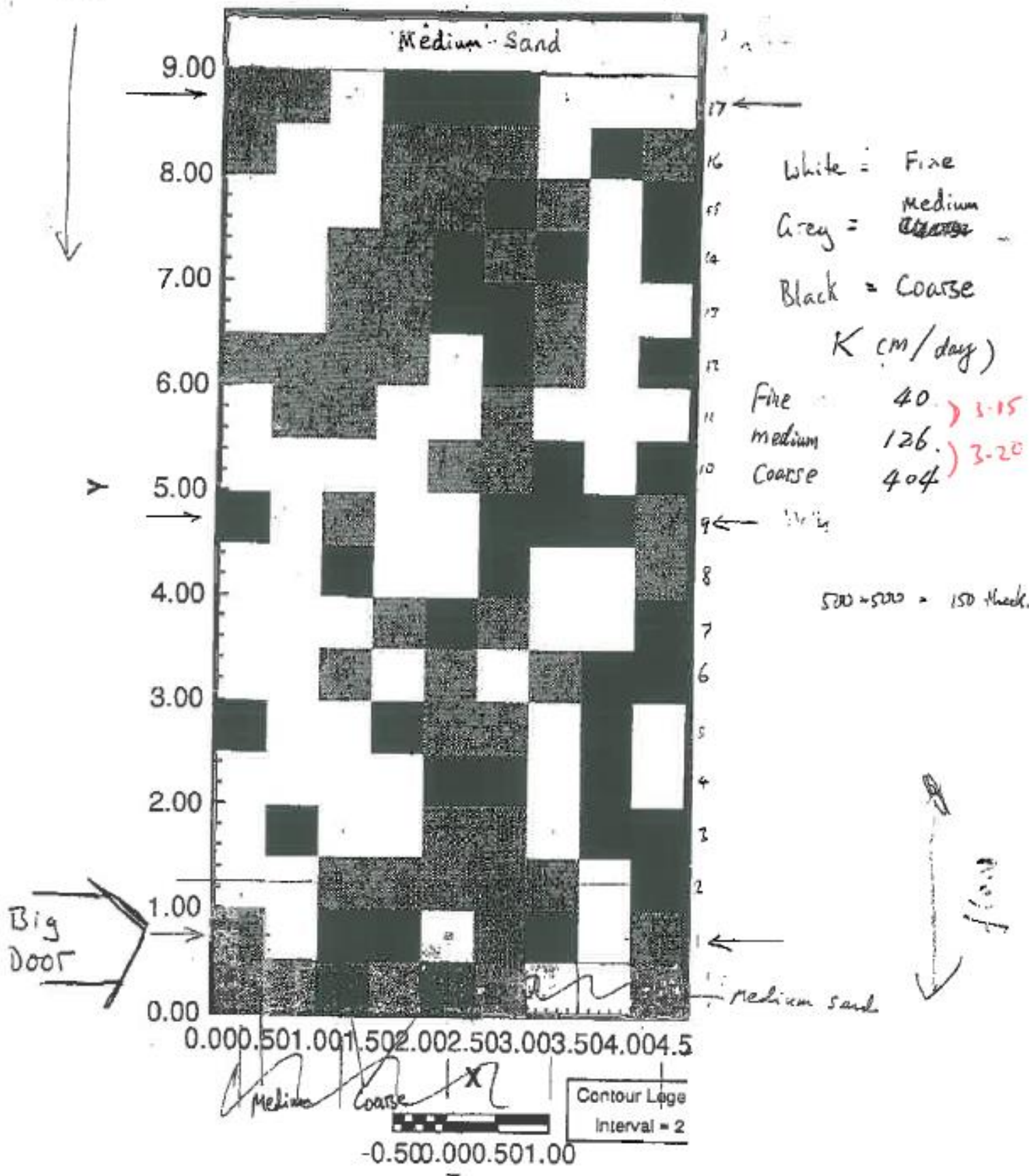




\section{Layer 2}

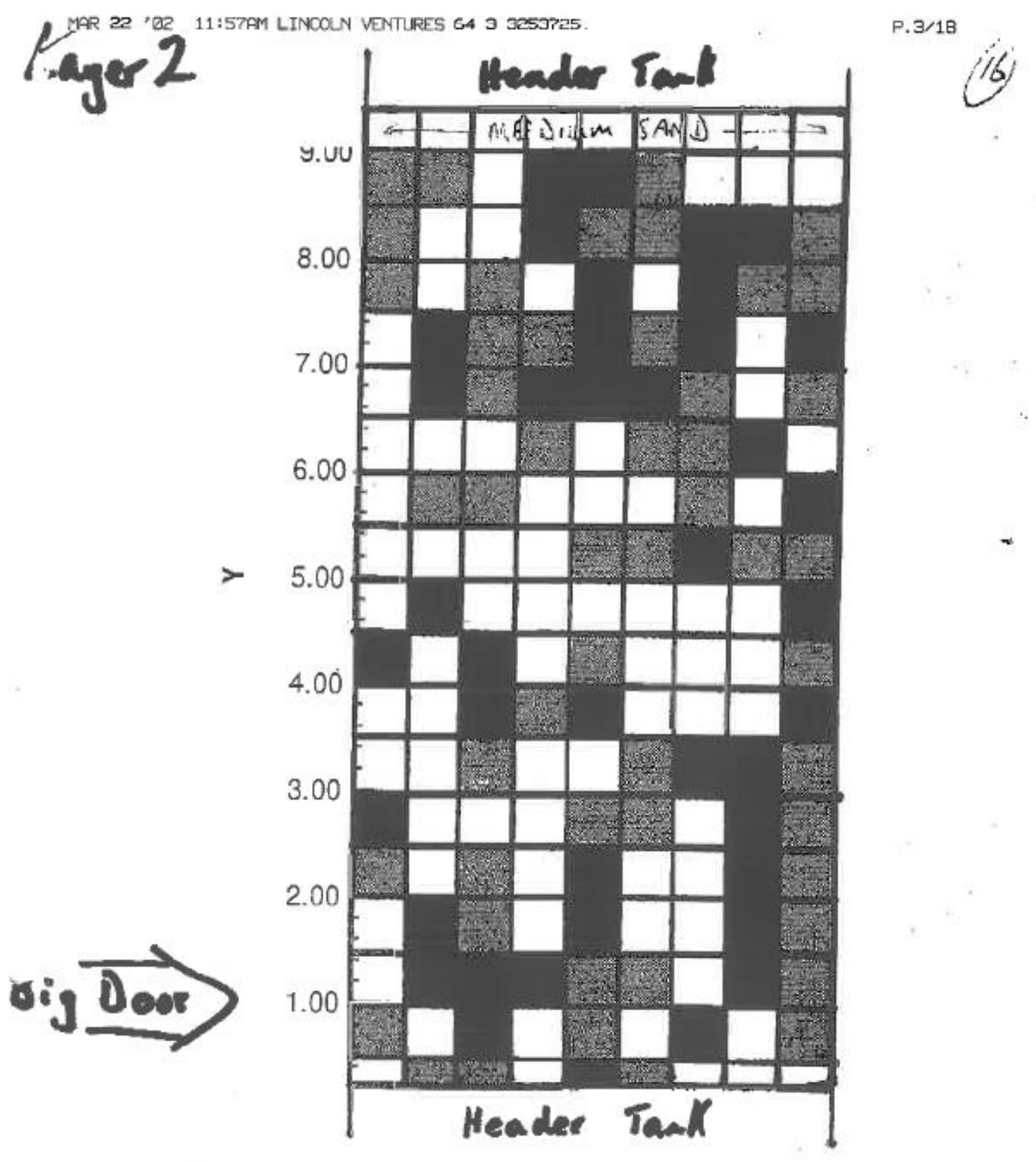




\section{Layer 3}

MAR 22 'B2 11:59AM LINCOLN VEITTURES̈ 643 3253725

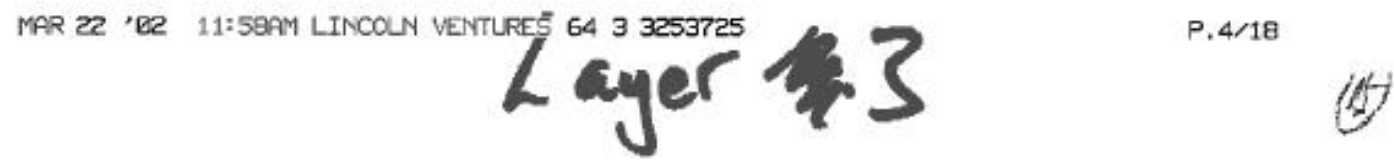

MAR 22 'B2 11:59AM LINCOLN VENTURES̈ 643 3253725

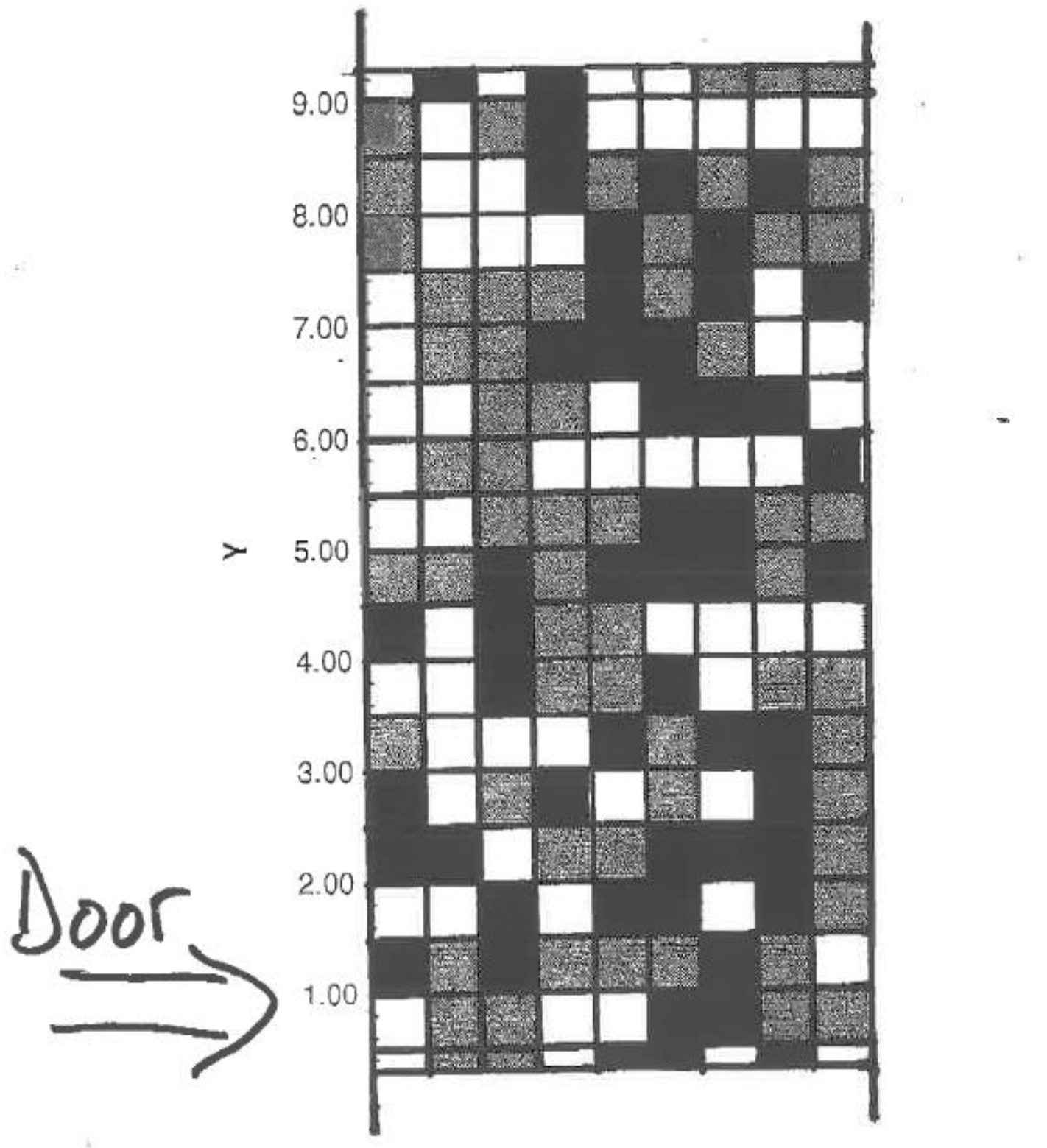




\section{Layer 4}

MAR 22 'O2 11:5BAM LINCOLN VENTURES 6433253725
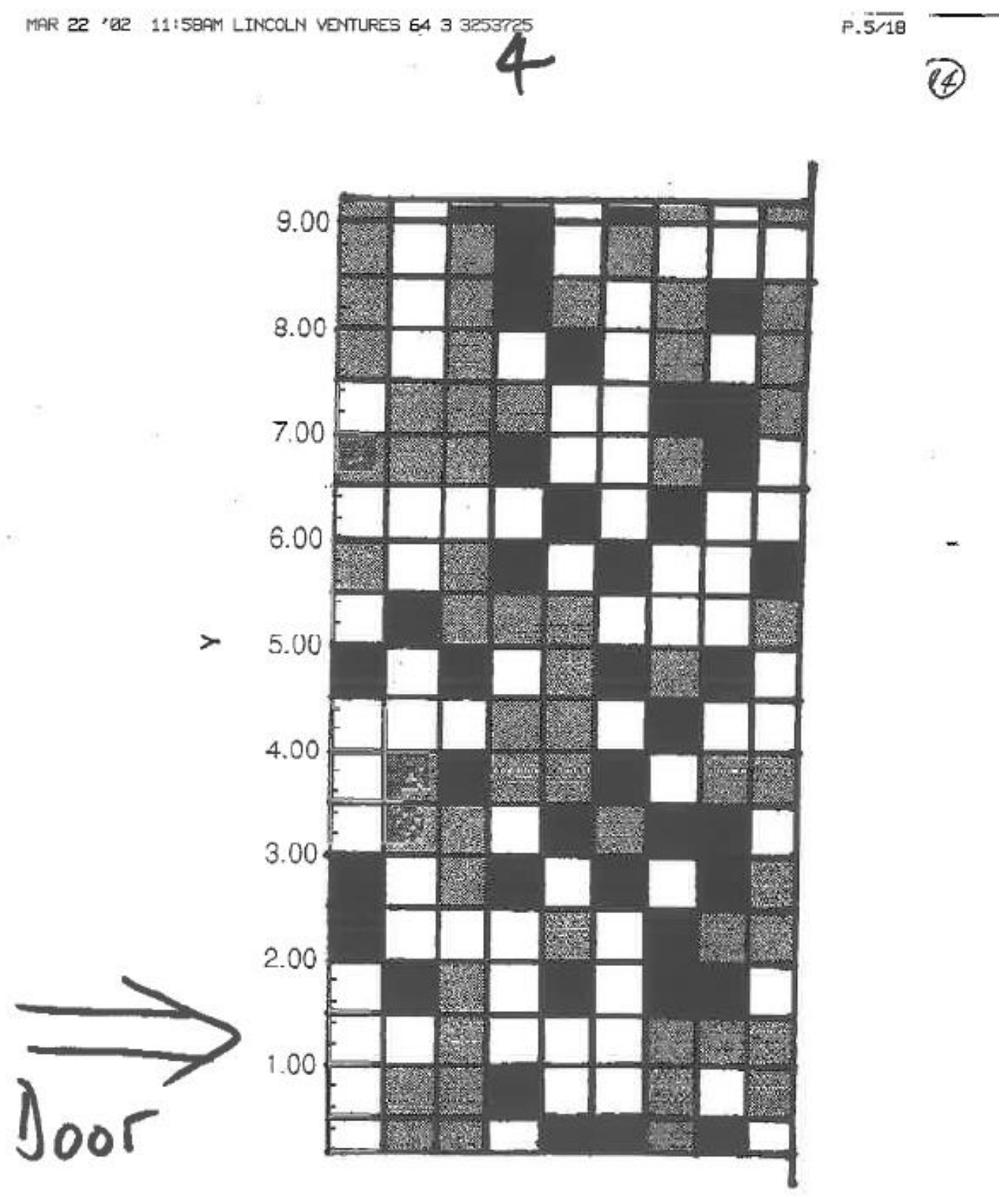


\section{Layer 5}

MAR 22 'D2 11:59AM LINCOLN VENTURES 6433253725

$P .6 / 18$

(3)

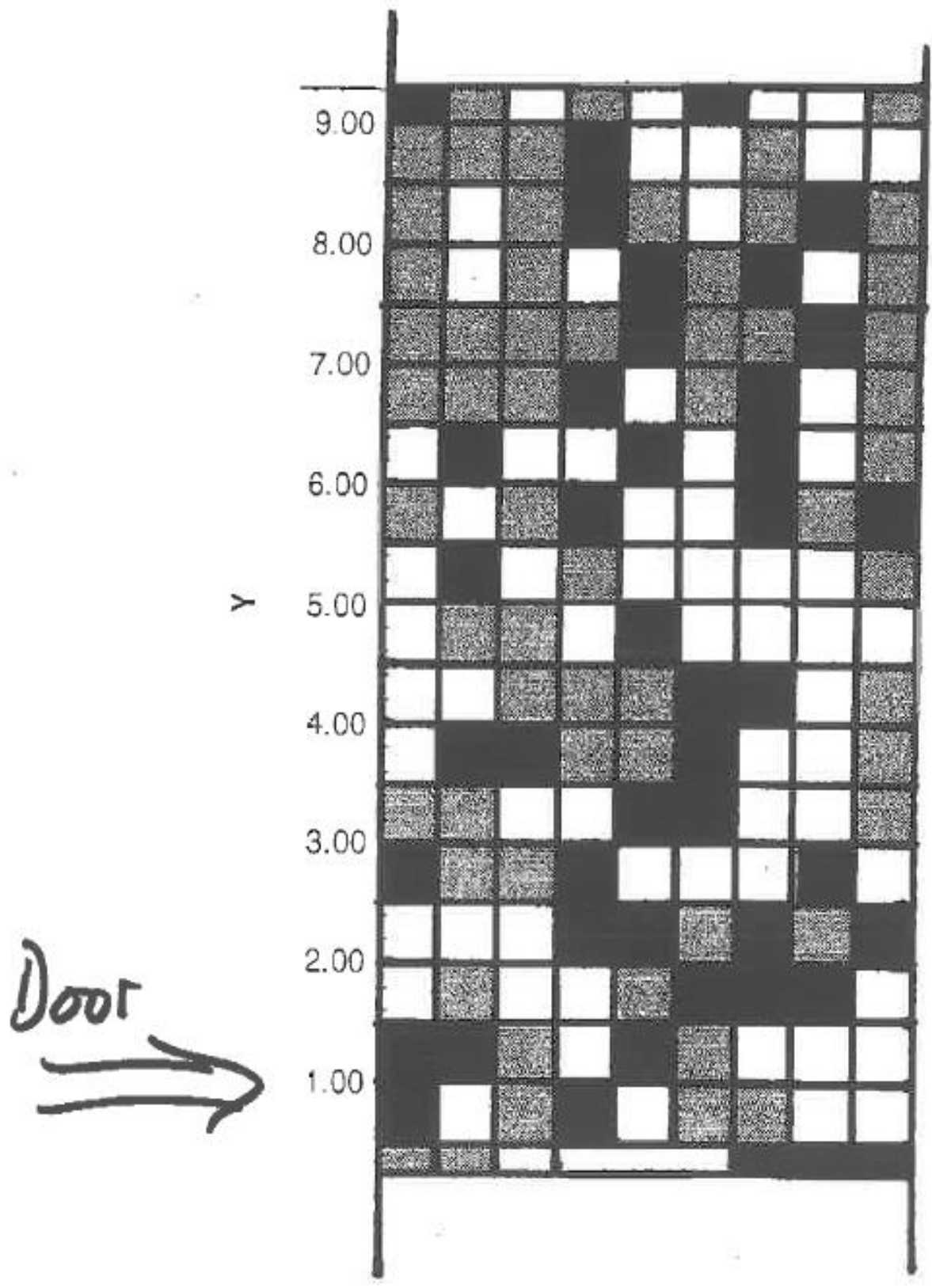




\section{Layer 6}

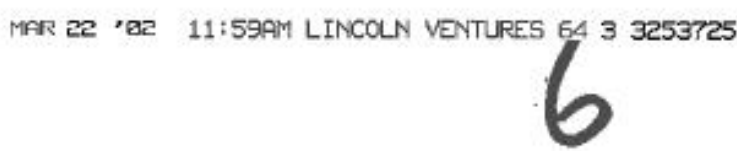

P. $7 / 18$

(12)

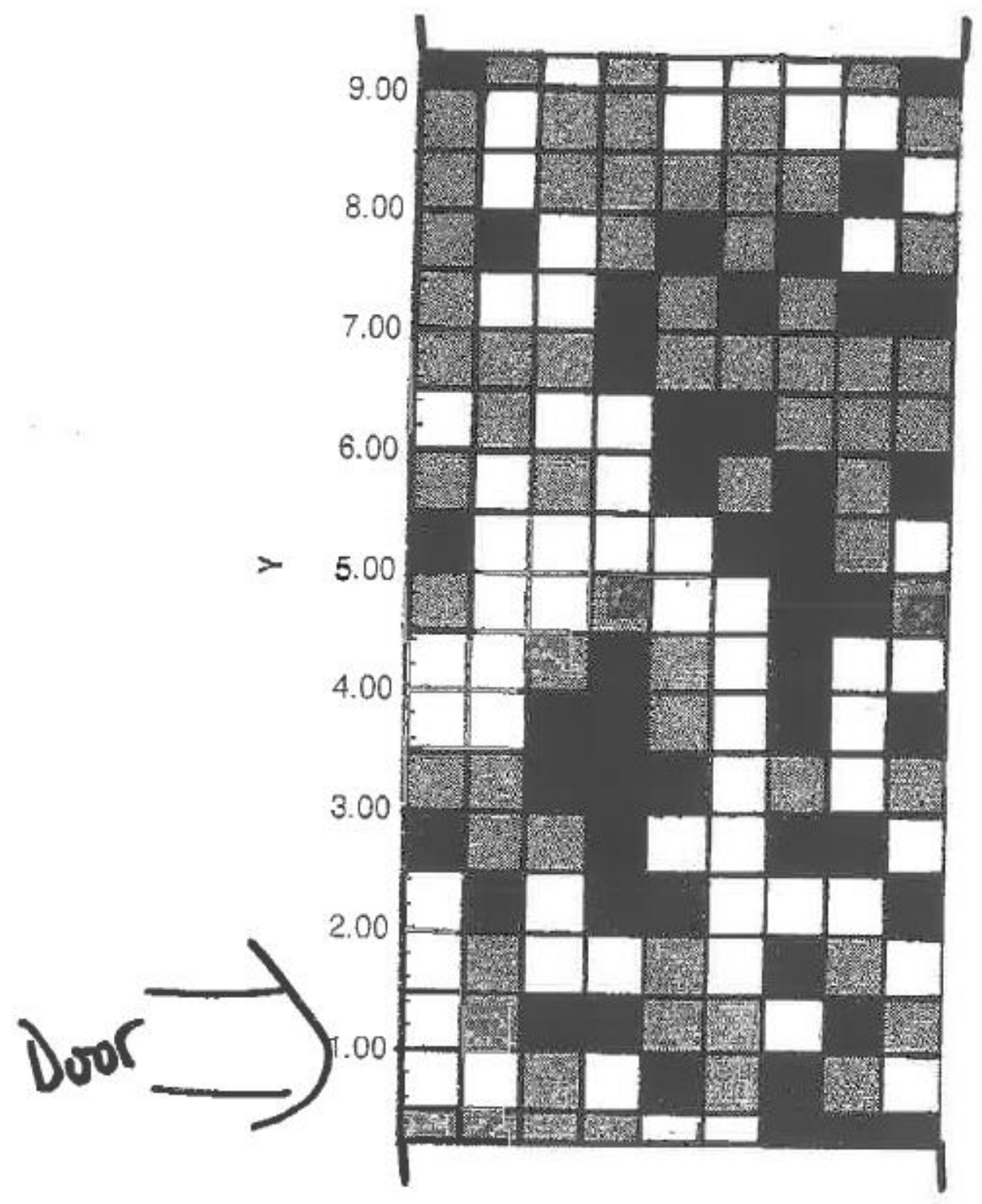




\section{Layer 7}

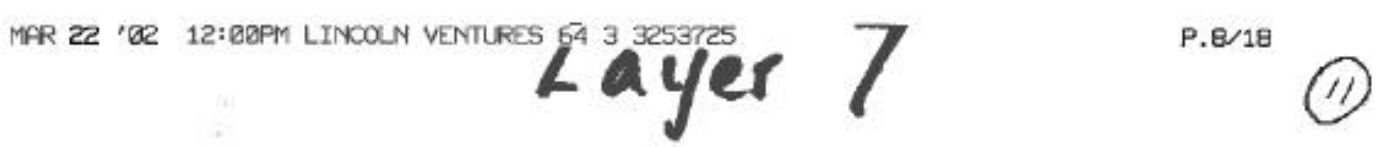

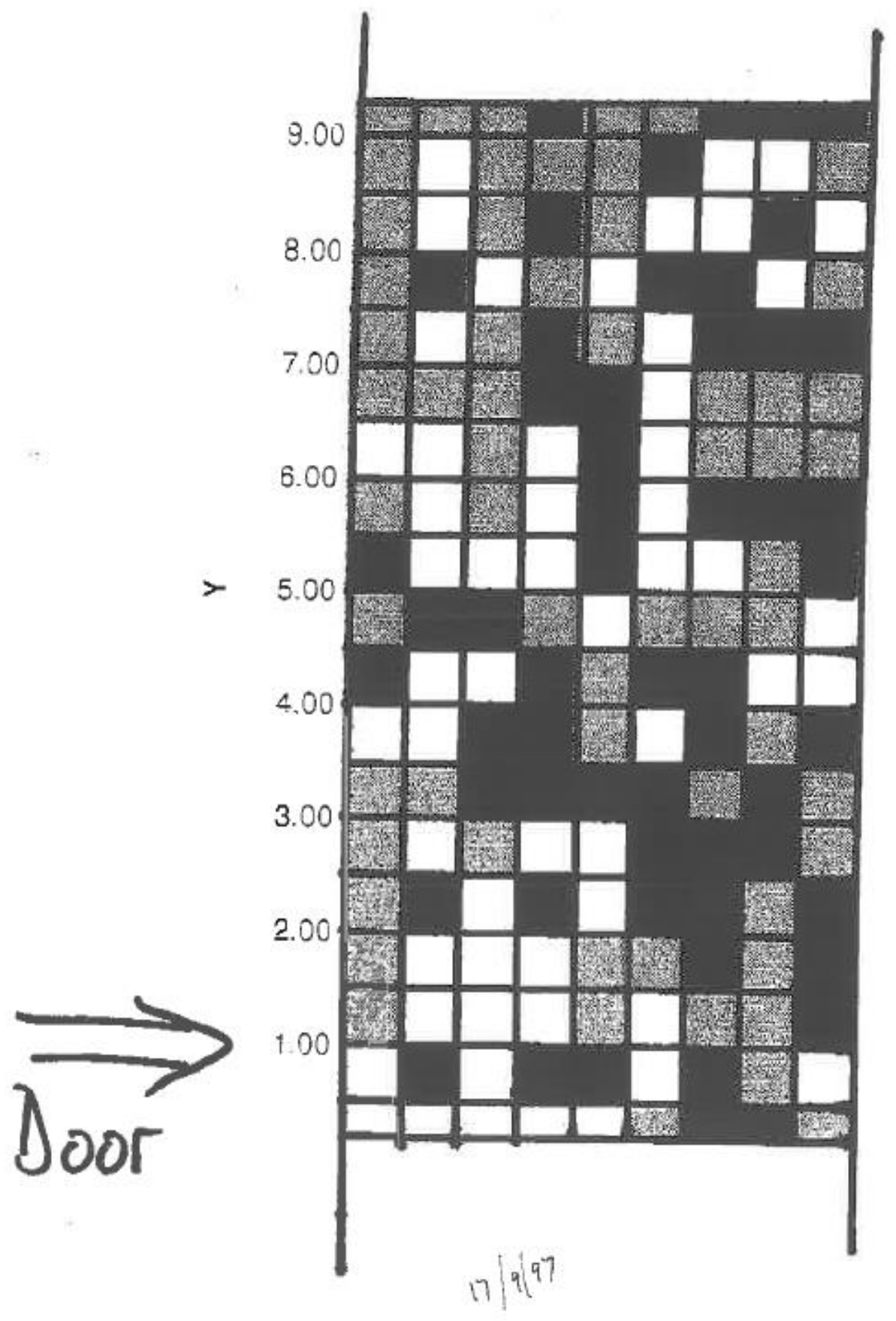




\section{Layer 8}

MAR 22 'B2 12:D1PM LINCOLN VENTLRES 6433253725

Level 8

P.9/18

(10)

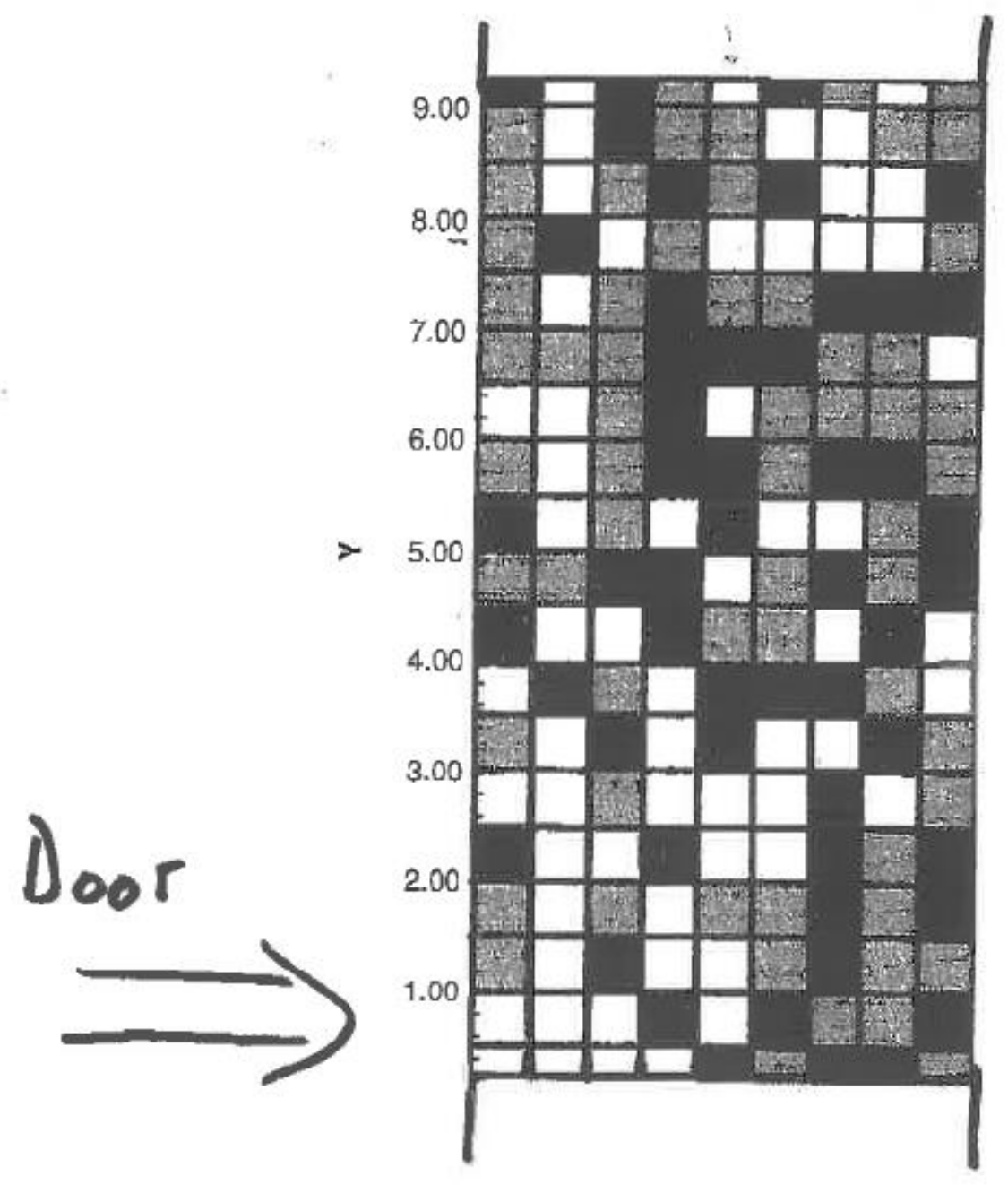




\section{Layer 9}

MAR 22 'D2 12: D1PM LINCOLN VENTLEES 64 3 3253725

P. $10 / 18$

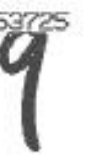

(9)

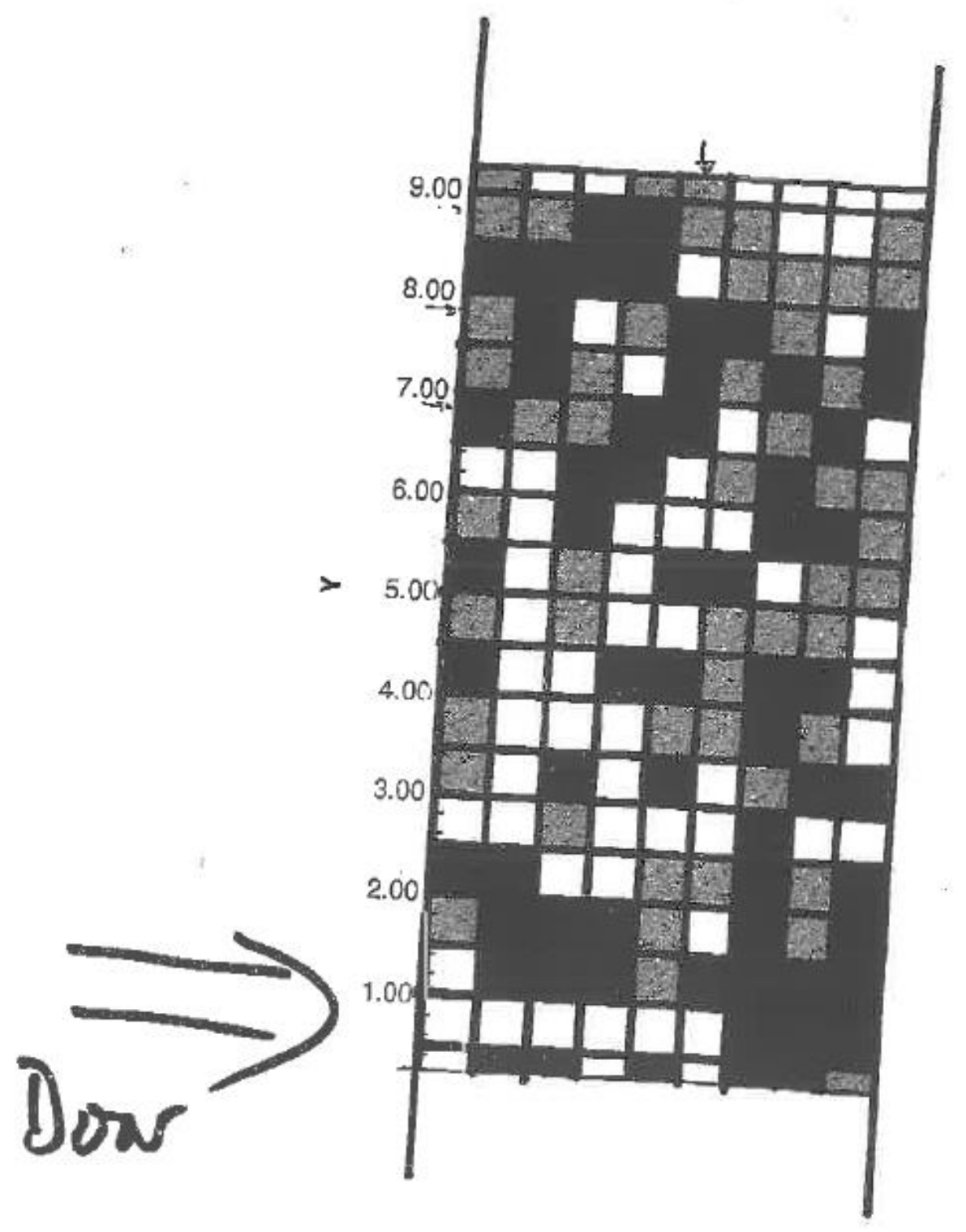




\section{Layer 10}

MAR 22 'BR 12:BPPM LINCOLN VENTURES 6433253725

P. 11/18

\section{0}

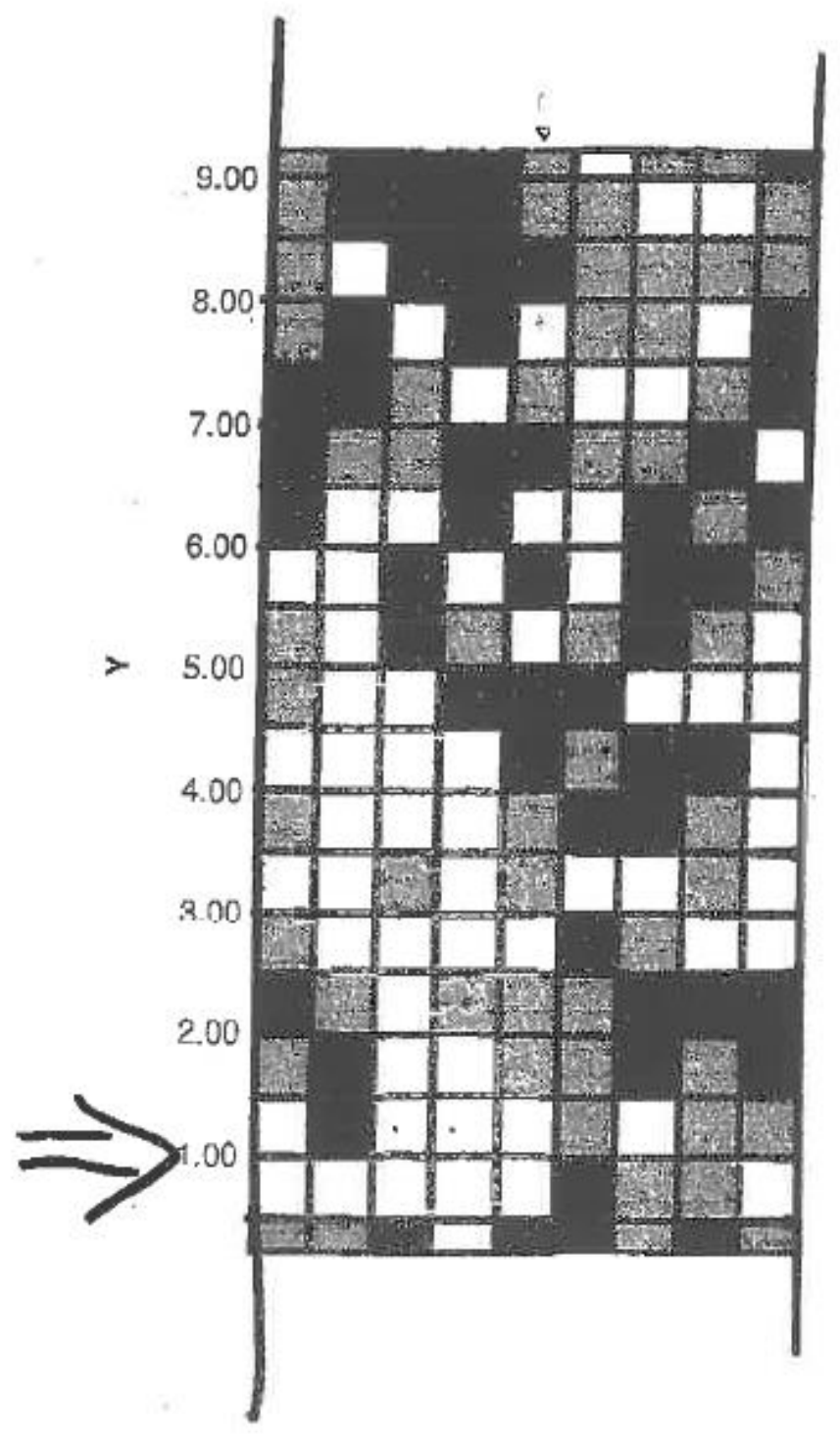




\section{Layer 11}
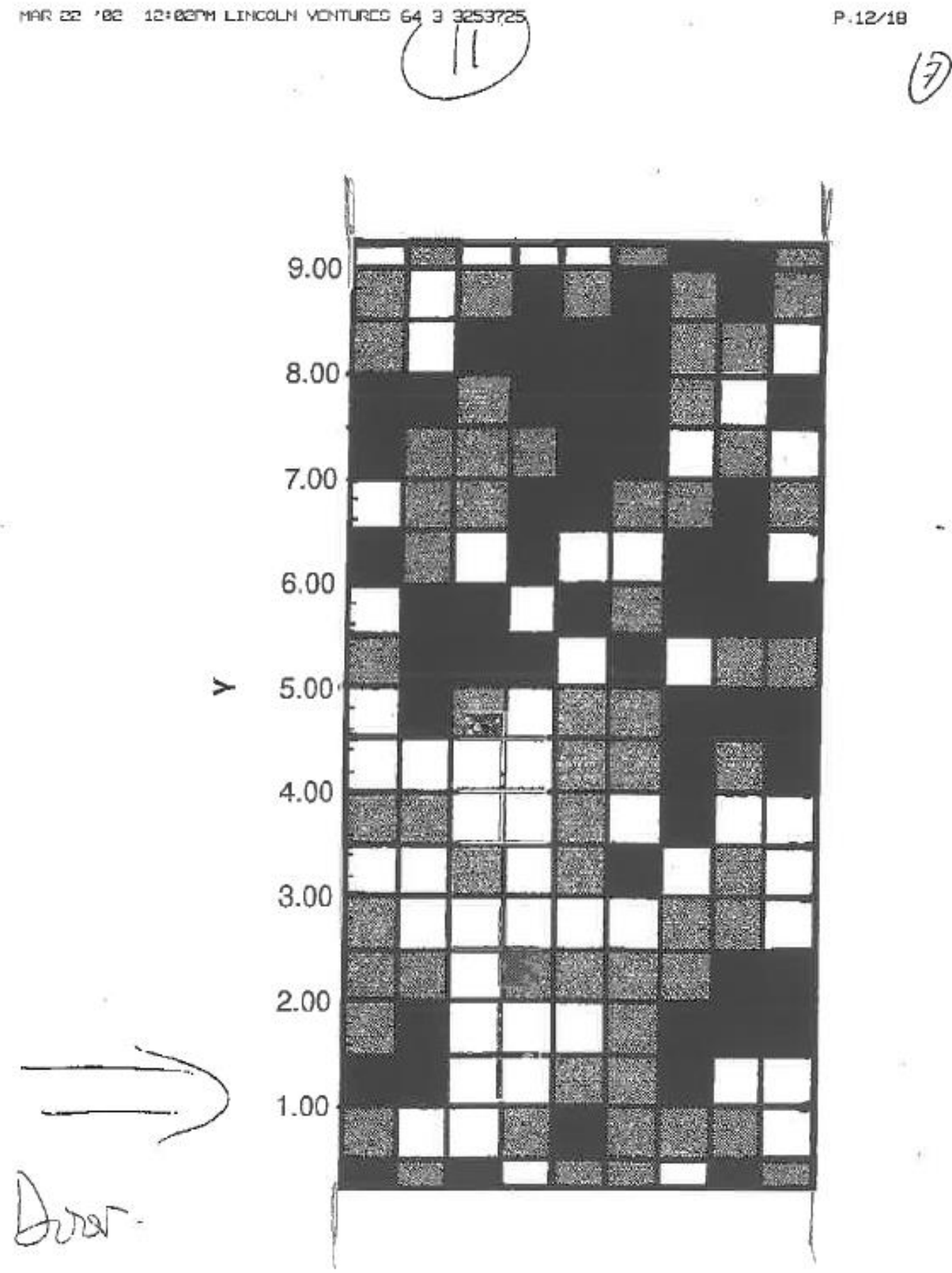


\section{Layer 12}

MAR 22 'BE 12: BOPM LIMCOLN VENTURES G4 3 3253T2S

P. $13 / 18$

\section{2}

(6)

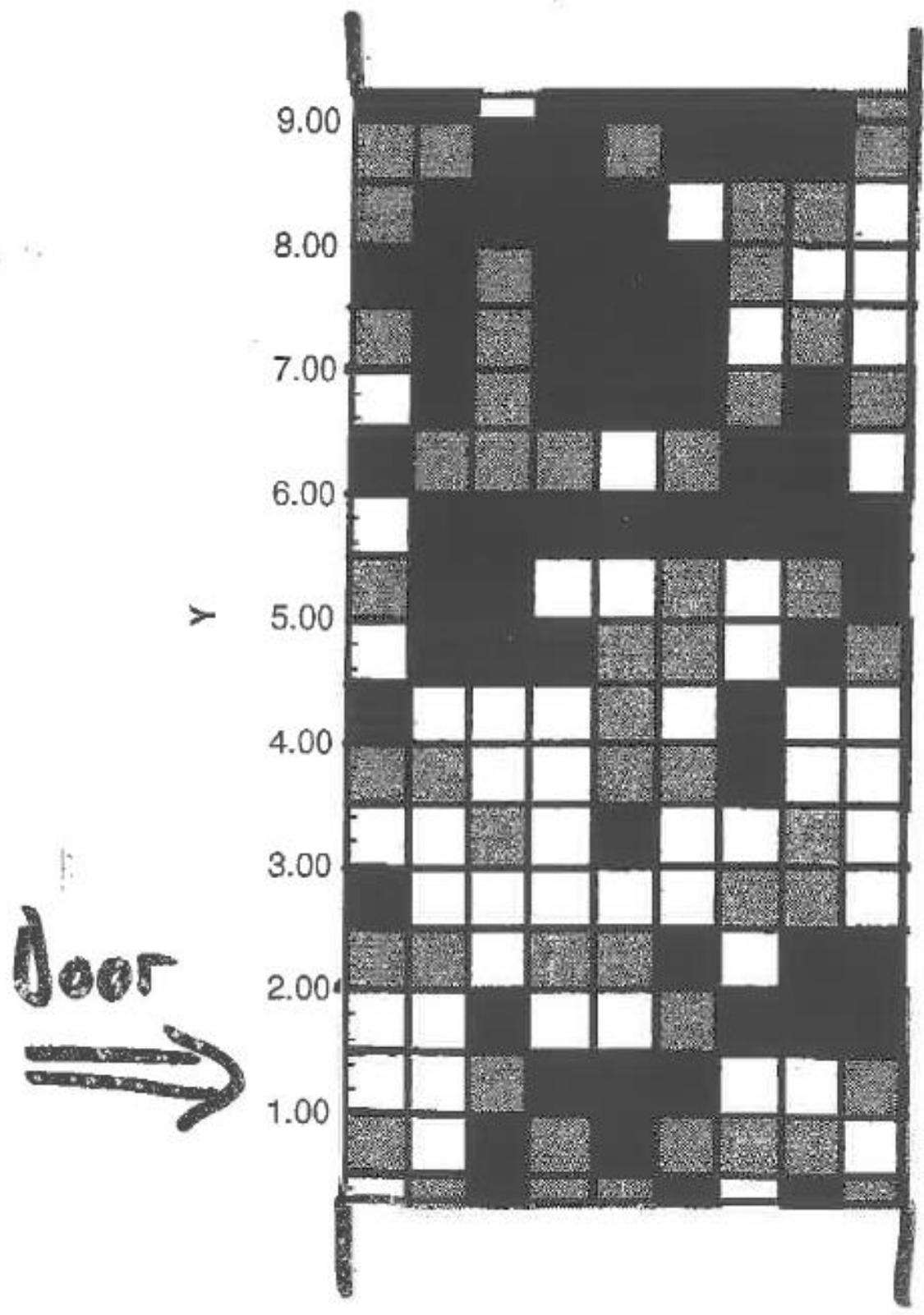




\section{Layer 13}

MAR ae 'Ge 12:BAPM LINCOLN VENTURES G4 3 SESTIES

P. $14 / 18$

B

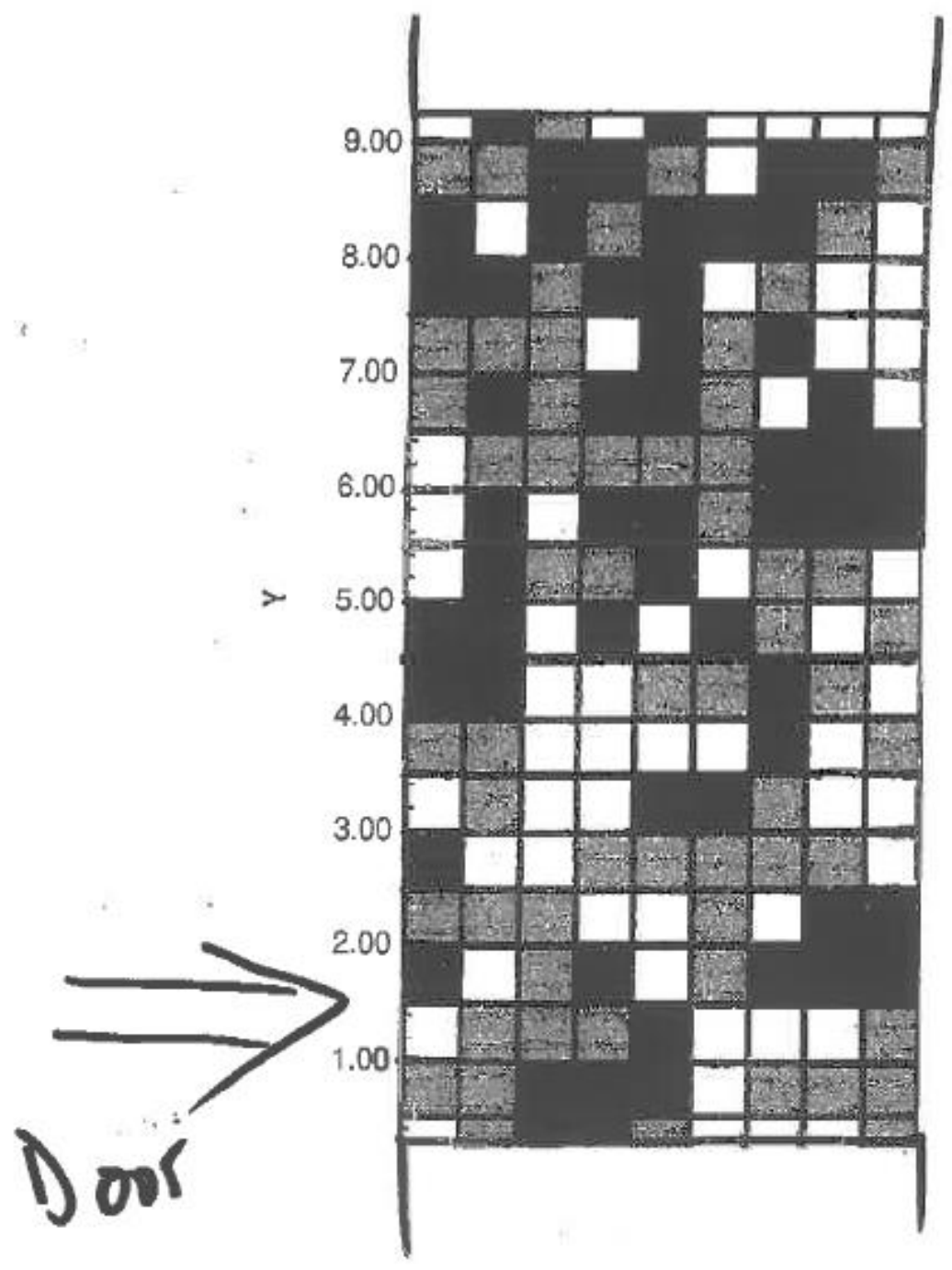




\section{Layer 14}

MAR 22 'B2 12:04PM LINCOLN VENTURES 6433253725

P. 15/1日

14

(4)

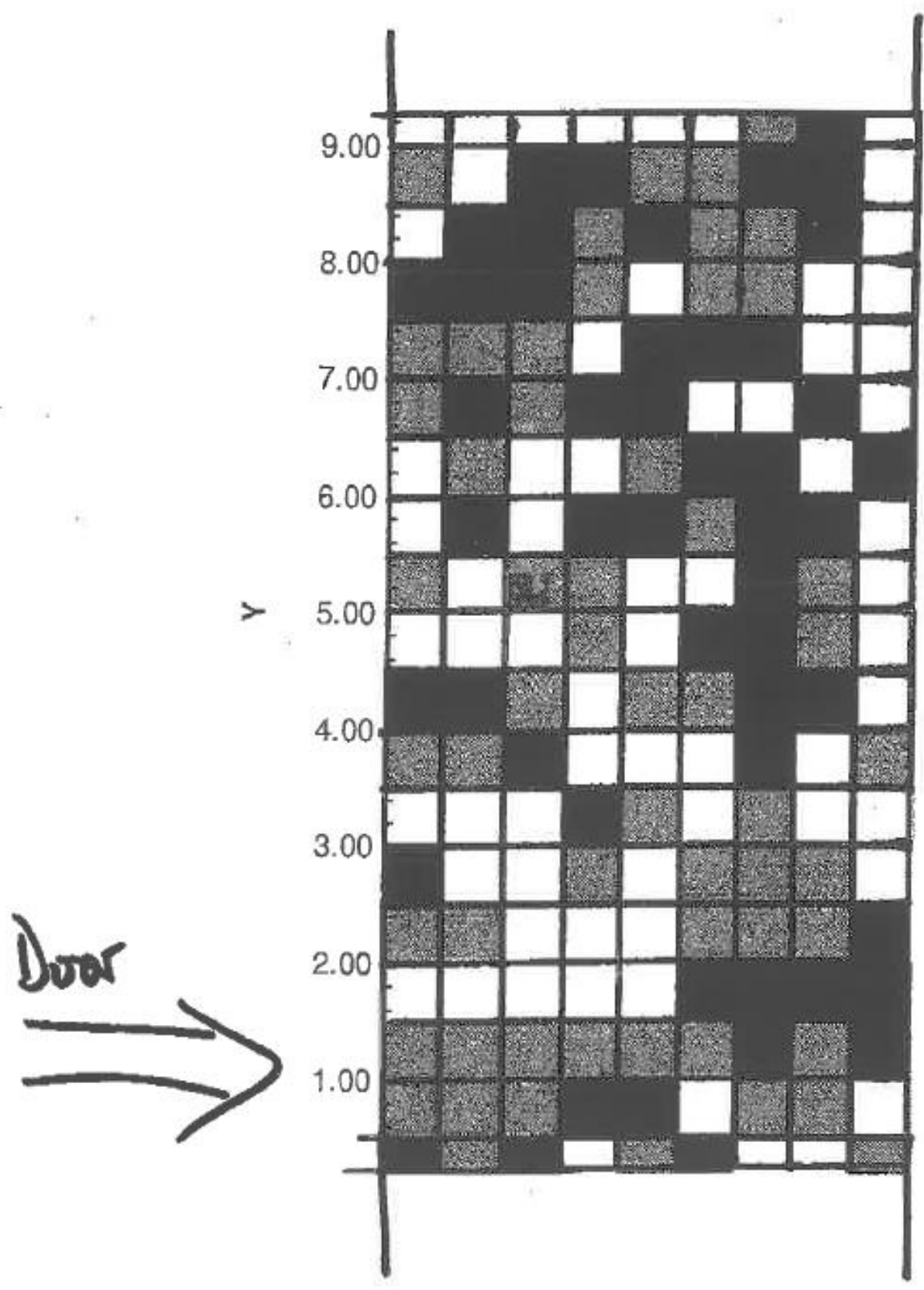




\section{Layer 15}

MAR 22 '62 12: G5PM LIMCOLN VENTURES 643 3253725 15

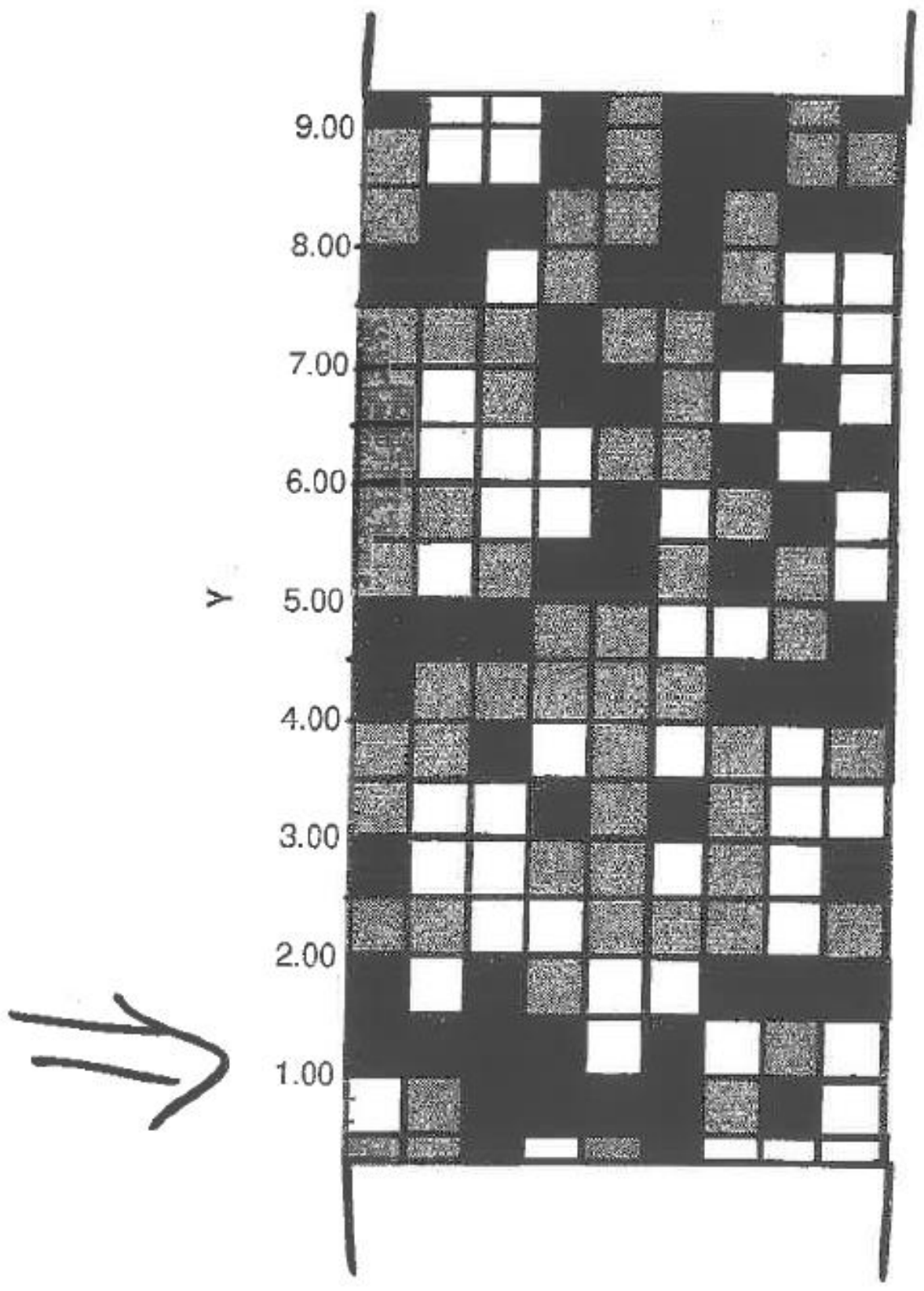




\section{Layer 16}

MAR 22 'Q2 12: ESPM LINCQLN VENTURES 6433253725 P.1778 -

16

Door

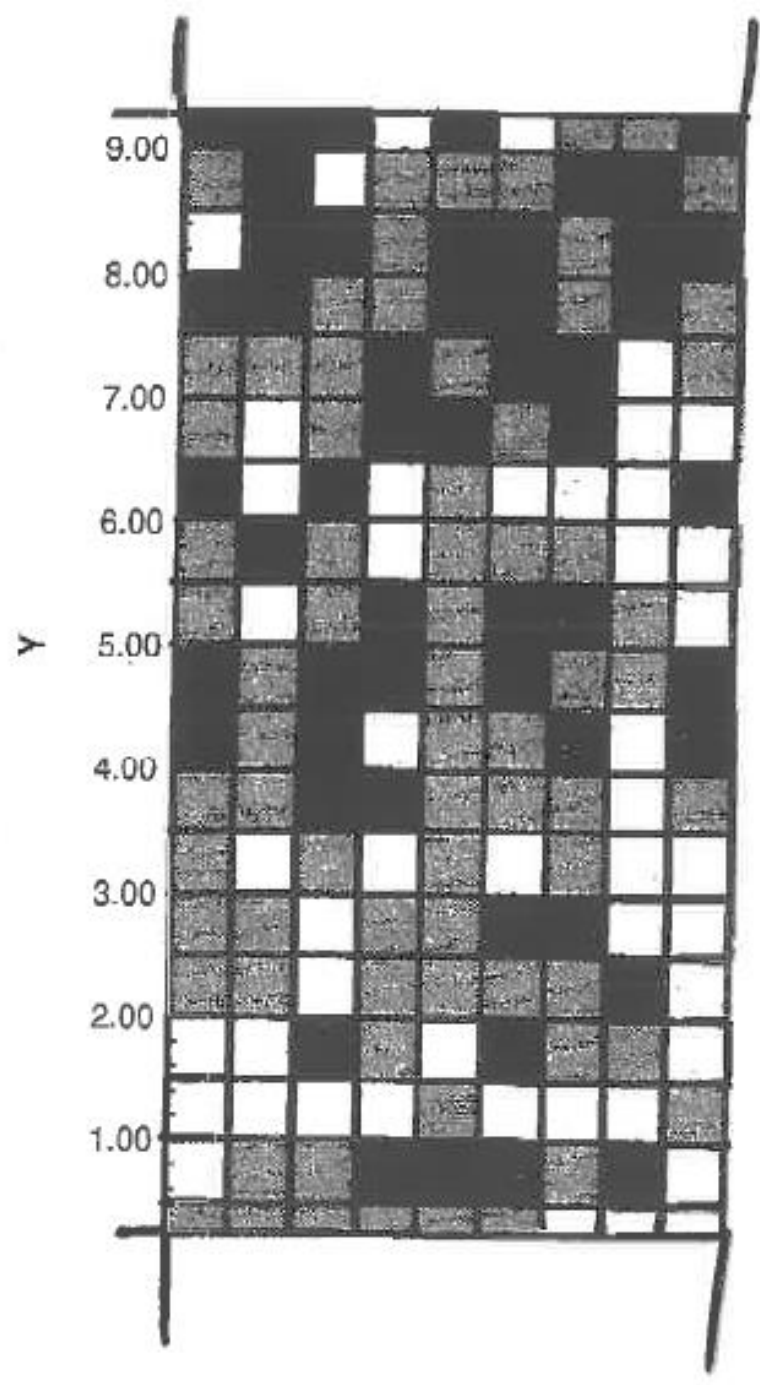




\section{Layer 17}

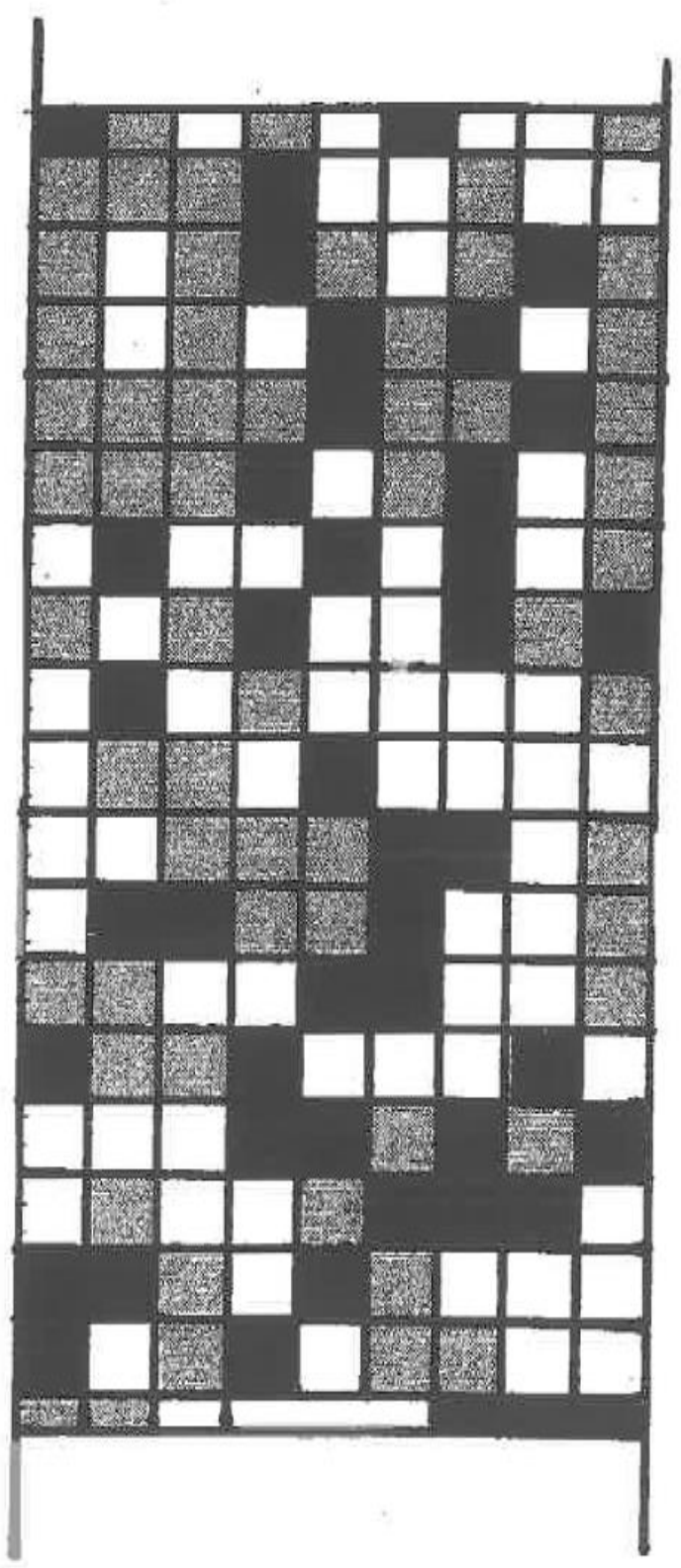




\section{Appendix B}

\section{D Analytical Modelling - Observed Versus \\ Modelled Results}



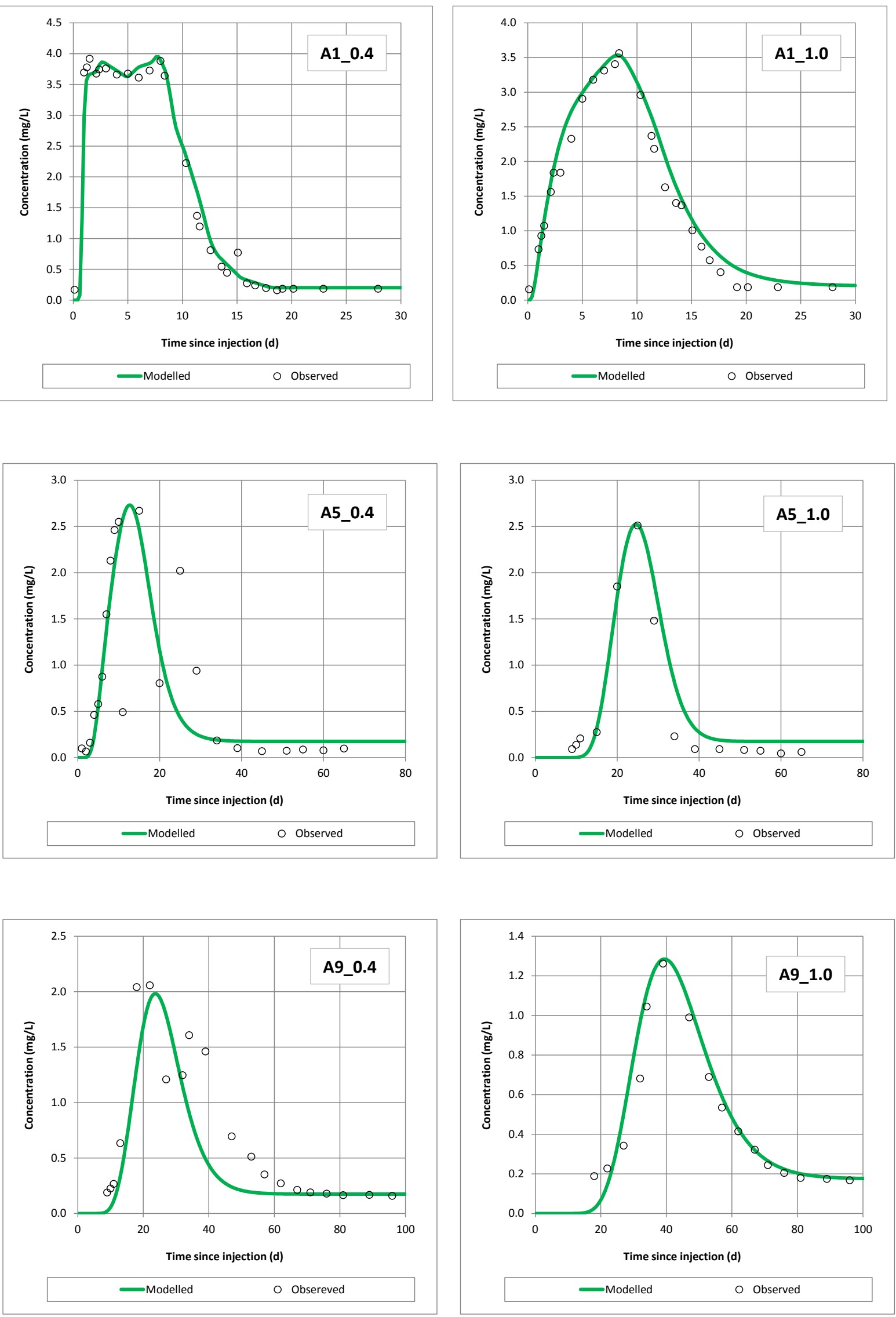

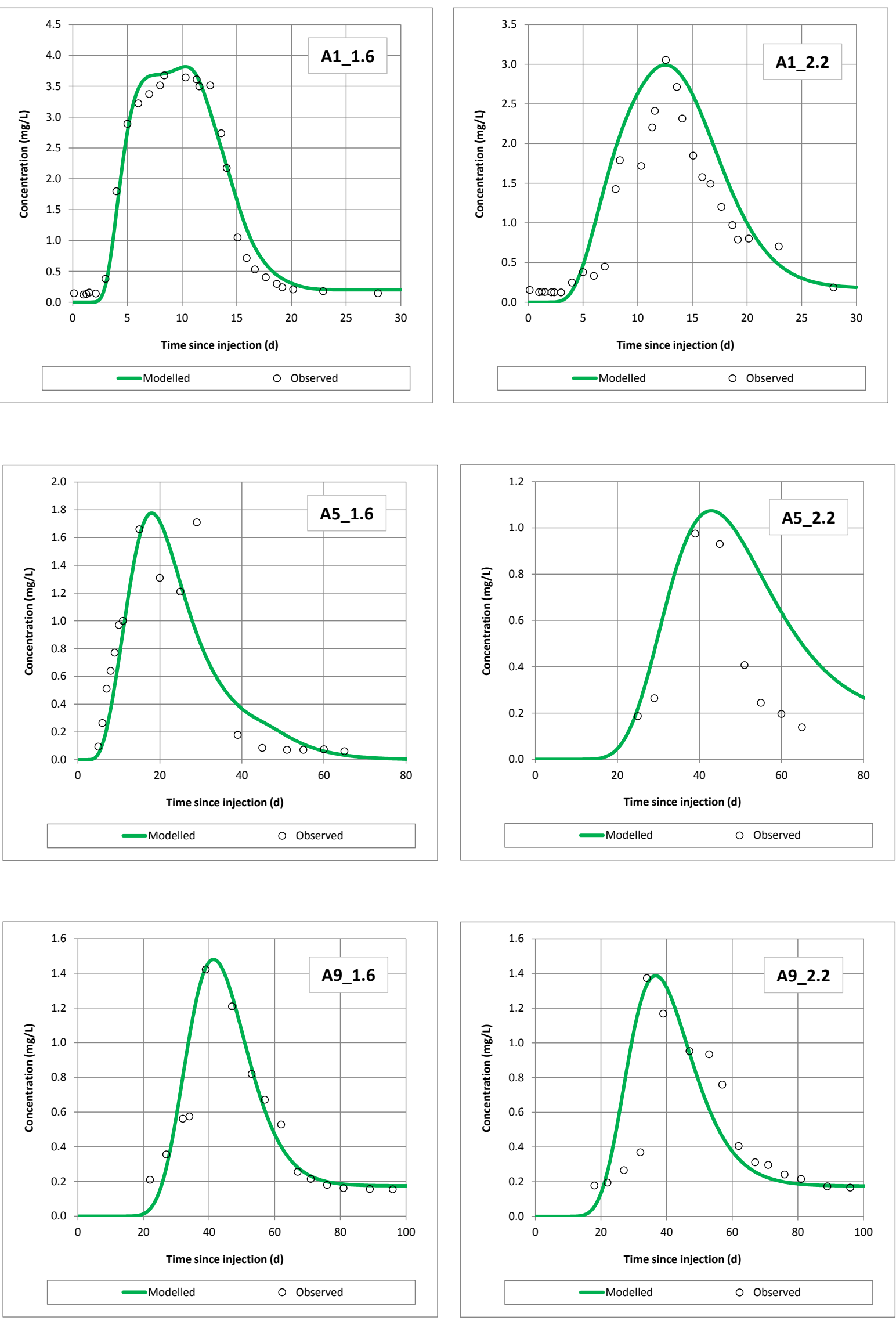

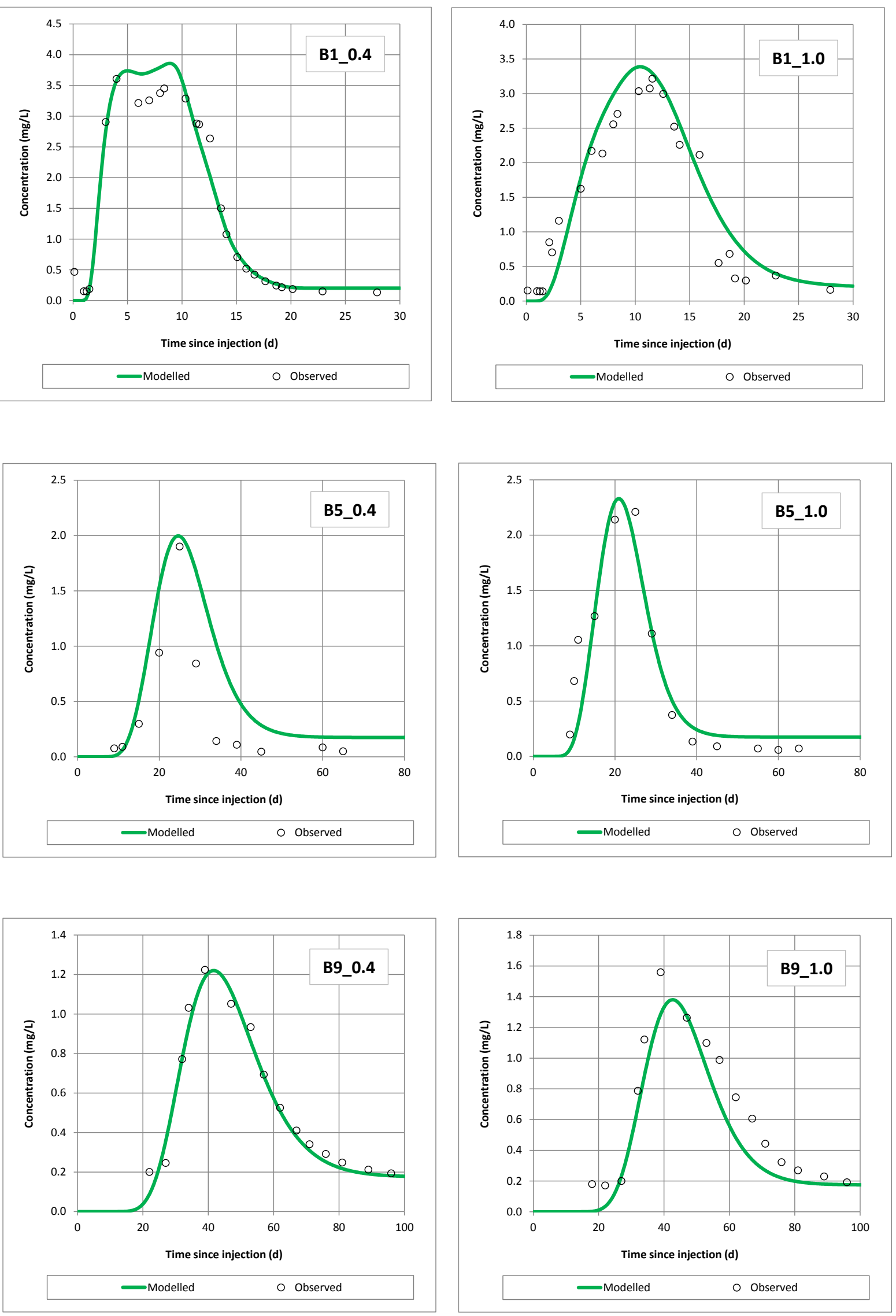

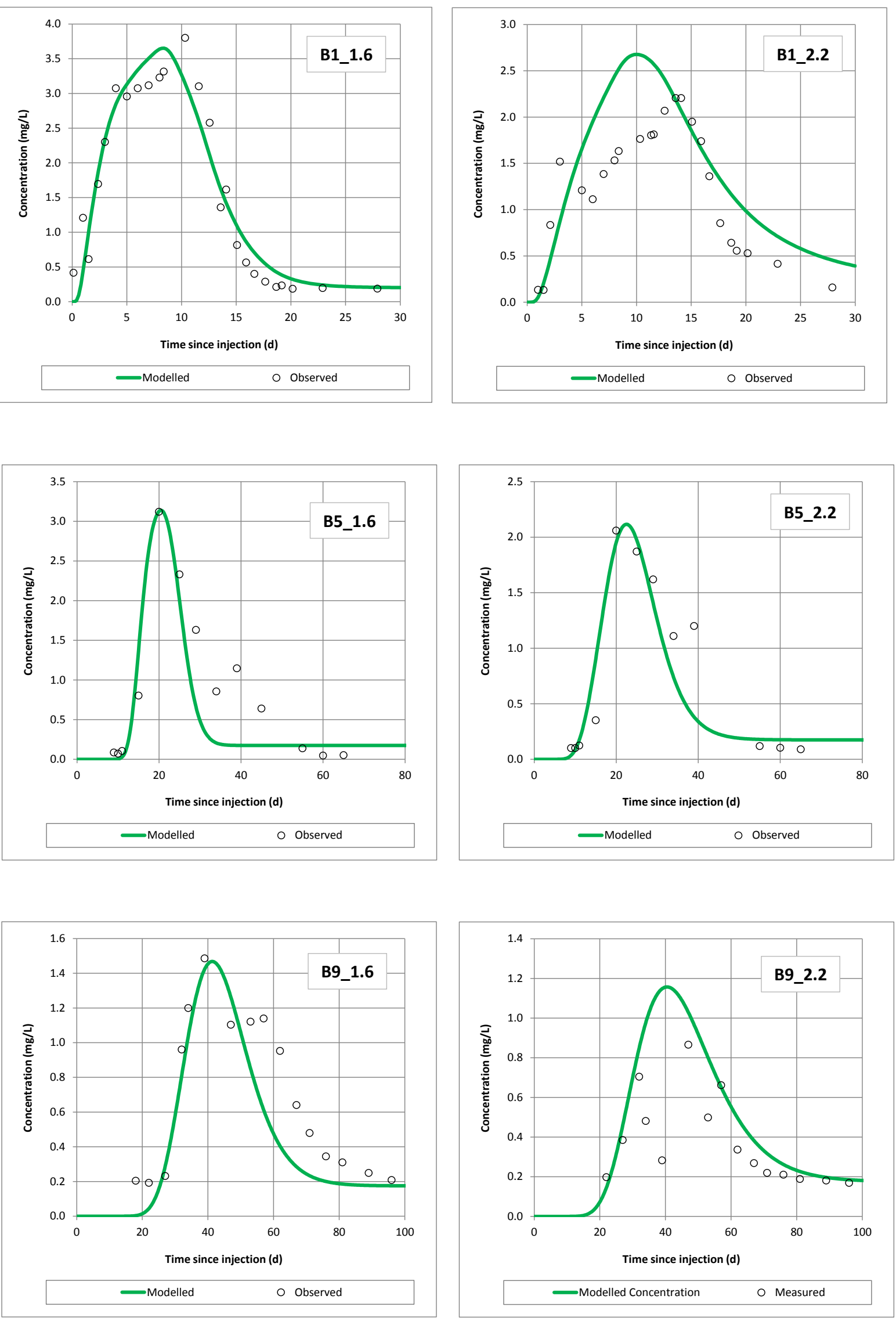

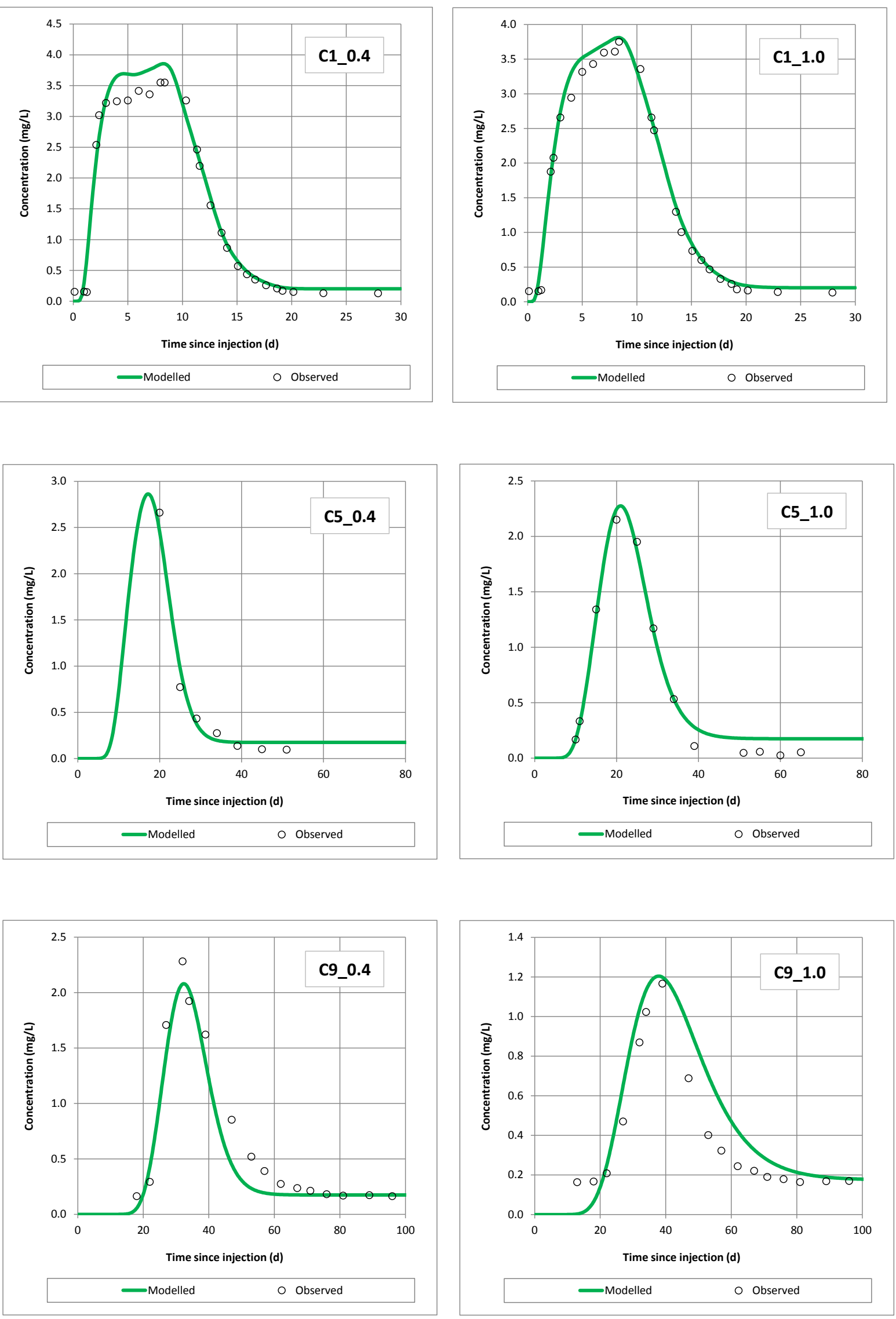

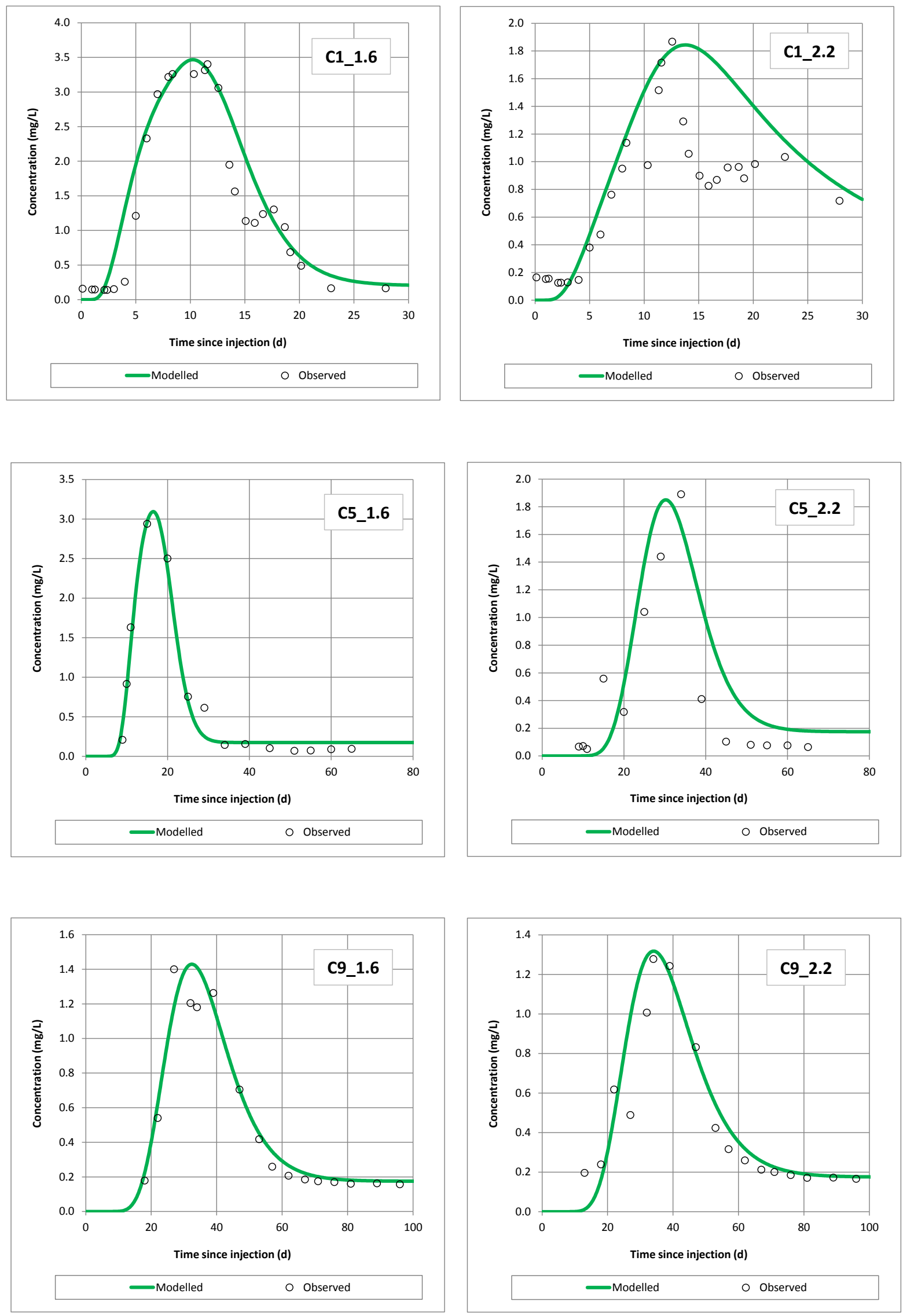

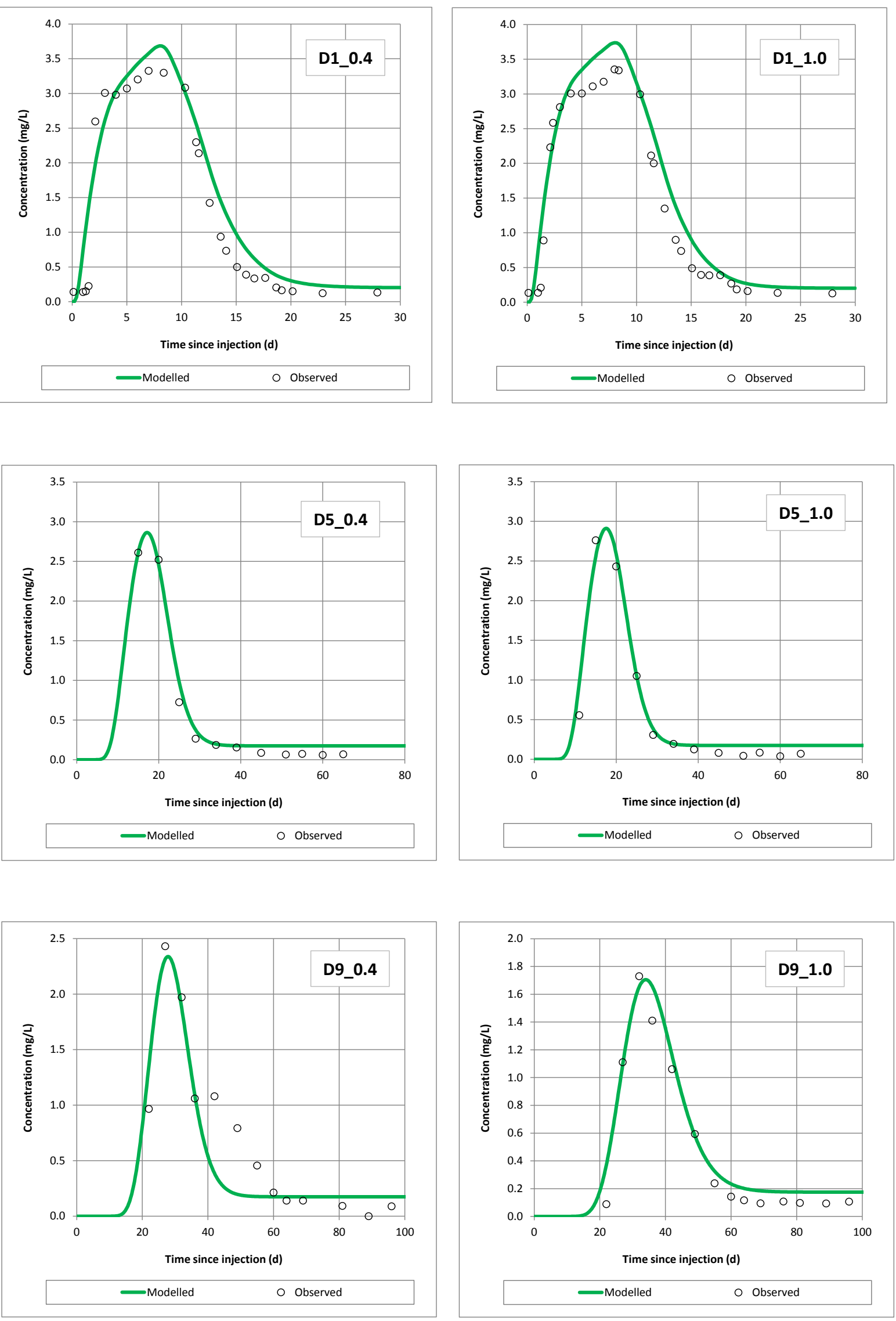

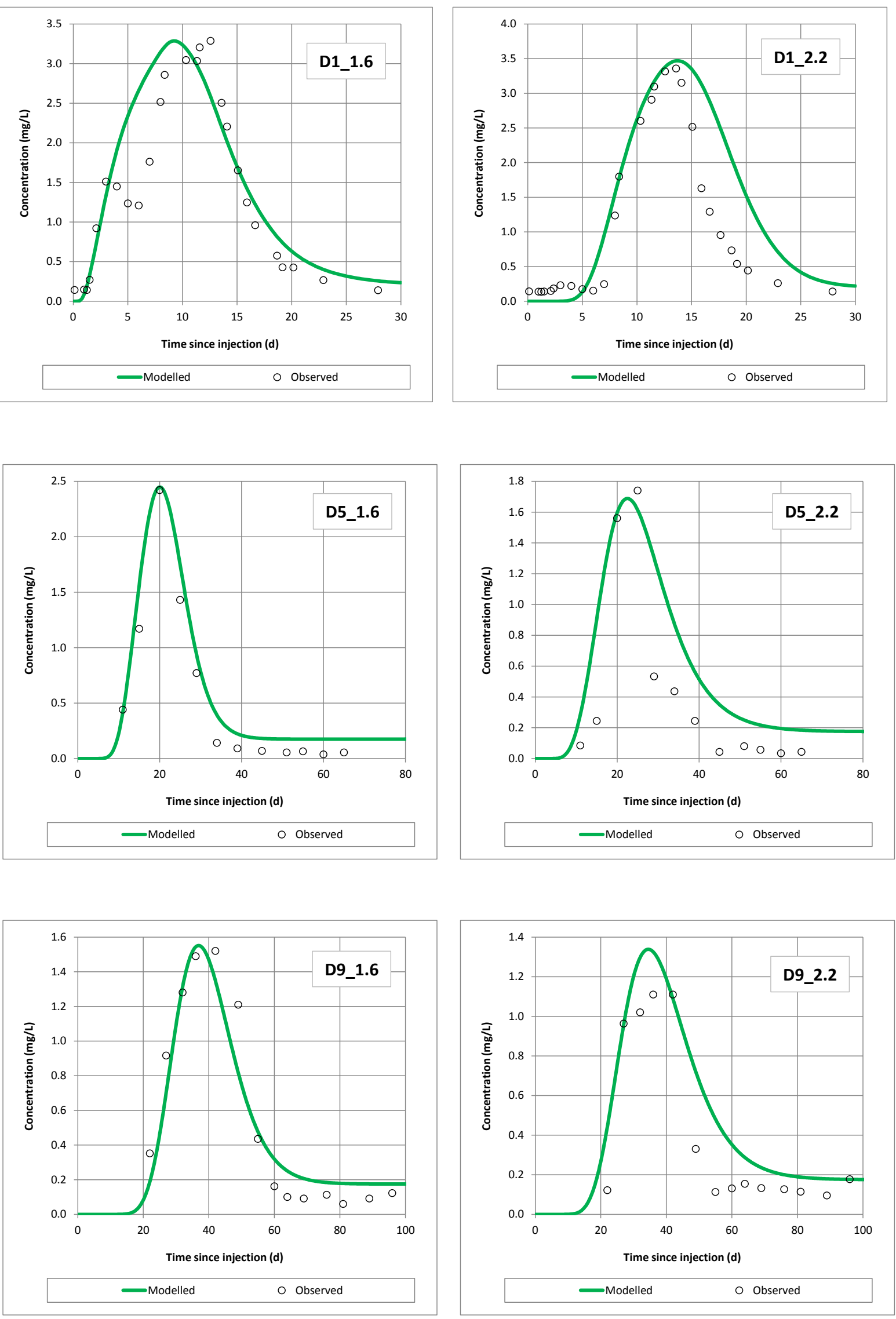

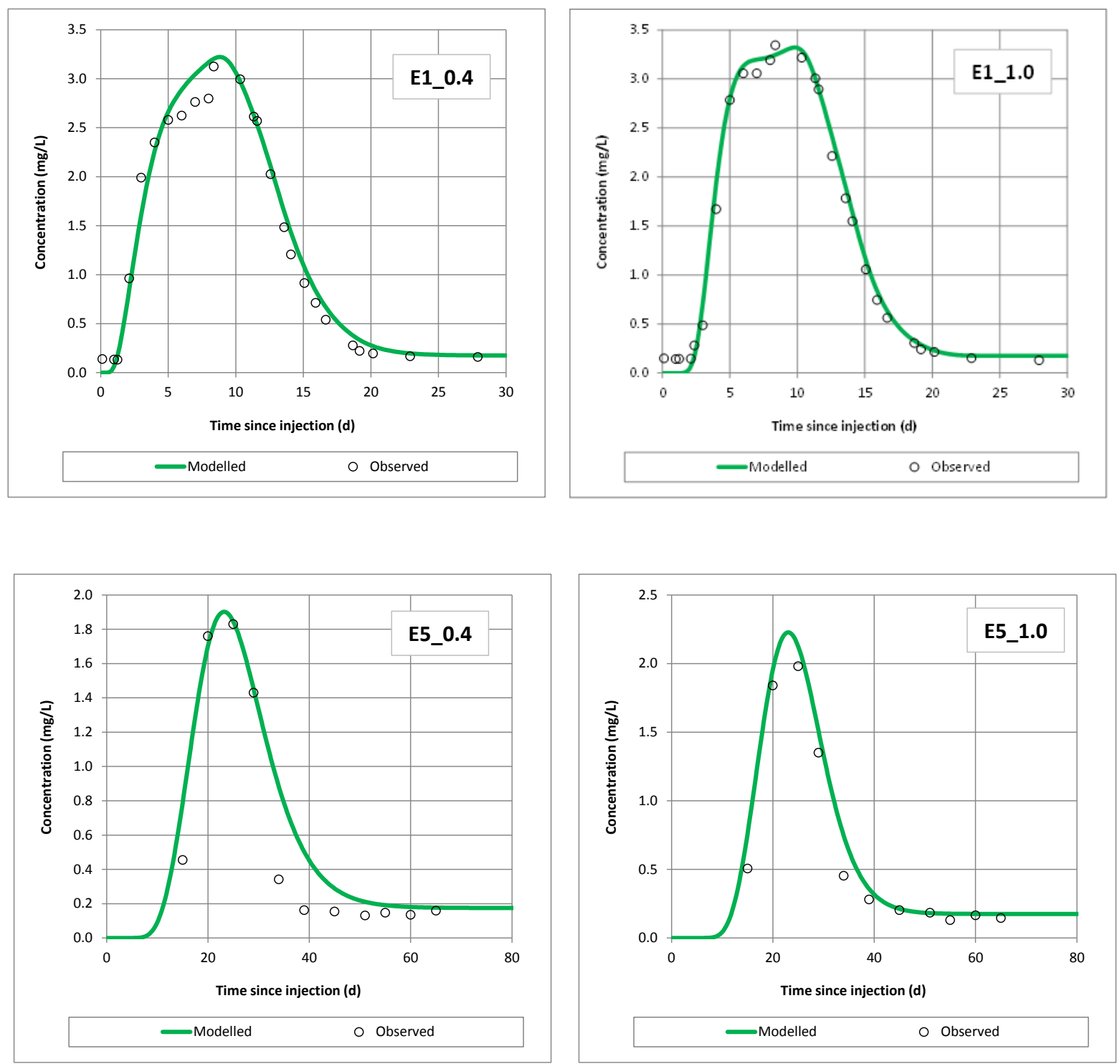

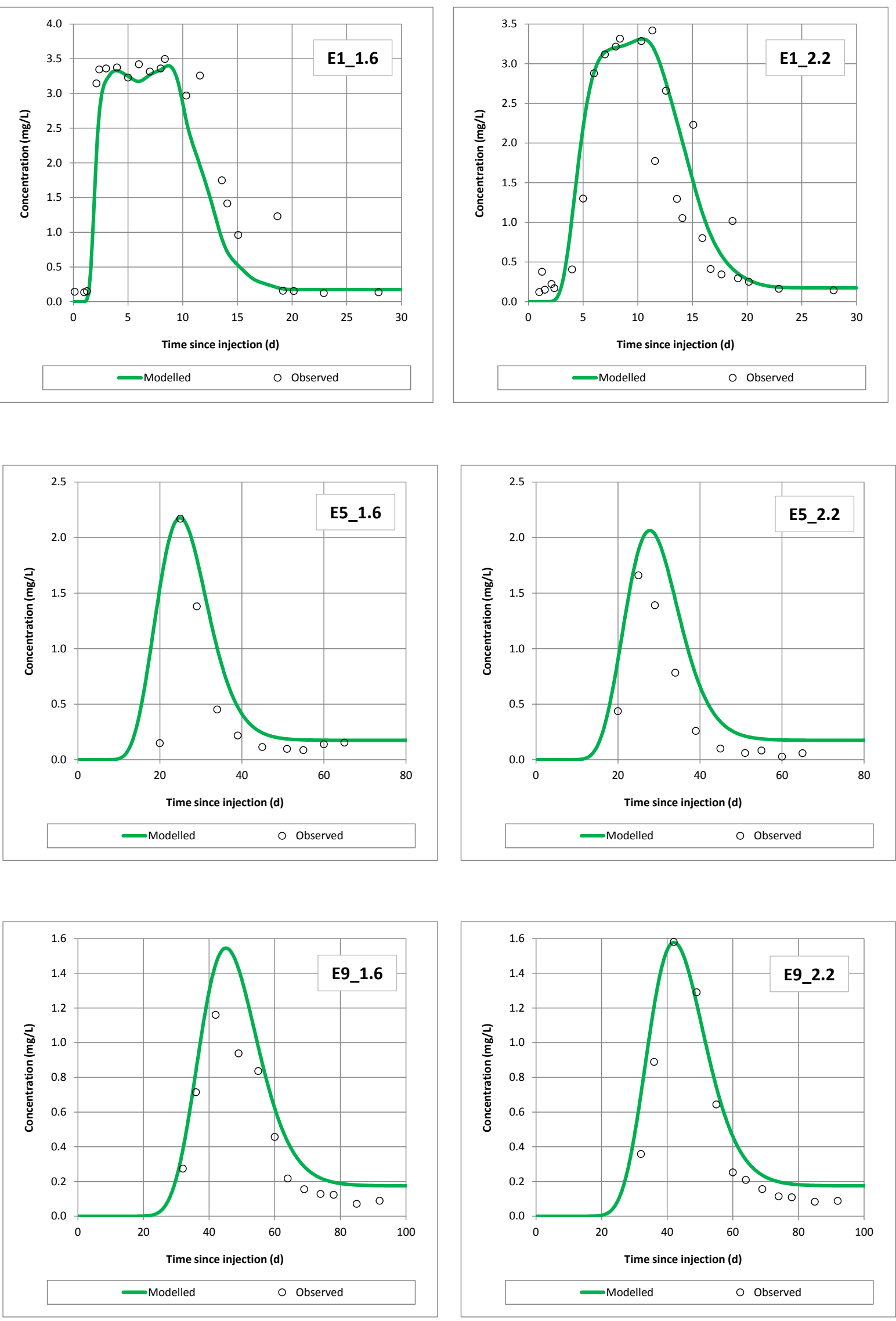

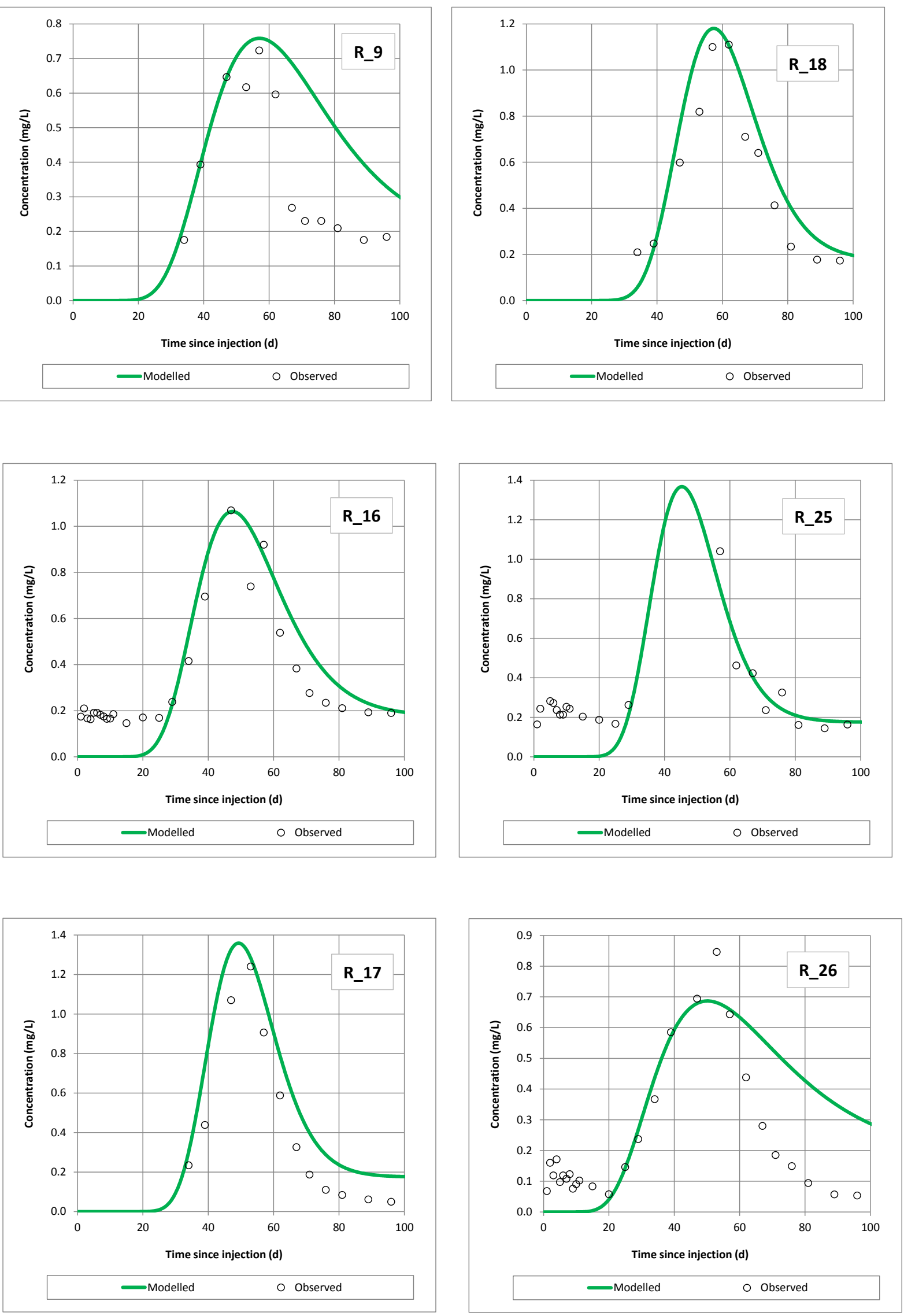

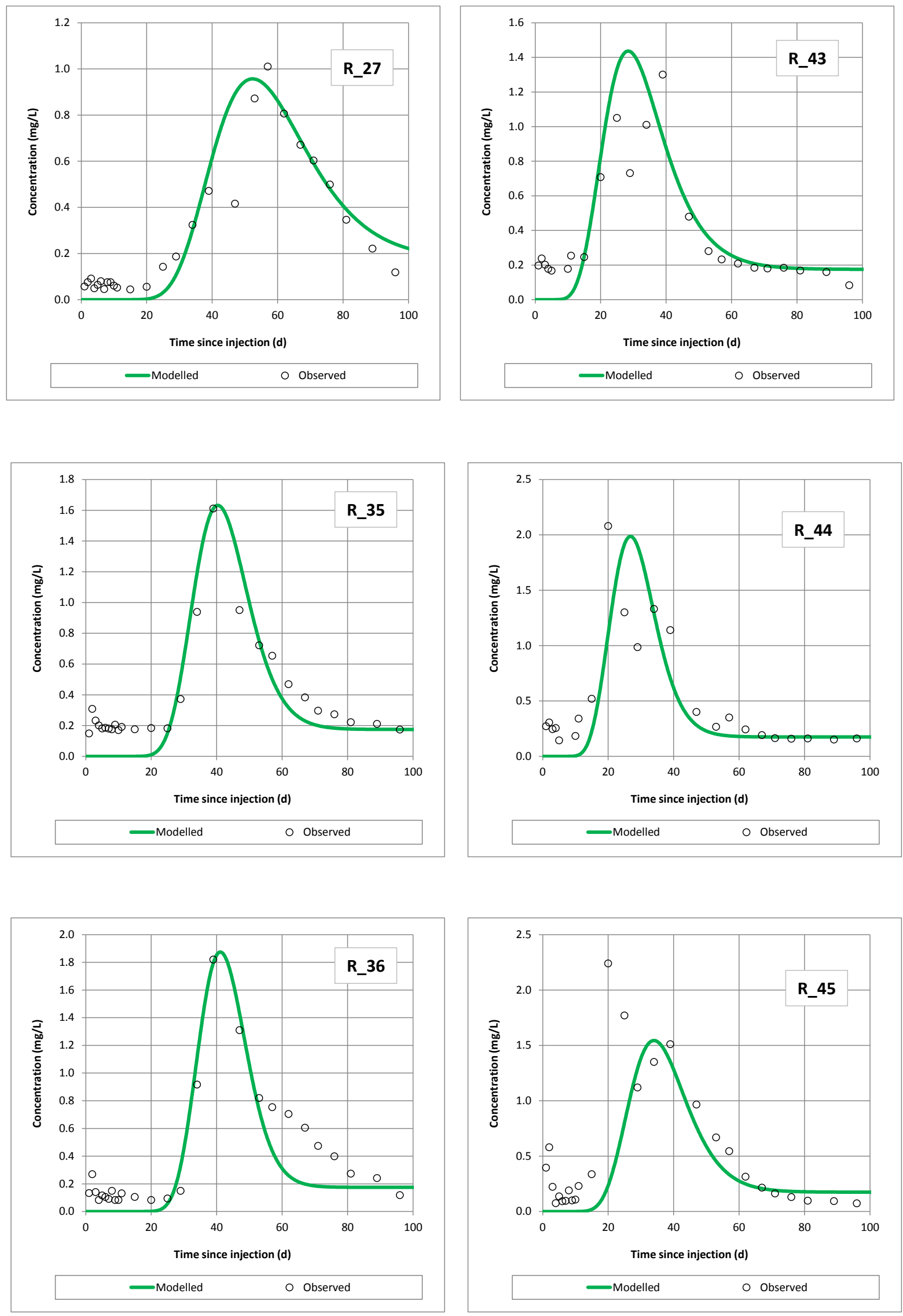

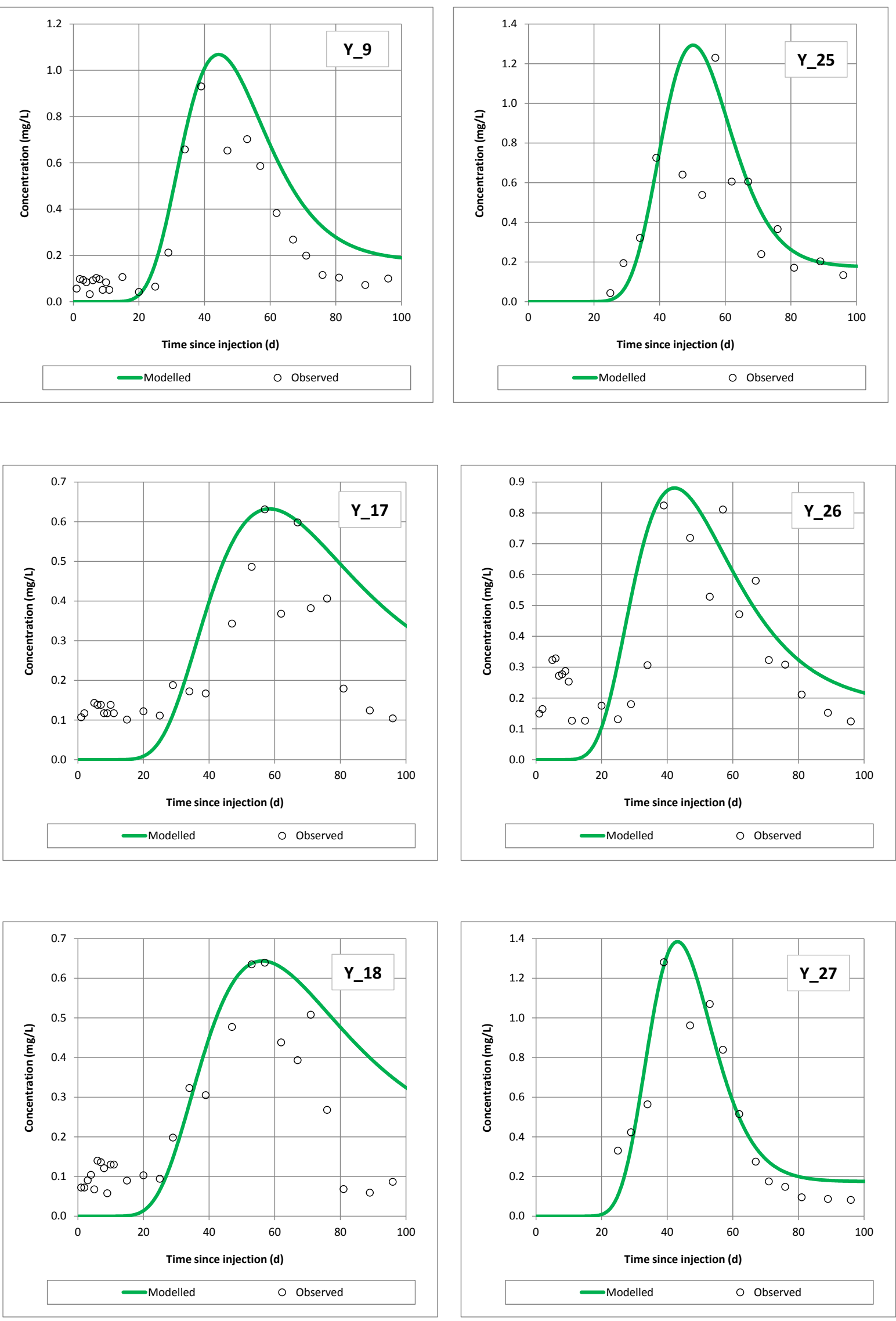

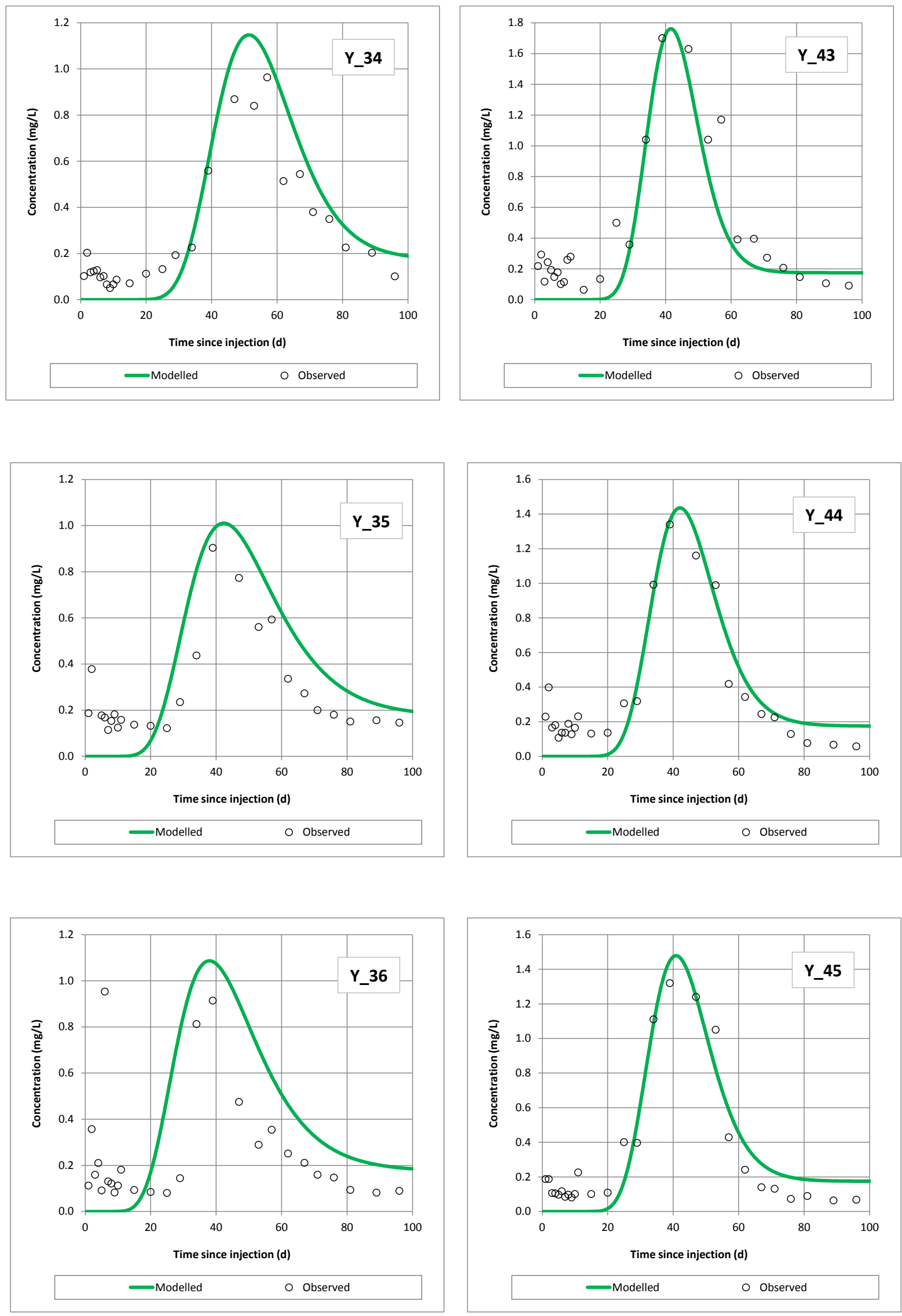

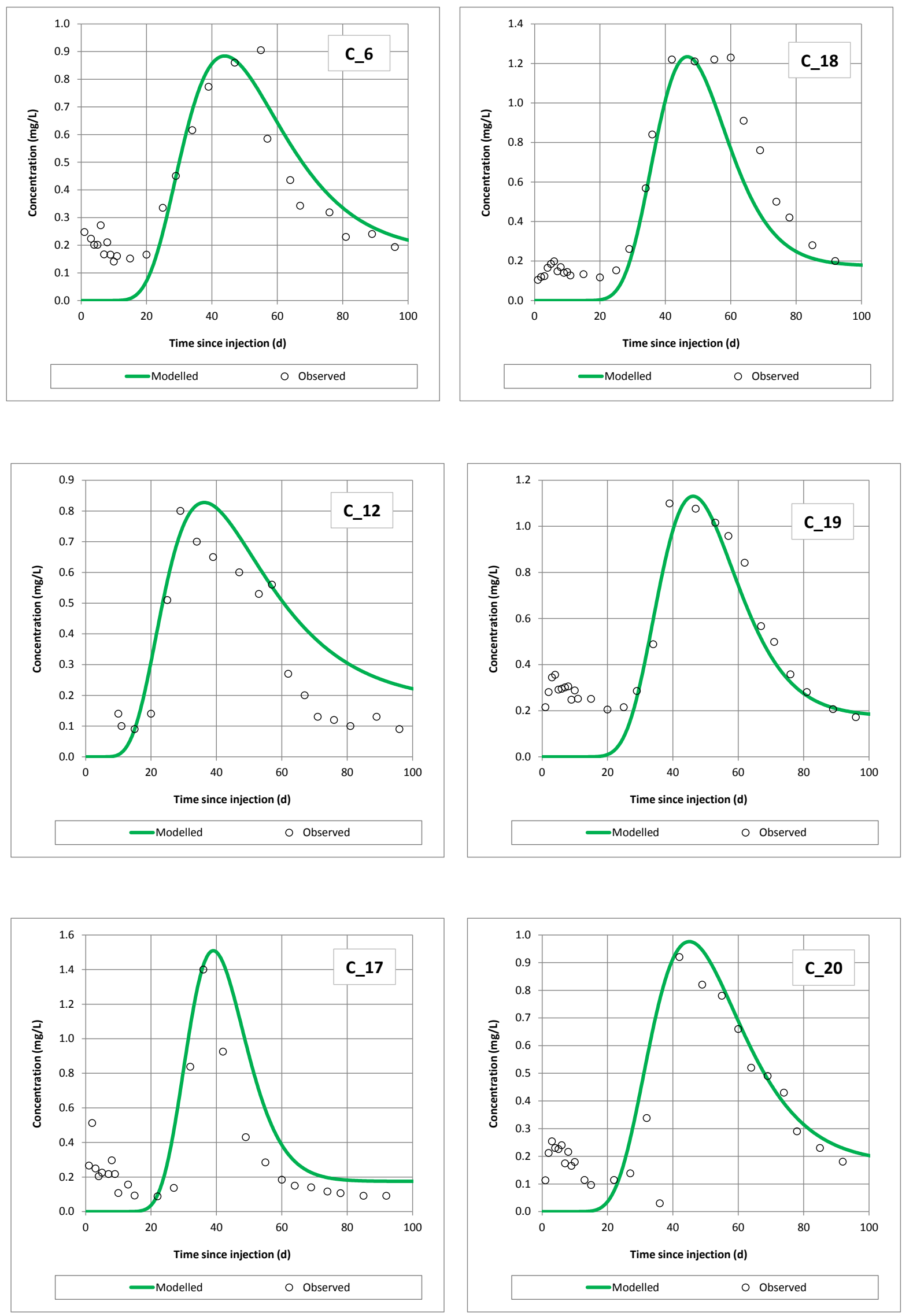

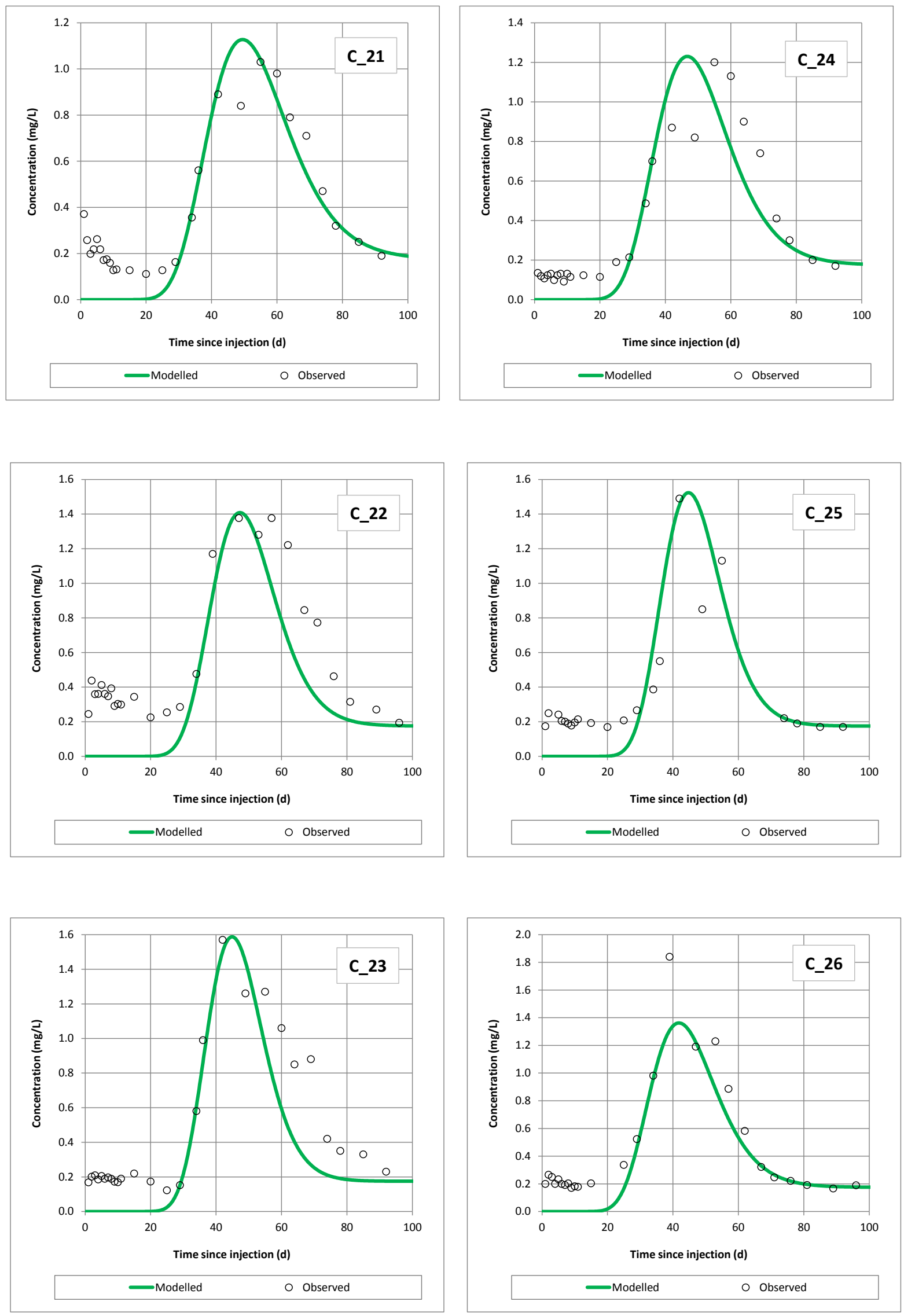

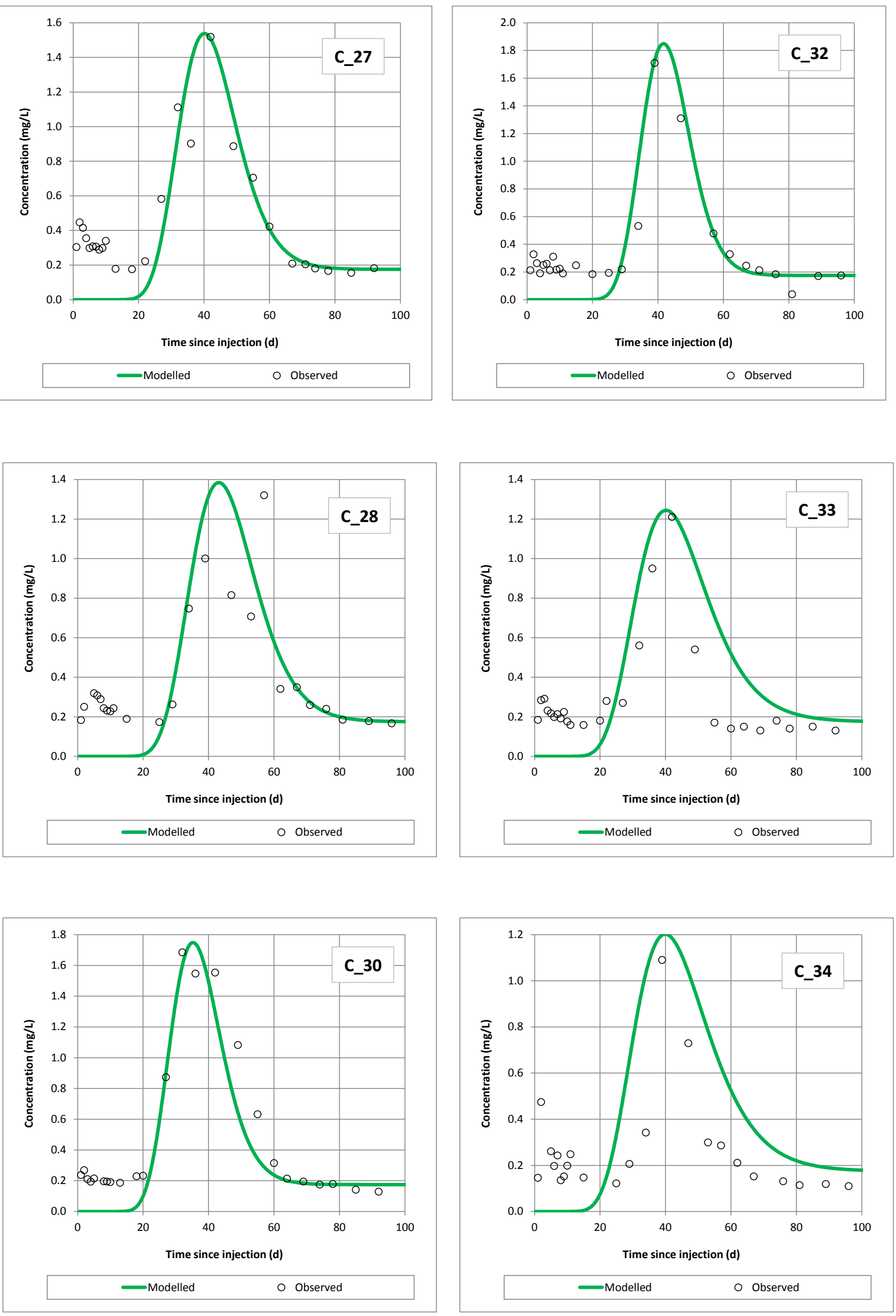

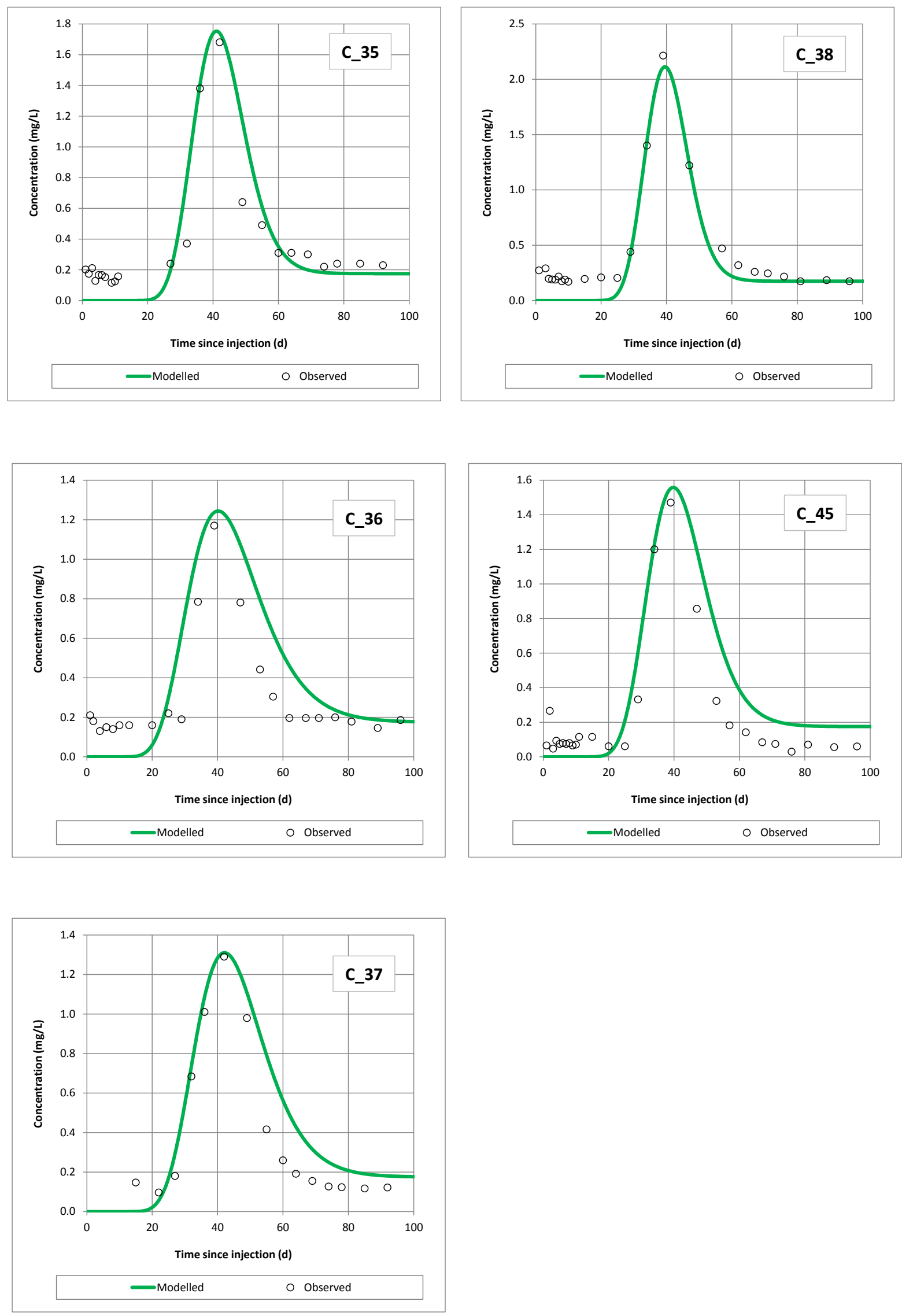

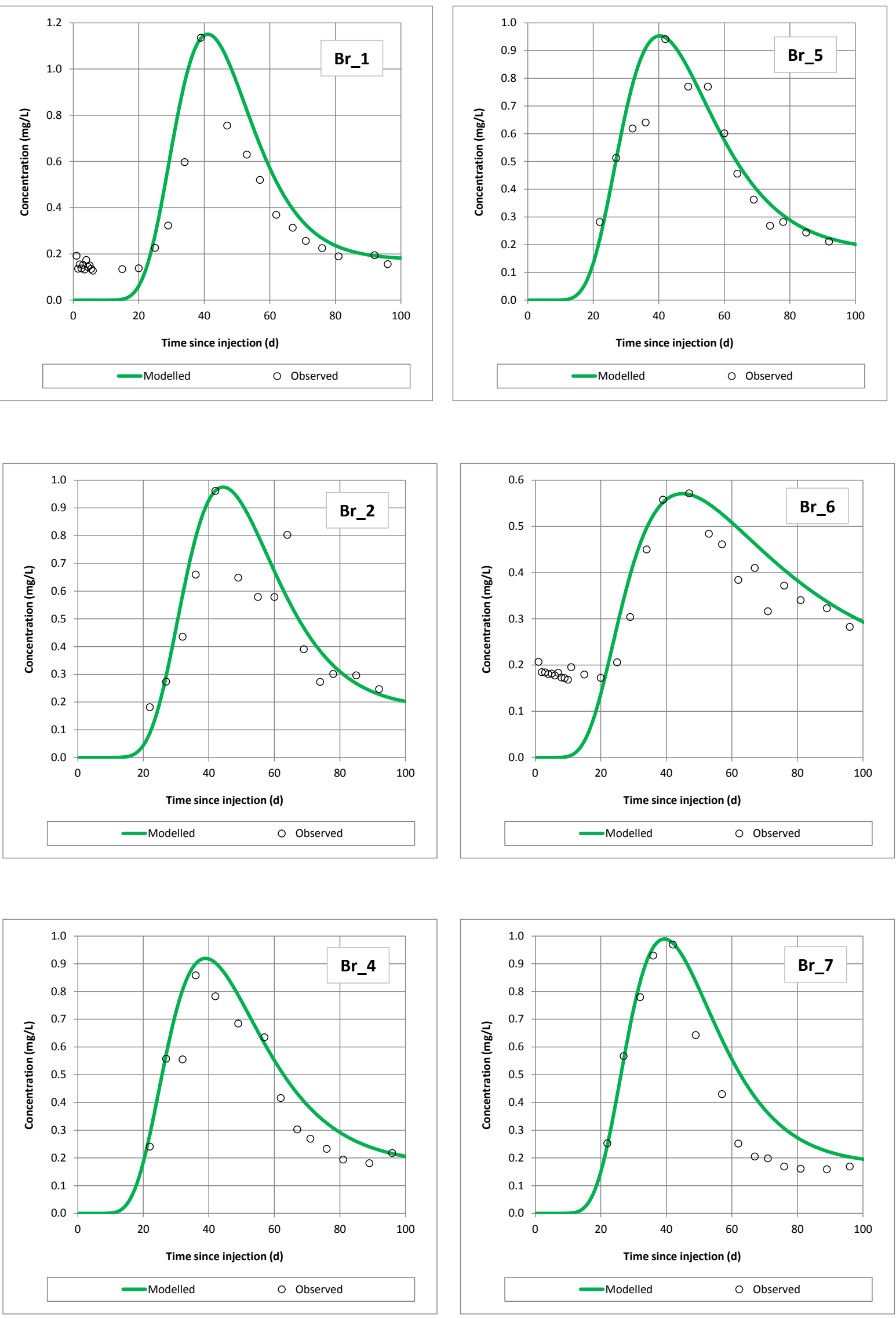

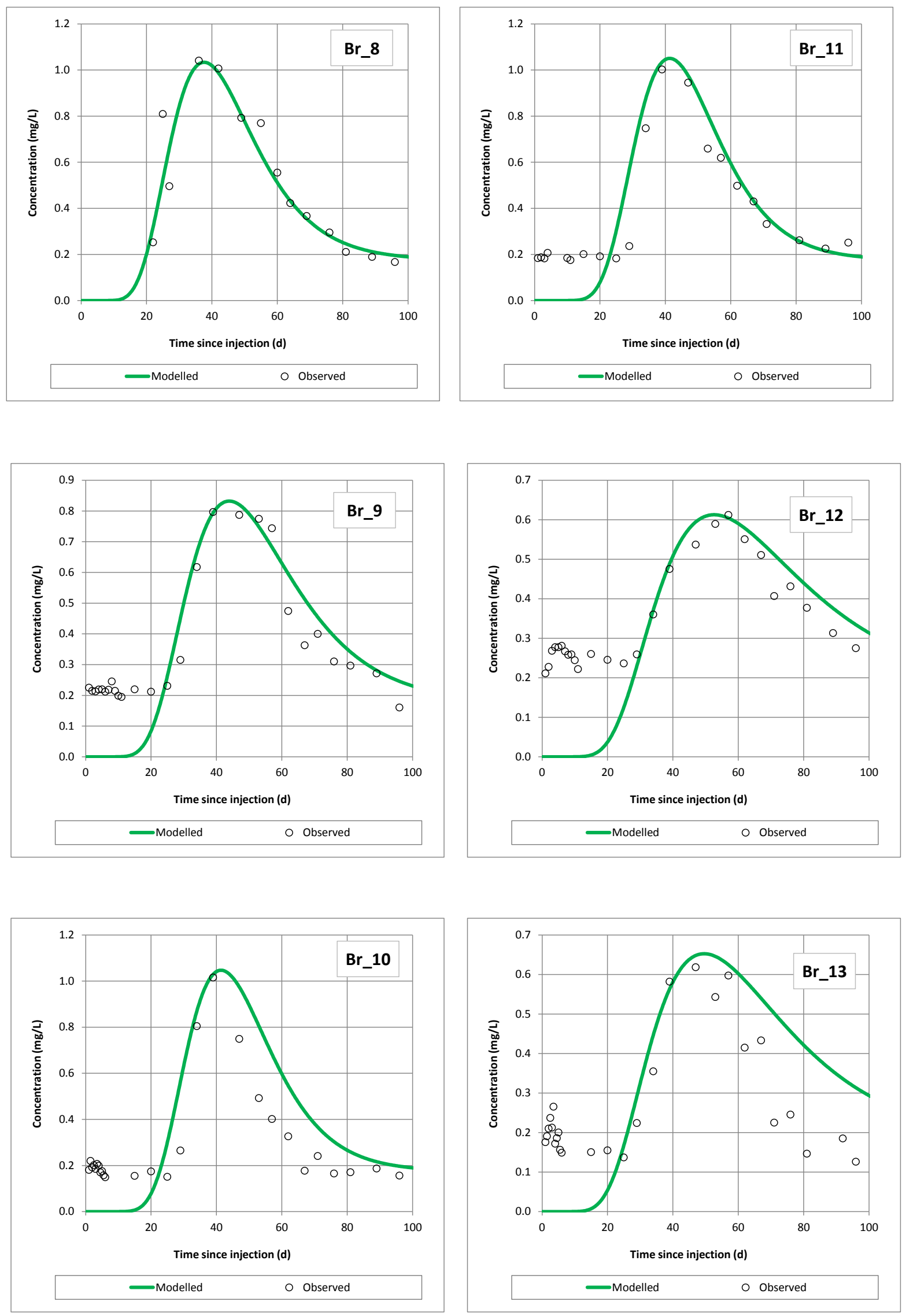

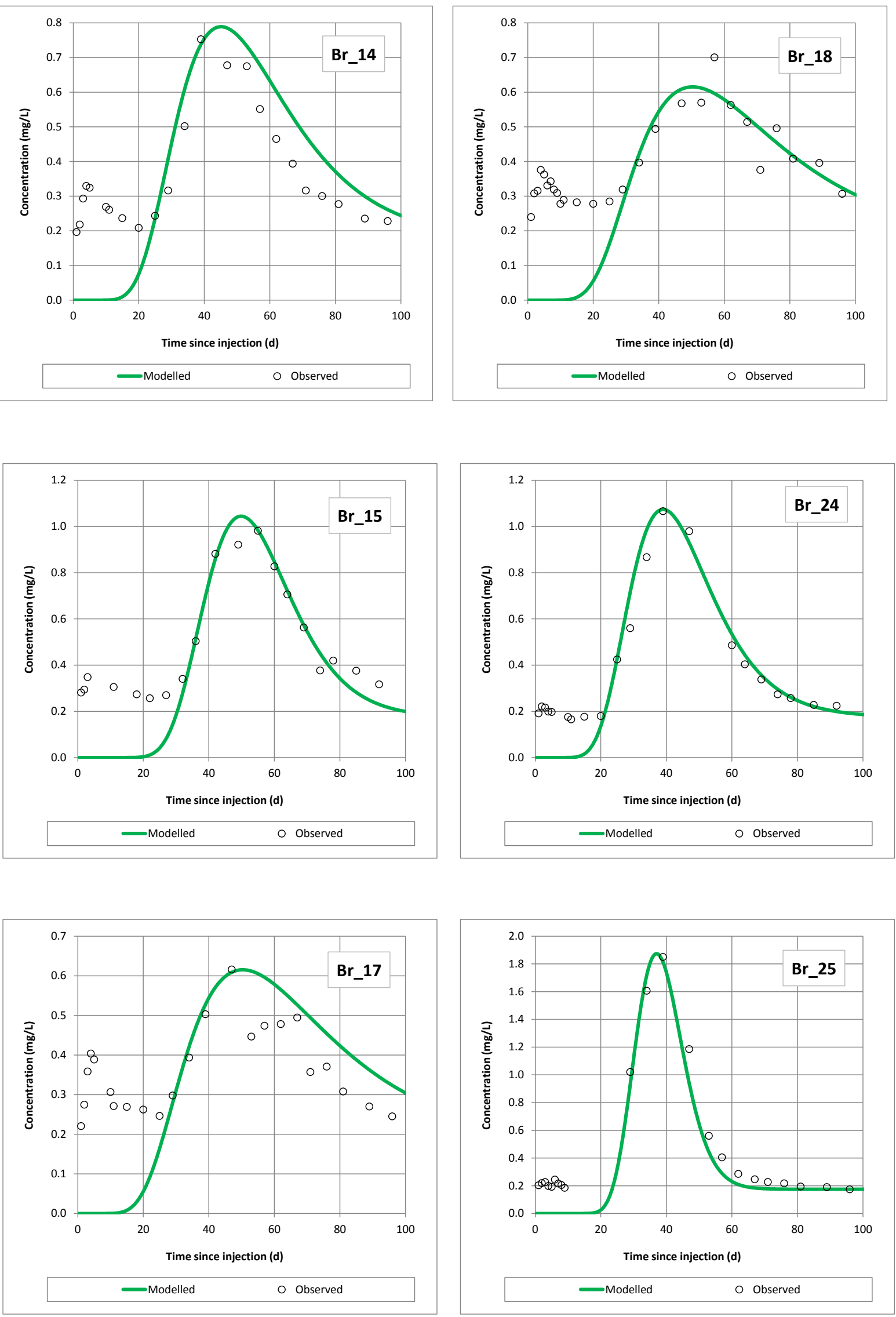

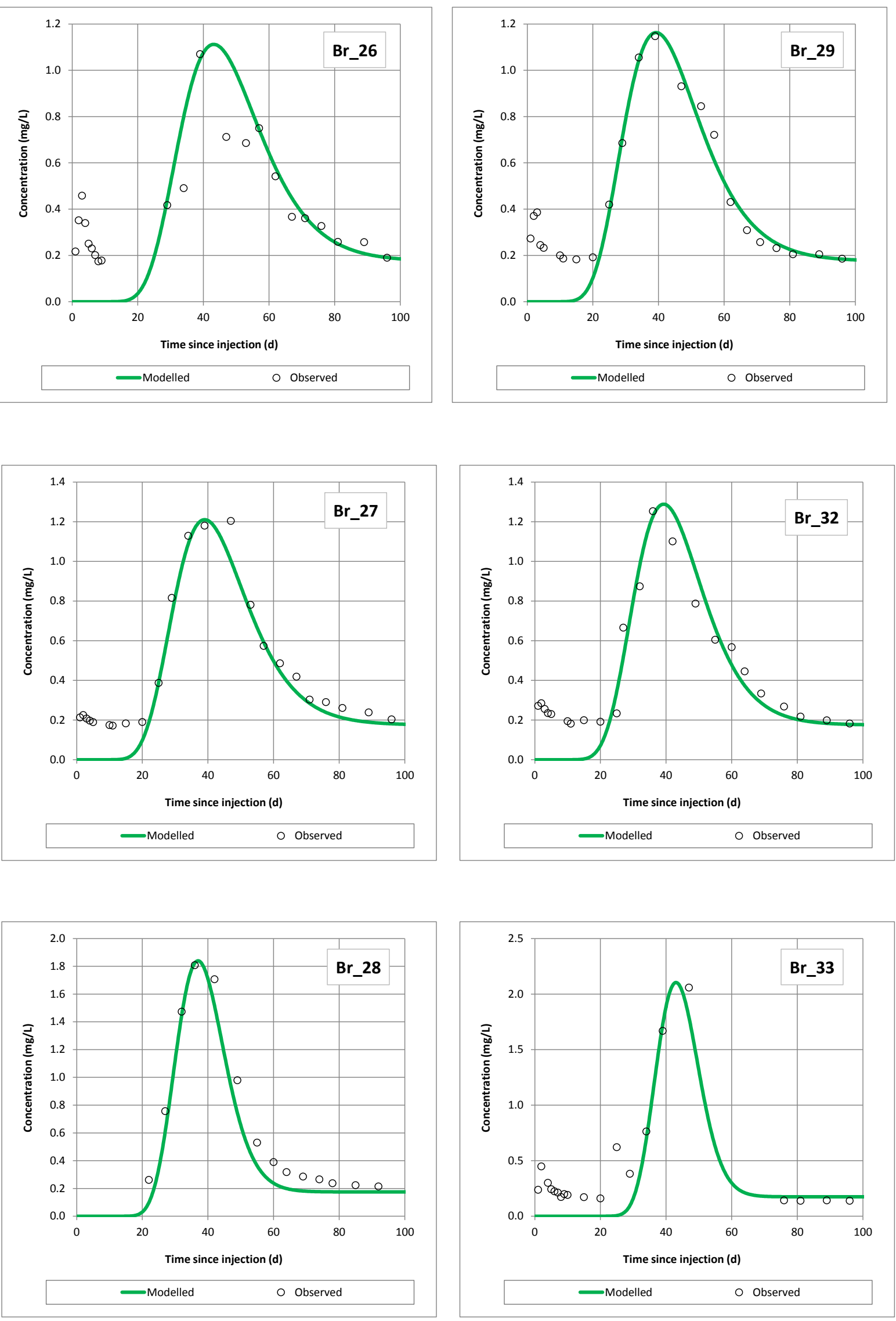

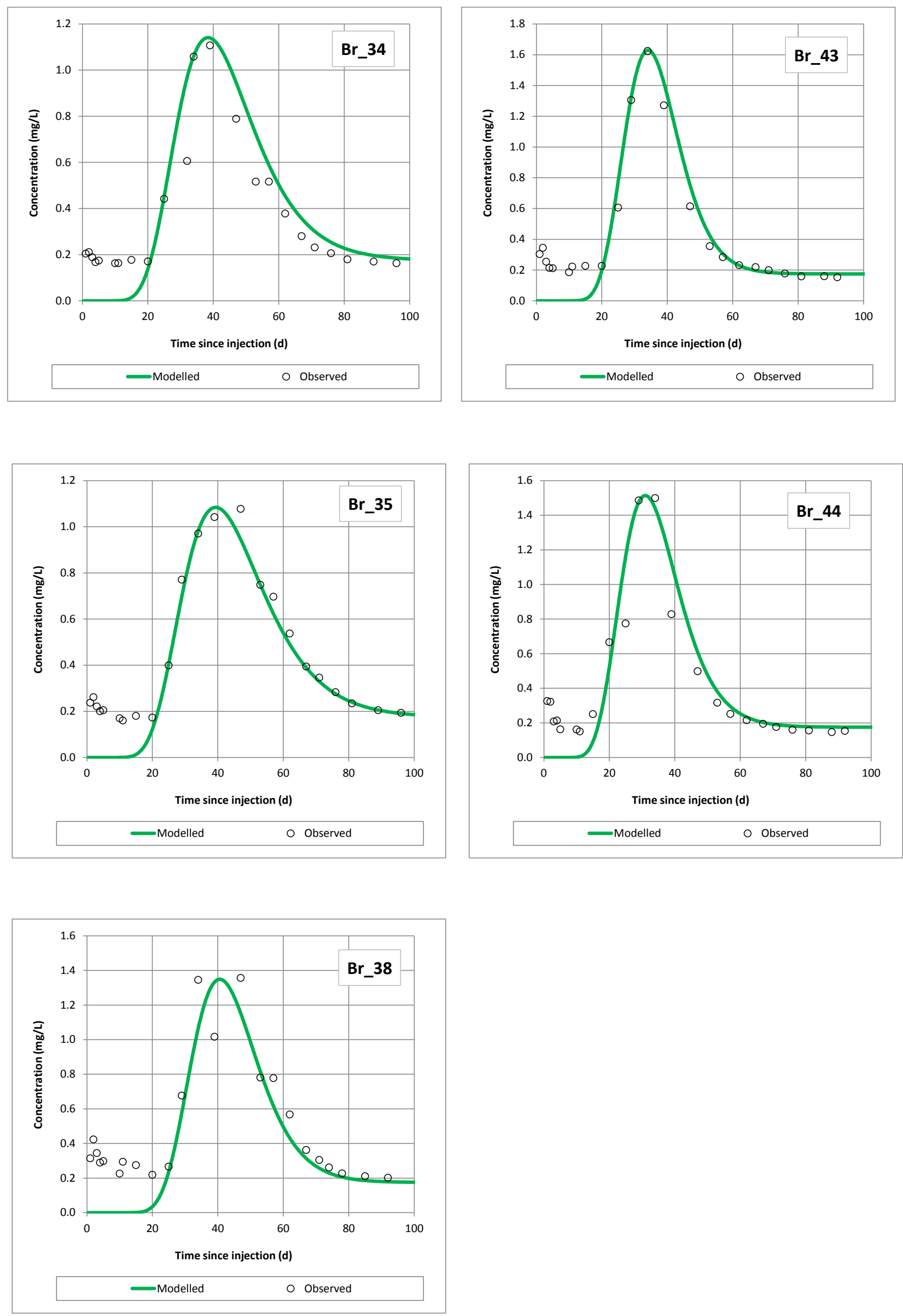

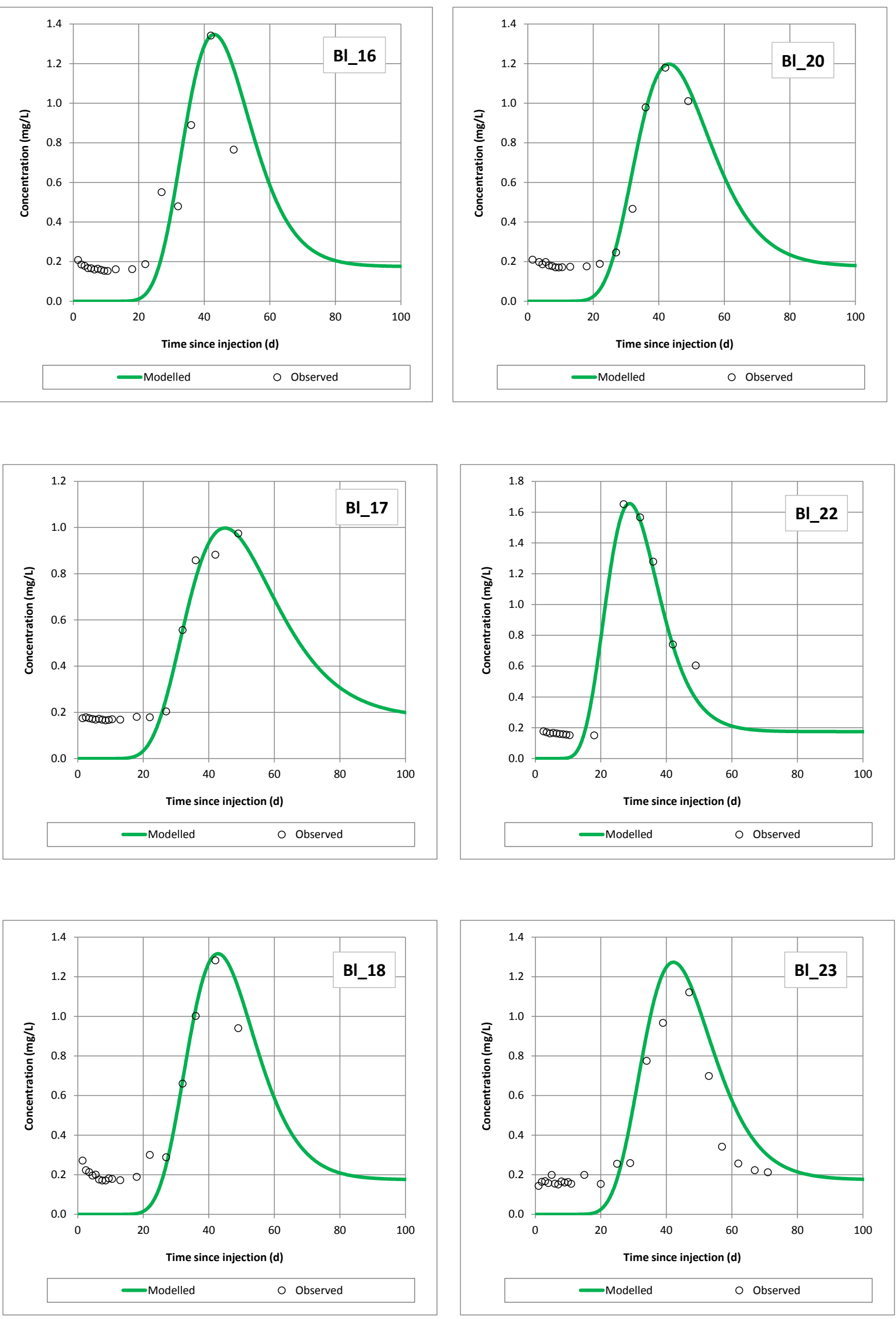

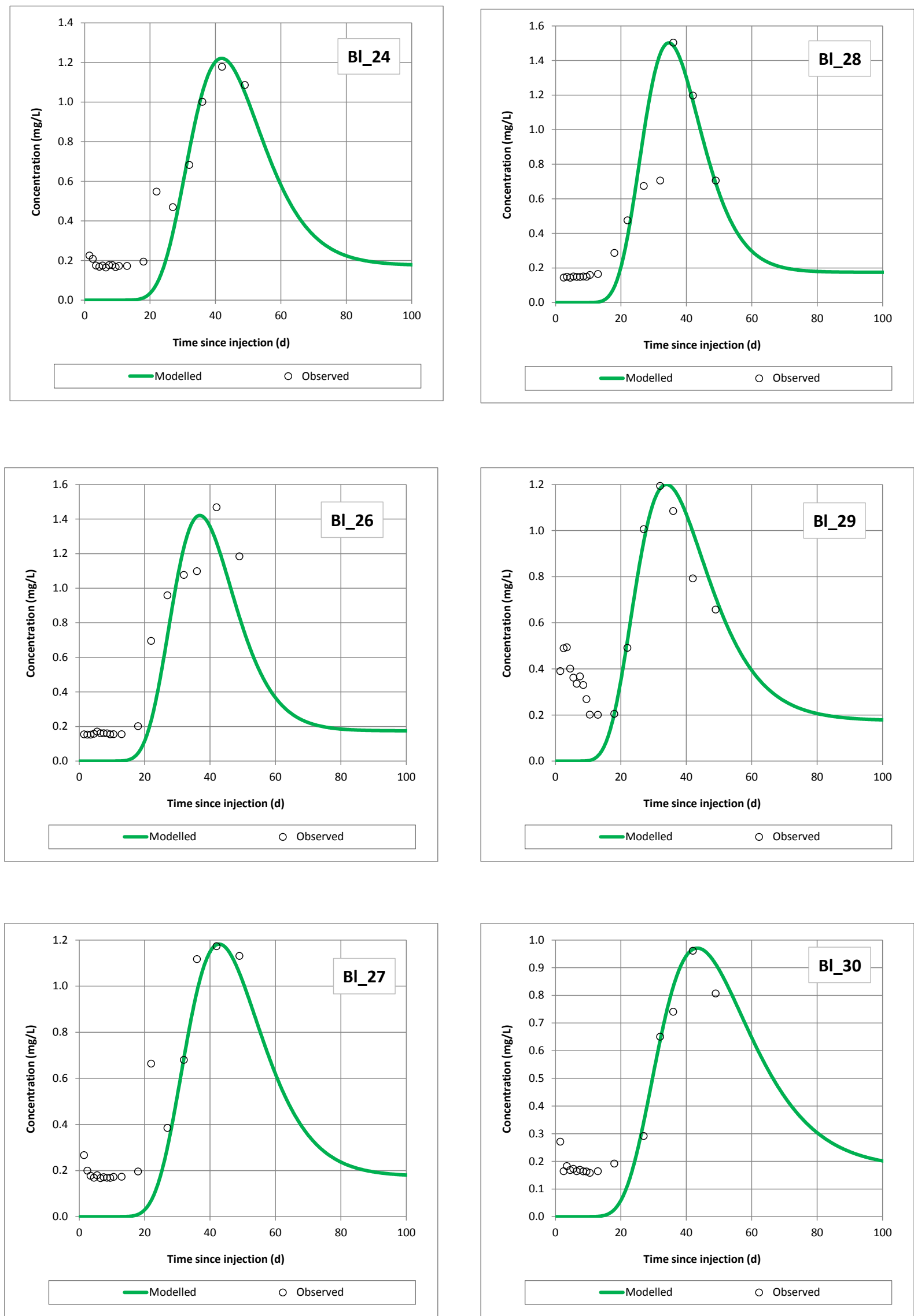

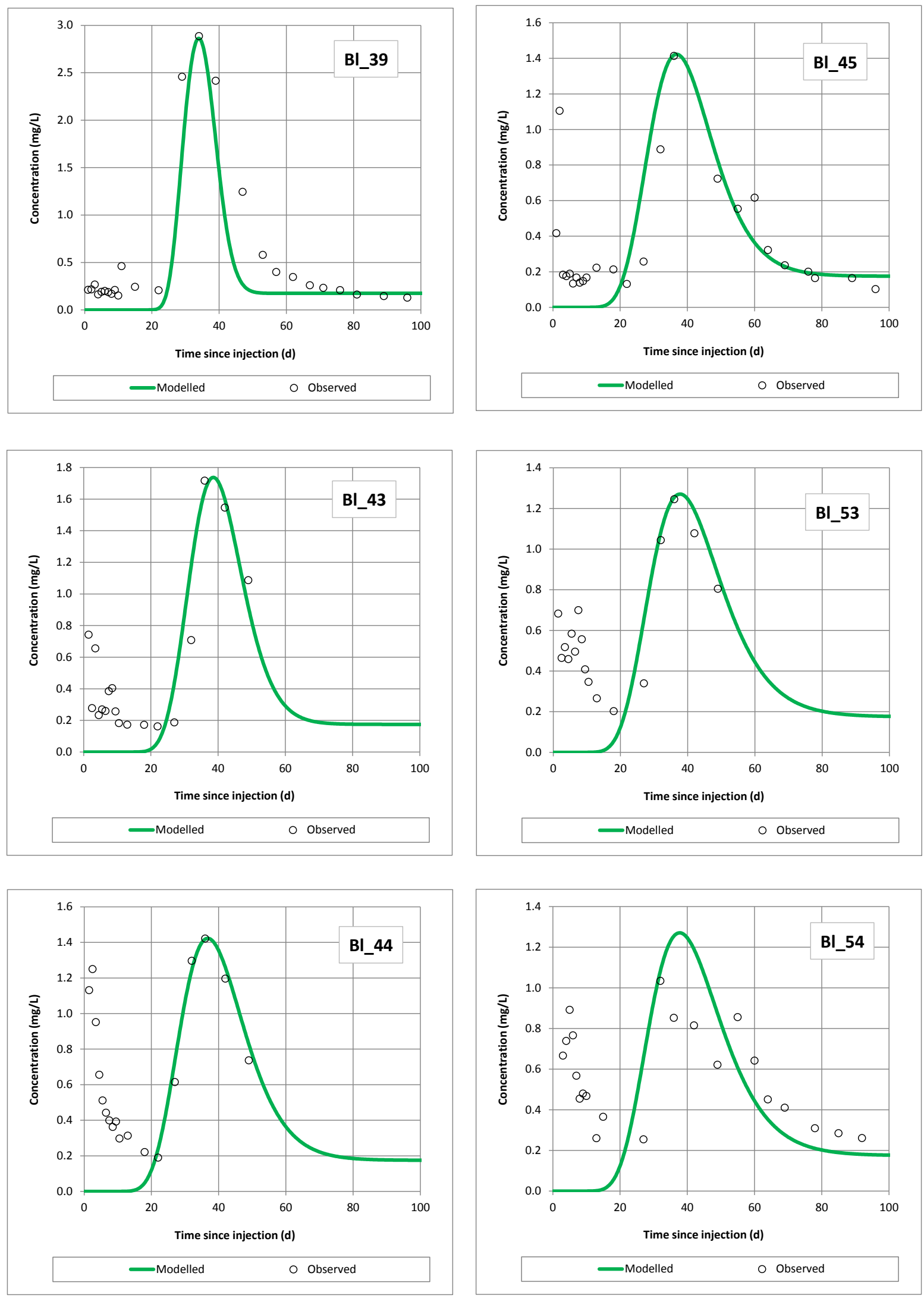

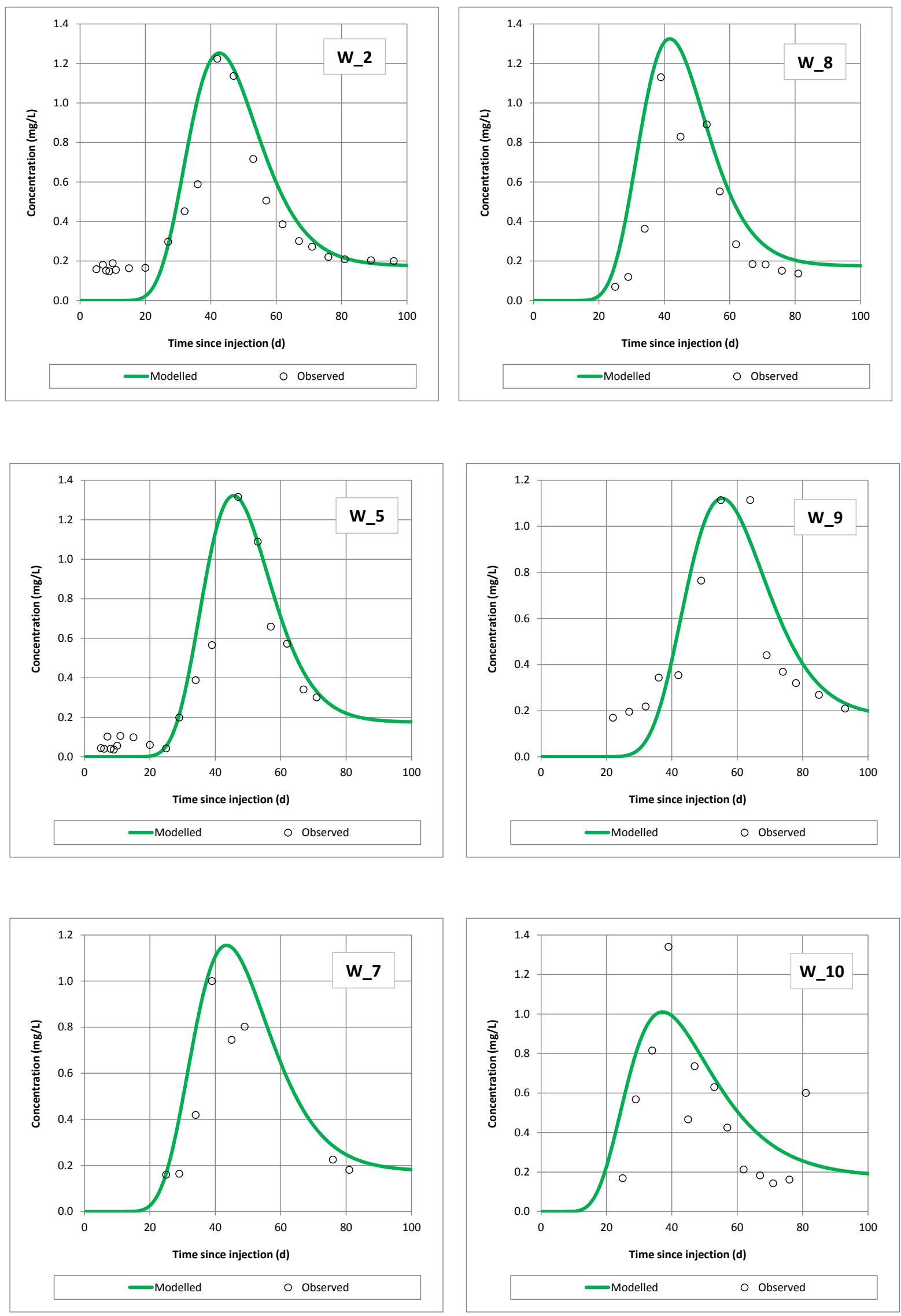

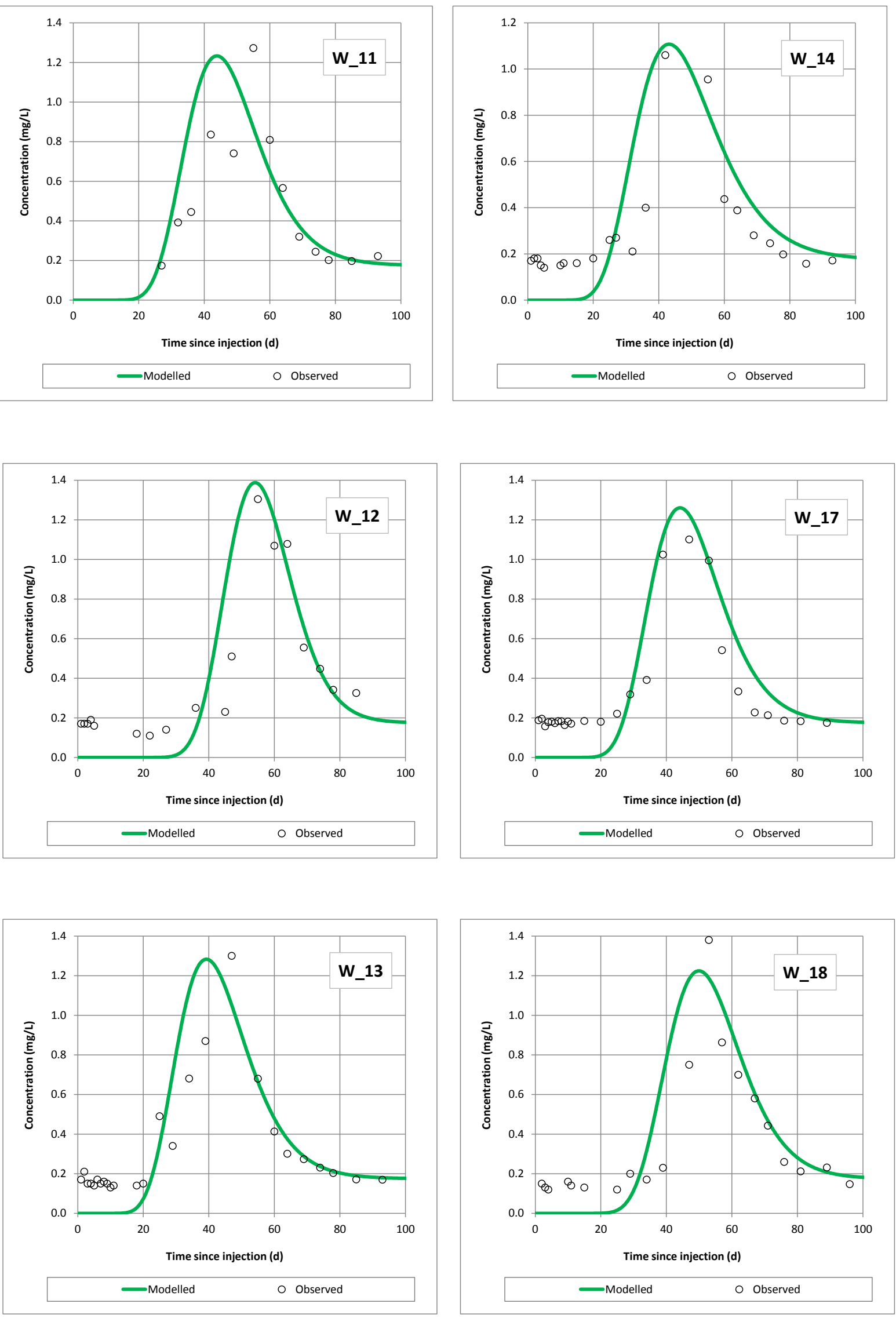

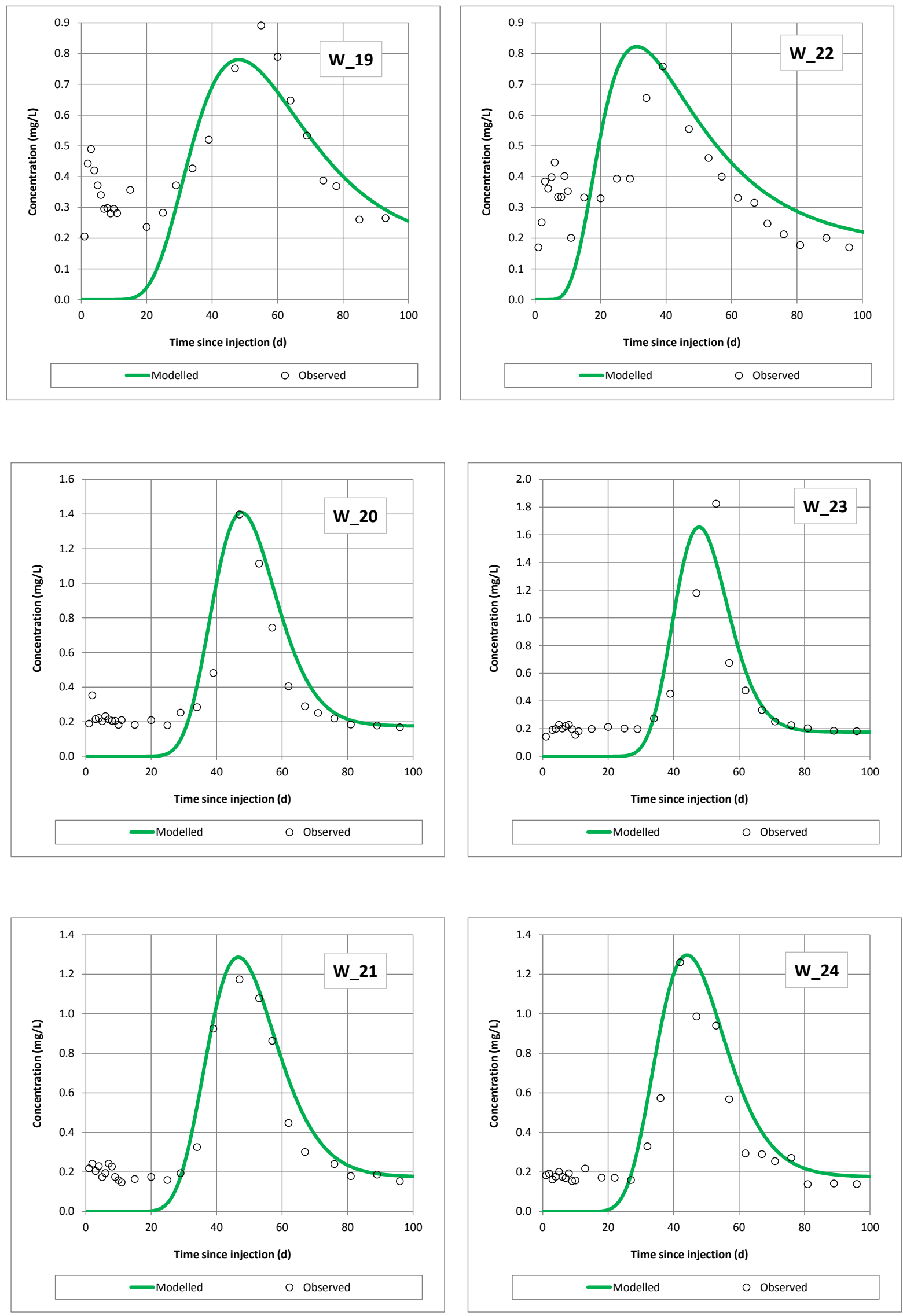

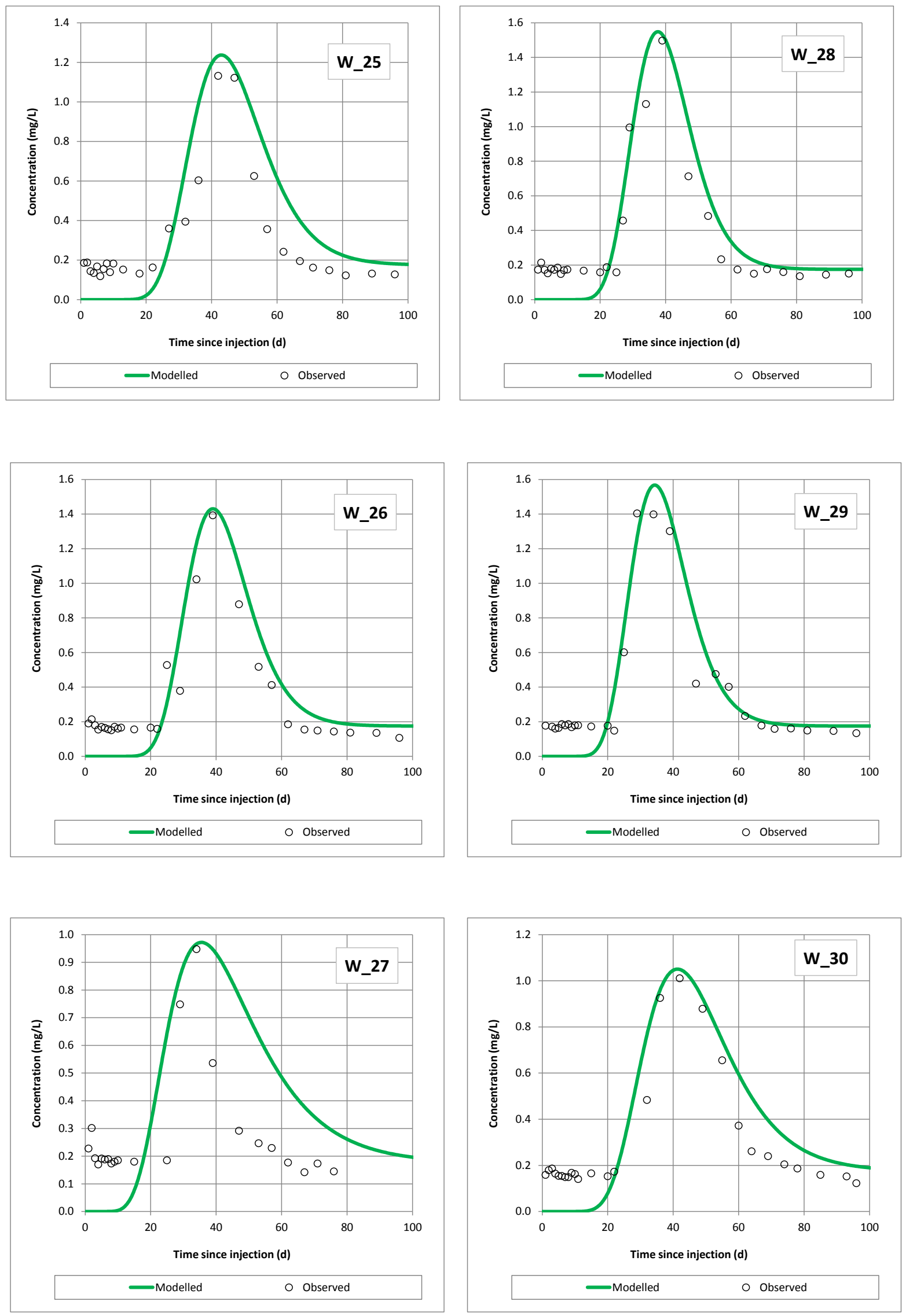

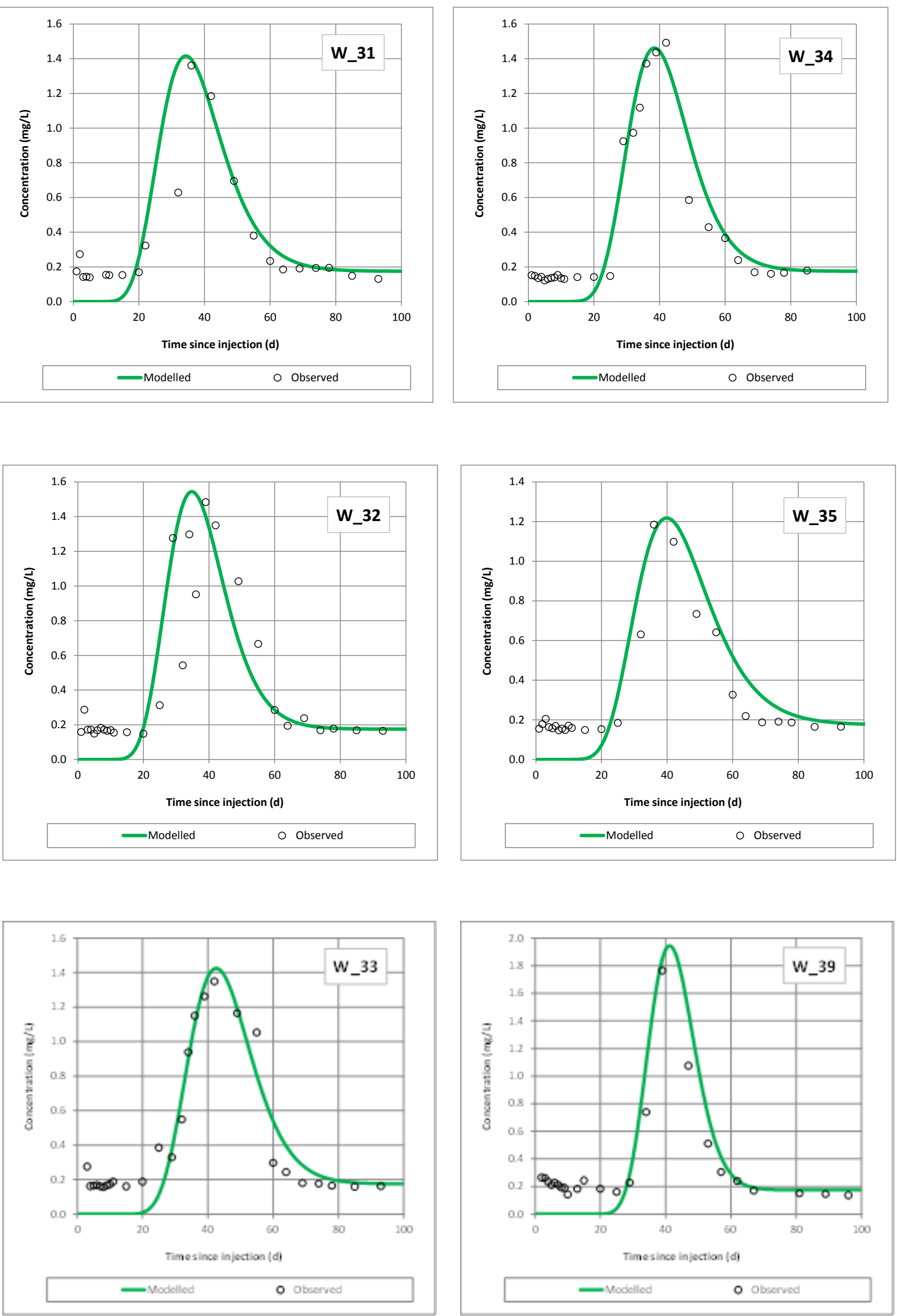

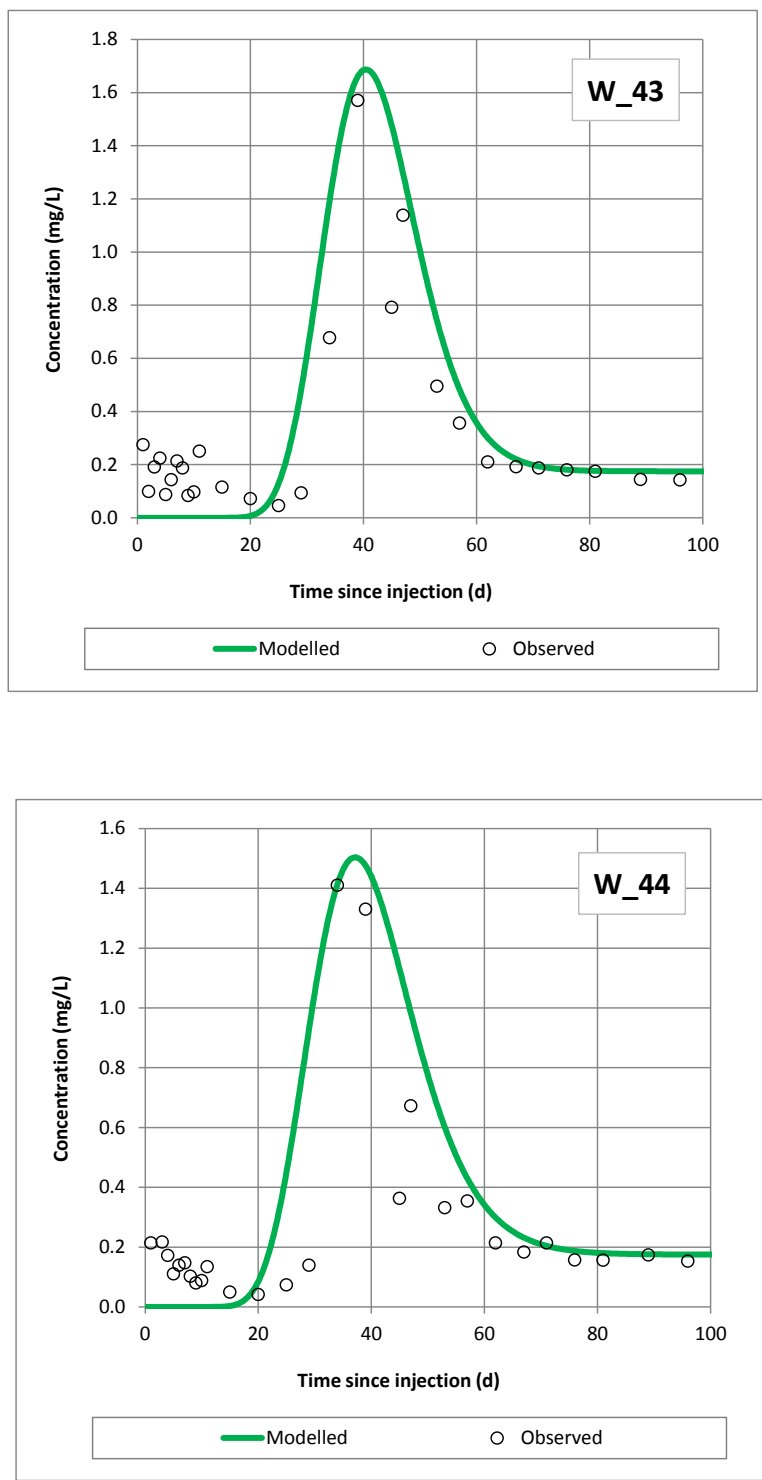


\section{Appendix C}

\section{D Analytical Modelling - Hydrogeological \\ Parameters Results}




\begin{tabular}{|c|c|c|c|c|c|c|}
\hline ID & $\mathbf{K}_{\mathbf{x}}(\mathbf{m} / \mathbf{d})$ & $\mathbf{v}_{\mathbf{x}}(\mathbf{m} / \mathbf{d})$ & $\eta_{\mathbf{e}}$ & $\boldsymbol{\alpha}_{\mathbf{x}}(\mathbf{m})$ & $D_{x}\left(m^{2} / d\right)$ & $\mathbf{P}_{\mathbf{e}(\mathbf{x})}$ \\
\hline A1_0.4 & 600 & 0.88 & 0.3 & 0.01 & 0.010 & 66 \\
\hline A1_1.0 & 220 & 0.32 & 0.3 & 0.31 & 0.100 & 2 \\
\hline A1_1.6 & 120 & 0.18 & 0.3 & 0.02 & 0.004 & 33 \\
\hline A1_2.2 & 70 & 0.10 & 0.3 & 0.04 & 0.005 & 16 \\
\hline A5_0.4 & 425 & 0.62 & 0.3 & 0.30 & 0.187 & 16 \\
\hline A5_1.0 & 165 & 0.24 & 0.3 & 0.10 & 0.025 & 46 \\
\hline A5_1.6 & 220 & 0.32 & 0.3 & 0.20 & 0.065 & 24 \\
\hline A5_2.2 & 80 & 0.12 & 0.3 & 0.34 & 0.040 & 14 \\
\hline A9_0.4 & 350 & 0.51 & 0.3 & 0.58 & 0.300 & 15 \\
\hline A9_1.0 & 165 & 0.24 & 0.3 & 0.38 & 0.093 & 23 \\
\hline A9_1.6 & 160 & 0.23 & 0.3 & 0.25 & 0.059 & 35 \\
\hline A9_2.2 & 180 & 0.26 & 0.3 & 0.38 & 0.100 & 23 \\
\hline B1_0.4 & 209 & 0.31 & 0.3 & 0.03 & 0.011 & 22 \\
\hline B1_1.0 & 99 & 0.15 & 0.3 & 0.10 & 0.015 & 7 \\
\hline B1_1.6 & 216 & 0.32 & 0.3 & 0.22 & 0.069 & 3 \\
\hline B1_2.2 & 90 & 0.13 & 0.3 & 0.30 & 0.040 & 2 \\
\hline B5_0.4 & 160 & 0.23 & 0.3 & 0.21 & 0.050 & 22 \\
\hline B5_1.0 & 200 & 0.29 & 0.3 & 0.20 & 0.060 & 23 \\
\hline B5_1.6 & 210 & 0.31 & 0.3 & 0.05 & 0.015 & 98 \\
\hline B5_2.2 & 180 & 0.26 & 0.3 & 0.23 & 0.060 & 21 \\
\hline B9_0.4 & 155 & 0.23 & 0.3 & 0.38 & 0.086 & 23 \\
\hline B9_1.0 & 154 & 0.23 & 0.3 & 0.27 & 0.062 & 32 \\
\hline B9_1.6 & 160 & 0.23 & 0.3 & 0.25 & 0.060 & 34 \\
\hline B9_2.2 & 158 & 0.23 & 0.3 & 0.45 & 0.105 & 19 \\
\hline C1_0.4 & 280 & 0.41 & 0.3 & 0.07 & 0.030 & 10 \\
\hline C1_1.0 & 239 & 0.35 & 0.3 & 0.11 & 0.040 & 7 \\
\hline C1_1.6 & 105 & 0.15 & 0.3 & 0.10 & 0.015 & 7 \\
\hline C1_2.2 & 42 & 0.06 & 0.3 & 0.24 & 0.015 & 3 \\
\hline C5_0.4 & 268 & 0.39 & 0.3 & 0.15 & 0.060 & 31 \\
\hline C5_1.0 & 199 & 0.29 & 0.3 & 0.22 & 0.064 & 22 \\
\hline C5_1.6 & 285 & 0.42 & 0.3 & 0.10 & 0.042 & 47 \\
\hline C5_2.2 & 125 & 0.18 & 0.3 & 0.16 & 0.029 & 30 \\
\hline C9_0.4 & 216 & 0.32 & 0.3 & 0.18 & 0.058 & 48 \\
\hline C9_1.0 & 170 & 0.25 & 0.3 & 0.48 & 0.120 & 18 \\
\hline C9_1.6 & 205 & 0.30 & 0.3 & 0.46 & 0.140 & 19 \\
\hline C9_2.2 & 192 & 0.28 & 0.3 & 0.50 & 0.140 & 18 \\
\hline D1_0.4 & 260 & 0.38 & 0.3 & 0.26 & 0.100 & 3 \\
\hline D1_1.0 & 270 & 0.40 & 0.3 & 0.23 & 0.090 & 3 \\
\hline D1_1.6 & 130 & 0.19 & 0.3 & 0.21 & 0.040 & 4 \\
\hline D1_2.2 & 60 & 0.09 & 0.3 & 0.03 & 0.003 & 22 \\
\hline D5_0.4 & 268 & 0.39 & 0.3 & 0.15 & 0.060 & 31 \\
\hline
\end{tabular}




\begin{tabular}{|c|c|c|c|c|c|c|}
\hline ID & $K_{x}(m / d)$ & $\mathbf{v}_{\mathbf{X}}(\mathbf{m} / \mathbf{d})$ & $\eta_{\mathrm{e}}$ & $\boldsymbol{\alpha}_{\mathbf{x}}(\mathbf{m})$ & $D_{x}\left(m^{2} / d\right)$ & $\mathbf{P}_{\mathbf{e}(\mathbf{x})}$ \\
\hline D5_1.0 & 260 & 0.38 & 0.3 & 0.13 & 0.050 & 36 \\
\hline D5_1.6 & 213 & 0.31 & 0.3 & 0.19 & 0.061 & 24 \\
\hline D5_2.2 & 170 & 0.25 & 0.3 & 0.40 & 0.100 & 12 \\
\hline D9_0.4 & 260 & 0.38 & 0.3 & 0.18 & 0.070 & 48 \\
\hline D9_1.0 & 201 & 0.29 & 0.3 & 0.28 & 0.081 & 32 \\
\hline D9_1.6 & 182 & 0.27 & 0.3 & 0.29 & 0.077 & 30 \\
\hline D9_2.2 & 190 & 0.28 & 0.3 & 0.47 & 0.131 & 19 \\
\hline E1_0.4 & 170 & 0.25 & 0.3 & 0.12 & 0.030 & 6 \\
\hline E1_1.0 & 138 & 0.20 & 0.3 & 0.03 & 0.006 & 26 \\
\hline E1_1.6 & 263 & 0.39 & 0.3 & 0.01 & 0.005 & 59 \\
\hline E1_2.2 & 115 & 0.17 & 0.3 & 0.02 & 0.004 & 32 \\
\hline E5_0.4 & 170 & 0.25 & 0.3 & 0.28 & 0.070 & 17 \\
\hline E5_1.0 & 176 & 0.26 & 0.3 & 0.18 & 0.048 & 26 \\
\hline E5_1.6 & 160 & 0.23 & 0.3 & 0.16 & 0.038 & 29 \\
\hline E5_2.2 & 140 & 0.21 & 0.3 & 0.14 & 0.030 & 33 \\
\hline E9_1.6 & 146 & 0.21 & 0.3 & 0.18 & 0.038 & 47 \\
\hline E9_2.2 & 158 & 0.23 & 0.3 & 0.21 & 0.048 & 42 \\
\hline R_9 & 115 & 0.17 & 0.3 & 0.59 & 0.100 & 16 \\
\hline R_16 & 145 & 0.21 & 0.3 & 0.42 & 0.090 & 22 \\
\hline R_17 & 143 & 0.21 & 0.3 & 0.22 & 0.047 & 42 \\
\hline R_18 & 121 & 0.18 & 0.3 & 0.22 & 0.040 & 42 \\
\hline R_25 & 157 & 0.23 & 0.3 & 0.27 & 0.061 & 36 \\
\hline R_26 & 125 & 0.18 & 0.3 & 0.92 & 0.170 & 10 \\
\hline R_27 & 130 & 0.19 & 0.3 & 0.43 & 0.082 & 22 \\
\hline R_35 & 180 & 0.26 & 0.3 & 0.23 & 0.060 & 42 \\
\hline R_36 & 175 & 0.26 & 0.3 & 0.15 & 0.040 & 61 \\
\hline R_43 & 255 & 0.37 & 0.3 & 0.67 & 0.250 & 14 \\
\hline R_44 & 290 & 0.43 & 0.3 & 0.35 & 0.150 & 27 \\
\hline R_45 & 215 & 0.32 & 0.3 & 0.38 & 0.120 & 25 \\
\hline Y_9 & 155 & 0.23 & 0.3 & 0.48 & 0.110 & 20 \\
\hline Y_17 & 108 & 0.16 & 0.3 & 0.82 & 0.130 & 12 \\
\hline Y_18 & 112 & 0.16 & 0.3 & 0.85 & 0.140 & 11 \\
\hline Y_25 & 140 & 0.21 & 0.3 & 0.24 & 0.050 & 39 \\
\hline Y_26 & 155 & 0.23 & 0.3 & 0.79 & 0.180 & 12 \\
\hline Y_27 & 165 & 0.24 & 0.3 & 0.29 & 0.070 & 33 \\
\hline Y_34 & 135 & 0.20 & 0.3 & 0.30 & 0.060 & 31 \\
\hline Y_35 & 160 & 0.23 & 0.3 & 0.59 & 0.140 & 16 \\
\hline Y_36 & 180 & 0.26 & 0.3 & 0.64 & 0.170 & 15 \\
\hline Y_43 & 175 & 0.26 & 0.3 & 0.17 & 0.045 & 54 \\
\hline Y_44 & 170 & 0.25 & 0.3 & 0.28 & 0.070 & 34 \\
\hline Y_45 & 176 & 0.26 & 0.3 & 0.28 & 0.072 & 34 \\
\hline C_6 & 150 & 0.22 & 0.3 & 0.73 & 0.160 & 13 \\
\hline
\end{tabular}




\begin{tabular}{|c|c|c|c|c|c|c|}
\hline ID & $K_{x}(m / d)$ & $\mathbf{v}_{\mathbf{X}}(\mathbf{m} / \mathbf{d})$ & $\eta_{\mathrm{e}}$ & $\boldsymbol{\alpha}_{\mathbf{x}}(\mathbf{m})$ & $D_{x}\left(m^{2} / d\right)$ & $\mathbf{P}_{\mathbf{e}(\mathbf{x})}$ \\
\hline C_12 & 171 & 0.25 & 0.3 & 1.19 & 0.300 & 8 \\
\hline C_17 & 185 & 0.27 & 0.3 & 0.29 & 0.080 & 32 \\
\hline C_18 & 150 & 0.22 & 0.3 & 0.31 & 0.069 & 30 \\
\hline C_19 & 150 & 0.22 & 0.3 & 0.39 & 0.086 & 24 \\
\hline C_20 & 150 & 0.22 & 0.3 & 0.56 & 0.124 & 17 \\
\hline C_21 & 140 & 0.21 & 0.3 & 0.34 & 0.070 & 28 \\
\hline C_22 & 150 & 0.22 & 0.3 & 0.23 & 0.050 & 42 \\
\hline C_23 & 160 & 0.23 & 0.3 & 0.19 & 0.045 & 50 \\
\hline C_24 & 150 & 0.22 & 0.3 & 0.32 & 0.070 & 30 \\
\hline C_25 & 160 & 0.24 & 0.3 & 0.21 & 0.050 & 45 \\
\hline C_26 & 170 & 0.25 & 0.3 & 0.32 & 0.080 & 30 \\
\hline C_27 & 180 & 0.26 & 0.3 & 0.26 & 0.070 & 36 \\
\hline C_28 & 165 & 0.24 & 0.3 & 0.29 & 0.070 & 33 \\
\hline C_30 & 210 & 0.31 & 0.3 & 0.26 & 0.080 & 37 \\
\hline C_32 & 175 & 0.26 & 0.3 & 0.15 & 0.039 & 62 \\
\hline C_33 & 175 & 0.26 & 0.3 & 0.43 & 0.110 & 22 \\
\hline C_34 & 175 & 0.26 & 0.3 & 0.47 & 0.120 & 20 \\
\hline C_35 & 178 & 0.26 & 0.3 & 0.18 & 0.048 & 52 \\
\hline C_36 & 175 & 0.26 & 0.3 & 0.43 & 0.110 & 22 \\
\hline C_37 & 168 & 0.25 & 0.3 & 0.34 & 0.085 & 28 \\
\hline C_38 & 187 & 0.27 & 0.3 & 0.12 & 0.033 & 79 \\
\hline C_45 & 182 & 0.27 & 0.3 & 0.26 & 0.070 & 36 \\
\hline Br_1 & 169 & 0.25 & 0.3 & 0.48 & 0.120 & 20 \\
\hline $\mathrm{Br} \_2$ & 152 & 0.22 & 0.3 & 0.58 & 0.130 & 16 \\
\hline $\mathrm{Br} \_4$ & 168 & 0.25 & 0.3 & 0.85 & 0.210 & 11 \\
\hline $\mathrm{Br} \_5$ & 165 & 0.24 & 0.3 & 0.74 & 0.180 & 13 \\
\hline Br_6 & 125 & 0.18 & 0.3 & 1.58 & 0.290 & 6 \\
\hline Br_7 & 170 & 0.25 & 0.3 & 0.72 & 0.180 & 13 \\
\hline $\mathrm{Br} \_8$ & 179 & 0.26 & 0.3 & 0.72 & 0.191 & 13 \\
\hline Br_9 & 147 & 0.22 & 0.3 & 0.82 & 0.177 & 12 \\
\hline Br_10 & 165 & 0.24 & 0.3 & 0.58 & 0.140 & 16 \\
\hline Br_11 & 165 & 0.24 & 0.3 & 0.58 & 0.140 & 16 \\
\hline Br_12 & 116 & 0.17 & 0.3 & 1.06 & 0.180 & 9 \\
\hline $\mathrm{Br} \_13$ & 124 & 0.18 & 0.3 & 1.04 & 0.190 & 9 \\
\hline $\mathrm{Br} \_14$ & 142 & 0.21 & 0.3 & 0.86 & 0.180 & 11 \\
\hline Br_15 & 138 & 0.20 & 0.3 & 0.39 & 0.080 & 24 \\
\hline Br_17 & 120 & 0.18 & 0.3 & 1.13 & 0.200 & 8 \\
\hline $\mathrm{Br}_{-} 18$ & 120 & 0.18 & 0.3 & 1.13 & 0.200 & 8 \\
\hline $\mathrm{Br} \_24$ & 175 & 0.26 & 0.3 & 0.62 & 0.160 & 15 \\
\hline Br_25 & 200 & 0.29 & 0.3 & 0.19 & 0.057 & 49 \\
\hline $\mathrm{Br} \_26$ & 160 & 0.23 & 0.3 & 0.47 & 0.110 & 20 \\
\hline Br_27 & 179 & 0.26 & 0.3 & 0.48 & 0.127 & 20 \\
\hline
\end{tabular}




\begin{tabular}{|c|c|c|c|c|c|c|}
\hline ID & $K_{x}(m / d)$ & $\mathbf{v}_{\mathbf{x}}(\mathbf{m} / \mathbf{d})$ & $\eta_{\mathrm{e}}$ & $\boldsymbol{\alpha}_{\mathbf{x}}(\mathbf{m})$ & $D_{x}\left(m^{2} / d\right)$ & $\mathbf{P}_{\mathbf{e}(\mathbf{x})}$ \\
\hline Br_28 & 200 & 0.29 & 0.3 & 0.20 & 0.060 & 46 \\
\hline Br_29 & 177 & 0.26 & 0.3 & 0.52 & 0.135 & 18 \\
\hline Br_32 & 180 & 0.26 & 0.3 & 0.42 & 0.110 & 23 \\
\hline Br_33 & 170 & 0.25 & 0.3 & 0.10 & 0.025 & 95 \\
\hline Br_34 & 180 & 0.26 & 0.3 & 0.57 & 0.150 & 17 \\
\hline Br_35 & 174 & 0.26 & 0.3 & 0.60 & 0.153 & 16 \\
\hline Br_38 & 175 & 0.26 & 0.3 & 0.35 & 0.090 & 27 \\
\hline Br_43 & 216 & 0.32 & 0.3 & 0.33 & 0.105 & 29 \\
\hline Br_44 & 236 & 0.35 & 0.3 & 0.49 & 0.170 & 19 \\
\hline B1_16 & 165 & 0.24 & 0.3 & 0.31 & 0.075 & 31 \\
\hline B1_17 & 151 & 0.22 & 0.3 & 0.54 & 0.120 & 18 \\
\hline Bl_18 & 165 & 0.24 & 0.3 & 0.33 & 0.080 & 29 \\
\hline B1_20 & 162 & 0.24 & 0.3 & 0.40 & 0.095 & 24 \\
\hline B1_22 & 260 & 0.38 & 0.3 & 0.47 & 0.180 & 20 \\
\hline B1_23 & 167 & 0.25 & 0.3 & 0.37 & 0.090 & 26 \\
\hline B1_24 & 167 & 0.25 & 0.3 & 0.41 & 0.100 & 23 \\
\hline B1_26 & 195 & 0.29 & 0.3 & 0.38 & 0.110 & 25 \\
\hline B1_27 & 163 & 0.24 & 0.3 & 0.42 & 0.100 & 23 \\
\hline B1_28 & 210 & 0.31 & 0.3 & 0.39 & 0.120 & 24 \\
\hline B1_29 & 210 & 0.31 & 0.3 & 0.71 & 0.220 & 13 \\
\hline B1_30 & 155 & 0.23 & 0.3 & 0.61 & 0.140 & 15 \\
\hline B1_39 & 224 & 0.33 & 0.3 & 0.05 & 0.018 & 174 \\
\hline B1_43 & 190 & 0.28 & 0.3 & 0.21 & 0.060 & 44 \\
\hline B1_44 & 196 & 0.29 & 0.3 & 0.38 & 0.111 & 25 \\
\hline B1_45 & 196 & 0.29 & 0.3 & 0.38 & 0.111 & 25 \\
\hline Bl_53 & 187 & 0.27 & 0.3 & 0.47 & 0.128 & 20 \\
\hline B1_54 & 187 & 0.27 & 0.3 & 0.47 & 0.128 & 20 \\
\hline W_2 & 165 & 0.24 & 0.3 & 0.37 & 0.090 & 26 \\
\hline W_5 & 155 & 0.23 & 0.3 & 0.28 & 0.065 & 33 \\
\hline W_7 & 160 & 0.23 & 0.3 & 0.42 & 0.100 & 22 \\
\hline W_8 & 170 & 0.25 & 0.3 & 0.34 & 0.086 & 28 \\
\hline W_9 & 125 & 0.18 & 0.3 & 0.27 & 0.050 & 35 \\
\hline W_10 & 180 & 0.26 & 0.3 & 0.78 & 0.206 & 12 \\
\hline W_11 & 160 & 0.23 & 0.3 & 0.36 & 0.085 & 26 \\
\hline W_12 & 130 & 0.19 & 0.3 & 0.17 & 0.033 & 54 \\
\hline W_13 & 180 & 0.26 & 0.3 & 0.42 & 0.111 & 23 \\
\hline W_14 & 160 & 0.23 & 0.3 & 0.47 & 0.111 & 20 \\
\hline W_17 & 159 & 0.23 & 0.3 & 0.34 & 0.079 & 28 \\
\hline W_18 & 140 & 0.21 & 0.3 & 0.28 & 0.057 & 34 \\
\hline W_19 & 134 & 0.20 & 0.3 & 0.78 & 0.153 & 12 \\
\hline W_20 & 149 & 0.22 & 0.3 & 0.22 & 0.049 & 43 \\
\hline
\end{tabular}




\begin{tabular}{|c|c|c|c|c|c|c|}
\hline ID & $\mathbf{K}_{\mathbf{x}}(\mathbf{m} / \mathbf{d})$ & $\mathbf{v}_{\mathbf{x}}(\mathbf{m} / \mathbf{d})$ & $\eta_{\mathbf{e}}$ & $\boldsymbol{\alpha}_{\mathbf{x}}(\mathbf{m})$ & $\mathbf{D}_{\mathbf{x}}\left(\mathbf{m}^{\mathbf{2}} / \mathbf{d}\right)$ & $\mathbf{P}_{\mathbf{e}(\mathbf{x})}$ \\
\hline W_21 & 151 & 0.22 & 0.3 & 0.29 & 0.064 & 33 \\
\hline W_22 & 190 & 0.28 & 0.3 & 1.61 & 0.450 & 6 \\
\hline W_23 & 150 & 0.22 & 0.3 & 0.15 & 0.033 & 63 \\
\hline W_24 & 160 & 0.23 & 0.3 & 0.32 & 0.075 & 30 \\
\hline W_25 & 163 & 0.24 & 0.3 & 0.37 & 0.090 & 25 \\
\hline W_27 & 185 & 0.27 & 0.3 & 0.92 & 0.250 & 10 \\
\hline W_26 & 184 & 0.27 & 0.3 & 0.33 & 0.090 & 28 \\
\hline W_28 & 193 & 0.28 & 0.3 & 0.30 & 0.085 & 32 \\
\hline W_29 & 213 & 0.31 & 0.3 & 0.36 & 0.112 & 27 \\
\hline W_30 & 165 & 0.24 & 0.3 & 0.58 & 0.140 & 16 \\
\hline W_31 & 210 & 0.31 & 0.3 & 0.45 & 0.140 & 21 \\
\hline W_32 & 210 & 0.31 & 0.3 & 0.36 & 0.112 & 26 \\
\hline W_33 & 168 & 0.25 & 0.3 & 0.28 & 0.069 & 34 \\
\hline W_34 & 187 & 0.27 & 0.3 & 0.33 & 0.090 & 29 \\
\hline W_35 & 176 & 0.26 & 0.3 & 0.45 & 0.117 & 21 \\
\hline W_39 & 178 & 0.26 & 0.3 & 0.14 & 0.036 & 69 \\
\hline W_43 & 180 & 0.26 & 0.3 & 0.21 & 0.055 & 46 \\
\hline W_44 & 195 & 0.29 & 0.3 & 0.33 & 0.095 & 29 \\
\hline
\end{tabular}

